\title{
PAULO MAZINI
}

AVALIAÇÃO DA ÁREA DE CONTATO DOS DENTES ARTIFICIAIS EM FUNÇÃ̃O DA FORMA OCLUSAL E DA FORMA DAS ARCADAS NA POSIÇÃO DE MÁXIMA INTERCUSPIDAÇÃO E NOS MOVIMENTOS EXCURSIVOS 


\section{Paulo Mazini}

\section{Avaliação da área de contato dos dentes artificiais em função da forma oclusal e da forma das arcadas na posição de máxima intercuspidação e nos movimentos excursivos}

Tese apresentada à Faculdade de Odontologia da Universidade de São Paulo, para obter o Título de Doutor, pelo Programa de Pós-Graduação em Odontologia.

Área de Concentração: Prótese Dentária.

Orientador: Prof. Dr. Atlas Edson Moleros Nakamae

São Paulo 
Catalogação-na-Publicação

Serviço de Documentação Odontológica

Faculdade de Odontologia da Universidade de São Paulo

Mazini, Paulo

Avaliação da área de contato dos dentes artificiais em função da forma oclusal e da forma das arcadas na posição de máxima intercuspidação e nos movimentos excursivos / Paulo Mazini; orientador Atlas Edson Moleros Nakamae. -- São Paulo, 2007.

193p. : fig., graf.; $30 \mathrm{~cm}$.

Tese (Doutorado - Programa de Pós-Graduação em Odontologia. Área de Concentração: Prótese Dentária) -- Faculdade de Odontologia da Universidade de São Paulo.

1. Prótese Total - Área de Contato - Avaliação 2. Contatos Oclusais

CDD 617.692

BLACK D32

AUTORIZO A REPRODUÇÃO E DIVULGAÇÃO TOTAL OU PARCIAL DESTE TRABALHO, POR QUALQUER MEIO CONVENCIONAL OU ELETRÔNICO, PARA FINS DE ESTUDO E PESQUISA, DESDE QUE CITADA A FONTE E COMUNICADO AO AUTOR A REFERÊNCIA DA CITAÇÃO.

São Paulo,

Assinatura:

E-mail: mazini@usp.br 


\section{FOLHA DE APROVAÇÃO}

Mazini P. Avaliação da área de contato dos dentes artificiais em função da forma oclusal e da forma das arcadas na posição de máxima intercuspidação e nos movimentos excursivos [Tese de Doutorado]. São Paulo: Faculdade de Odontologia da USP; 2007.

São Paulo: 12007

\section{Banca Examinadora}

1) $\operatorname{Prof}(a) \cdot \operatorname{Dr}(a)$.

Titulação:

Julgamento: Assinatura:

2) $\operatorname{Prof}(a) \cdot \operatorname{Dr}(a)$.

Titulação:

Julgamento:

Assinatura:

3) $\operatorname{Prof}(a) \cdot \operatorname{Dr}(a)$.

Titulação:

Julgamento:

Assinatura:

4) $\operatorname{Prof}(a) \cdot \operatorname{Dr}(a)$.

Titulação:

Julgamento:

Assinatura:

5) $\operatorname{Prof}(a) \cdot \operatorname{Dr}(a)$.

Titulação:

Julgamento:

Assinatura: 
Assim como no Mestrado, assim como tudo em minha vida, continuo a dedicar este trabalho à minha família, responsável pela minha formação moral e intelectual, pelo constante apoio, tolerância e amor incondicionais.

\author{
Meu pai Valter, \\ Minha mãe Maria de Lurdes, \\ Minhas irmãs Juliana e Bianca, \\ E meu "bonhado" Neto,
}

Todo o meu Amor 


\section{AGRADECIMENTOS}

Ao Diretor da Faculdade de Odontologia da Universidade de São Paulo, Prof.

Dr. Carlos de Paula Eduardo e ao Chefe do Departamento de Prótese, Prof. Dr. Carlos Gil, pela oportunidade;

Ao Presidente da Comissão de Pós-graduação da Faculdade de Odontologia da Universidade de São Paulo, Prof. Dr. Reinaldo Brito e Dias e à Coordenadora do curso de Pós-graduação, na época de meu ingresso, Profa. Dra. Maria Cecília Miluzzi, pela sóbria e coerente condução do curso;

Ao Meu orientador, Prof. Dr. Atlas Esdon Moleros Nakamae, grande exemplo, pela confiança e amizade;

Aos professores das disciplinas de Prótese Total, Prótese Fixa e Prótese Parcial Removível da FOUSP, pelos ensinamentos transmitidos, pelo convívio e amizade, que contribuíram para meu crescimento pessoal e profissional;

Aos professores Luciano Natividade, Naya Clasen, Andréia Traina, José Eduardo Pelino, Edgar Tanji, Cristina Fiúza, Marcelo Cecchetti, Celso Zilbovícius, Mayra Morlin, Elaine Gebara, Patrícia Haypek, Cássio Volponi, Ricardo Navarro e Lis Sandra do curso de Odontologia da UniFMU, pelo convívio e amizade;

À Ana Cristina Fruges e família, pelo convívio e aprendizado;

Ao Exmo.Sr. Brigadeiro-Intendente Paulo da Silveira, pela confiança em meu trabalho, amizade e incentivo;

Aos amigos da Força Aérea Brasileira, em especial: Major Roberto, Major Amoêdo, Capitão Miki, aos Tenentes Alvarenga, Armentano, Daniela Biasi, Vanessa, Munhóes, Daniel, Bispo, Monteiro, Remo, Renata, Arruda, Glauce, Fischer, Suzana, 
Andréa Gobbo, Nellice Cardoso, Ricciardelli e João Marcus, aos Sub-Oficiais Toshio e Mael e aos Sargentos Cavalcanti e Emílson;

À Sra. Luzia Maria Z. M. Moraes, pela revisão das referências e da configuração deste trabalho;

À Profa. Dra. Denise Botter, do Instituto de Matemática e Estatística, pelo tratamento estatístico;

À Dental Vipi, que forneceu os dentes artificiais Biolux e Vipi Dent Plus utilizados nesta pesquisa;

À Ivoclar Vivadent, na pessoa do Sr. Herbert Mendes e Sra. Izilda, que me ajudaram na obtenção dos dentes artificiais Ivostar - Gnathostar e Antaris Postaris, utilizados nesta pesquisa;

Ao Prof. Dr. Paulo César Gianinni e ao Engenheiro Isaac Sayeg, pela acolhida no Laboratório de Petrografia Sedimentar (LabPetro), do Instituto de Geociências da Universidade de São Paulo, onde realizei a parte prática deste trabalho;

Aos amigos de sempre: Frederico Gonzalez, Fernando Vianna, Rodrigo Pedroso, Eduardo Arazans Júnior e André Armentano;

Aos amigos ninjas da Odonto Metodista: Marcelo, Rafael, Sandro, Guigo, Denis, Léo, Fred, Mauricy, Wagner, Marcos e Roni;

A todos os colegas de Curso, em especial aos amigos: Éder, Flavio Jun, Ricardo, Tatiana, Ricardo Jun e Roger;

Às secretárias do Departamento de Prótese da FOUSP, Regina de Carvalho Tognassoli, Sandra Maria Gomes da Silva, Valdinéa Barreto da Silva Santos e Coraci Aparecida de Moraes, pelas informações e cooperação; 
Aos funcionários do Departamento de Prótese, Luís Cláudio R. Cavalheiro, Ana Paula Reingruber, Maria José S. Barros, Aldecir F. S. Matos, Marco Antônio M. da Silva, Marlene S. da Silva, Ana Paula Gomes a Maria da Glória D. Colen, pela solicitude e agradável convívio no Departamento;

Às secretárias da seção de Pós-graduação Cátia Tiezzi dos Santos, Nair Natsuko Tanaka Costa e Emília Caetano Pereira, pela amizade e ajuda nas questões da Pós-Graduação;

À CAPES, pela bolsa cedida para esta pesquisa;

E a todas as pessoas, que aqui não foram citadas, mas que de alguma forma ajudaram na realização deste trabalho. 
"Se você conhece o inimigo e conhece a si mesmo, não precisa temer o resultado de cem batalhas. Se você se conhece mas não conhece o inimigo, para cada vitória ganha sofrerá também uma derrota. Se você não conhece nem o inimigo nem a si mesmo, perderá todas as batalhas..."

Sun Tzu 
Mazini P. Avaliação da área de contato dos dentes artificiais em função da forma oclusal e da forma das arcadas na posição de máxima intercuspidação e nos movimentos excursivos [Tese de Doutorado]. São Paulo: Faculdade de Odontologia da USP; 2007.

\section{RESUMO}

Nesta pesquisa, foi analisada a área dos contatos oclusais, em posição de máxima intercuspidação e nos movimentos excursivos de protrusão e lateralidades direita e esquerda. Para tanto, foram utilizados dentes artificiais anatômicos e funcionais, nacionais e importados, montados em arcadas de formas triangular, quadrada e oval. Após o devido ajuste oclusal e, a partir das imagens digitalizadas das próteses em cera, foi realizada a mensuração das áreas demarcadas pelo papel carbono, empregando-se o software Leica Qwin ${ }^{\circledR}$ 550. Os resultados, em milímetros quadrados, foram submetidos à análise estatística (ANOVA e Teste de Tukey). A partir das relações estabelecidas entre os fatores, pode-se concluir que, tanto para o modelo superior quanto para o modelo inferior, as áreas totais em MIC foram maiores que as áreas totais em protrusão. Ainda em protrusão, os segmentos posterior direito, anterior e posterior esquerdo apresentaram áreas iguais. Nos movimentos de lateralidade direita e esquerda, as áreas totais foram menores ou iguais às áreas totais obtidas em MIC. Nas lateralidades, as áreas no lado de trabalho foram maiores que as áreas no lado de balanceio. Na lateralidade direita, a área no lado de trabalho foi maior que a área direita do registro obtido em MIC. Na lateralidade esquerda, a área no lado de trabalho foi maior que a área do segmento esquerdo do registro em MIC. Na lateralidade direita, a área no lado de balanceio foi 
menor que a área do segmento esquerdo do registro em MIC. Na lateralidade esquerda, a área no lado de balanceio foi menor que a área do segmento direito do registro em MIC.

Descritores: Dentes artificiais, área de contato, oclusão, movimentos excursivos, prótese total 
Mazini P. Measurement of occlusal area in prosthetic teeth according to tooth form, arch form and during maximum voluntary clenching and excursive movements [Tese de Doutorado]. São Paulo: Faculdade de Odontologia da USP; 2007.

\section{ABSTRACT}

This study regards the measurement of occlusal area of prosthetic arches, all assembled in triangular, squared and oval arch forms, with functional prosthetic teeth from different manufacturers; occlusal area was measured during maximum voluntary clenching (MVC), protrusive and laterotrusive (right and left) movements. Following arch assembly and occlusal adjustment, occlusal contacts for MVC and eccentric movement were marked by carbon paper, and occlusal areas were measured by means of analysis of standardized digital images and appropriate software (Leica Qwin $\Theta-550)$. Occlusal areas were measured in square millimiters, and resulting values underwent statistical tests (ANOVA and Tukey). Statistical results showed that, for both upper and lower arches, occlusal areas during MVC were greater than during protrusion; also during protrusion, buccal tooth segments, both right and left, showed similar areas. During right and left laterotrusion, occlusal areas were smaller in comparison to MVC, and working sides presented larger areas than balancing sides. During laterotrusion to the right side, occlusal areas measured at the working side were larger than during MVC (right side), and same was observed for the left side during laterotrusion to the left. During laterotrusion to the right side, occlusal areas measured at the balancing side were smaller than during MVC (left side), and similar differences were observed during laterotrusion to the left side. 
Keywords: Artificial tooth; Dental occlusion; Complete denture; Excursive movements 


\section{LISTA DE ILUSTRAÇÕES}

Figura 4.1 - Bases de acetato, conformadas a vácuo

61

Figura 4.2 - Planos de cera superior e inferior 63

Figura 4.3 - Articulador semi-ajustável 64

Figura 4.4 - Modelo superior montado no articulador 65

Figura 4.5 - Guia em cera 66

Figura 4.6 - Camada reta de gesso tipo IV 67

Figura 4.7 - Colocação do gesso tipo IV, com articulador inclinado 67

Figura 4.8 - Camada de espessura uniforme de gesso 68

Figura 4.9 - Modelos montados no articulador 69

Figura 4.10 - Planos de orientação duplicados 70

Figura 4.11 - Plano de orientação fixado na base da mufla 71 
Figura 4.12 - Muralha de gesso pedra

Figura 4.13 - Abertura da mufla para remoção da base e cera pastosa 73

Figura 4.14 - Remoção completa dos excessos de cera 73

Figura 4.15 - Abertura das muflas após a polimerização da resina 74

Figura 4.16 - Planos de orientação após a desinclusão das muflas 75

Figura 4.17 - Planos de orientação - formas quadrada, triangular e oval 76

Figura 4.18 - Planos de orientação de forma triangular 76

Figura 4.19 - Planos de orientação de forma quadrada 77

Figura 4.20 - Planos de orientação de forma oval 77

Figura 4.21 - Plano de orientação superior duplicado 78

Figura 4.22 - Plano de orientação inferior duplicado 79

Figura 4.23 - Planos de orientação em cera (E) e em resina (D) 79

Figura 4.24 - Recorte na cera, para início da montagem dos dentes 81 
Figura 4.25 - Alinhamento vestibular dos dentes em relação ao plano

Figura 4.26 - Alinhamento vestibular dos dentes em relação ao plano 82

Figura 4.27 - Contato dos dentes contra a superfície oclusal do plano 82

Figura 4.28 - Contato dos dentes contra a superfície oclusal do plano 83

Figura 4.29 - Montagem dos dentes do hemiarco direito 83

Figura 4.30 - Prótese total superior, com os dentes anatômicos Vipi-Dent Plus, montados de forma oval 85

Figura 4.31 - Prótese total inferior, com os dentes anatômicos Vipi-Dent Plus, montados de forma oval 85

Figura 4.32 - Prótese total superior, com os dentes anatômicos Vipi-Dent Plus, montados de forma quadrada 86

Figura 4.33 - Prótese total inferior, com os dentes anatômicos Vipi-Dent Plus, montados de forma quadrada 86

Figura 4.34 - Prótese total superior, com os dentes anatômicos Vipi-Dent Plus, montados de forma triangular 87 
Figura 4.35 - Prótese total inferior, com os dentes anatômicos Vipi-Dent Plus, montados de forma triangular 87

Figura 4.36 - Tiras de carbono, posicionadas com auxílio das pinças, entre as próteses totais superior e inferior 90

Figura 4.37 - Base metálica contendo a réplica do modelo mestre superior 92

Figura 4.38 - Base metálica contendo a réplica do modelo mestre inferior. 92

Figura 4.39 - Aletas de metal, para o reposicionamento das bases metálicas sob a lente macroscópica 93

Figura 4.40 - Lente macroscópica digital 94

Figura 4.41 - Tela inicial do programa Leica Qwin ${ }^{\circledR} 550$ 95

Figura 4.42 - Rotina para o tratamento das imagens digitalizadas 96

Figura 4.43 - Seleção e abertura da imagem a ser tratada 97

Figura 4.44 - Identificação inicial das marcas do carbono 98

Figura 4.45 - Zoom aplicado sobre a imagem 99 
Figura 4.46 - Reconhecimento completo das marcas do carbono 100

Figura 4.47 - Identificação completa dos contatos oclusais 101

Figura 4.48 - Delimitação da região de interesse 102

Figura 4.49 - Reconhecimento das superfícies oclusais 103

Figura 4.50 - Imagem tratada, antes da mensuração 104

Figura 4.51 - Alteração na rotina, para mensuração de segmento de dentes ....... 104 


\section{LISTA DE TABELAS}

Tabela 5.1 - Média e desvio padrão (DP) para a variável Área em protrusão inferior 107

Tabela 5.2 - Média e desvio padrão (DP) para a variável Área em protrusão superior 107

Tabela 5.3 - Análise de Variância (ANOVA) para a variável Área em protrusão inferior 108

Tabela 5.4 - Análise de Variância (ANOVA) para a variável Área em protrusão superior 109

Tabela 5.5 - Análise de Variância (ANOVA) para a variável Área (ProTotal - Inferior) 110

Tabela 5.6 - Agrupamento de médias (ProTotal - Inferior) 110

Tabela 5.7 - Análise de Variância (ANOVA) para a variável Área (PostDir - Inferior) 111

Tabela 5.8 - Análise de Variância (ANOVA) para a variável Área (PostEsq - Inferior) 112 
Tabela 5.9 - Agrupamento de médias (PostDir e PostEsq - Inferior)

Tabela 5.10 - Análise de Variância (ANOVA) para a variável Área (Ant - Inferior) 113

Tabela 5.11 - Agrupamento de médias (Ant - Inferior) 113

Tabela 5.12 - Análise de Variância (ANOVA) para a variável Área (ProTotal Superior) 114

Tabela 5.13 - Agrupamento de médias (ProTotal - Superior) 114

Tabela 5.14 - Análise de Variância (ANOVA) para a variável Área (PostDir Superior) 115

Tabela 5.15 - Análise de Variância (ANOVA) para a variável Área (Ant - Superior)116

Tabela 5.16 - Agrupamento de médias (Ant - Superior) 116

Tabela 5.17 - Análise de Variância (ANOVA) para a variável Área (PostEsq Superior) 117

Tabela 5.18 - Agrupamento de médias (PostEsq - Superior) 117 
Tabela 5.19 - Comparações das médias da variável Área entre algumas categorias da variável Movimento para os tratamentos AIO, AIQ, ANO, FIT e FNT - Protrusão inferior 118

Tabela 5.20 - Comparações das médias da variável Área entre algumas categorias da variável Movimento para o tratamento ANQ, ANT, FIO, FIQ, FNO e FNQ - Protrusão inferior 118

Tabela 5.21 - Comparações das médias da variável Área entre algumas categorias da variável Movimento para o tratamento AIT - Protrusão inferior .. 118

Tabela 5.22 - Comparações das médias da variável Área entre algumas categorias da variável Movimento para os tratamentos ANQ, ANT, ANO, FIO, FNO e FNQ - Protrusão superior 119

Tabela 5.23 - Comparações das médias da variável Área entre algumas categorias da variável Movimento para os tratamentos AIT, AIQ, AIO, FIT, FIQ e FNT - Protrusão superior 119

Tabela 5.24 - Média e desvio padrão (DP) para a variável Área (Lateralidade direita) 120

Tabela 5.25 - Média e desvio padrão (DP) para a variável Área (Lateralidade esquerda) 121 
Tabela 5.26 - Análise de Variância (ANOVA) em lateralidade direita para a variável Área.

Tabela 5.27 - Análise de Variância (ANOVA) em lateralidade esquerda para a variável Área 123

Tabela 5.28 - Análise de Variância (ANOVA) para a variável Área (LDTotal) 124

Tabela 5.29 - Agrupamento de médias (LDTotal) 124

Tabela 5.30 - Análise de Variância (ANOVA) para a variável Área (LDTrab) 125

Tabela 5.31 - Agrupamento de médias (LDTrab) 125

Tabela 5.32 - Análise de Variância (ANOVA) para a variável Área (LDBal). 126

Tabela 5.33 - Agrupamento de médias (LDBal) 126

Tabela 5.34 - Análise de Variância (ANOVA) para a variável Área (LETotal)

Tabela 5.35 - Agrupamento de médias (LETotal). 127

Tabela 5.36 - Análise de Variância (ANOVA) para a variável Área (LETrab). 128

Tabela 5.37 - Agrupamento de médias (LETrab) 128 
Tabela 5.39 - Agrupamento de médias (LEBal) 130

Tabela 5.40 - Comparações das médias da variável Área entre algumas categorias da variável Movimento para os tratamentos ANQ e ANO (Lado direito inferior) 130

Tabela 5.41 - Comparações das médias da variável Área entre algumas categorias da variável Movimento para o tratamento ANT (Lado direito inferior)131

Tabela 5.42 - Comparações das médias da variável Área entre algumas categorias da variável Movimento para os tratamentos AIQ, AIT e FIT (Lado direito inferior) 131

Tabela 5.43 - Comparações das médias da variável Área entre algumas categorias da variável Movimento para os tratamentos AIO, FIQ e FIO (Lado direito inferior) 131

Tabela 5.44 - Comparações das médias da variável Área entre algumas categorias da variável Movimento para o tratamento FNQ (Lado direito inferior)131

Tabela 5.45 - Comparações das médias da variável Área entre algumas categorias da variável Movimento para os tratamentos FNT e FNO (Lado direito inferior) 
Tabela 5.46 - Comparações das médias da variável Área entre algumas categorias da variável Movimento para os tratamentos ANQ e FIT (Lado esquerdo inferior) 132

Tabela 5.47 - Comparações das médias da variável Área entre algumas categorias da variável Movimento para o tratamento ANT e FIQ (Lado esquerdo inferior) 132

Tabela 5.48 - Comparações das médias da variável Área entre algumas categorias da variável Movimento para os tratamentos AIO, AIT, ANO e FIO (Lado esquerdo inferior) 132

Tabela 5.49 - Comparações das médias da variável Área entre algumas categorias da variável Movimento para o tratamento $\mathrm{AIQ}$ (Lado esquerdo inferior) 132

Tabela 5.50 - Comparações das médias da variável Área entre algumas categorias da variável Movimento para o tratamento FNQ (Lado esquerdo inferior) 132

Tabela 5.51 - Comparações das médias da variável Área entre algumas categorias da variável Movimento para os tratamentos FNT e FNO (Lado esquerdo inferior) 133 
Tabela 5.52 - Média e desvio padrão (DP) para a variável Área (Lateralidade direita) 133

Tabela 5.53 - Média e desvio padrão (DP) para a variável Área (Lateralidade esquerda) 134

Tabela 5.54 - Análise de Variância (ANOVA) em lateralidade direita para a variável Área. 135

Tabela 5.55 - Análise de Variância (ANOVA) em lateralidade esquerda para a variável Área 135

Tabela 5.56 - Comparações entre médias da variável Área (LDTotal) 136

Tabela 5.57 - Agrupamento de médias (LDTotal) 136

Tabela 5.58 - Análise de Variância (ANOVA) para a variável Área (LDTrab) 137

Tabela 5.59 - Agrupamento de médias (LDTrab)

Tabela 5.60 - Análise de Variância (ANOVA) para a variável Área (LDBal). 138

Tabela 5.61 - Agrupamento de médias (LDBal) 138

Tabela 5.62 - Análise de Variância (ANOVA) para a variável Área (LETotal 139 
Tabela 5.63 - Agrupamento de médias (LETotal)

Tabela 5.64 - Análise de Variância (ANOVA) para a variável Área (LETrab)........ 140

Tabela 5.65 - Agrupamento de médias (LETrab) …....................................... 140

Tabela 5.66 - Análise de Variância (ANOVA) para a variável Área (LEBal) .......... 141

Tabela 5.67 - Agrupamento de médias (LEBal) …......................................... 141

Tabela 5.68 - Comparações das médias da variável Área entre algumas categorias da variável Movimento para o tratamento ANQ (Lado direito superior) 141

Tabela 5.69 - Comparações das médias da variável Área entre algumas categorias da variável Movimento para os tratamentos ANT, ANO e AIO (Lado direito superior) 141

Tabela 5.70 - Comparações das médias da variável Área entre algumas categorias da variável Movimento para os tratamentos AIQ, AIT e FIT (Lado direito superior) 142

Tabela 5.71 - Comparações das médias da variável Área entre algumas categorias da variável Movimento para os tratamentos FNO, FIQ e FNQ (Lado direito superior) 142 
Tabela 5.72 - Comparações das médias da variável Área entre algumas categorias da variável Movimento para o tratamento FNT (Lado direito superior) 142

Tabela 5.73 - Comparações das médias da variável Área entre algumas categorias da variável Movimento para o tratamento FIO (Lado direito superior)142

Tabela 5.74 - Comparações das médias da variável Área entre algumas categorias da variável Movimento para o tratamento ANQ (Lado esquerdo superior) 142

Tabela 5.75 - Comparações das médias da variável Área entre algumas categorias da variável Movimento para os tratamentos ANT, ANO, AIT e AIO (Lado esquerdo superior) 142

Tabela 5.76 - Comparações das médias da variável Área entre algumas categorias da variável Movimento para os tratamentos AIQ, FIQ e FIT (Lado esquerdo superior) 143

Tabela 5.77 - Comparações das médias da variável Área entre algumas categorias da variável Movimento para os tratamentos FNO e FNQ (Lado esquerdo superior) 143 
Tabela 5.78 - Comparações das médias da variável Área entre algumas categorias da variável Movimento para o tratamento FNT (Lado esquerdo

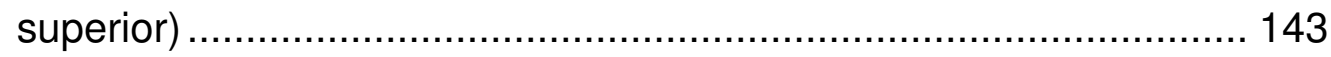

Tabela 5.79 - Comparações das médias da variável Área entre algumas categorias da variável Movimento para o tratamento FIO (Lado esquerdo superior) 


\section{LISTA DE ABREVIATURAS E SIGLAS}

O.C. - Oclusão Central

R.C. - Relação Central

(E) - Esquerda

(D) - Direita

MIC - Máxima intercuspidação

Anat. - Anatomia

Orig. - Origem

PROT. - Protrusão

Lat.trab. - Lado de trabalho

Lat.Bal. - Lado de balanceio

Lat.Dir. - Lateralidade direita

Lat.Esq. - Lateralidade esquerda

Mont. - Tipos de montagem

mm² - Milímetros quadrados 


\section{SUMÁRIO}

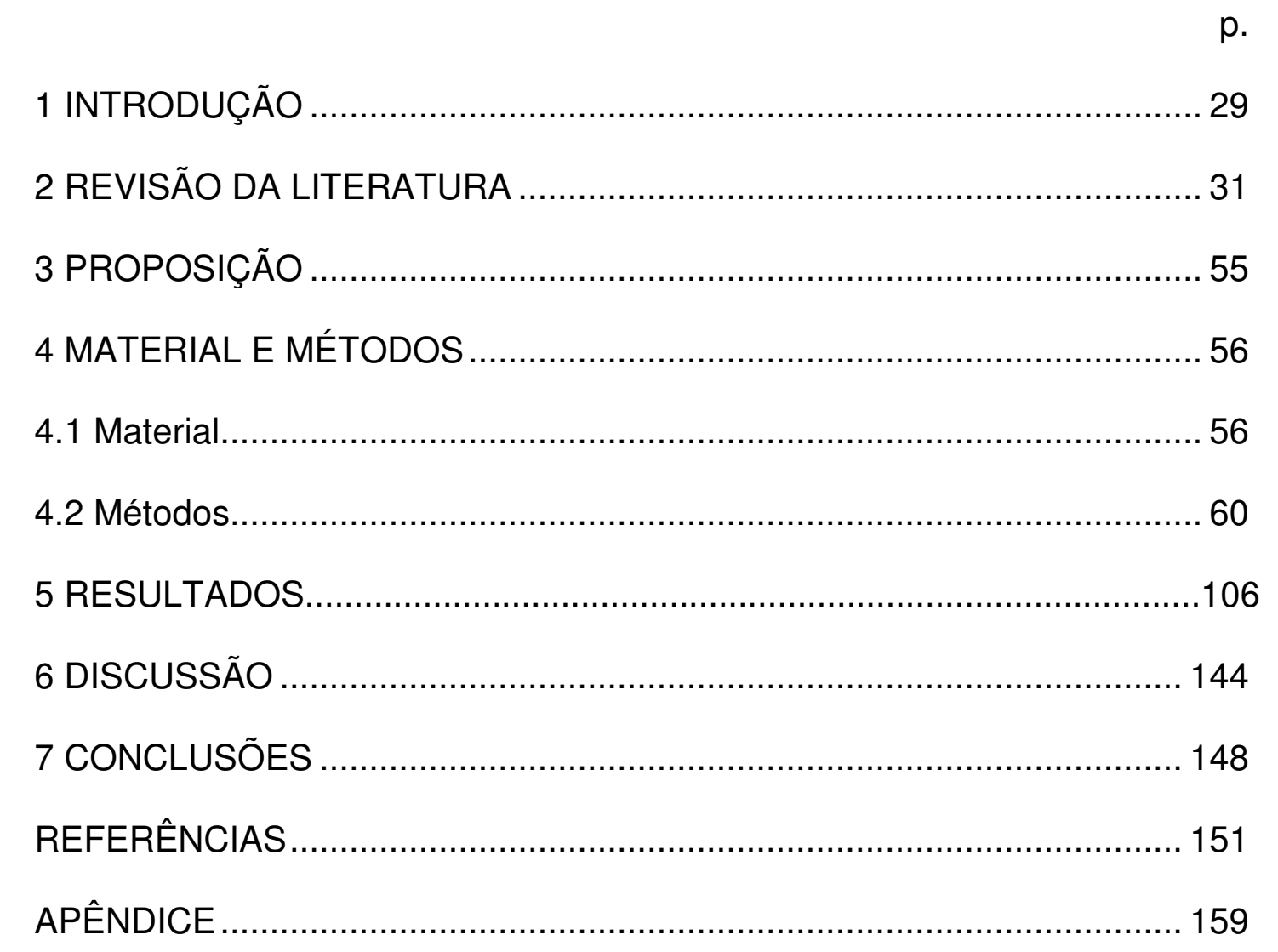




\section{INTRODUÇÃO}

As relações oclusais entre os dentes, sejam esses naturais ou artificiais, na reabilitação de pacientes dentados ou não mostram-se tão fundamentais quanto negligenciadas, ultimamente, na realização de ajustes oclusais ou confecção de próteses dentárias. Na confecção das próteses totais, um correto relacionamento entre os dentes artificiais, de forma que todas as cúspides toquem com igual pressão quaisquer que sejam as direções excursivas da mandíbula durante os movimentos fisiológicos (MEYER, 1934), mostra-se fundamental para que haja um perfeito sincronismo com o padrão de contração dos músculos mastigatórios (RAMFJORD, 1982) e um alinhamento ideal entre os dentes.

Ciente de sua responsabilidade, a Disciplina de Prótese Total da Faculdade de Odontologia da Universidade de São Paulo tem realizado diversas pesquisas com o propósito de contribuir ao máximo com a especialidade. Nesse sentido, foram estudadas e desenvolvidas diversas metodologias, tanto para procedimentos laboratoriais quanto clínicos, na busca de elaborar um protocolo de atendimento mais próximo do ideal. Nessa linha de pesquisa da Disciplina, encontram-se estudos como a adesão entre dentes artificiais e bases de próteses (HONDA, 2001), tipos de muralha empregado nas muflas durante o processamento das próteses (RIBEIRO, 2002), alterações dimensionais das resinas acrílicas para bases de próteses totais (YAMAGUCHI, 2006; GUARNIERI, 2006), estudo dos movimentos de laterotrusão condilar nos movimentos de lateralidade centrífuga e de Bennett em edentados completos (HATUSHIKANO, 2006), entre outros. 
Portanto, ao saber que os dentes são um dos fatores determinantes da oclusão e importantes para as estruturas de suporte da prótese total e demais componentes do sistema estomatognático, faz-se necessário um amplo conhecimento quanto às suas características, formas e relações oclusais. Diante dessas premissas, a presente pesquisa vem contribuir para a elucidação desse assunto por meio da mensuração dos contatos oclusais obtidos nos movimentos excursivos de protrusão e lateralidades direita e esquerda, em dentes artificiais anatômicos e funcionais, nacionais e importados. 


\section{REVISÃO DA LITERATURA}

Ao continuarmos os estudos dos dentes artificiais, os quais apresentaram como variáveis a anatomia (dentes anatômicos ou funcionais), a disposição dos dentes nas diferentes formas anatômicas do rebordo alveolar residual (formas quadrangular, triangular e oval) e a origem dos dentes artificiais (nacional ou importado), procuramos sintetizar a revisão da literatura existente no sentido de nos atermos às referências que tratam exclusivamente das características morfológicas dos dentes artificiais e dos aspectos relacionados à oclusão entre os dentes, sejam eles naturais ou artificiais. Dessa forma, apesar de cientes do vasto histórico de estudos sobre os dentes artificiais, deixaremos de abordar as características dos dentes artificiais quanto a sua constituição, de resina ou porcelana, com recobrimento metálico ou não, por entendermos não ser este o cerne de nossa discussão. A partir dessa premissa, apresentamos uma revisão de literatura cronológica, baseada na morfologia dos dentes e dos aspectos relacionados à oclusão entre os mesmos.

A articulação balanceada foi introduzida em 1899 por Bonwill, segundo Saizar (1972), quando do lançamento de seu articulador baseado na "Teoria do triângulo equilátero", o qual apresentava as guias condílicas em posição horizontal. Para o autor, o arco dentário protético deve ter no mínimo três pontos de contato com o antagonista sendo dois laterais, um de cada lado, e um anterior, quaisquer que fossem as excursões mandibulares realizadas.

Em 1926, Hanau enunciou as "Leis da articulação balanceada" embasada em cinco variáveis que, quando inter-relacionadas harmoniosamente, asseguravam o 
balanceio da articulação: guia condilar, curva de compensação, guia incisal, altura das cúspides e plano de orientação.

Preocupado em obter uma oclusão balanceada e funcional, Meyer (1934) descreveu o seu método de confecção das próteses totais, o qual procurava conseguir que todas as cúspides tocassem com igual pressão, quaisquer que fossem as direções excursivas da mandíbula durante os movimentos fisiológicos. Para isso, determinava a trajetória percorrida pelos dentes durante os movimentos mandibulares, isto é, estabelecia a curva de compensação própria de cada indivíduo nos roletes de cera, fisiologicamente, e, com base na mesma, realizava a montagem dos dentes. A experiência levou o autor às seguintes conclusões:

a- nas próteses totais bimaxilares, os contatos do lado de balanceio devem ser previstos para as excursões extremas da mandíbula visando assegurar o balanceio, qualquer que seja o intervalo do percurso;

b- a correta curva oclusal do paciente deve ser conhecida e registrada para que as próteses possam ser construídas com balanceio adequado;

c- o balanceio oclusal proporciona estabilidade da prótese total por mais tempo.

Schuyler (1935) relatou que o estresse anormal ou excessivo seria uma das principais causas da destruição dos tecidos de suporte dos dentes naturais e dos rebordos desdentados. Por isso, enfatizou a necessidade da redução das forças essenciais aplicadas no ato da mastigação, promovendo a distribuição das mesmas de maneira a favorecer aqueles tecidos de suporte. Dentre os fatores que influem na desarmonia oclusal dos arcos dentários, natural e artificial, apontou como fundamentais: a inclinação de face palatina dos dentes anteriores superiores, a inclinação da guia ocluso-lingual dos dentes posteriores inferiores e a vestíbulooclusal dos dentes posteriores superiores. A relação harmônica entre os referidos 
fatores induzem a uma distribuição mais adequada das pressões quando a mandíbula passa da posição de oclusão excêntrica para a oclusão cêntrica. Nesse caso, no lado de balanceio, a cúspide palatina superior é um ponto de contato que desliza ao longo da vertente de balanceio vestíbulo-oclusal do dente inferior. Este plano de balanceio deve estar em harmonia com os correspondentes do lado oposto, de trabalho. Para o autor, nas próteses totais, não há necessidade dos contatos dos dentes anteriores em relação cêntrica (R.C.) maxilo-mandibular para distribuição da pressão mastigatória em toda área basal.

Thompson (1937), ao acreditar que a eficiência mastigatória se mostrava essencial para a reabilitação do órgão mastigatório, desenvolveu um experimento in vivo, no qual comparou a eficiência mastigatória de dentes artificiais anatômicos, com inclinação cuspídica de 30 e 20 graus, com aquela de dentes artificiais nãoanatômicos. A partir dos resultados obtidos, concluiu que os dentes artificiais anatômicos com inclinação cuspídica de 30 e 20 graus foram mais eficientes do que os artificiais não- anatômicos.

Para Dahlberg (1942), a eficiência mastigatória dos dentes naturais é determinada pelo maior número de contatos interoclusais. Registrou que, normalmente, em oclusão cêntrica (O.C.), existem 32 contatos, sendo 26 nos dentes posteriores e nos caninos e 6 nos incisivos.

Schuyler (1947) constatou que em posição de O.C., a relação intercuspídica deveria apresentar 28 pontos de contato dados pelas cúspides de contenção. No mesmo trabalho o autor apresentou o notável esquema ordenado do desgaste seletivo para os dentes naturais, cujos fundamentos são respeitados ainda na atualidade e consistem essencialmente em:

a- coordenação das posições O.C. e R.C. - nesta posição, a decisão do desgaste 
deveria ser tomada com base nos seguintes critérios:

- se as cúspides prematuras interferiam nos deslizes cêntricos e excêntricos, os ajustes eram realizados nas cúspides traumatizadas;

- se as interferências das cúspides prematuras fossem verificadas apenas em cêntrica e não nas posições excêntricas, os ajustes seriam feitos nos dentes antagonistas.

b- em excursão protrusiva - neste movimento, o desgaste seletivo tem por objetivo propiciar contatos entre as bordas incisais dos dentes anteriores e ao mesmo tempo a ausência de contatos entre os dentes posteriores.

c- em excursões laterais - tem por objetivo conseguir contatos uniformes no lado de trabalho e ausência de contato do lado de balanceio.

Manly e Vinton (1951), ao investigarem in vivo os fatores que consideraram relevantes à eficiência mastigatória em pacientes portadores de próteses, afirmaram não ser evidente a indicação de que o desempenho mastigatório proporcionado por dentes artificiais anatômicos fosse melhor do que aquele obtido por dentes artificiais não-anatômicos. Notaram também, que a estabilidade da prótese tem ação significante sobre a eficiência mastigatória, uma vez que próteses mais estáveis apresentaram resultados de 38 a $47 \%$ melhores em relação à eficiência mastigatória, quando comparadas a outras próteses pouco estáveis. Outro fator considerado, a extensão do movimento de lateralidade, também demonstrou ser capaz de afetar o desempenho mastigatório: a restrição desse movimento limita a eficiência mastigatória.

Em continuidade à pesquisa anteriormente publicada quanto à eficiência mastigatória, Manly e Vinton (1951) também consideraram que pacientes mais jovens desenvolviam uma força de mordida maior do que pacientes idosos, com 
conseqüente melhora do desempenho mastigatório. Quanto ao sexo, os autores afirmaram não haver indícios de sua influência no grau de eficiência mastigatória e reforçaram, como no artigo anterior, a idéia de não haver diferença estatisticamente comprovada entre o desempenho mastigatório proporcionado por dentes artificiais anatômicos e não-anatômicos.

Payne (1951) realizou experimento in vivo, no qual dentes artificiais anatômicos com inclinação cuspídica de 33 graus e dentes artificiais não-anatômicos foram comparados quanto à eficiência mastigatória, atuando na trituração de amendoins e cenouras cruas. Considerando-se o aspecto visual final dos alimentos triturados, o autor afirmou que os dentes artificiais anatômicos apresentavam uma melhor eficiência mastigatória.

Jordan (1951), ao verificar que as superfícies oclusais dos dentes artificiais poderiam interferir na estabilização e retenção da prótese, escreveu, baseado em sua experiência clínica, que os dentes artificiais não- anatômicos oferecem melhor estabilização à base da prótese e, conseqüentemente, maior conforto ao paciente.

Shanahan (1952), estudando a fisiologia mastigatória em desdentados totais, observou que, em alguns movimentos mandibulares, os dentes inferiores contactavam os superiores e, em outros movimentos, não. Dividiu os movimentos que envolvem contatos dentários em dois tipos: mastigatórios e não-mastigatórios. Nos mastigatórios, a mandíbula se move em ciclos, e os contatos oclusais ocorrem na fase final de cada ciclo. Os movimentos não-mastigatórios são relativos às excursões laterais e protrusivas. $\mathrm{O}$ autor sugeriu que $\mathrm{o}$ ajuste oclusal fosse feito tanto nas excursões laterais e protrusivas como em função dos ciclos de mastigação.

Trapozzano e Lazzari (1952), ao pesquisarem a forma oclusal do dente 
artificial posterior capaz de oferecer uma melhor eficiência mastigatória, divulgaram um experimento in vivo, em que dentes artificiais anatômicos com inclinação cuspídica de 20 graus foram comparados a dentes artificiais não-anatômicos quanto à eficiência mastigatória na trituração de alimentos como cenoura e amendoim. Com o resultado, os autores enfatizaram que os pacientes portadores de próteses com dentes não-anatômicos apresentaram maior quantidade de ulcerações na fibromucosa, o que não foi verificado nos pacientes portadores de próteses com dentes artificiais anatômicos, sendo que estas últimas apresentaram-se mais confortáveis e $32,5 \%$ mais eficientes na mastigação do que as primeiras.

Payne (1952), ao verificar por meio de sua experiência clínica, que a presença de cúspides ocasionava um aumento da instabilidade da base da prótese, indicou os dentes artificiais não-anatômicos para pacientes que apresentavam um rebordo ósseo alveolar plano e grande distância intermaxilar. Concluiu, desse modo, que, na ocorrência de uma maior quantidade de forças verticais e um mínimo de forças horizontais durante a mastigação, a utilização desses dentes minimiza o deslizamento da base da prótese sobre os tecidos de suporte.

Jankelson et al. (1953), com base em estudo fisiológico, notaram que a oclusão central era a única posição em que ocorriam contatos dentários de algum significado durante as funções do sistema estomatognático e que não se observou o balanceio dentário excêntrico durante a mastigação. Concluíram então que o balanceio nas posições excêntricas não seria uma necessidade fisiológica ou que a falta do mesmo contribuísse para uma função mastigatória pior.

Pleasure (1953), ao estudar as formas oclusais existentes em dentes artificiais posteriores, relatou que o dente artificial anatômico possibilita a obtenção de uma oclusão balanceada, o que favorece a estabilização da prótese durante a 
mastigação. O autor atribuiu extrema importância a essa característica, pois, dessa forma, menor será o deslocamento da base da prótese sobre a fibromucosa e, conseqüentemente, a possibilidade de irritação do tecido mole subjacente.

Frechette (1955), ao analisar in vivo a relação entre as diferentes formas oclusais dos dentes artificiais posteriores e a direção da carga mastigatória transmitida ao rebordo ósseo alveolar, observou que o dente artificial anatômico com inclinação cuspídica de 30 graus possibilitou uma diminuição da pressão vertical e o aumento da pressão lateral transmitidas à base da prótese. $O$ autor também verificou a inversão dos resultados quando dentes artificiais não-anatômicos foram utilizados.

Stromberg (1955), partindo do princípio de que a magnitude da pressão lateral transmitida à base da prótese variava de acordo com a morfologia oclusal do dente artificial posterior, afirmou, por meio de experimento realizado in vivo, que o dente artificial anatômico com inclinação cuspídica de 33 graus, quando comparado ao dente artificial não-anatômico, gerou, em pacientes com acentuada potência muscular, o dobro da pressão lateral transmitida à base da prótese.

Sharry et al. (1956) questionaram a relação entre as diversas formas oclusais dos dentes artificiais posteriores e a magnitude da carga mastigatória que atinge o rebordo ósseo alveolar. Observaram, em trabalho executado in vitro, que próteses totais confeccionadas com plano oclusal com inclinação de 30 graus transmitiram uma carga maior ao rebordo ósseo alveolar do que aquela transmitida por próteses totais confeccionadas com plano oclusal horizontal, ao serem submetidas a uma força de 6 quilos. Quatro anos depois, ao refazerem o experimento, os autores obtiveram os mesmos resultados (SHARRY et al., 1960). 
Kydd (1956), ao relacionar in vivo o grau de deformação horizontal que poderia ocorrer na base da prótese com as diversas formas oclusais dos dentes artificiais posteriores, concluiu que a deformação verificada mostrou-se diretamente proporcional à resultante horizontal, proveniente da força mastigatória, e que o dente artificial anatômico com inclinação cuspídica de 33 graus provocou uma pressão horizontal na base da prótese $50 \%$ maior do que aquela causada pelo dente artificial não- anatômico.

Kaires (1957), ao realizar um estudo sobre os contatos oclusais em portadores de próteses totais, notou que os contatos do lado de balanceio eram mais numerosos do que os do lado de trabalho. Atribuiu esse fato à movimentação da prótese quando em função mastigatória devido ao deslocamento da fibromucosa da área de suporte.

Swenson (1958), ao relatar que a seleção do dente artificial posterior variava de acordo com a necessidade de cada caso, indicou o dente artificial de resina acrílica para situações em que o espaço intermaxilar fosse reduzido. A colocação de um dente artificial de porcelana nesses espaços exigiria um grande desgaste do elemento, possibilitando uma fratura da porcelana durante o esforço mastigatório. Para a utilização do dente artificial de porcelana, indicou os casos clínicos em que existe a presença de espaço intermaxilar suficiente para a sua colocação.

Kaires (1958) analisou in vivo a distribuição da carga mastigatória que ocorre sobre o dente suporte e as estruturas adjacentes, em pacientes portadores de prótese parcial removível de extremidade livre bilateral. Concluiu que dentes artificiais anatômicos com menor dimensão de superfície oclusal reduzem a carga mastigatória que incide sobre esses elementos. Entretanto, notou também uma 
redução de $9 \%$ na eficiência mastigatória, quando comparados a dentes artificiais anatômicos com maior dimensão de superfície oclusal.

Trapozzano (1959), consciente de que a eficiência mastigatória apresenta-se como um requisito fundamental para a seleção do dente artificial, pesquisou in vivo qual anatomia oclusal do dente artificial propiciaria melhores conforto e eficiência mastigatória. Concluiu que o dente artificial anatômico com inclinação cuspídica de 30 graus mostrou-se mais eficiente e também mais confortável, quando comparado ao dente artificial não-anatômico.

Tamaki (1960) em um estudo sobre a curva de compensação, concluiu que a "Técnica do desgaste de Paterson" determinava uma curva oclusal individual bastante confiável e que as próteses totais cujos dentes eram montados em conformidade com essa curva apresentavam contatos intercuspídicos, tanto no lado de trabalho como no de balanceio.

Trapozzano (1960), ao realizar um estudo comparativo entre a oclusão balanceada e não-balanceada em próteses totais, constatou que, na opinião dos pacientes que se submeteram aos testes, não foram verificadas diferenças significativas no que tange à mastigação ou a comodidade.

Brewer e Hudson (1961), por meio da aplicação de um aparelho eletrônico miniaturizado, estudaram os contatos dentários em próteses totais. Observaram que o número de contatos variava de indivíduo para indivíduo, conforme a morfologia cuspídica e também com as diferentes consistências dos alimentos. No estudo piloto realizado em dois pacientes, um deles exibiu um número muito maior de contatos do que o outro.

Woelfel et al. (1962), ao visualizarem a possível interferência das diferentes formas oclusais dos dentes artificiais na estabilidade da base da prótese e no 
conforto do paciente, salientaram, por meio de trabalho realizado in vivo, que a forma oclusal do dente artificial interfere na estabilidade da base da prótese apenas quando as condições do rebordo ósseo alveolar eram desfavoráveis. E que, os dentes artificiais anatômicos com inclinação cuspídica de 30 e 20 graus e os nãoanatômicos, desde que corretamente posicionados e balanceados, não atuariam negativamente, de forma significante, no conforto e na estabilidade da base da prótese.

Franks (1962), ao questionar a resistência à abrasão, que poderia ocorrer no dente artificial de resina acrílica, realizou um experimento in vivo, em que 140 pacientes receberam próteses totais superior e inferior com dentes artificiais anatômicos de resina acrílica. Após um acompanhamento de cinco anos, o autor indicou que havia uma relação entre a incidência de fraturas de base das próteses e o grau de desgaste dos dentes artificiais presentes. Revelou também não existir correlação entre o desgaste do dente artificial e o período diário em que as próteses foram usadas, sugerindo que o desgaste verificado deu-se pela abrasão causada por alimentos e não pelo contato dentário. Como conseqüência do desgaste dos dentes artificiais posteriores, houve perda da oclusão em relação central, o que fez com que o paciente deslocasse sua mandíbula para uma posição mais protrusiva, na tentativa de obter uma nova posição de oclusão central.

Landa (1962) escreveu: "a oclusão balanceada nas direções ânteroposteriores e laterais é essencial para a função das próteses totais, pois promove equilíbrio, retenção e estabilidade". Segundo o autor, a maior diferença entre as próteses com e sem a articulação balanceada não estaria tanto na eficácia mastigatória mas na contribuição para o conforto e retenção, resultante do desenvolvimento de uma intimidade de contato entre a base das mesmas e a 
mucosa da área de suporte.

Trapozzano (1963) apresentou uma revisão analítica das "Leis de articulação de Hanau" e declarou que dos cinco fatores variáveis considerados pelo autor, apenas três eram necessários para obtenção da articulação balanceada: guia condilar, guia incisal e cúspides. Na apresentação das suas leis eliminou, portanto, a inclinação do plano-de-orientação e a curva de compensação e enunciou a sua "Tríade da oclusão", de maneira muito mais simples do que as leis propostas por Hanau.

Weinberg (1964) observou que $81 \%$ dos 100 indivíduos dentados estudados apresentavam contatos intercuspídicos no lado de trabalho durante as excursões laterais, e desses, apenas $19 \%$ eram guiados pelo canino. Afirmou também que a presença de contatos intercuspídicos no lado de balanceio, em pacientes dentados, mostra-se potencialmente mais destrutiva ao periodonto de suporte e que este tipo de contato seria desejável apenas em próteses totais.

Adams e Zander (1964) confirmaram a existência de contatos dentários laterais durante o ciclo mastigatório. Pesquisando os contatos funcionais em cêntrica e lateralidade, usando um rádio-transmissor em miniatura, registraram um total de 666 contatos laterais, sendo 412 durante o movimento de fechamento e 254 durante o movimento de abertura.

Kapur et al. (1965), em estudo in vivo, analisaram a interferência de alguns fatores na eficiência mastigatória como: dimensão ântero-posterior da superfície oclusal, sulcos oclusais e a presença de dispositivos metálicos denominados cutters bars. Como achados, os autores declararam que não houve mudança na média da eficiência mastigatória obtida pela redução ou aumento na dimensão da superfície 
oclusal no sentido ântero-posterior e que houve aumento significativo na eficiência mastigatória, tanto pela inserção de sulcos oclusais, como das cutters bars.

Johnson (1965), ao verificar in vitro que fatores como a forma oclusal dos dentes artificiais posteriores e a sua disposição em relação à crista do rebordo ósseo alveolar podem influenciar na magnitude da tensão interna que acomete a base da prótese, concluiu que tanto a utilização do dente artificial não-anatômico como sua colocação na região correspondente ao topo da crista do rebordo ósseo alveolar reduzem a carga transmitida a essa estrutura.

Thomson (1965) declarou que o desgaste que acomete o dente artificial de resina pode acarretar tanto a instabilidade da base da prótese, como o trauma nos tecidos subjacentes. Esse desgaste pode ser causado ou pelo contato entre o dente artificial e o dente oponente, ou pelo contato entre o dente artificial e o alimento, 0 que é notório especialmente em pacientes que têm por hábito a ingestão de verduras, doces duros ou nozes.

Swoope e Kydd (1966) avaliaram in vivo o efeito da dimensão da superfície oclusal e a presença de cúspides sobre a deformação da base da prótese. Salientaram que a utilização do dente artificial não-anatômico resultou em uma diminuição da carga mastigatória horizontal, direcionada a essa estrutura, quando comparado ao dente artificial anatômico com inclinação cuspídica de 33 graus. Acrescentaram ainda a existência de dúvidas quanto ao efeito da redução da dimensão da superfície oclusal sobre a carga mastigatória horizontal, devido aos duvidosos resultados obtidos.

Nars et al. (1967), enfatizando a eficiência mastigatória numa reabilitação bucal, realizaram experimento in vitro no qual observaram o efeito da angulação cuspídica do dente artificial posterior sobre a trituração de alimentos como 
amendoim torrado e cenoura crua. De acordo com os resultados obtidos, declararam não haver diferença significativa na eficiência mastigatória quando dentes artificiais anatômicos com inclinação cuspídica de 33 e 20 graus foram comparados a dentes artificiais não-anatômicos. Entretanto, verificaram diferença estatisticamente significante na comparação entre 0 dente artificial anatômico com inclinação cuspídica de 45 graus e o dente artificial não-anatômico.

Neill (1967) estudou, em seis pacientes, os contatos das superfícies oclusais de suas dentaduras completas, por meio de transmissores colocados nas dentaduras inferiores. Concluiu que a maioria dos contatos ocorreu em cêntrica, e que, nos 413 ciclos registrados, o número de contatos foi maior no lado de balanceio (69\%) do que no lado de trabalho $(29 \%)$.

Moses (1968), discutindo as diferentes formas oclusais dos dentes artificiais posteriores, verificou que a utilização do dente artificial com cúspides pode gerar a presença de interferências oclusais durante os movimentos excursivos da mandíbula, com conseqüente instabilidade da base da prótese e formação de cargas regionais prejudiciais, as quais poderão resultar em reorganização dos elementos ósseo e mucoso subjacentes. Baseando-se nesses fatos, o autor declarou que a ausência de cúspides, por causar redução de cargas localizadas, é mais compatível tanto para a dentição natural, como para a artificial.

Beyron (1969) relatou que os contatos que ocorrem durante a mastigação eram, em sua maioria, realizados na posição de oclusão. Na deglutição, os contatos poderiam ocorrer no intervalo entre a oclusão e a retrusão, posições essas que não coincidem na maioria das pessoas. Para o autor, os contatos dentários em excursões laterais mostram-se ocorrências normais na mastigação, sendo mais 
favoráveis quando vários dentes entram em contato, e por isso, o contato em um só dente deveria ser evitado ou restrito.

Griffiths et al. (1970) estudaram o problema da perda de eficiência mastigatória que ocorre devido ao desgaste do dente artificial de resina acrílica. Desenvolveram uma técnica simples e acessível, em que restaurações de amálgama foram feitas nas superfícies oclusais dos dentes artificiais posteriores de resina acrílica, sem que houvesse qualquer envolvimento de ponta de cúspide. Os autores atribuíram resultados satisfatórios a essa técnica, tais como conforto, estética e eficiência mastigatória durável.

Jozefowicz (1970), em estudo in vivo da influência que a utilização de prótese tem sobre a atrofia do rebordo ósseo alveolar, declarou que a ação mecânica desfavorável da base da prótese, ou seja, sua instabilidade, poderia acarretar distúrbios inflamatórios no tecido mole subjacente, os quais resultariam, por algum mecanismo desconhecido, em um processo irreversível na perda da altura do rebordo ósseo alveolar remanescente.

Kelsey (1971), ao reconhecer que o processo de reabsorção óssea alveolar é considerado fisiologicamente normal, declarou que sua magnitude pode ser influenciada por alguns fatores inerentes à prótese. Dentre eles, o autor cita o material com que foi construído o dente artificial, bem como sua forma oclusal e a deformação que pode ocorrer na base da prótese. Opinou contrariamente ao uso do dente artificial anatômico, por ser questionável sua superioridade mastigatória e possibilitar a presença de desarmonias oclusais durante a mastigação, as quais, quando são direcionadas à base da prótese, acabam sendo transmitidas ao rebordo ósseo alveolar subjacente. 
Atwood (1971), ao descrever que a reabsorção do rebordo ósseo alveolar é um processo crônico, progressivo e irreversível, afirmou que essa tem provavelmente origem multifatorial. Os fatores anatômicos são representados pela largura e forma do rebordo ósseo alveolar, tipo de osso e microperiósteo presente; os metabólicos incluem fatores como idade, sexo e o equilíbrio hormonal; por fim, os fatores protéticos são representados pela forma oclusal e tipo de dente artificial usado. $\mathrm{O}$ autor acrescentou ainda que, estando presentes os três co-fatores em um mesmo indivíduo, a chance de haver alto grau de reabsorção óssea mostra-se mais previsível.

Para Tamaki e Tamaki (1971), quando as próteses são confeccionadas com base na R.C., como a mandíbula é forçada para uma posição simétrica, o paciente tem dificuldade em ocluir. Segundo os autores, nas próteses totais, a posição da mandíbula funcionalmente adquirida deveria ser respeitada, porque o esforço aplicado para a centralização poderia atuar maleficamente, prejudicando a estabilidade e a retenção das mesmas.

De acordo com Larkin (1971), para se obter uma oclusão ótima em próteses completas, deveriam ser propiciados múltiplos contatos na relação de trabalho, sendo um único contato suficiente para o balanceio funcional, mas que pelo menos esse contato deveria ser obtido.

Goodkind (1971), ao discutir o controvertido assunto dos contatos nos lados de trabalho e balanceio, opinou que o arranjo balanceado de dentes anatômicos deveria apresentar oito dentes posteriores contatando no lado de trabalho, sete dentes no lado de balanceio e quatorze dentes posteriores em posição protrusiva.

Para Christensen (1971), a guia incisal nos pacientes desdentados deveria ser estabelecida pelo dentista quando do posicionamento dos dentes anteriores, 
considerando-se a estética, o tipo do rebordo e o relacionamento entre os rebordos. O autor enfatizou que, pelo fato de o ângulo da guia incisal ser freqüentemente alterado pelo dentista durante a prova da prótese total, a angulação da cúspide também deveria ser proporcionalmente alterada no articulador, já que uma diminuição da inclinação da guia incisal reduziria as forças horizontais durante a mastigação, influenciando na estabilidade das próteses.

Araújo (1972), ao estudar os contatos entre as arcadas dentárias naturais em O.C., concluiu que a média dos contatos observados em 31 pacientes foi de 32,9 pontos, com desvio-padrão de $9,56 \%$, e que a maioria dos contatos foi observada nos dentes posteriores.

Ingervall (1972) pesquisou os contatos dos lados de trabalho e balanceio em crianças e adultos jovens. Encontrou uma pequena porcentagem de pacientes com proteção canina e, em cada dente, a média de contatos no lado de trabalho foi de apenas dois. Em movimentos excêntricos, 64\% dos pacientes apresentaram contatos bilaterais e $20 \%$ contatos unilaterais. Quando havia contato de balanceio, esse geralmente envolvia um único contato entre os dentes posteriores.

Saizar (1972) disse que a articulação balanceada, no tratamento dos edentados bimaxilares, poderia ser conseguida em praticamente todos os casos em que as relações intermaxilares se apresentassem normais e utilizando-se dentes posteriores anatômicos. Afirmou ainda que o equilíbrio e a harmonia dos contatos dependem da correção dos registros mandibulares e da adaptabilidade do articulador; nos casos com irregularidades das relações intermaxilares e nos edentados unimaxilares, de acordo com a disposição do arco remanescente, o balanceio total poderia não ser obtido. Nesses casos, deveria-se procurar propiciar o máximo de contatos do lado ativo para facilitar a eficácia mastigatória, e um pelo 
menos, no lado de balanceio para manter o equilíbrio da prótese.

Tallgren (1972), ao desenvolver in vivo um estudo longitudinal de 25 anos a respeito da redução do rebordo ósseo alveolar, afirmou que o processo de reabsorção óssea é contínuo e está relacionado com a presença de fatores anatômicos, funcionais e protéticos. Destacou ainda que o grau de reabsorção óssea da região anterior da mandíbula é, aproximadamente, quatro vezes maior do que aquele que ocorre na região anterior da maxila, e que esse é mais acentuado no primeiro ano de utilização da prótese. Com base nesses dados, o autor declarou ser fundamental a prevenção de desarmonias oclusais, as quais, quando direcionadas à base da prótese, acabariam por interferir na estabilidade do aparelho e na saúde do rebordo ósseo alveolar.

Eid e Razek (1972), em estudo in vivo, salientaram que dentes artificiais de resina acrílica em pacientes portadores de próteses totais superiores e inferiores, foram reduzidos praticamente à metade, após um período de controle de três anos. Tal comportamento fez com que tais próteses, a partir de então, fossem consideradas inválidas, devido à perda considerável da dimensão vertical e pela dificuldade em se realizarem os vários movimentos mandibulares. Com base nesse resultado, os autores recomendaram a construção de novas próteses após três anos de uso de próteses com dentes artificiais em resina acrílica.

Wesley et al. (1973) chamaram atenção para o fato da diminuição dos pontos de contatos oclusais após o processamento das bases das próteses totais. No estudo realizado, a média de contatos antes do processamento foi de 9,59 pontos e, depois de processadas, caiu para 4,33.

Kelsey et al. (1976) perceberam que a carga mastigatória direcionada à base da prótese estava relacionada às diferentes configurações oclusais do dente artificial 
posterior. Desenvolveram um experimento in vivo, em que questionaram qual forma oclusal causaria a maior incidência de pressões laterais na base da prótese, com conseqüente transmissão para o rebordo ósseo alveolar subjacente. Com os dados obtidos, divulgaram que o dente artificial anatômico com inclinação cuspídica de 33 graus gerou uma pressão lateral interna maior na base da prótese, do que aquela verificada pela utilização do dente artificial não-anatômico.

Woelfel et al. (1976), por meio da cefalometria, estudaram durante cinco anos o grau de reabsorção do rebordo mandibular em 45 pacientes portadores de próteses totais com diferentes formas oclusais dos dentes posteriores. Nessa pesquisa, constatou-se maior diminuição da dimensão vertical de oclusão (násiomento) no grupo não-anatômico (3,6 mm); um resultado intermediário no grupo semi-anatômico (3,2 mm); e a menor diminuição foi constatada para o grupo anatômico $(2,8 \mathrm{~mm})$.

Para Saito et al. (1977), os contatos dos dentes posteriores poderiam acontecer de duas formas:

a- tripoidismo - a cúspide de suporte contata no perímetro das vertentes da fossa oponente em três pontos.

b- ponta de cúspide a fossa - a ponta de cúspide faz contato com a base plana da fossa do dente oposto somente em um ponto.

Levin (1978), reavaliando as Leis da articulação de Hanau (1926), concluiu que as mesmas deveriam ser utilizadas como uma ajuda no entendimento da oclusão balanceada em próteses totais. Considerou que a curva de compensação mostra-se o fator mais importante para se obter o balanceio e que os dentes com cúspides têm inclinações adequadas para a obtenção da oclusão balanceada, desde que posicionados segundo a curva de compensação. 
Para Woda et al., (1979), no que diz respeito aos contatos oclusais durante o movimento de lateralidade voluntária, esses variavam em número e localização, conforme o tipo de desoclusão apresentado pelo paciente: proteção canina ou função de grupo.

Gaver (1981), ao publicar que a componente horizontal oriunda da força mastigatória mostra-se altamente destrutiva para a dentição natural e artificial, afirmou que sua presença na reabilitação bucal, estará relacionada à anatomia oclusal do dente artificial posterior, sendo que o dente artificial não-anatômico mostrou-se melhor indicado quando comparado ao anatômico, por fazer com que a força mastigatória seja representada apenas pela componente vertical e permitir o mesmo grau de eficiência mastigatória que é verificado na utilização do dente anatômico e maior liberdade de movimento durante a mastigação, sem que haja a presença de possíveis interferências oclusais.

Ramfjord (1982), ao realizar testes de eficiência mastigatória, verificou que a fase mais importante da performance mastigatória ocorria durante os contatos intercuspídicos em excursões laterais.

Em relação à inclinação das cúspides dos dentes artificiais, Appelbaum (1984) classifica-os em 3 tipos. Os dentes cujas inclinações cuspídicas medem ao redor de $33^{\circ}$ do sulco central ao ápice da cúspide são chamados de dentes anatômicos. Esses apresentam uma morfologia semelhante à dos dentes naturais. Os dentes artificiais que apresentam inclinações cuspídicas menores do que $33^{\circ}$ são chamados de dentes modificados ou semi-anatômicos, e os que não têm uma altura de cúspide são denominados dentes não-anatômicos ou dentes planos. Esse autor considera o perfil do rebordo alveolar como fator de maior influência na eleição de dentes artificiais. Os dentes anatômicos são indicados para rebordos amplos e bem 
formados, por apresentarem melhor capacidade de resistir aos esforços de deslocamento lateral. Os dentes não-anatômicos são indicados para rebordos reabsorvidos, principalmente quando a distância entre a superficie oclusal e a base da prótese for grande, pois quanto maior o braço de alavanca, maior é a tendência de deslocamento da prótese.

Shetti (1984) estudou in vivo a influência que as diferentes formas oclusais dos dentes artificiais posteriores exercem sobre a estética e a eficiência mastigatória. Declarou que pacientes portadores de próteses totais com dentes artificiais posteriores anatômicos, durante um período de seis meses de controle, apresentaram melhor desempenho mastigatório comparativamente aos pacientes portadores de próteses totais com dentes artificiais posteriores não-anatômicos. Observou ainda, em relação à estética, que $87,5 \%$ dos pacientes portadores de próteses totais com dentes artificiais não-anatômicos passaram a apresentar prognatismo mandibular ao final do experimento.

Lindquist e Carlsson (1985) evidenciaram que, após um período de dois meses a três anos da instalação de próteses totais fixas sobre implantes, os pacientes registravam um aumento médio de $39 \%$ na força oclusal.

Utilizando um articulador totalmente ajustável, Gomes (1987) avaliou os contatos oclusais nos lados de trabalho e balanceio em 14 próteses totais. A montagem dos dentes seguiu a orientação preconizada por Tamaki (1988) e, pelos resultados obtidos, concluiu que: a) esse tipo de montagem proporciona contatos oclusais simultâneos no lado de trabalho e no de balanceio; b) computando os contatos do lado de trabalho e de balanceio, em lateralidade direita e esquerda, o intervalo de variação foi de 7 a 13 pontos, com média de 10,21 pontos para o lado esquerdo e 10,71 para o lado direito; o intervalo de variação dos contatos de 
balanceio, de ambos os lados, foi de 1 a 6 pontos, com média de 4,28 pontos para o lado esquerdo e 4,14 para o lado direito; as médias de contato dos lados de balanceio e de trabalho são altamente positivas quanto à estabilização, à eficiência mastigatória e ao conforto das próteses totais.

Bergs (1988) estudou in vivo a influência que o dente artificial anatômico com inclinação cuspídica de 30 graus e o dente artificial não- anatômico exercem sobre fatores como a eficiência mastigatória, estética, retenção e conforto. Concluiu, após dois anos de controle, que a presença ou ausência de cúspides nos dentes artificiais posteriores mostrou-se de pequena importância quanto à satisfação pessoal de cada paciente examinado.

Zarb e Schmitt (1990) relataram que próteses totais superiores convencionais quando ocluíam contra próteses totais fixas implantossuportadas apresentavam uma maior incidência de fraturas da área basal ao longo da linha mediana.

Boening e Walter (1992) analisaram a pressão dos contatos oclusais em pacientes portadores de próteses totais bimaxilares, com auxílio do sistema TScan® (Tekscan Inc., Boston, EUA), que permite a quantificação da pressão dos contatos entre os dentes por meio de um sensor interoclusal. Verificaram que 0 processo de remontagem das próteses no articulador potencializava o número de contatos e também a distribuição das forças oclusais.

Jacobs et al. (1993) registraram índices maiores de reabsorção óssea em pacientes portadores de próteses totais superiores convencionais, que ocluíam contra próteses totais fixas implantossuportadas quando comparados a pacientes portadores de próteses totais superiores convencionais, que ocluíam contra sobredentaduras retidas por dois implantes. 
Suzuki et al. (1999) estudaram in vivo a força oclusal e a área de contato no relacionamento entre próteses totais bimaxilares convencionais e próteses totais superiores convencionais com próteses totais inferiores implantossuportadas. Para tanto, utilizaram o sistema Dental Prescale® (Fuji Photo, Tókio, Japão), um sistema digital que registra os contatos oclusais a partir de um dispositivo interoclusal sensível à pressão. Observaram que tanto a força, como as áreas de contato foram significativamente maiores nas próteses construídas sobre implantes. Nos dois grupos, não verificaram diferenças significantes entre os contatos dos lados direito e esquerdo. Também observaram que o centro das cargas oclusais, nos usuários das próteses sobre implantes, localizava-se mais anteriormente ao centro dos usuários de próteses convencionais. Em função desse achado, sugeriram que os contatos oclusais entre próteses convencionais antagonistas a próteses sobre implantes deveriam ser mais regularmente checados, em função dos contatos mais anteriorizados, que provocavam maior instabilidade na prótese superior e conseqüentemente maior reabsorção do rebordo superior.

Kumagai et al. (1999), em estudo realizado in vivo, analisaram a intensidade dos contatos oclusais em indivíduos dentados com auxílio do sistema Dental Prescale ${ }^{\circledR}$ (Fuji Photo, Tókio, Japão), e verificaram que o aumento da intensidade de força dos músculos mastigatórios na posição de máxima intercuspidação resultava em maior pressão oclusal na região dos molares. Em contra-partida, diante do mesmo aumento de força, a pressão oclusal na região dos pré-molares e dentes anteriores diminuía.

Ohguri et al. (1999), em estudo in vitro, demonstraram que a oclusão balanceada apresenta-se como o arranjo oclusal para próteses totais que necessita de menor força para triturar alimentos duros, se comparada a oclusão monoplana. 
Baba et al. (2000), em revisão de literatura, compararam os dados disponíveis sobre os sensores de contatos oclusais (T-Scan System®) e os filmes barossensíveis (Dental Prescale® - Fuji Photo, Tókio, Japão). Concluíram que esses aparelhos não oferecem resultados confiáveis, pois a espessura dos sensores de registro mostra-se capaz de alterar a propriocepção do paciente em máxima intercuspidação. Verificaram também, que a espessura dos sensores gerava marcas mais fortes nos dentes posteriores que nos dentes anteriores, E, portanto, preconizaram que a espessura do meio de registro oclusal ideal deveria ser menor que 24 micrômetros.

Mazini (2003) analisou a área dos contatos oclusais em posição de máxima intercuspidação entre dentes artificiais anatômicos e funcionais, nacionais e importados, montados em arcadas de formas triangular, quadrada e oval. Com auxílio do software Leica $Q$ win ${ }^{\circledR} 550$, os autor realizou a mensuração das áreas demarcadas pelo papel carbono, e, a partir dos resultados, concluiu que entre os dentes nacionais, nas montagens para o modelo superior, os dentes funcionais apresentaram uma maior área de contato que os dentes anatômicos, principalmente nas montagens ovais. Ainda no modelo superior, na utilização dos dentes anatômicos, os dentes importados apresentaram maiores áreas de contato que os dentes nacionais. Nas montagens de forma triangular e quadrada, a utilização dos dentes anatômicos proporcionou uma maior área de contato. Esses mesmos dentes, quando utilizados em montagens ovais, produziram uma menor área de contato. No modelo inferior, os dentes importados apresentaram maiores áreas de contato que os dentes nacionais, sendo que, nas montagens ovais e quadradas, as maiores áreas foram obtidas com a utilização dos dentes funcionais. 
Pela revista da literatura, pode-se notar que, na área da oclusão, a anatomia oclusal e os contatos intercuspídicos nos diferentes movimentos realizados mostram-se um assunto amplamente estudado, e que as opiniões são ainda bastante discutíveis. 


\section{PROPOSIÇÃO}

Objetivo geral:

Analisar as áreas dos contatos oclusais de dentes artificiais dispostos em arcadas de diferentes formas, relacionando-as nas posições de máxima intercuspidação e nos movimentos excursivos.

Objetivo específico:

Analisar as áreas dos contatos oclusais, nos movimentos de protrusão e lateralidades direita e esquerda, de dentes artificiais anatômicos e funcionais, nacionais e importados, dispostos em arcadas de formas triangular, quadrada e oval, correlacionando-as estatisticamente, quando possível, e ainda identificar as variações decorrentes da comparação dessas na posição de máxima intercuspidação, em relação àquelas obtidas durante os movimentos excursivos. 


\section{MATERIAL E MÉTODOS}

\subsection{Material}

Neste estudo realizou-se uma análise dos contatos oclusais obtidos nos movimentos excursivos de protrusão e lateralidades direita e esquerda de próteses totais bimaxilares, ainda em sua fase de montagem na cera, confeccionadas a partir do manequim idealizado e utilizado pela disciplina de Prótese Total da Faculdade de Odontologia da Universidade de São Paulo. Para tanto, utilizou-se como base a seqüência laboratorial proposta por Tamaki (1980), alterando-se apenas a confecção das bases de prova, pois este trabalho limitou-se à obtenção e análise das imagens das superfícies oclusais dos dentes artificiais após seu adequado ajuste (Mazini, 2003).

\subsubsection{Confecção das bases de prova}

- Manequim desenvolvido pela Disciplina de Prótese Total da Faculdade de Odontologia da Universidade de São Paulo;

- Modelos edentados e não-retentivos superior e inferior, desenvolvidos pela Disciplina de Prótese Total da Faculdade de Odontologia da Universidade de São Paulo;

- Lápis cópia - Faber Castell (BRA);

- Plastificadora a vácuo - Vacuum Former (EUA);

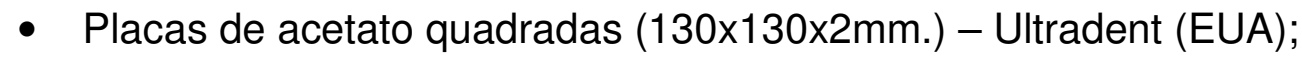


- Caneta de tinta permanente - Pilot (BRA);

- Tesoura - Mundial (BRA);

- Motor de baixa rotação com peça reta - Scandyna (EUA);

- Fresa periforme Maxicut - Edenta (ALE), distribuída por Labordental;

- Pedras montadas para peça de mão, para acabamento das bases de acetato;

- Tiras de lixa, granulação 00 - Tigre (BRA).

4.1.2 Confecção dos planos de cera

- cera rosa $\mathrm{n} .-7$ - Epoxyglass (BRA);

- espátulas $\mathrm{n} . \stackrel{0}{7}$, n.ำ 31 e Le Cron - Duflex (BRA);

- lamparina a álcool - Evang (BRA);

- lamparina a álcool tipo Hanau - Evang (BRA);

- álcool etílico hidratado 92,8 INPM - Copersucar (BRA);

- isqueiro - Bic (BRA);

- placa de vidro;

- vaselina sólida - Sidepal (BRA);

- pincel $n . .012-$ Tigre (BRA).

\subsubsection{Colocação do abrasivo}

- planos de cera superior e inferior;

- abridor de canaleta "TT" - Golgran (BRA);

- Mistura abrasiva, constituída por $80 \%$ (volume) de gesso comum e $20 \%$ (volume) de pó de carburundum de granulação 60. 
4.1.4 Montagem dos modelos no articulador e duplicação dos planos de cera

- articulador parcialmente ajustável, com arco facial, modelo 2240 - WhipMix (EUA);

- gesso tipo IV - Dentsply (BRA);

- gral de borracha;

- espátula para gesso;

- compressas de gaze - Cremer (BRA).

4.1.5 Seleção, montagem e ajuste oclusal dos dentes artificiais

- 9 placas de dentes artificiais anteriores superiores Ivostar, tamanho O01, cor 2B Ivoclar (ALE);

- 9 placas de dentes artificiais anteriores inferiores Ivostar, tamanho 12, cor 2B Ivoclar (ALE);

- 9 placas de dentes artificiais posteriores superiores Gnathostar, tamanho D80, cor 2B - Ivoclar (ALE);

- 9 placas de dentes artificiais posteriores inferiores Gnathostar, tamanho D80, cor 2B - Ivoclar (ALE);

- 9 placas de dentes artificiais anteriores superiores Antaris, tamanho A52, cor 2B Ivoclar (ALE);

- 9 placas de dentes artificiais anteriores inferiores Antaris, tamanho A3, cor 2B Ivoclar (ALE);

- 9 placas de dentes artificiais posteriores superiores Postaris, tamanho PU1, cor 2B - Ivoclar (ALE); 
- 9 placas de dentes artificiais posteriores inferiores Postaris, tamanho PL1, cor 2B - Ivoclar (ALE);

- 9 placas de dentes artificiais anteriores superiores Biolux, tamanho V21, cor 66 Dental Vipi (BRA);

- 9 placas de dentes artificiais anteriores inferiores Biolux, tamanho V3, cor 66 Dental Vipi (BRA);

- 9 placas de dentes artificiais posteriores superiores Biolux, tamanho P3, cor 66 Dental Vipi (BRA);

- 9 placas de dentes artificiais posteriores inferiores Biolux, tamanho P3, cor 66 Dental Vipi (BRA);

- 9 placas de dentes artificiais anteriores superiores Vipi-Dent Plus, tamanho A23, cor 66 - Dental Vipi (BRA);

- 9 placas de dentes artificiais anteriores inferiores Vipi-Dent Plus, tamanho A23, cor 66 - Dental Vipi (BRA);

- 9 placas de dentes artificiais posteriores superiores Vipi-Dent Plus, tamanho 30M, cor 66 - Dental Vipi (BRA);

- 9 placas de dentes artificiais posteriores inferiores Vip-Dent Plus, tamanho 30M, cor 66 - Dental Vipi (BRA);

- Pinças curvas, para papel de articulação - Bausch (ALE);

- Papel para articulação verde, espessura de 8 micras - Bausch (ALE).

4.1.6 Obtenção das imagens das superfícies oclusais das próteses em cera

- Próteses Totais bimaxilares concluídas em cera;

- Fita adesiva dupla face - 3M do Brasil (BRA); 
- Computador, com base operacional Windows® 98 - Microsoft (EUA);

- Software Leica Qwin 550 - Leica (ALE);

- Lente Macroscópica Digital, com base - Kaiser (ALE).

\subsection{Métodos}

$\mathrm{Na}$ realização da presente pesquisa, os corpos-de-prova consistem de 36 próteses totais bimaxilares, ainda em cera, confeccionadas a partir de planos de orientação com as curvaturas ântero-posterior e látero-lateral padronizadas, sobre os quais foram montados dentes artificiais de resina anatômicos e funcionais, nacionais e importados. Para tanto, utilizou-se como base a metodologia preconizada por Mazini e Nakamae (2003).

\subsubsection{Confecção das bases de prova}

A partir dos modelos de trabalho superior e inferior, delimitou-se a área basal dos mesmos com auxílio de um lápis cópia. Em seguida, uma placa de acetato quadrada foi posicionada na haste da plastificadora a vácuo e o modelo disposto na mesa da mesma. A placa de acetato foi então aquecida na plastificadora e, após sua plastificação, a mesma foi levada em direção ao modelo. Ligou-se, então, a sucção a vácuo do aparelho. Após seu resfriamento, o conjunto modelo/placa de acetato foi retirado do aparelho. Com auxílio de uma caneta de tinta permanente, transferiu-se a delimitação da área basal do modelo para a superfície externa da placa de acetato. Realizado este procedimento, a placa de acetato foi recortada seguindo-se esta 
delimitação e recebeu o acabamento com auxílio de um mandril com tiras de lixa (Figura 4.1).

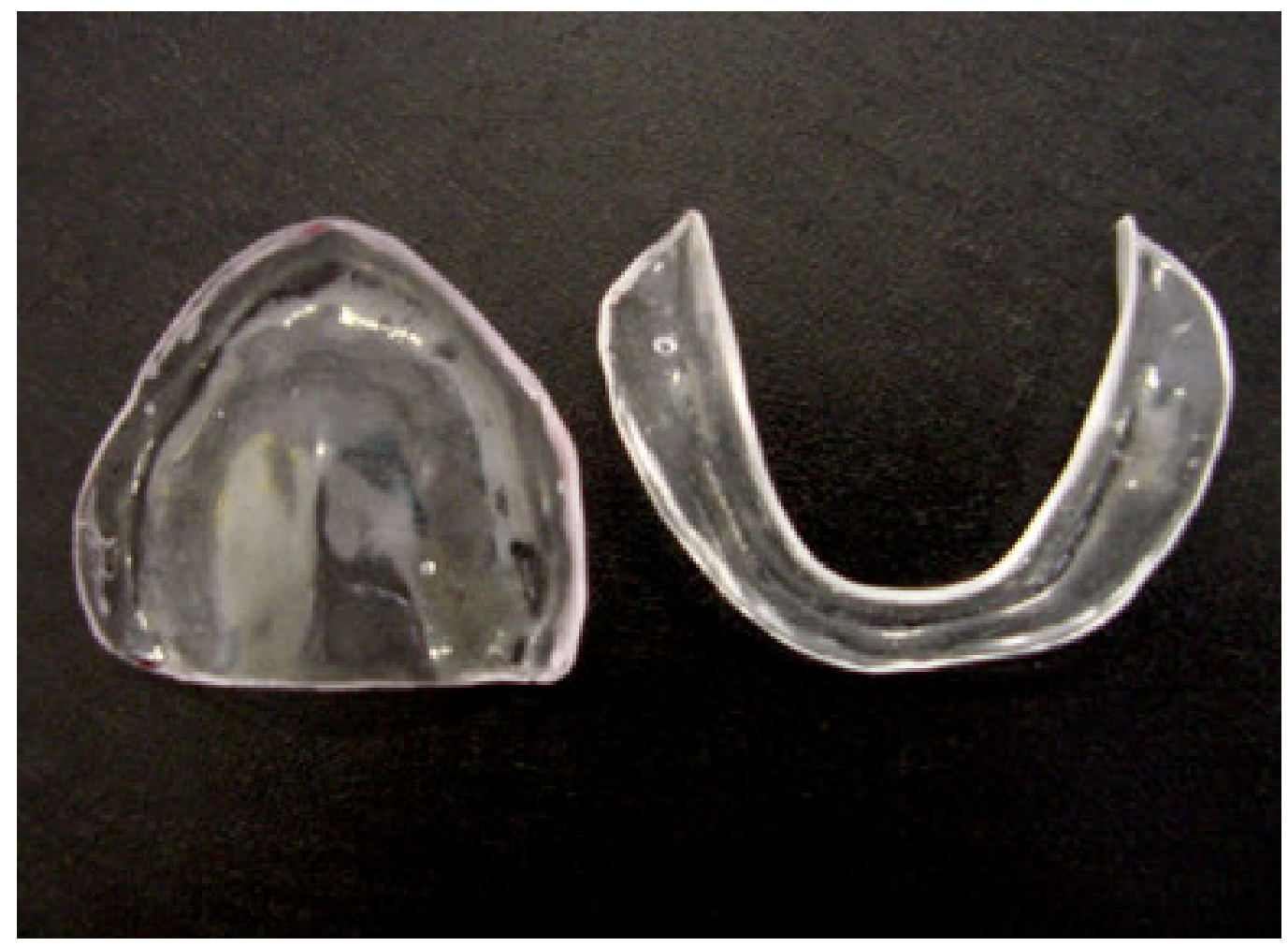

Figura 4.1 - Bases de acetato, conformadas a vácuo

Estes procedimentos foram executados diversas vezes, nos modelos superior e inferior até obter-se 39 bases de prova para o modelo superior e 39 bases de prova para o modelo inferior.

\subsubsection{Confecção dos planos de cera}

Após plastificar uma lâmina e meia de cera 7 sobre a chama da lamparina, a mesma foi dobrada de uma extremidade a outra até obter-se um rolete. O rolete foi dobrado ao meio e conformado visando sua adaptação sobre a base de prova do modelo superior. Conformou-se arbitrariamente uma curva de compensação ânteroposterior (Curva de Monson) e uma curva de compensação vestíbulo-palatina (Curva 
de Wilson). $\mathrm{O}$ acabamento foi executado com uma espátula para gesso aquecida, o plano de cera foi levado ao modelo montado no manequim para avaliação de sua altura, dos limites vestibulares e a inclinação da curva de compensação.

Concluído o plano de cera superior, confeccionou-se o plano de cera inferior seguindo-se a mesma seqüência de plastificação da cera e adaptação à base de prova. Após a adaptação do rolete de cera à base de prova, o conjunto foi posicionado no modelo inferior do manequim e levado em oclusão junto ao plano de cera superior, previamente isolado com vaselina, de forma a obter-se a dimensão vertical de oclusão determinada pelo manequim. Os planos de cera foram separados e procedeu-se à remoção dos excessos de cera e acabamento do plano de cera inferior. Em seguida, o plano inferior foi novamente levado ao manequim onde se verificou a perfeita adaptação do mesmo ao plano superior (Figura 4.2). Com o instrumento específico, foi confeccionada uma canaleta na porção central da face oclusal de cada plano. As canaletas foram preenchidas com a mistura de pó abrasivo, após sua espatulação com água, de forma a obter-se um excesso de 2 milímetros sobre a altura oclusal dos planos. 


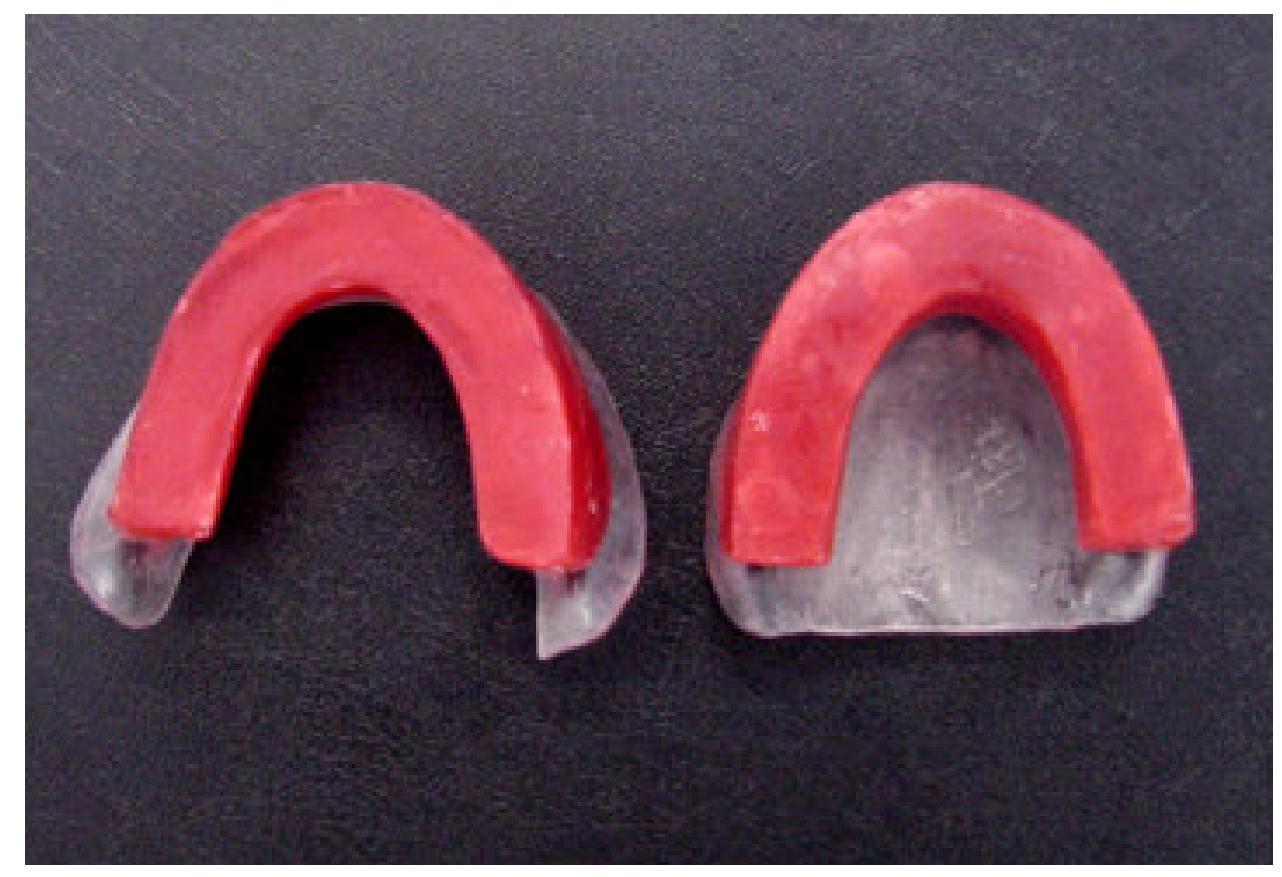

Figura 4.2 - Planos de cera superior e inferior

\subsubsection{Simulação da individualização da curva de compensação}

A partir do método fisiológico de individualização da curva de compensação proposto por Paterson (1928), hidrataram-se os planos de cera para facilitar o desgaste entre as superfícies abrasivas. Os planos foram posicionados no manequim onde foram simulados movimentos mandibulares ântero-posteriores e látero-laterais até que os planos retornassem à dimensão vertical proposta pelo manequim.

Traçaram-se então, as linhas de referência para orientação da seleção e montagem dos dentes: mediana, sorriso forçado e dos caninos.

Estes planos, a partir desta etapa, foram considerados planos de orientação. 
4.2.4 Transferência dos modelos superior e inferior para o articulador semiajustável

O plano de orientação superior foi então fixado no garfo do arco facial e reposicionado no manequim. Manequim este, que apresenta também pequenos pinos que permitem o posicionamento e fixação das olivas do arco facial, possibilitando a transferência do posicionamento espacial do modelo a partir manequim para o ramo superior do articulador (Figura 4.3). Com a incorporação do conjunto garfo/plano de orientação pelo arco facial, este último foi posicionado no ramo superior do articulador com a guia condilar fixada em 30 graus.

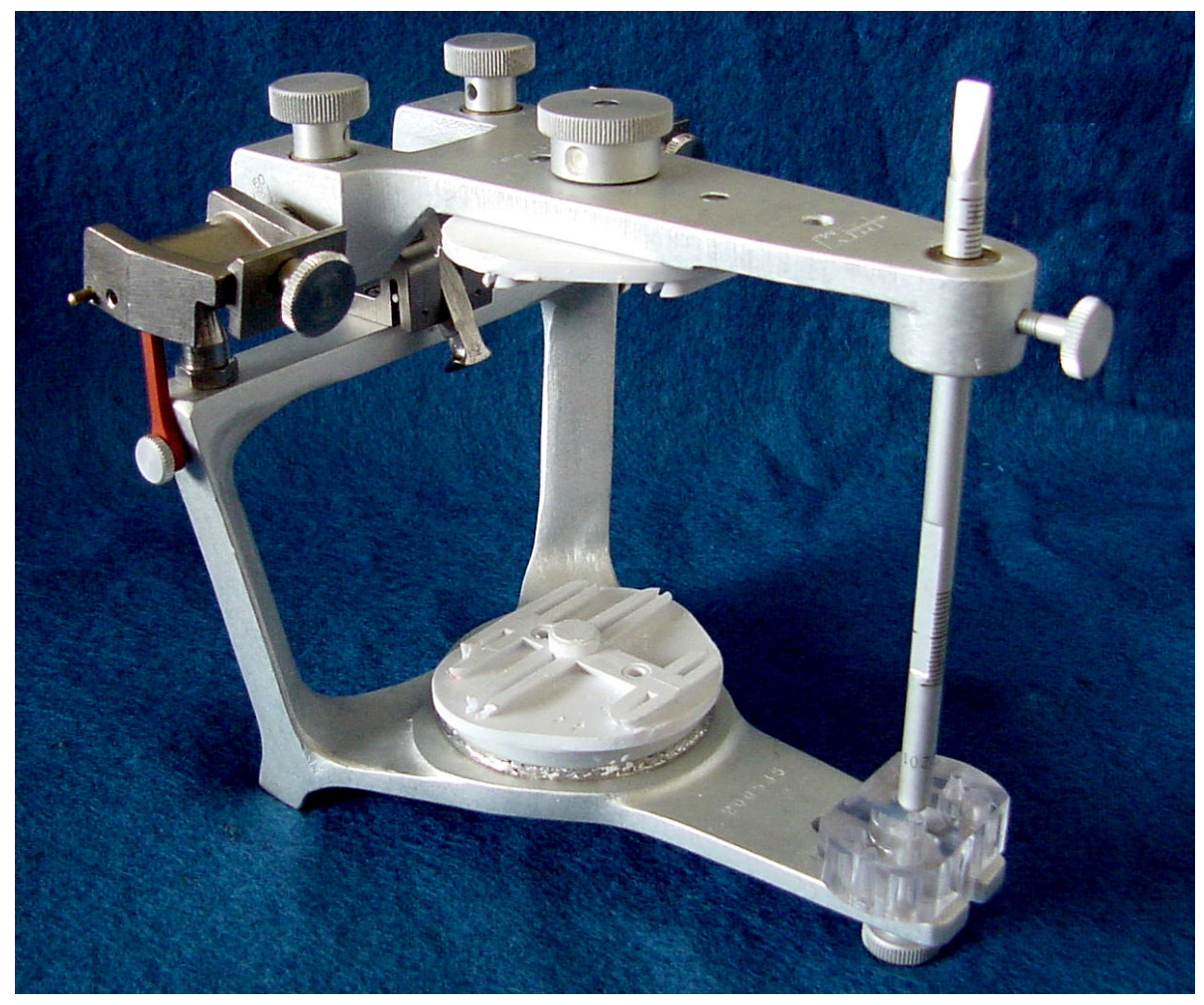

Figura 4.3 - Articulador semi-ajustável

Preparado o articulador, fixou-se o modelo superior na base de prova com auxílio de cera fundida e promoveu-se a hidratação da porção plana do modelo com 
auxílio de compressas de gaze umedecida. No gral de borracha, espatulou-se o gesso tipo IV que foi disposto sobre o modelo de gesso e também sobre a placa de montagem do articulador. $\mathrm{O}$ ramo superior do articulador foi posicionado sobre $\mathrm{o}$ arco facial e aguardou-se a reação de presa do gesso (Figura 4.4).

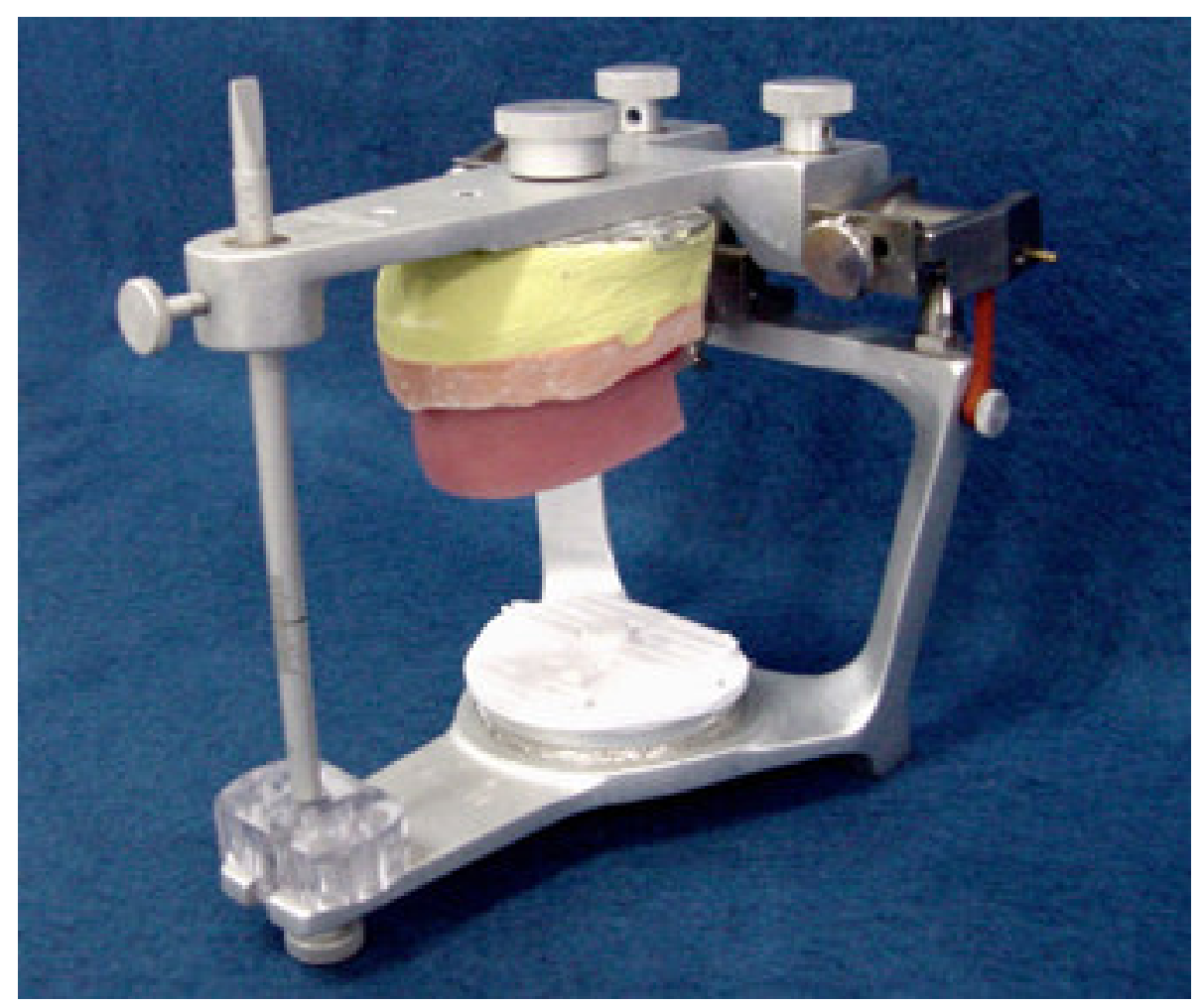

Figura 4.4 - Modelo superior montado no articulador

Em seguida, desmontou-se o arco facial, removendo o plano de orientação superior do garfo para levá-lo novamente ao manequim para que este fosse fixado ao plano de orientação inferior em suas superfícies vestibular e lingual por meio de cera fundida. Para minimizar ainda mais as possibilidades de distorção do gesso, no ramo inferior do articulador, foi confeccionada uma guia em cera (Figura 4.5) para a acomodação de uma primeira camada plana de gesso tipo IV (Figura 4.6). 
Após sua presa final, outra camada, esta inclinada (figura 4.7), também foi colocada na guia, para que conseguisse, uma camada de espessura uniforme de gesso (Figura 4.8).

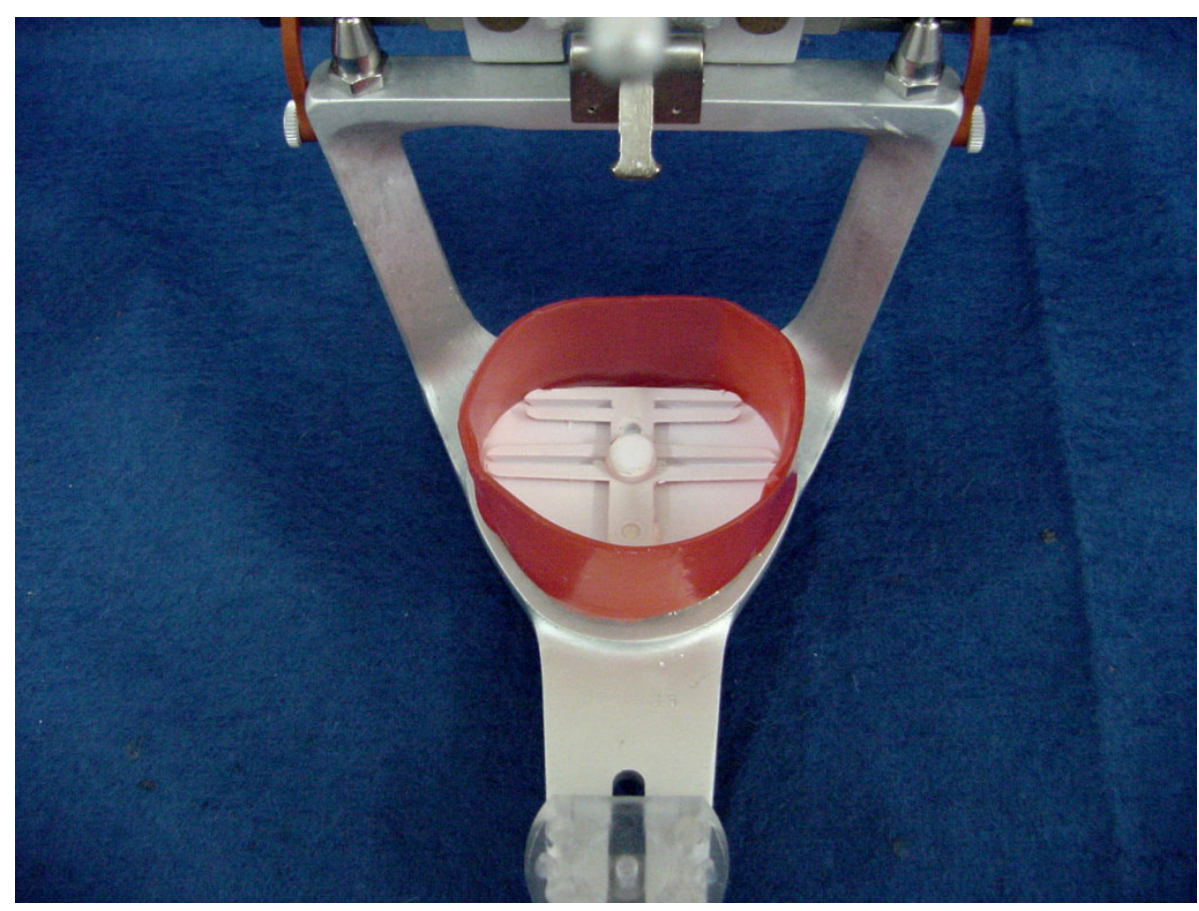

Figura 4.5 - Guia em cera 


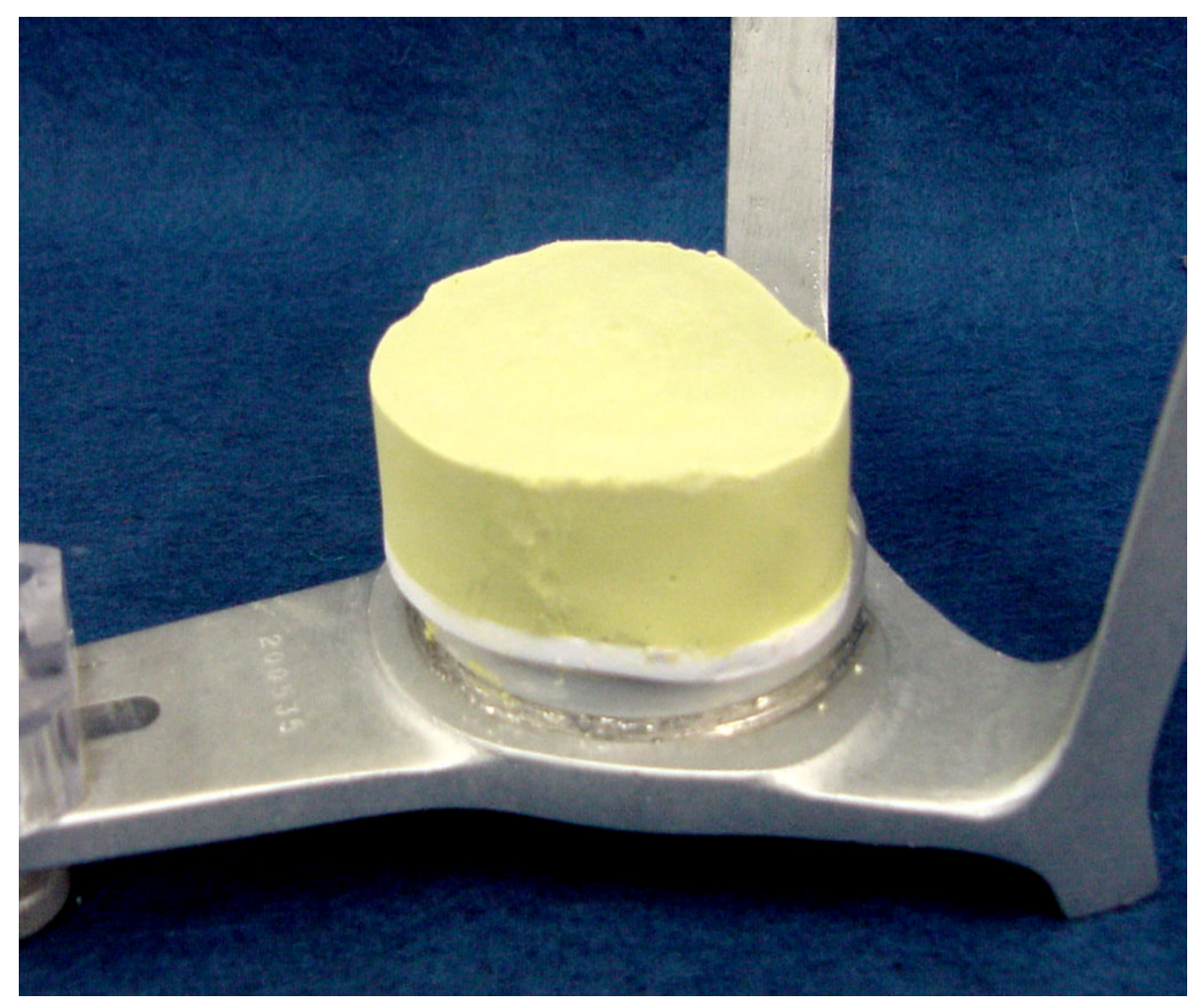

Figura 4.6 - Camada reta de gesso tipo IV

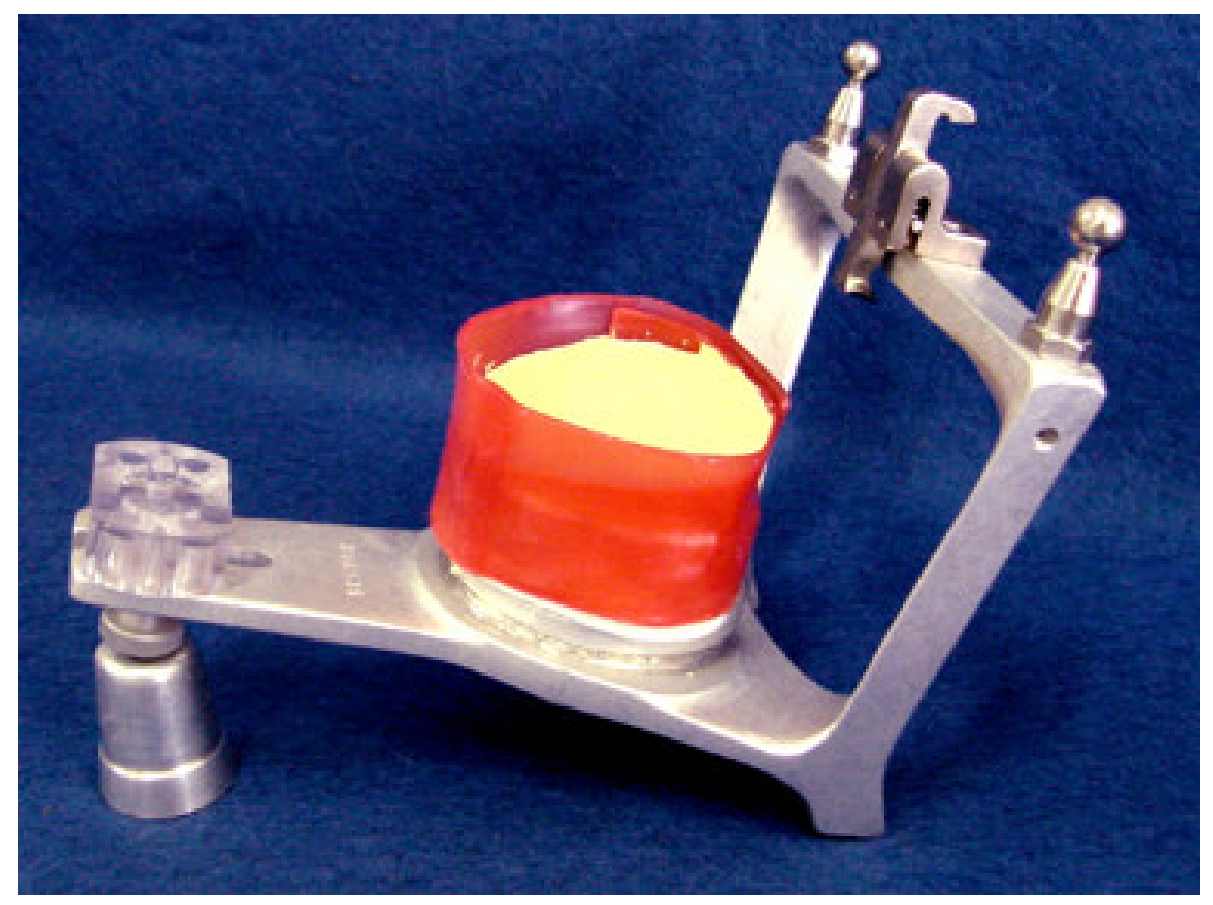

Figura 4.7 - Colocação do gesso tipo IV, com articulador inclinado 


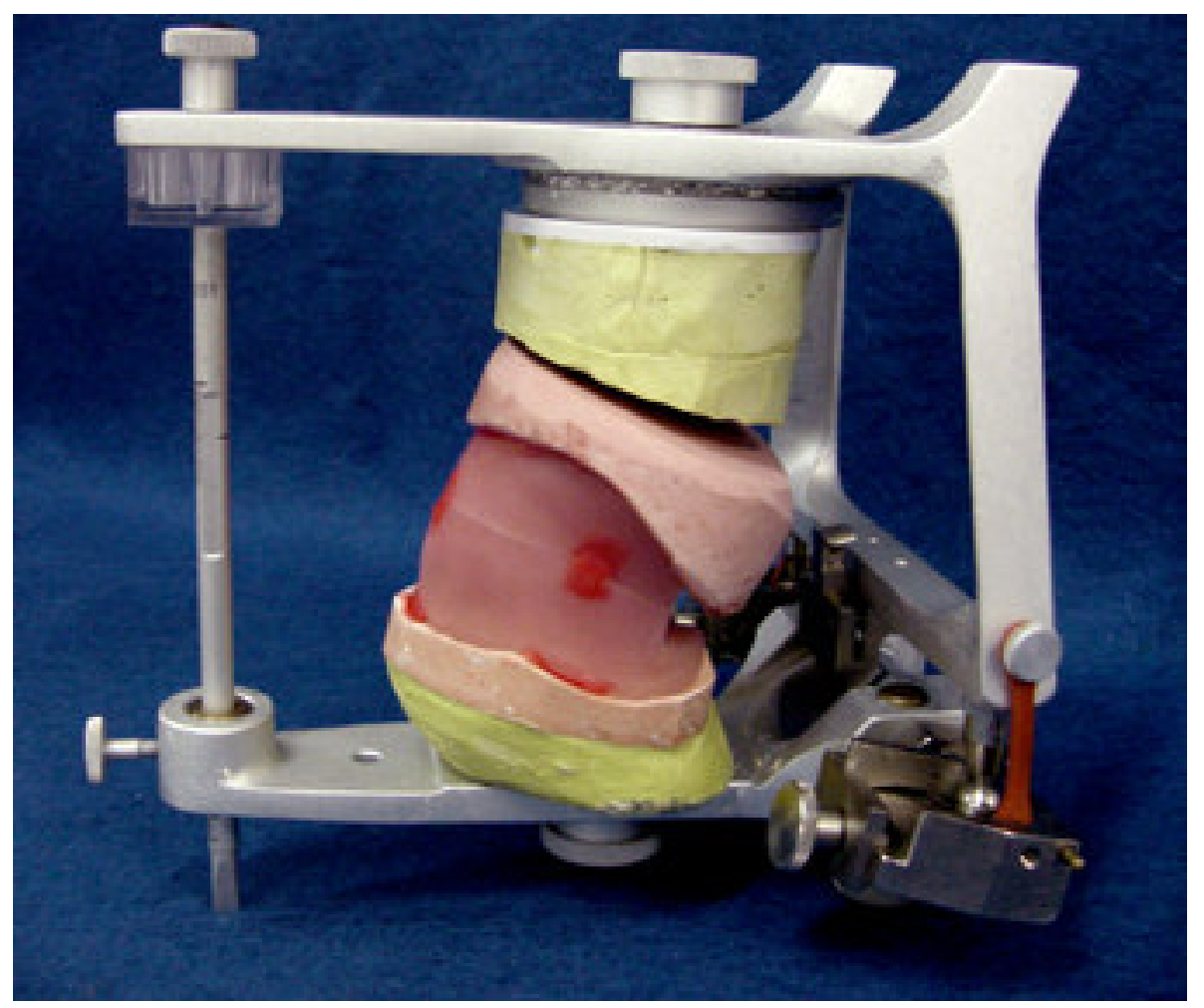

Figura 4.8 - Camada de espessura uniforme de gesso

Isto feito, no articulador, posicionou-se o pino incisal na marcação indicada, com o intuito de deixar os ramos do articulador paralelos entre si e, como descrito anteriormente, montou-se o modelo inferior finalizando a montagem dos modelos e planos no articulador (Figura 4.9). 


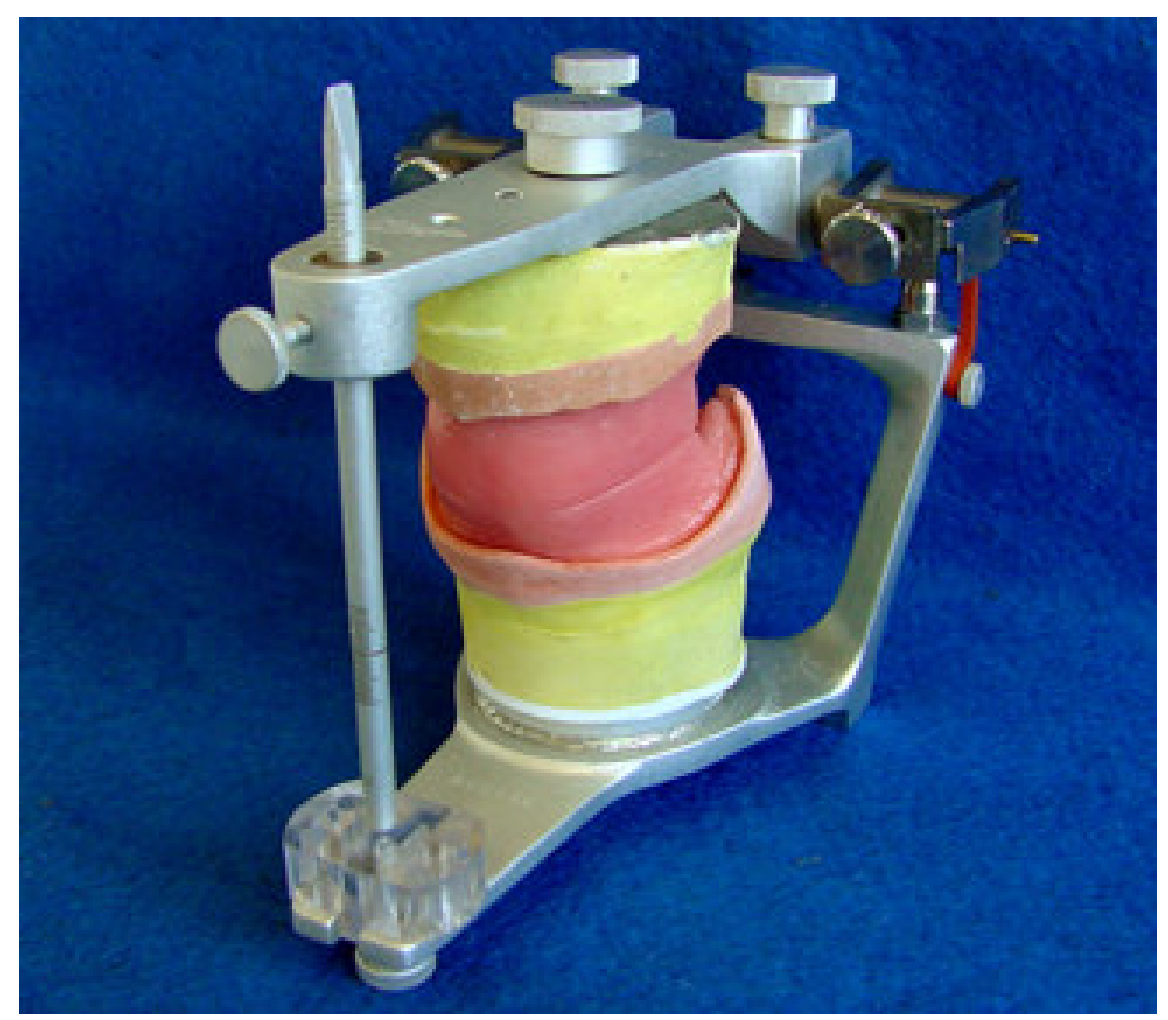

Figura 4.9 - Modelos montados no articulador

4.2.5 Obtenção dos planos de orientação em resina acrílica termopolimerizável

Com o plano de orientação inferior posicionado sobre o modelo e após isolarse a sua superfície oclusal, confeccionou-se um rolete de cera 7 como descrito anteriormente e adaptou-se à nova base de prova superior. Com esse conjunto posicionado sobre o modelo superior, fechou-se o articulador de modo que o pino incisal tocasse a mesa correspondente. Removeu-se o conjunto e procedeu-se ao acabamento com a espátula de gesso aquecida. Separaram-se os planos. Repetiuse o mesmo procedimento para o modelo inferior, tendo como referência o plano superior já duplicado (Figura 4.10). 


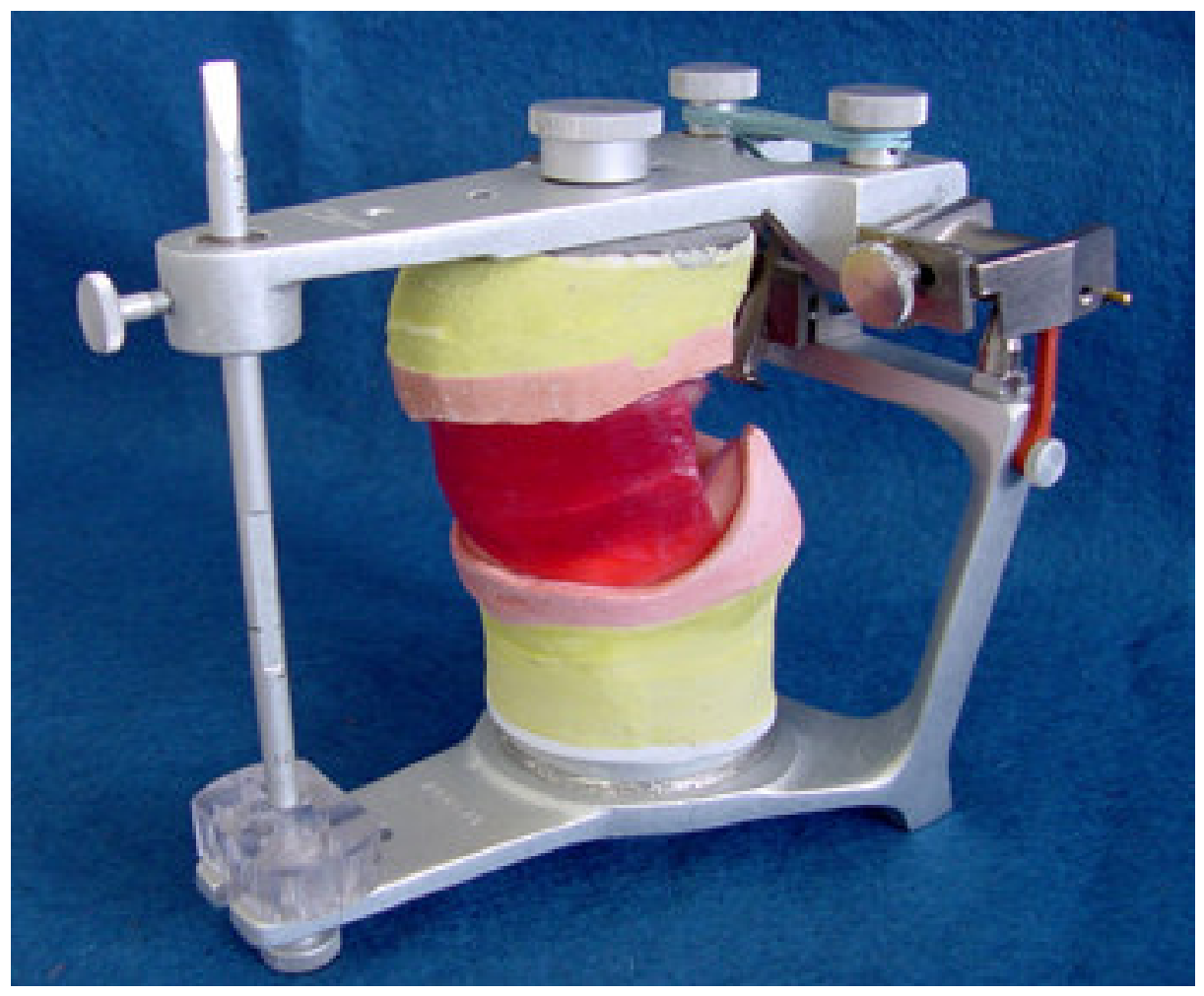

Figura 4.10 - Planos de orientação duplicados

Em 1825, Nelson, ao estudar a forma dos dentes e sua correlação com o formato do rosto dos pacientes, estabeleceu a análise e conseqüente correlação de um terceiro fator: a forma dos rebordos alveolares. Segundo o autor, a forma dos rebordos alveolares também poderia ser dividida em triangular, ovóide e quadrada. $E$ acrescentou que estes formatos, também acompanhavam a forma do rosto e dos incisivos centrais superiores. A partir de então, esta tríplice coincidência recebeu a denominação de "Triângulo Estético de Nelson".

Partindo-se desta premissa, optou-se por reproduzir estas formas, triangular, oval e quadrada, nos planos de orientação e conseqüentemente na montagem dos dentes artificiais.

Confeccionados os três pares de planos de orientação, foi acrescentada uma porção de gesso tipo IV sobre a área interna das bases de prova, incluíndo-se as bordas das mesmas e aguardou-se a presa do gesso. Verificou-se a adaptação do 
conjunto modelo/plano de orientação às muflas metálicas, preservando-se uma distância de cinco milímetros das paredes vertical e horizontal das mesmas. As muflas foram untadas com vaselina sólida, seguindo-se o preenchimento de suas bases com gesso comum. Os planos com gesso tipo IV foram então posicionados nas bases das muflas (Figura 4.11).

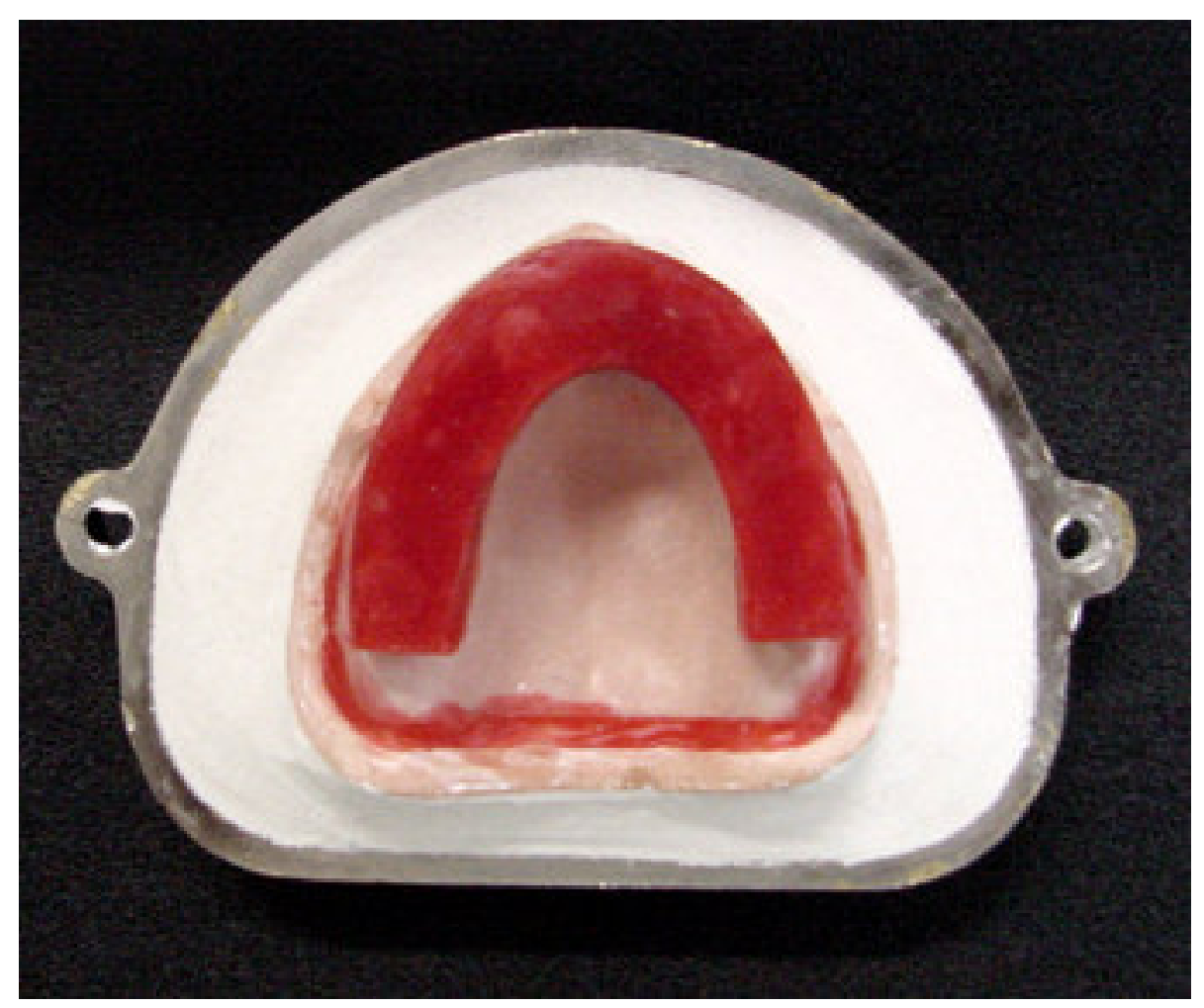

Figura 4.11 - Plano de orientação fixado na base da mufla

Após a presa total do gesso, untou-se com vaselina toda a superfície de gesso. Sobre os planos de orientação construiu-se uma muralha em gesso pedra (Figura 4.12). 


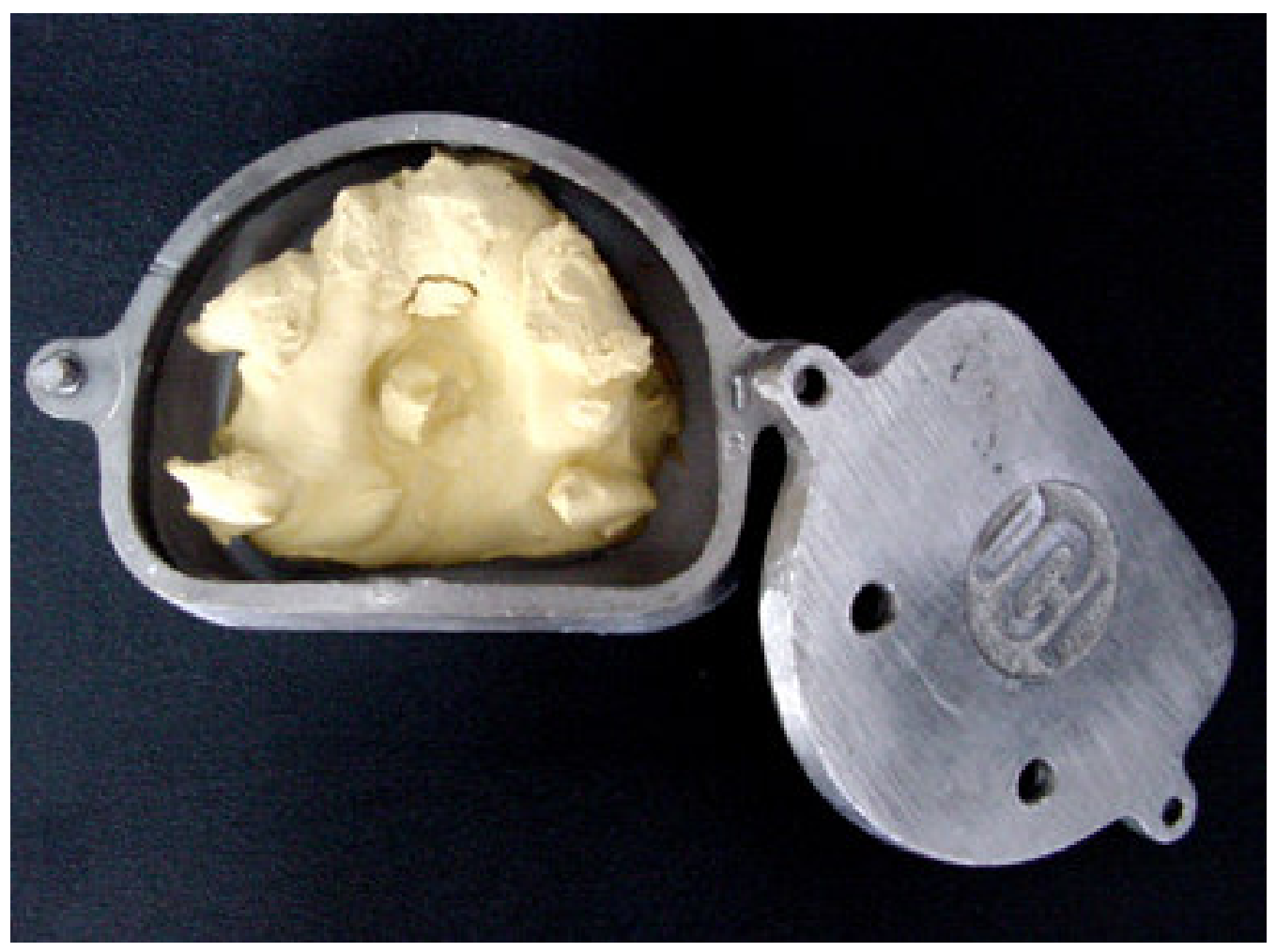

Figura 4.12 - Muralha de gesso pedra

Assentaram-se as contra-muflas sobre suas bases, acrescentando gesso comum até o seu completo preenchimento. As muflas foram mantidas sob pressão em uma prensa de bancada até a completa cristalização do gesso.

Após este período, as muflas foram aquecidas em água por cinco minutos e em seguida abertas com o cuidado de se preservar a integridade do conjunto (Figura 4.13). A base de prova e a cera pastosa foram removidas com auxílio de uma espátula LeCron e a cera remanescente removida com água fervente (Figura 4.14). O gesso foi isolado com vaselina para receber a resina acrílica termopolimerizável. A resina foi então colocada na mufla e esta foi adequadamente fechada e posicionada na prensa de bancada para uma distribuição uniforme da resina em seu interior. 


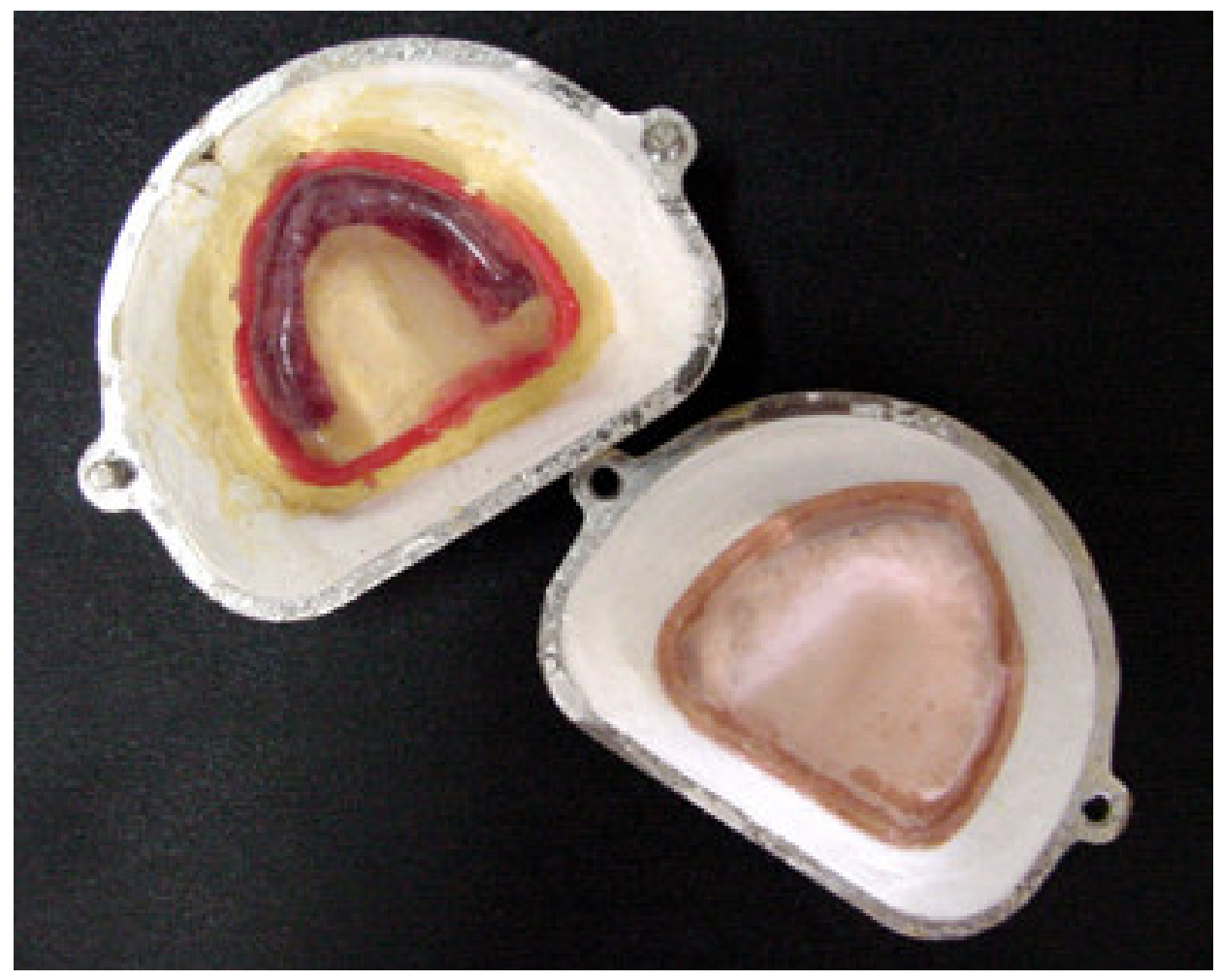

Figura 4.13 - Abertura da mufla para remoção da base e cera pastosa

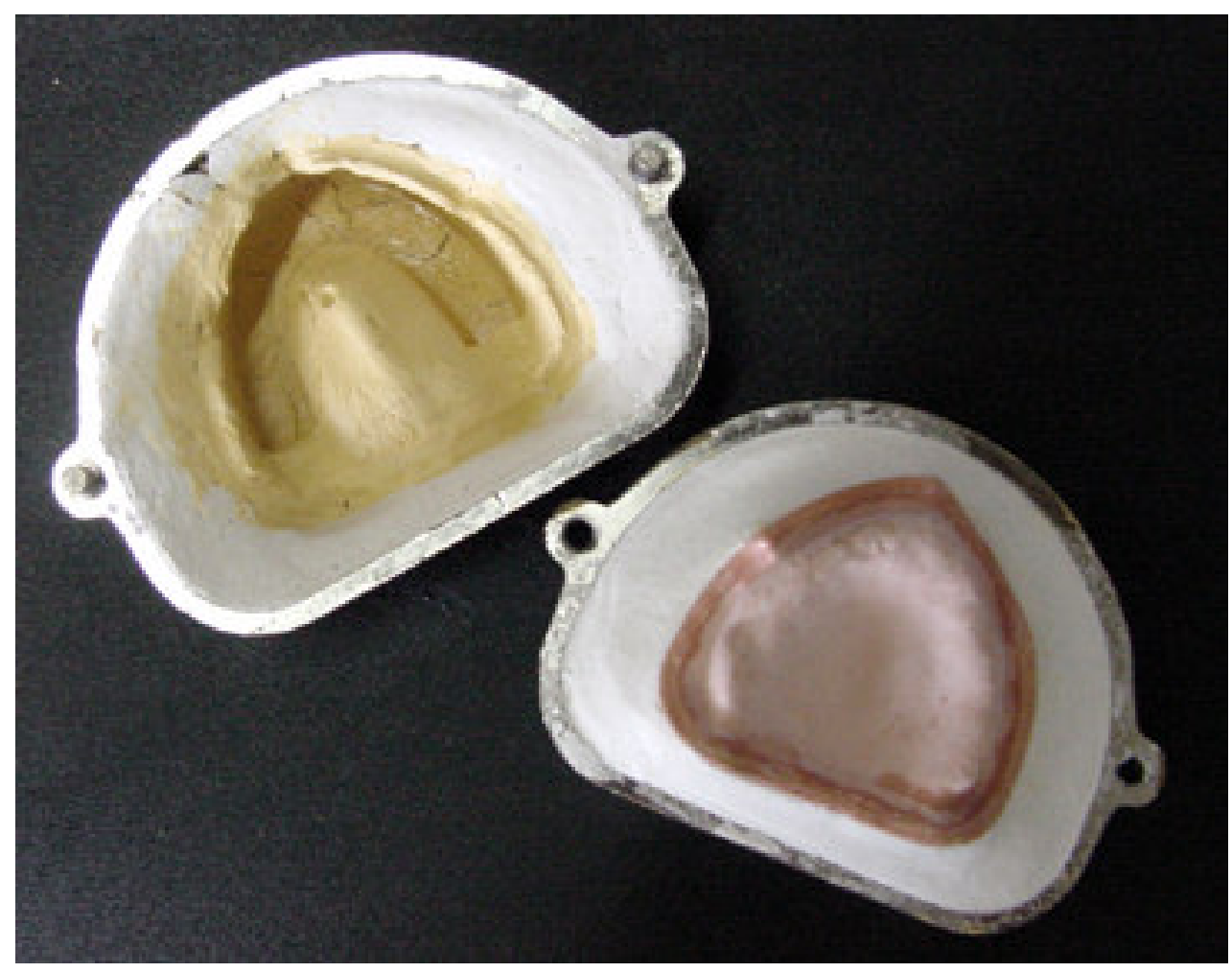

Figura 4.14 - Remoção completa dos excessos de cera 
Na polimerização da resina acrílica foi utilizado ciclo de 12 horas a 70 graus Celsius.

\subsubsection{Acabamento e polimento}

Após a desinclusão (Figura 4.15), o acabamento correspondeu à remoção das rebarbas, imperfeições e aspereza (Figura 4.16) com auxílio das fresas, pedra de carborundum e tiras de lixa. Para o acabamento final seguiu-se respectivamente a seqüência: polimento com cone de feltro e pedra-pomes, polimento com escova preta e pedra pomes e polimento final com escova branca e branco-de-espanha.

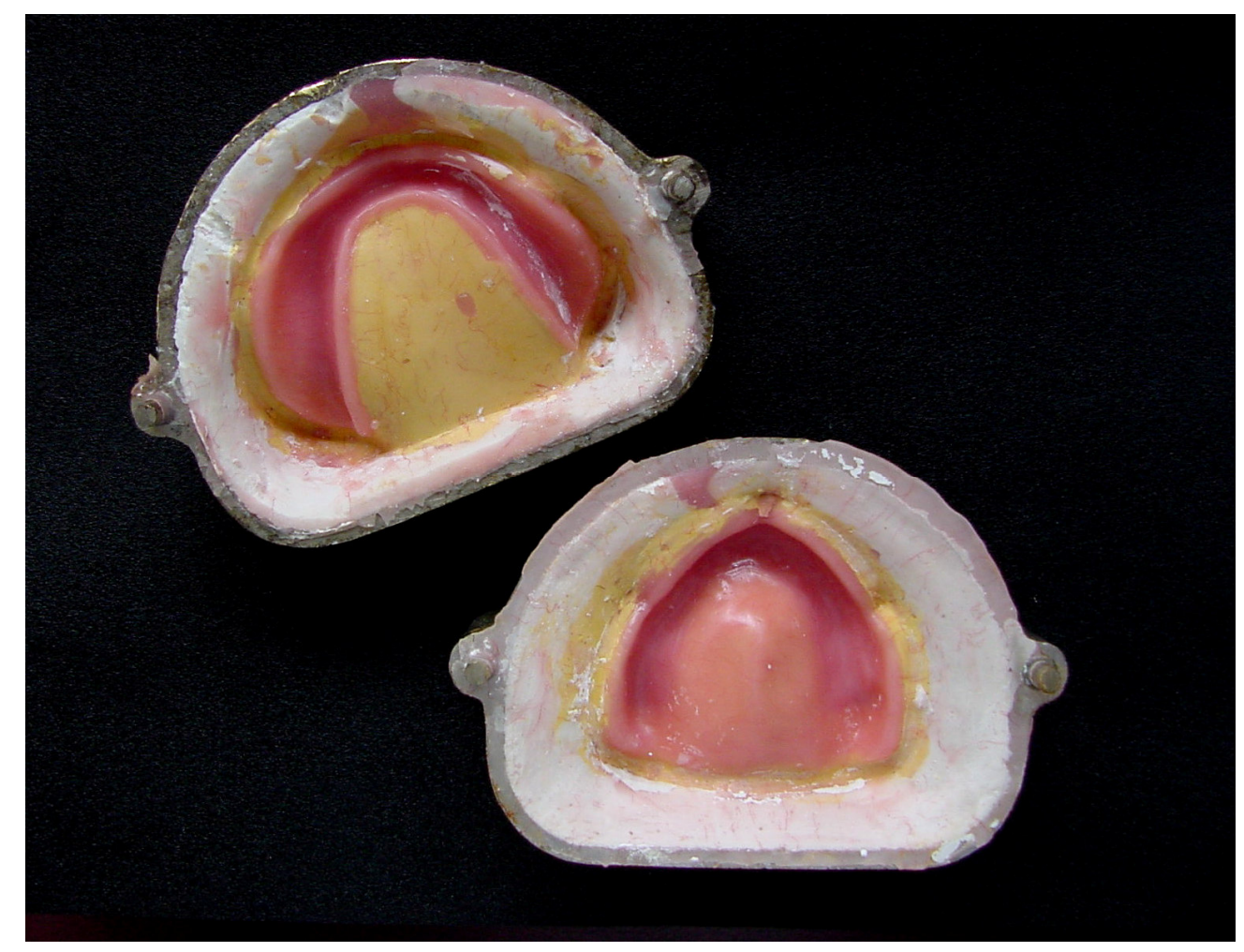

Figura 4.15 - Abertura das muflas após a polimerização da resina 


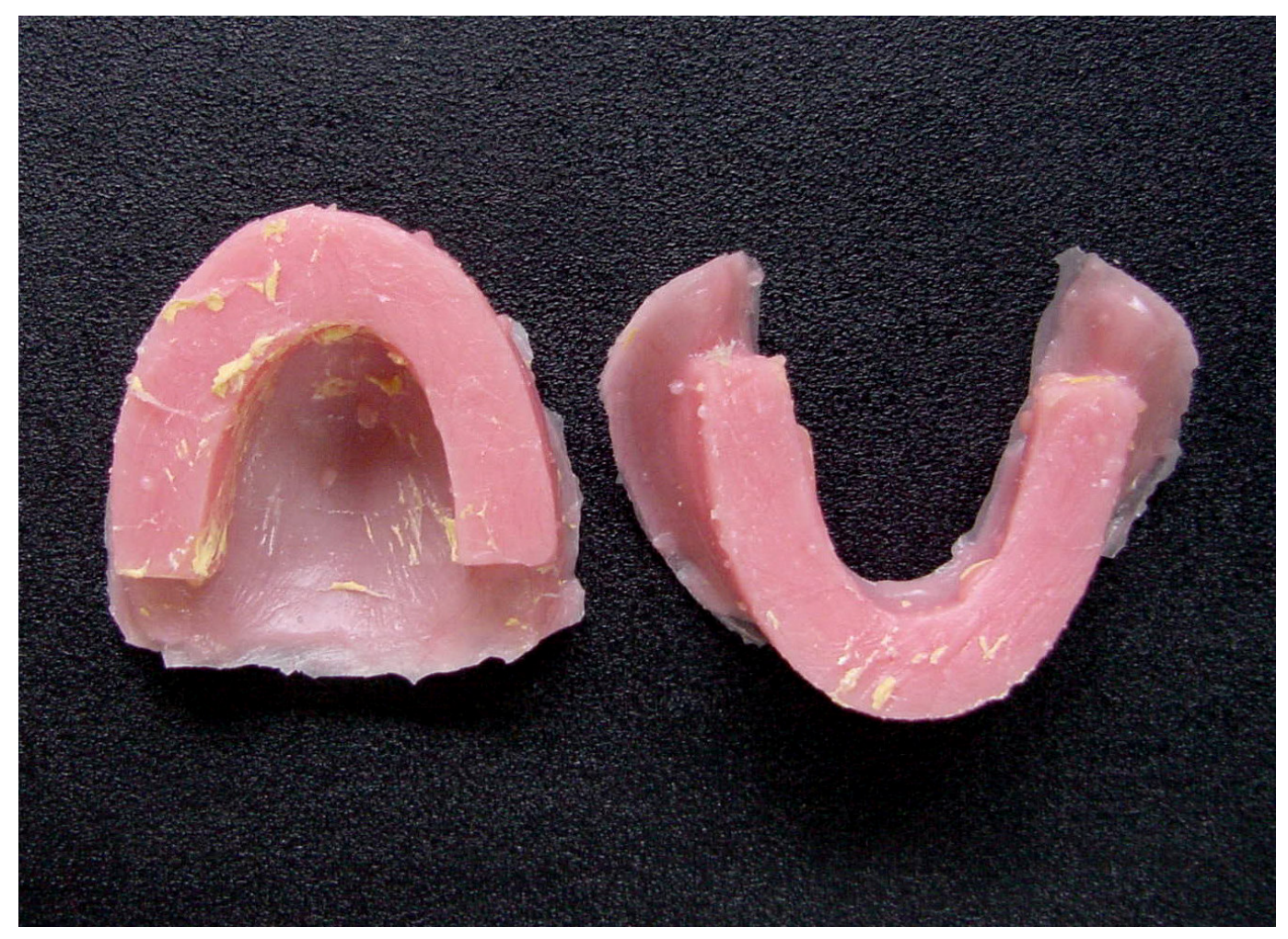

Figura 4.16 - Planos de orientação após a desinclusão das muflas

Assim, foram obtidos planos de orientação em resina acrílica, reproduzindo as três formas básicas de arcadas dentárias (Figura 4.17): triangular (Figura 4.18), quadrada (Figura 4.19) e oval (Figura 4.20). 


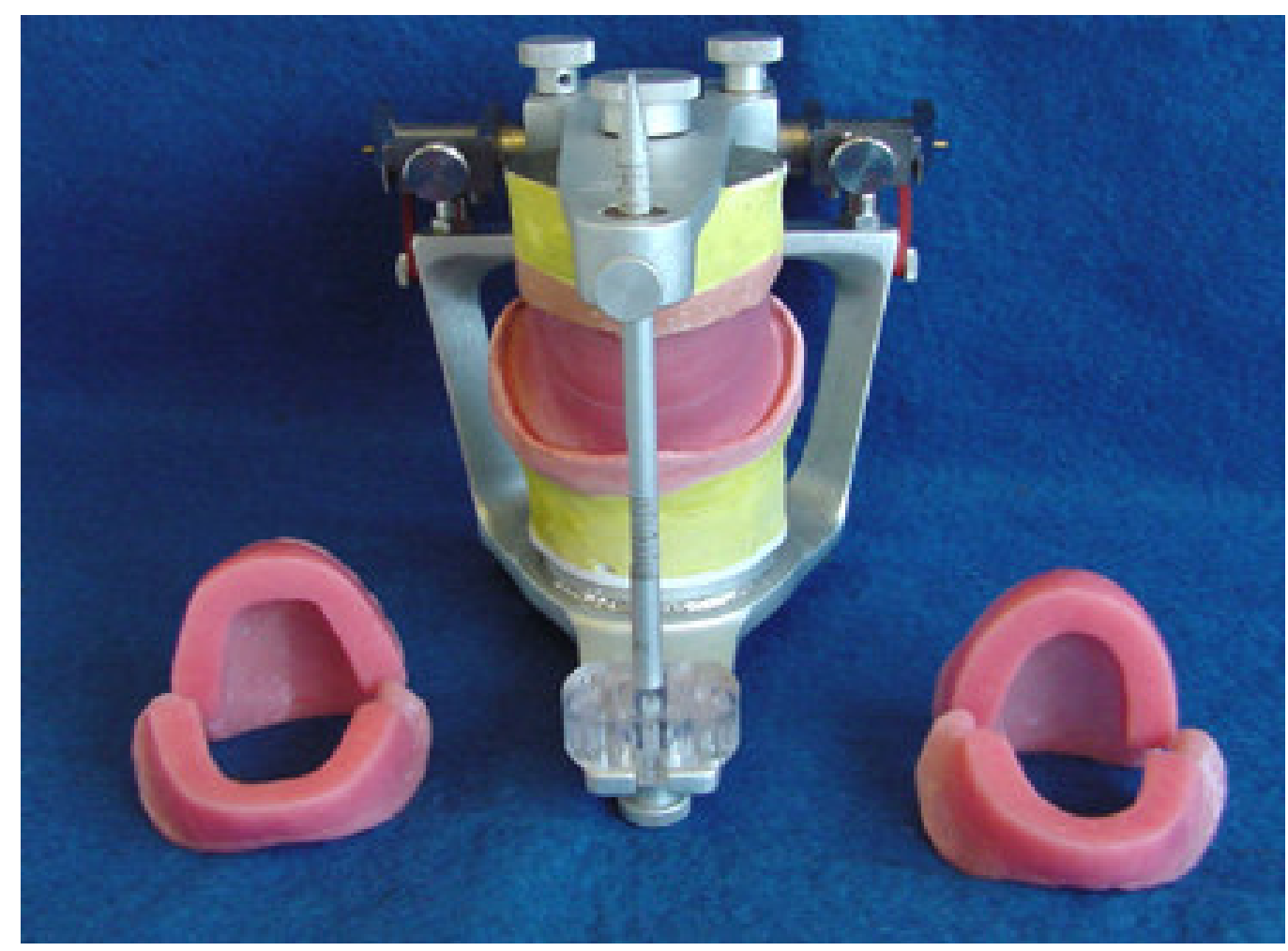

Figura 4.17 - Planos de orientação - formas quadrada, triangular e oval

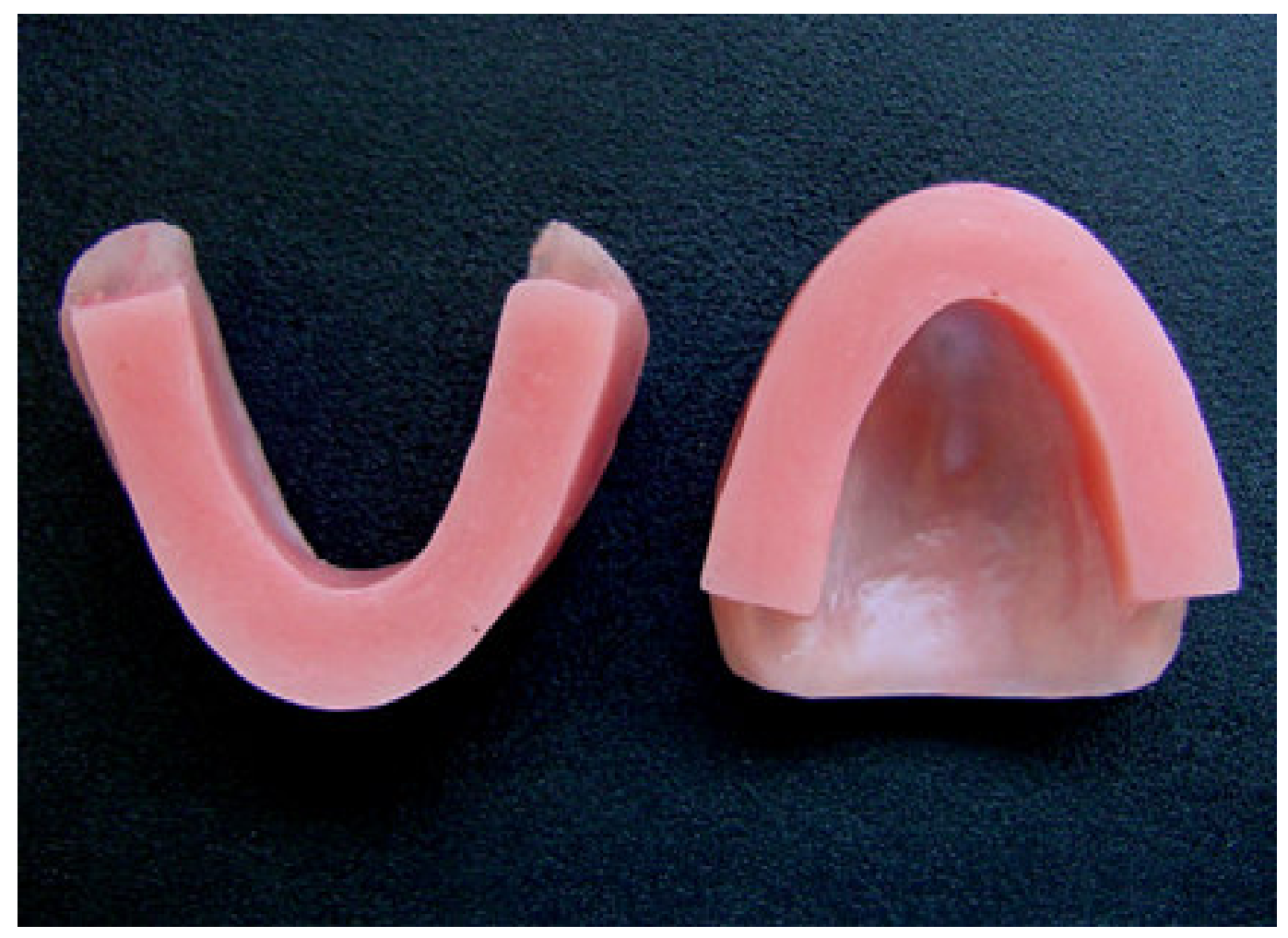

Figura 4.18 - Planos de orientação de forma triangular 


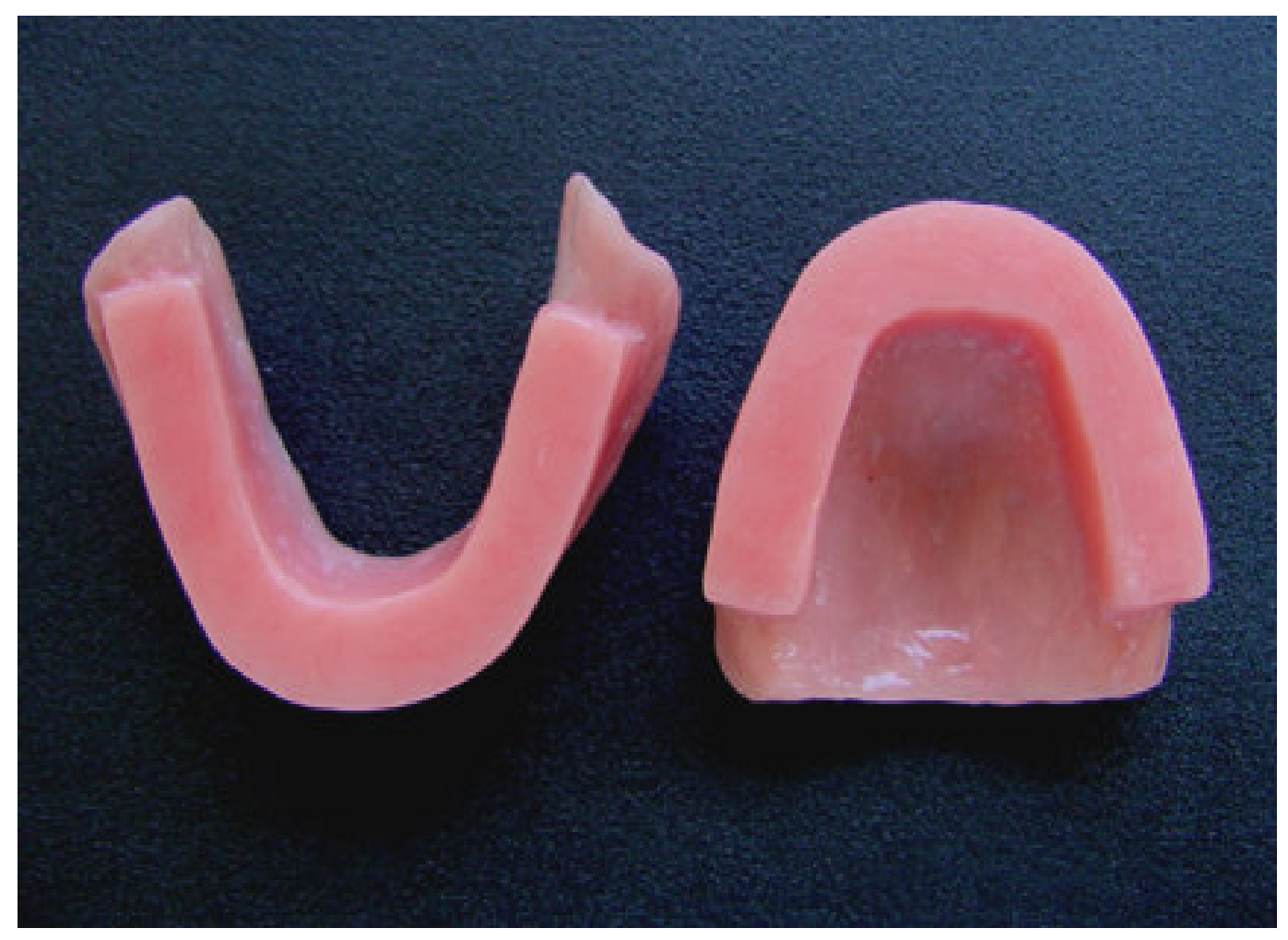

Figura 4.19 - Planos de orientação de forma quadrada

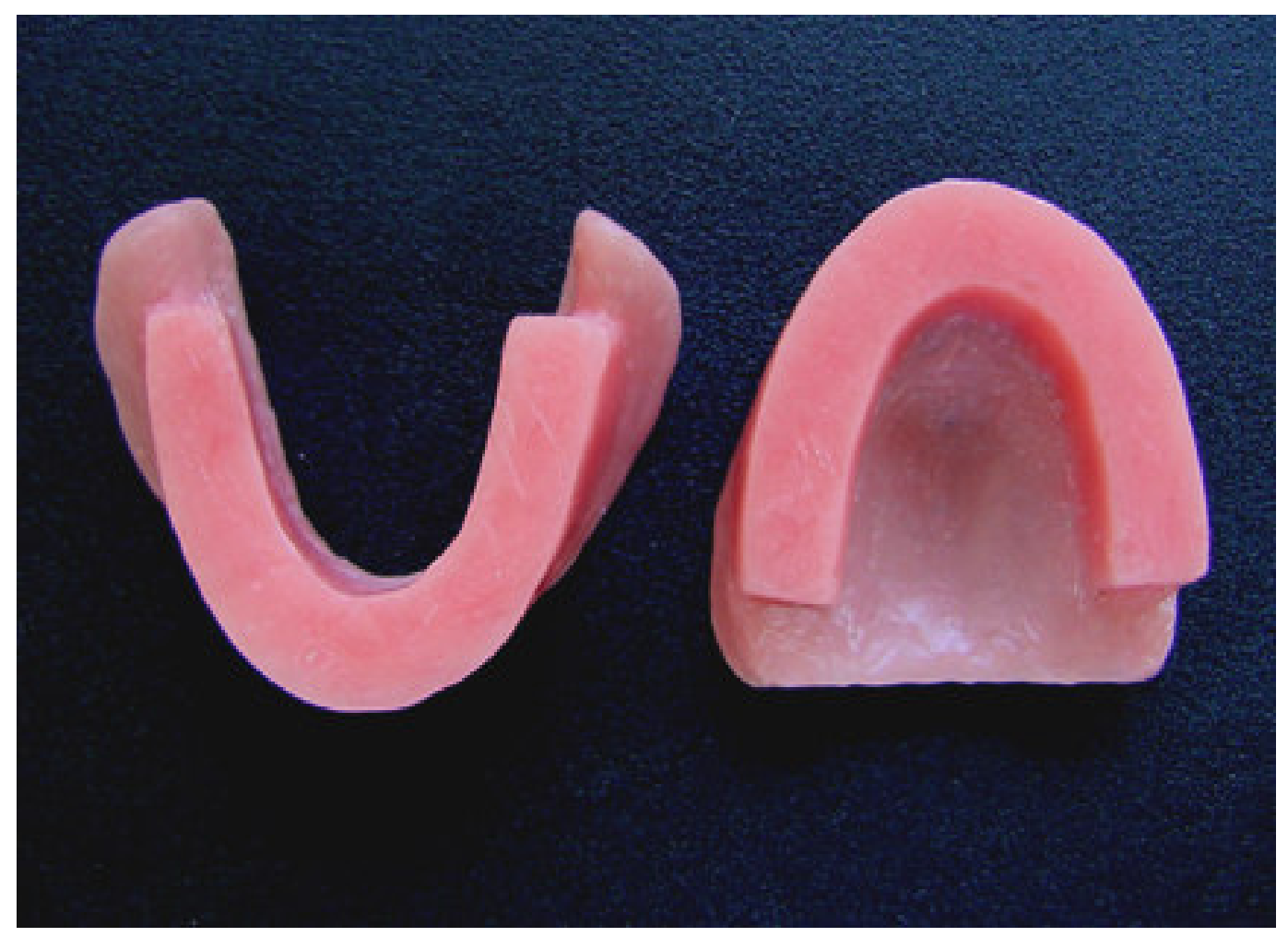

Figura 4.20 - Planos de orientação de forma oval 


\subsubsection{Duplicação dos planos de orientação}

Os planos de orientação inferiores em resina - triangular, quadrado e oval foram reposicionados, um após outro, no articulador e, com uma base de prova confeccionada anteriormente, duplicaram-se os planos de orientação superiores (Figura 4.21) e, sobre estes, os planos de orientação inferiores em cera (Figuras 4.22 e 4.23).

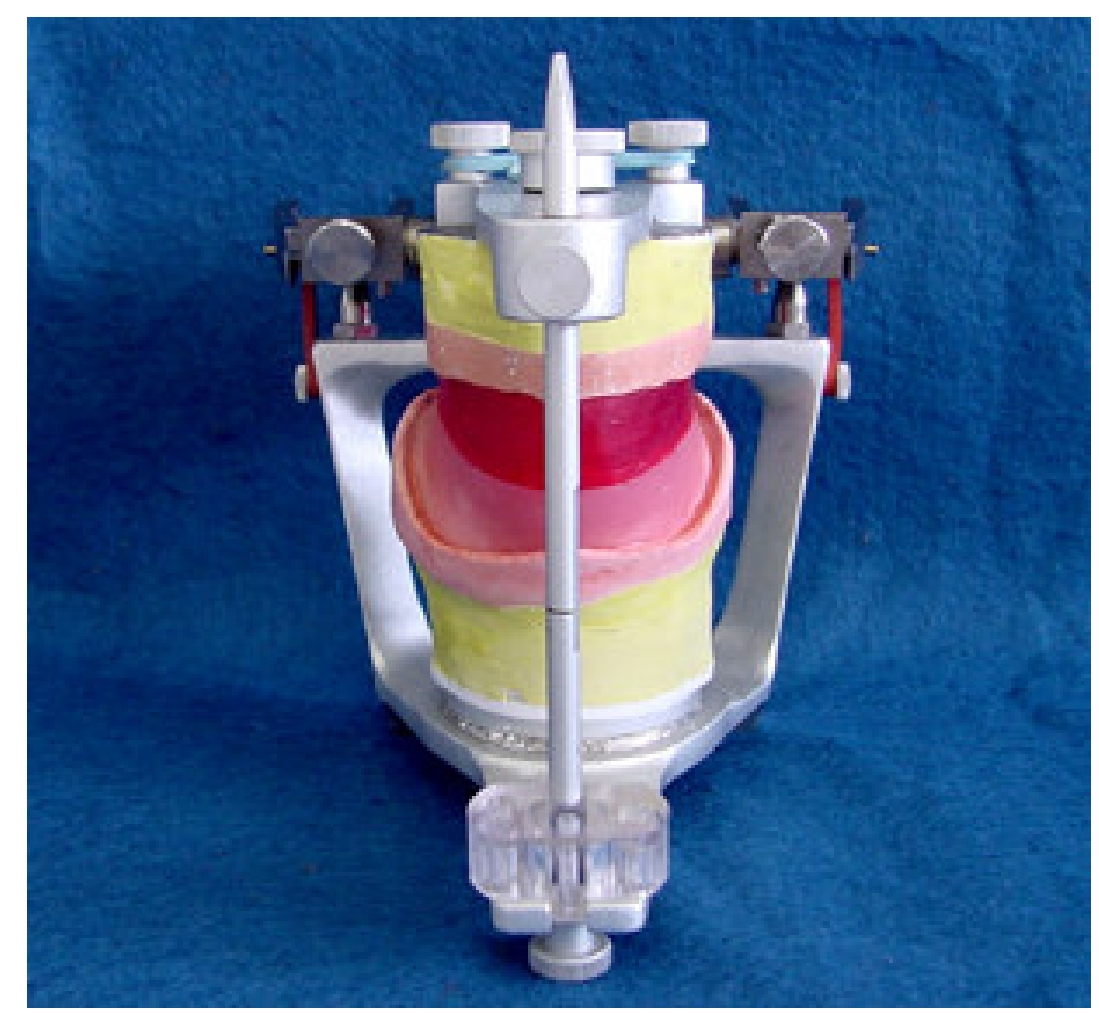

Figura 4.21 - Plano de orientação superior duplicado 


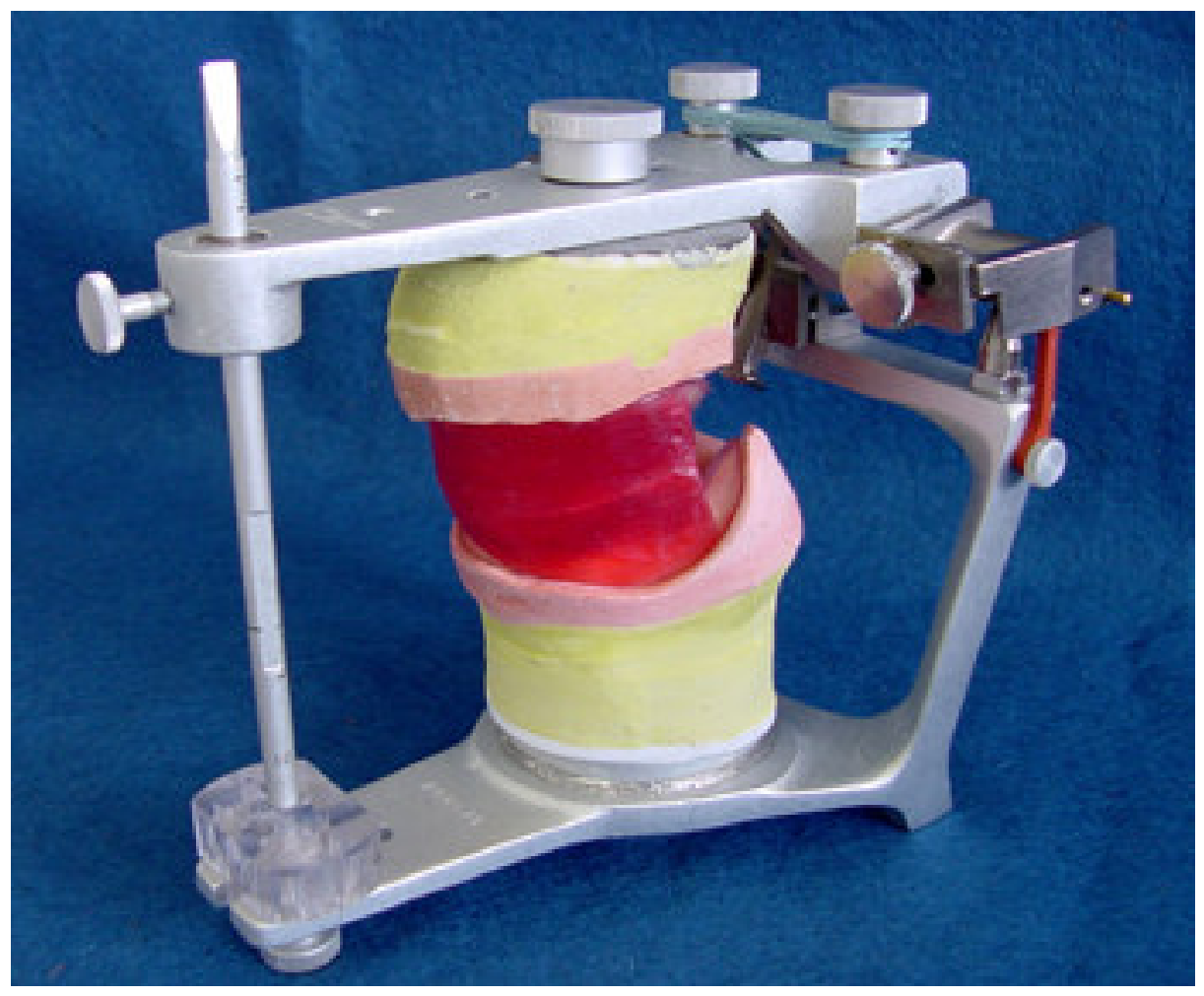

Figura 4.22 - Plano de orientação inferior duplicado

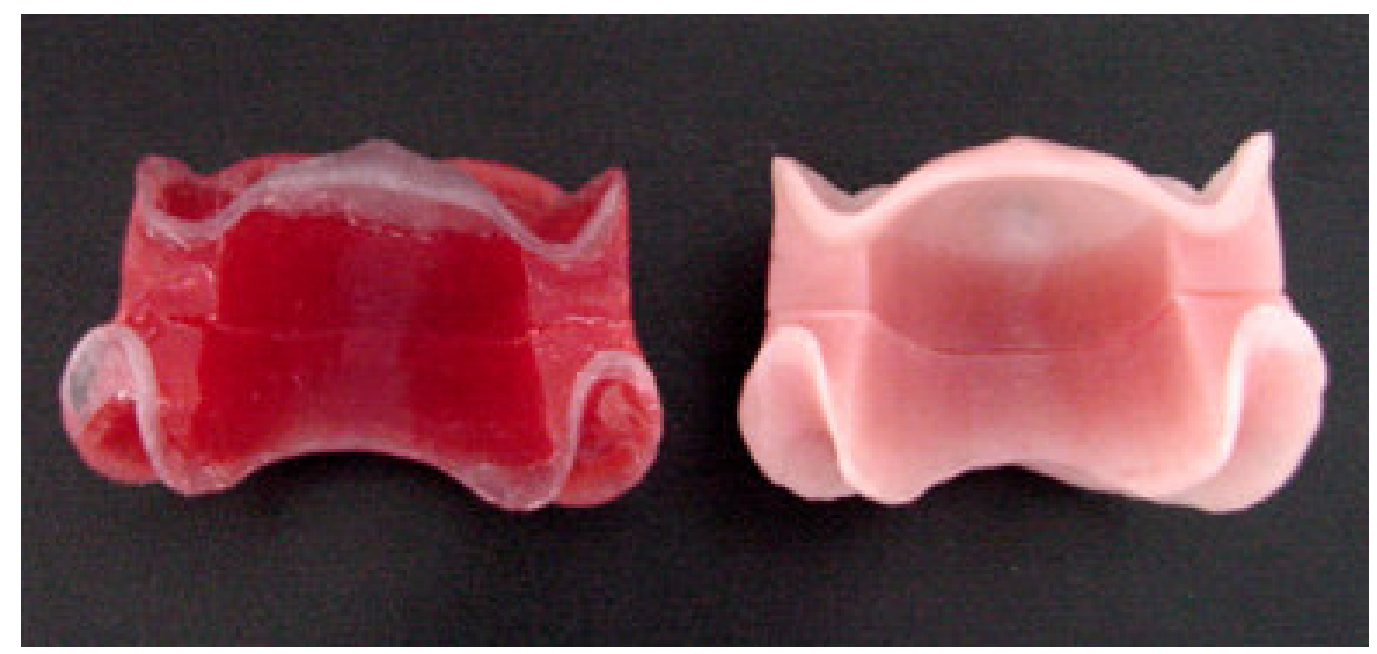

Figura 4.23 - Planos de orientação em cera (E) e em resina (D) 
4.2.8 Seleção e montagem dos dentes artificiais

A seleção do tamanho dos dentes artificiais obedeceu aos critérios propostos também por Tamaki (1988), baseando-se na largura dos seis dentes anteriores superiores e no comprimento total do plano de orientação superior.

Para a montagem dos dentes, foram considerados os seguintes fatores: disposição, alinhamento, oclusão, articulação e posição dos dentes. A montagem foi iniciada recortando-se a cera (Figura 4.24), com auxílio da espátula LeCron aquecida sobre a lamparina a álcool, na seguinte seqüência: hemiarco superior esquerdo, promovendo e verificando o alinhamento dos dentes por vestibular (Figuras 4.25 e 4.26) e também o contato dos dentes contra a superfície oclusal do plano de orientação (Figuras 4.27 e 4.28), hemiarco superior direito (Figura 4.29), hemiarco inferior esquerdo e hemiarco inferior direito. 


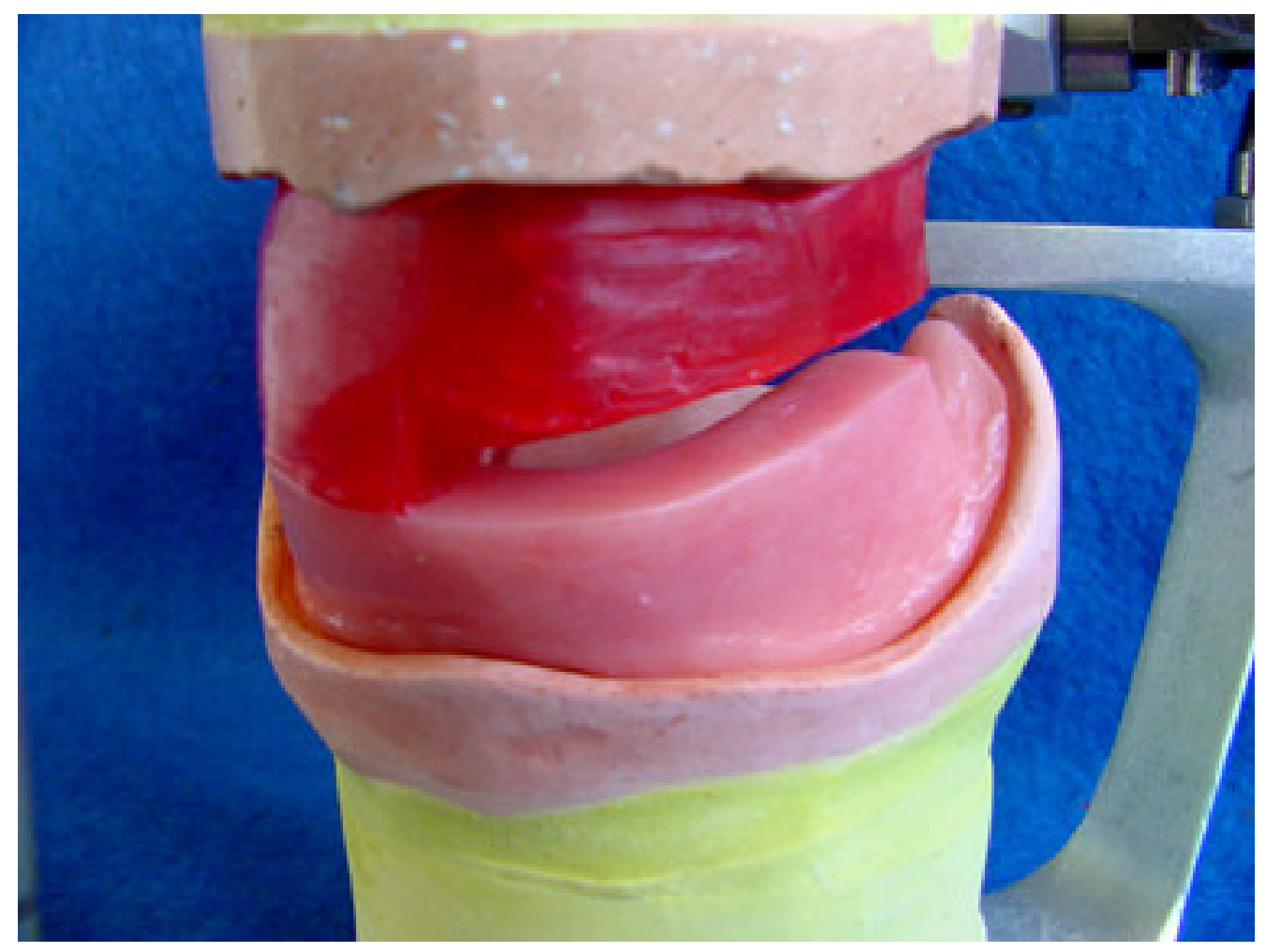

Figura 4.24 - Recorte na cera, para início da montagem dos dentes

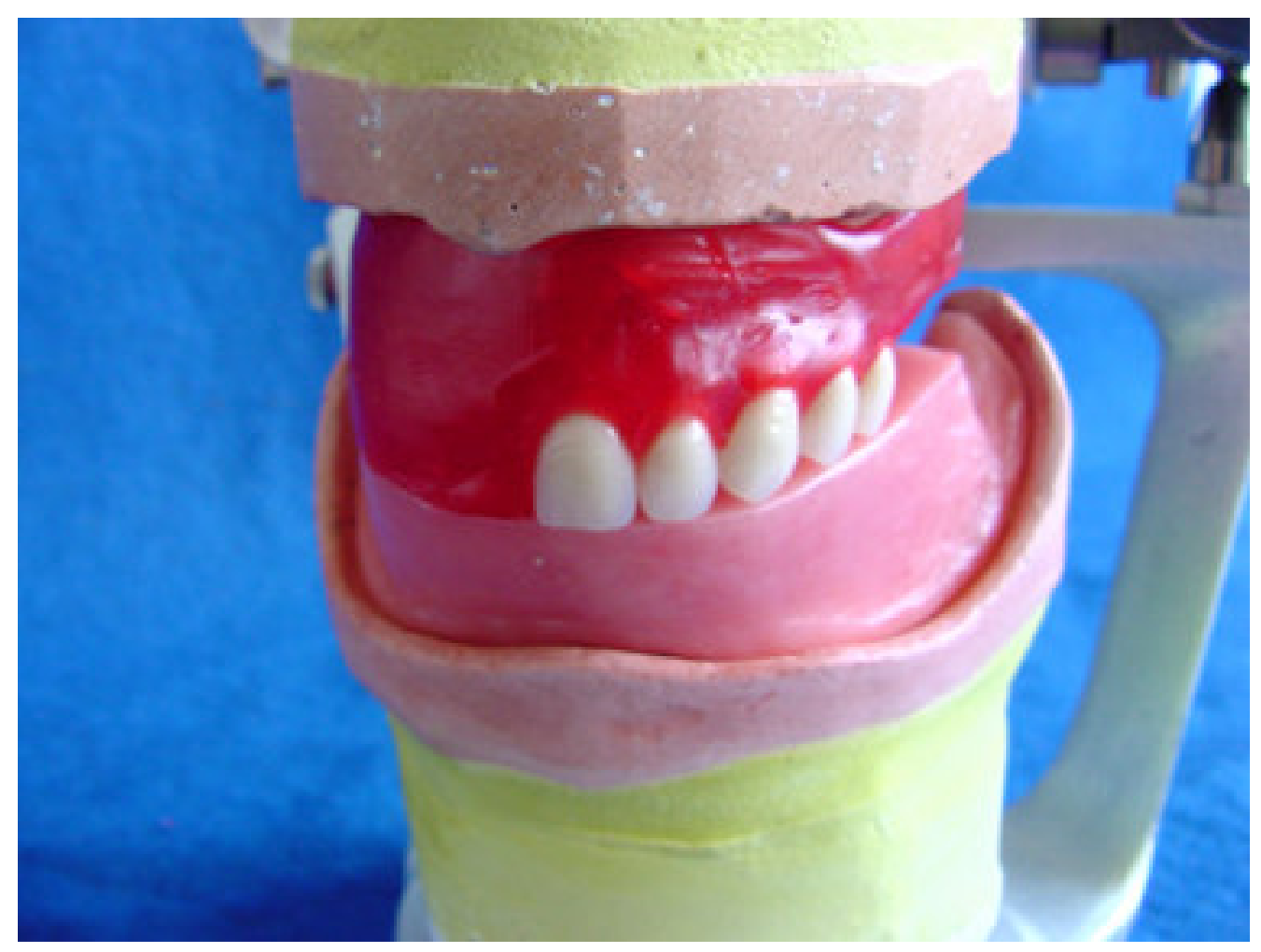

Figura 4.25 - Alinhamento vestibular dos dentes em relação ao plano 


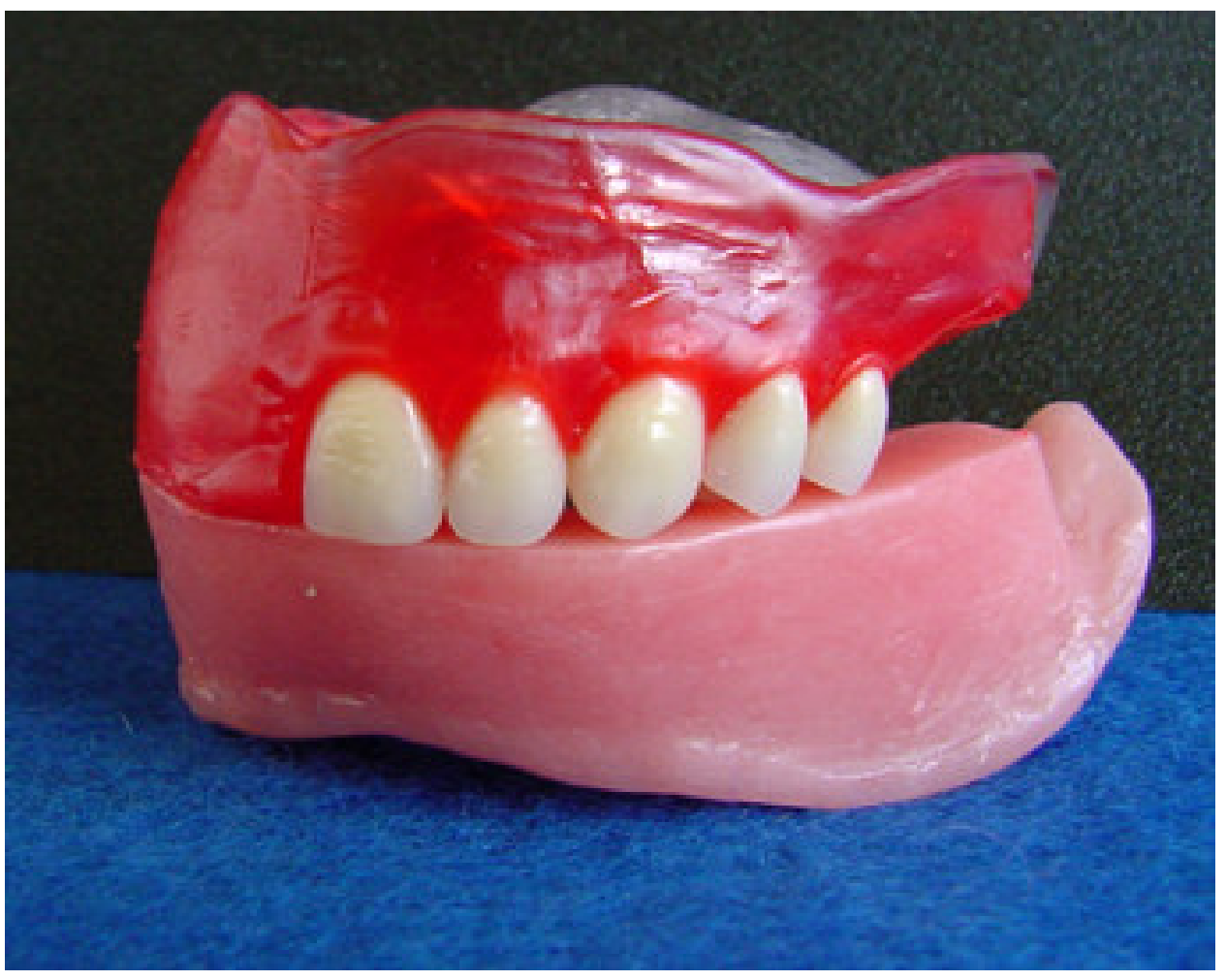

Figura 4.26 - Alinhamento vestibular dos dentes em relação ao plano

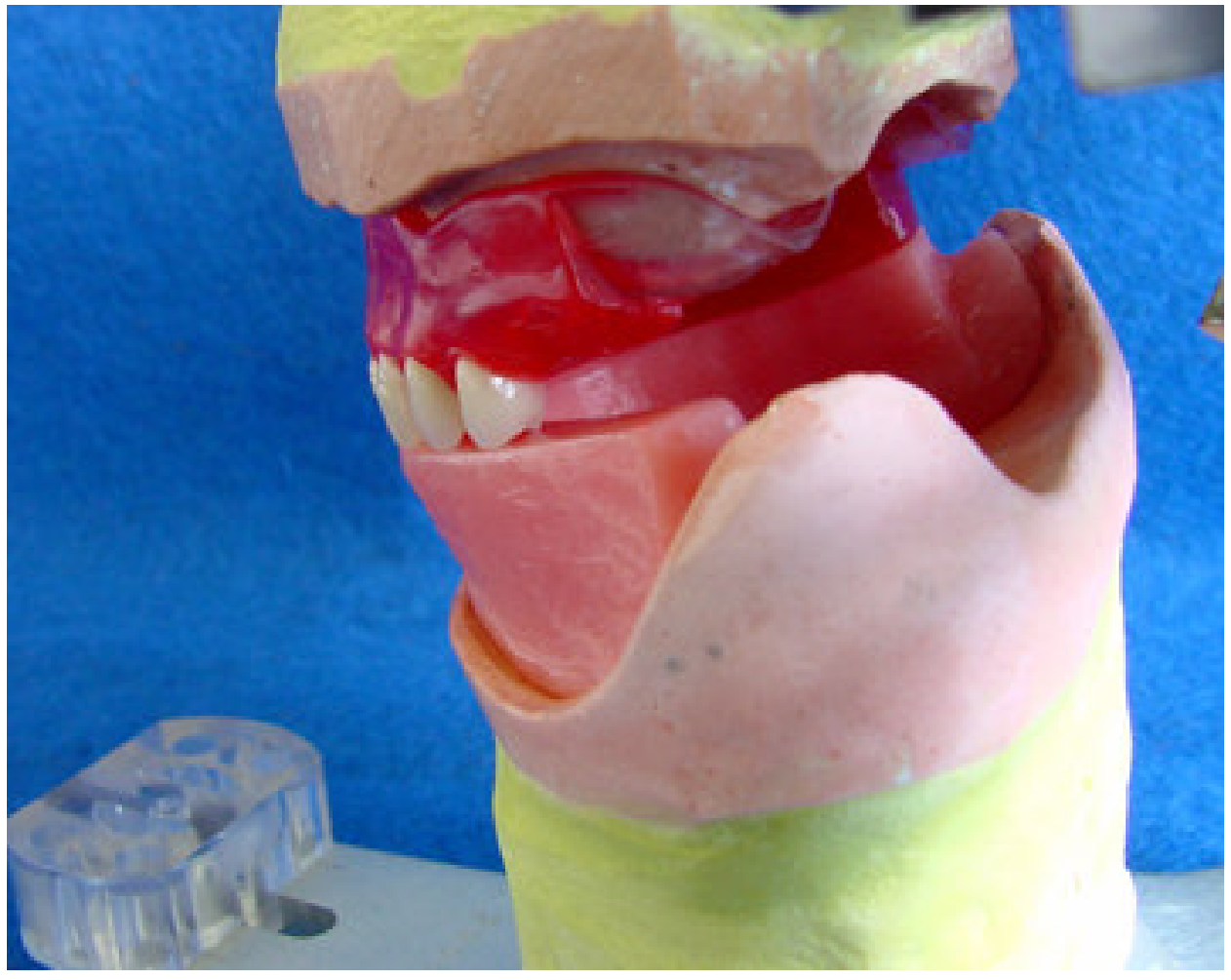

Figura 4.27 - Contato dos dentes contra a superfície oclusal do plano 


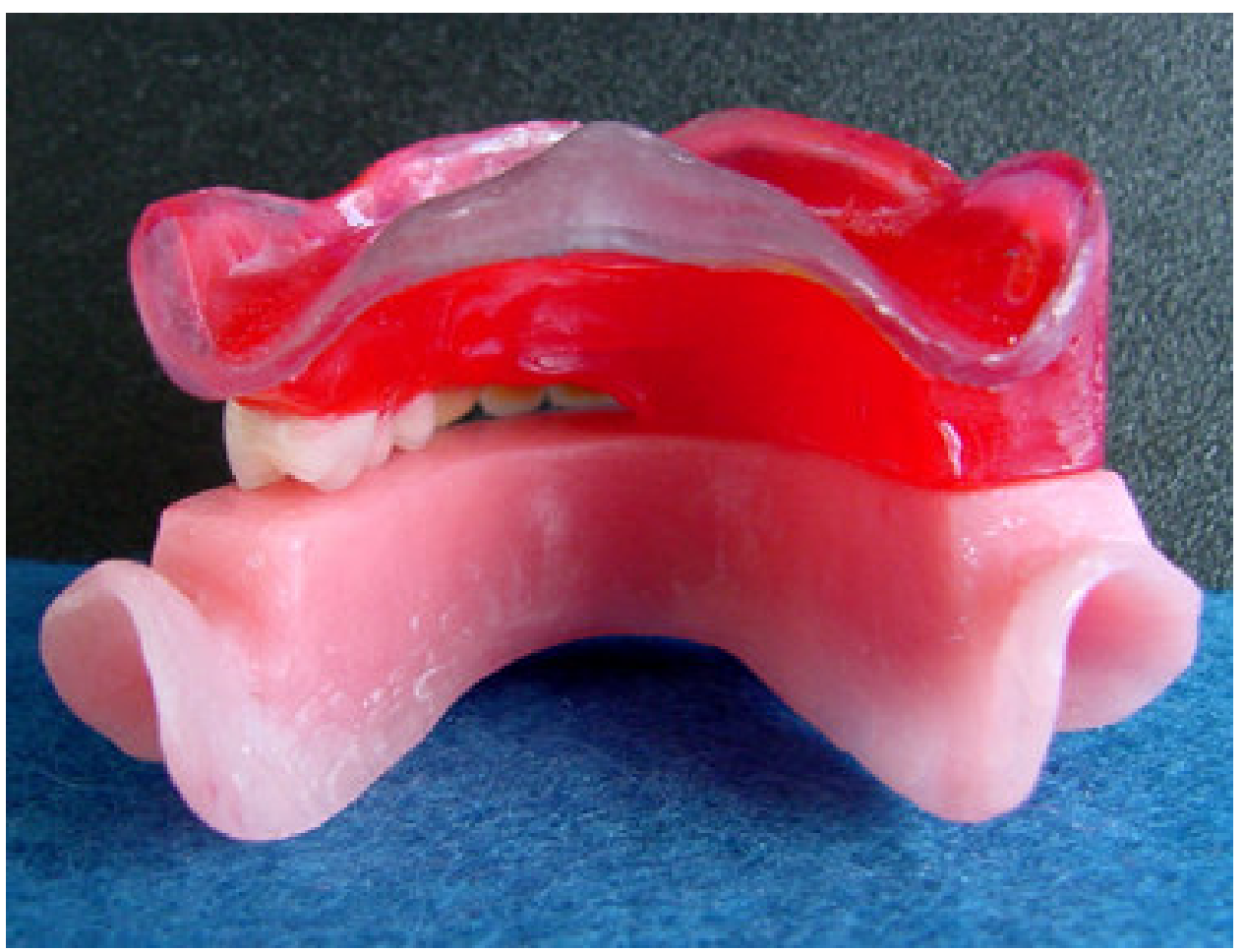

Figura 4.28 - Contato dos dentes contra a superfície oclusal do plano

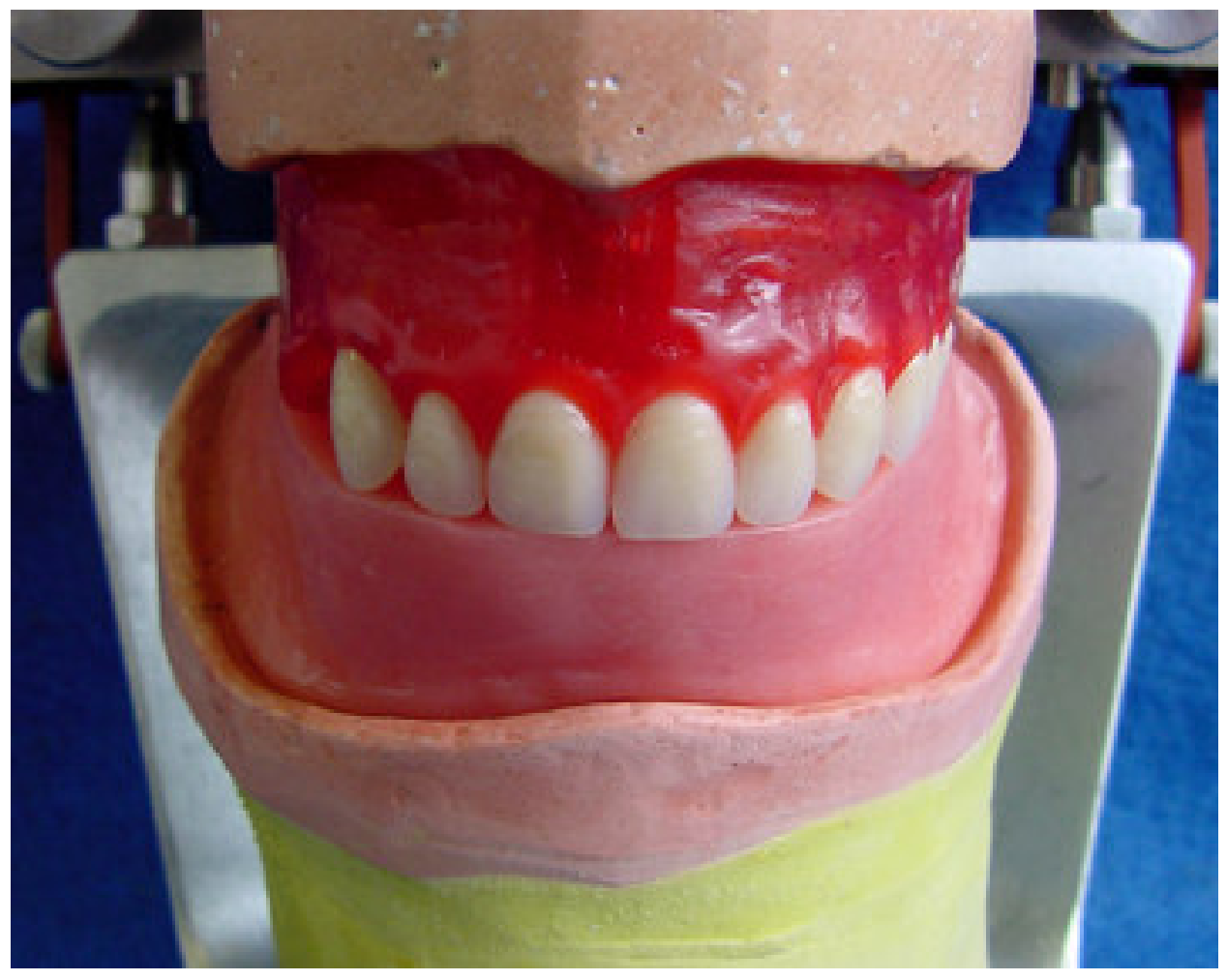

Figura 4.29 - Montagem dos dentes do hemiarco direito 
Entretanto, e sabendo-se que os rebordos alveolares podem apresentar três formas básicas; triangular, quadrada e oval, optou-se pelo aumento na quantidade de corpos-de-prova, para considerar também esta variável. Assim sendo, os corposde-prova foram confeccionados de modo a obter-se: 
- Três próteses totais bimaxilares, montadas com os dentes anatômicos Dental Vipi - anteriores superiores Vipi-Dent Plus tamanho A23, anteriores inferiores Vipi-Dent Plus tamanho A23 e posteriores superiores e inferiores Vipi-Dent Plus tamanho 30M, todos na cor 66 - dispostos de forma oval sobre os planos de cera (Figuras 4.30 e 4.31);

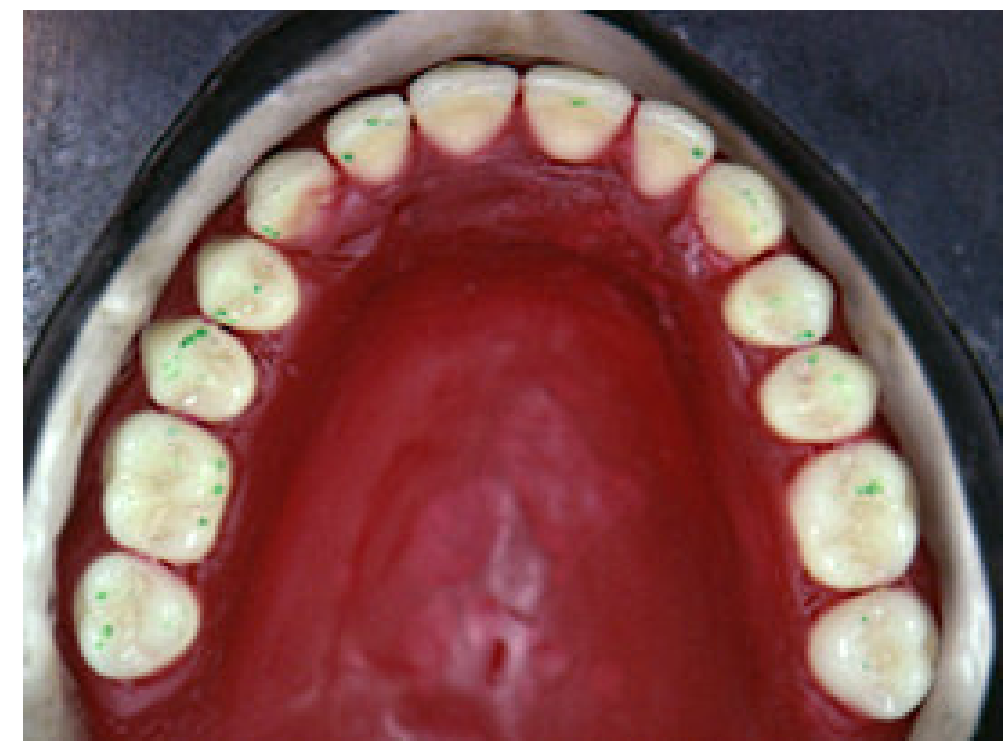

Figura 4.30 - Prótese total superior, com os dentes anatômicos Vipi-Dent Plus, montados de forma oval

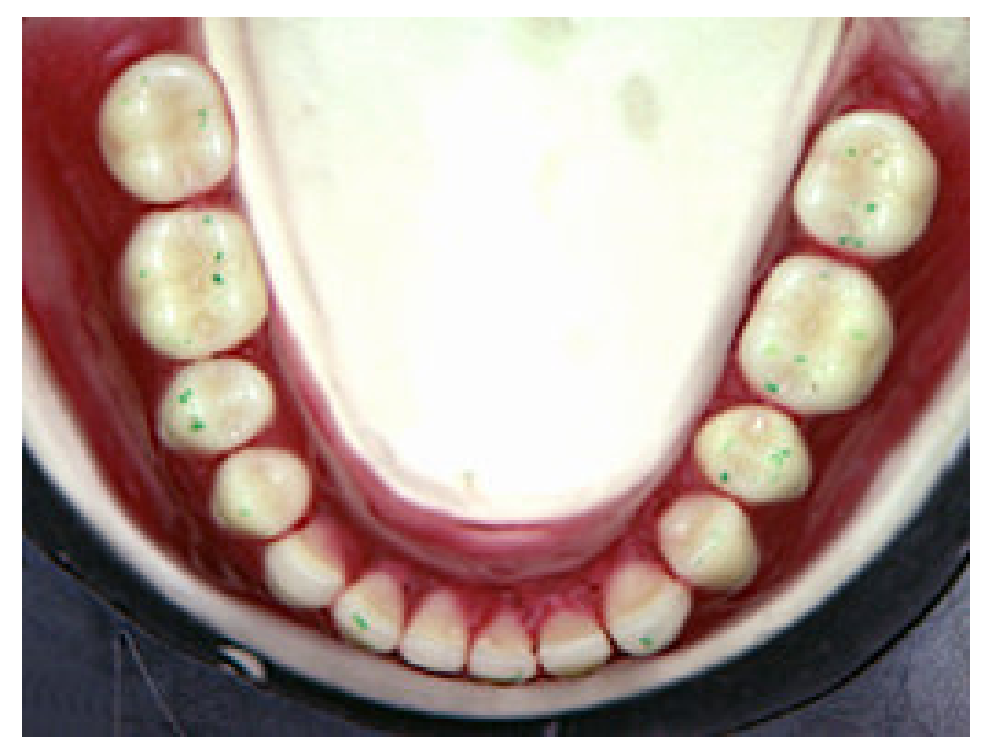

Figura 4.31 - Prótese total inferior, com os dentes anatômicos Vipi-Dent Plus, montados de forma oval 
- Três próteses totais bimaxilares, montadas com os dentes anatômicos Dental Vipi - anteriores superiores Vipi-Dent Plus tamanho A23, anteriores inferiores Vipi-Dent Plus tamanho A23 e posteriores superiores e inferiores Vipi-Dent Plus tamanho 30M, todos na cor 66 - dispostos de forma quadrada sobre os planos de cera (Figuras 4.32 e 4.33 );

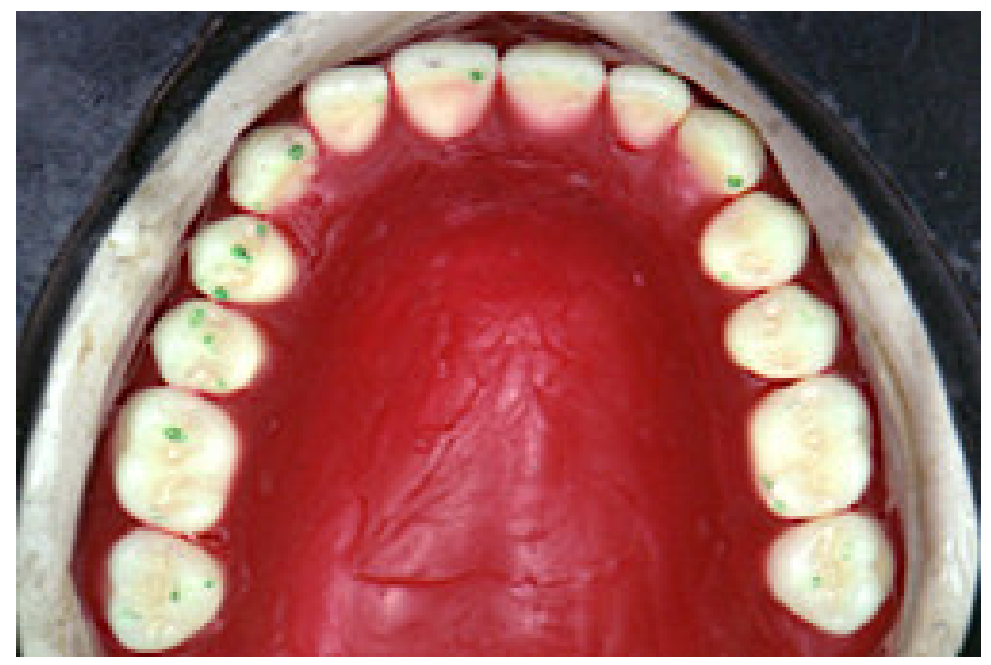

Figura 4.32 - Prótese total superior, com os dentes anatômicos Vipi-Dent Plus, montados de forma quadrada

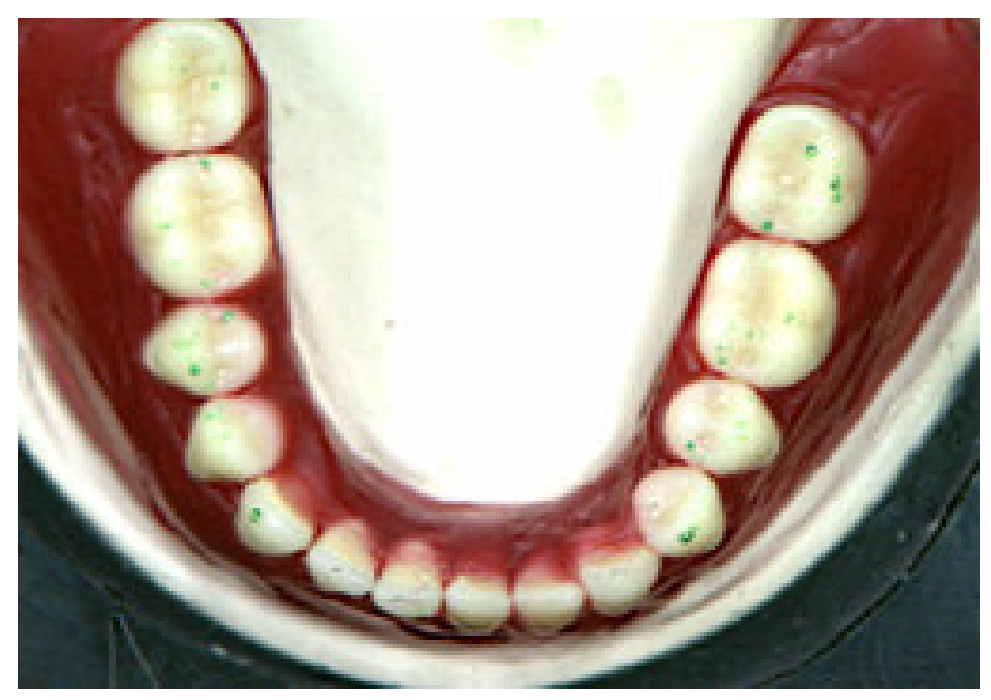

Figura 4.33 - Prótese total inferior, com os dentes anatômicos Vipi-Dent Plus, montados de forma quadrada 
- Três próteses totais bimaxilares, montadas com os dentes anatômicos Dental Vipi - anteriores superiores Vipi-Dent Plus tamanho A23, anteriores inferiores Vipi-Dent Plus tamanho A23 e posteriores superiores e inferiores Vipi-Dent Plus tamanho 30M, todos na cor 66 - dispostos de forma triangular sobre os planos de cera (Figuras 4.34 e 4.35$)$;

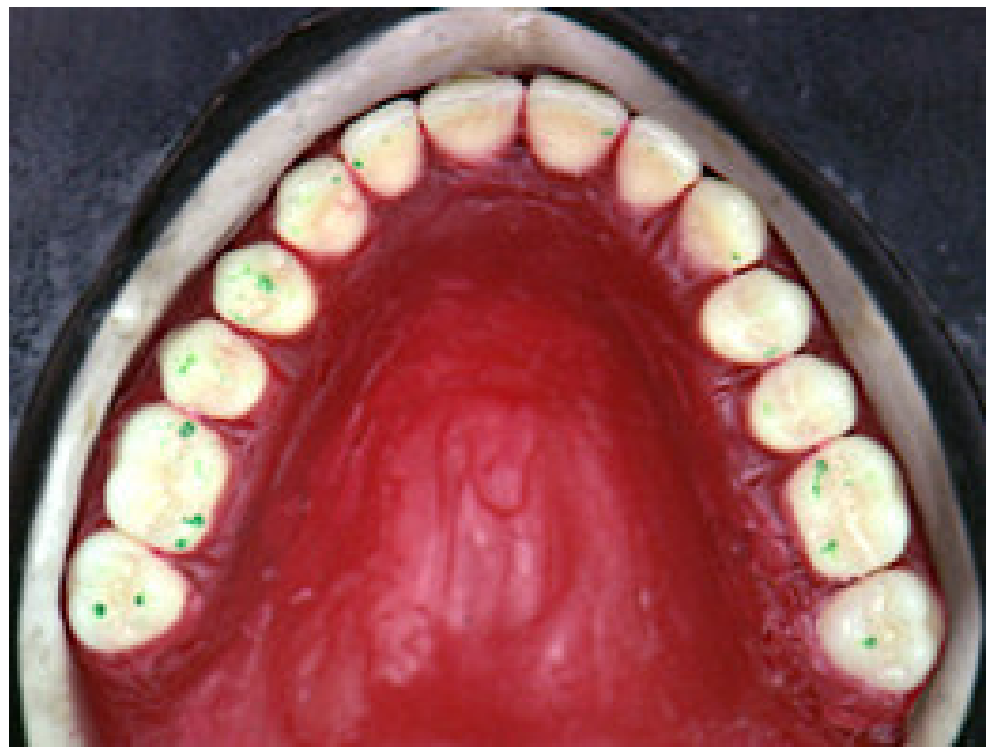

Figura 4.34 - Prótese total superior, com os dentes anatômicos Vipi-Dent Plus, montados de forma triangular

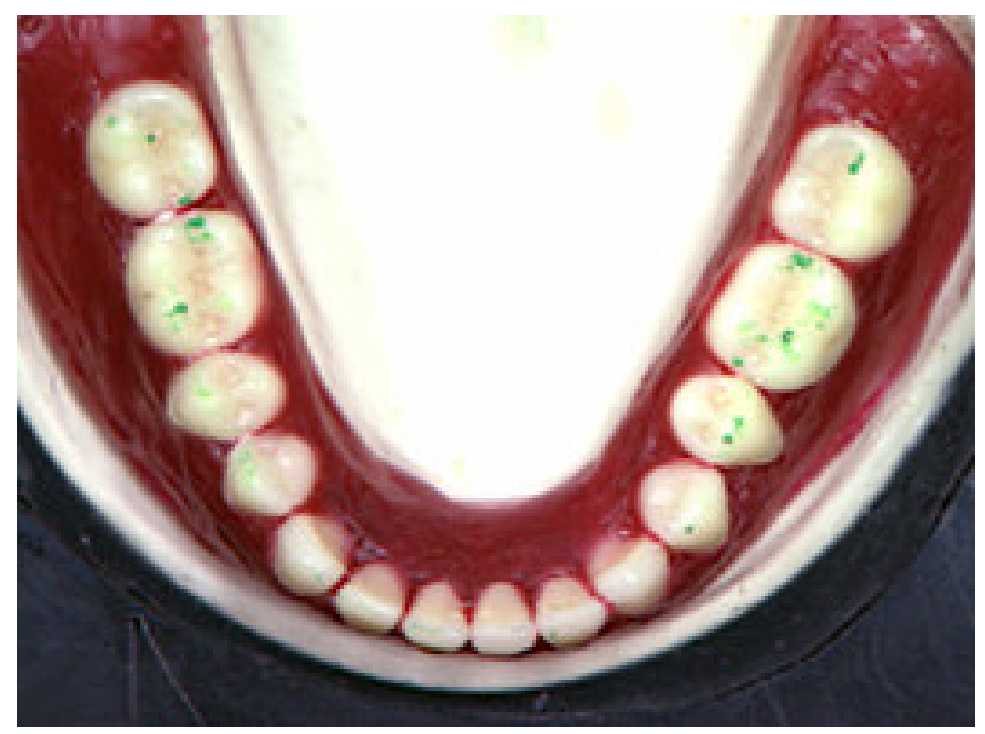

Figura 4.35 - Prótese total inferior, com os dentes anatômicos Vipi-Dent Plus, montados de forma triangular 
- Três próteses totais bimaxilares, montadas com os dentes anatômicos Ivoclar anteriores superiores Antaris tamanho A52, anteriores inferiores Antaris tamanho A3 e posteriores superiores e inferiores Postaris tamanhos PU1 e PL1, todos na cor 2B - dispostos de forma oval sobre os planos de cera;

- Três próteses totais bimaxilares, montadas com os dentes anatômicos Ivoclar anteriores superiores Antaris tamanho A52, anteriores inferiores Antaris tamanho A3 e posteriores superiores e inferiores Postaris tamanhos PU1 e PL1, todos na cor 2B - dispostos de forma quadrada sobre os planos de cera;

- Três próteses totais bimaxilares, montadas com os dentes anatômicos Ivoclar anteriores superiores Antaris tamanho A52, anteriores inferiores Antaris tamanho A3 e posteriores superiores e inferiores Postaris tamanhos PU1 e PL1, todos na cor 2B - dispostos de forma triangular sobre os planos de cera;

- Três próteses totais bimaxilares, montadas com os dentes funcionais Ivoclar anteriores superiores Ivostar tamanho O01, anteriores inferiores Ivostar tamanho 12 e posteriores superiores e inferiores Gnathostar tamanho D80, todos na cor 2B - dispostos de forma oval sobre os planos de cera;

- Três próteses totais bimaxilares, montadas com os dentes funcionais Ivoclar anteriores superiores Ivostar tamanho O01, anteriores inferiores Ivostar tamanho 12 e posteriores superiores e inferiores Gnathostar tamanho D80, todos na cor 2B - dispostos de forma quadrada sobre os planos de cera; 
- Três próteses totais bimaxilares, montadas com os dentes funcionais Ivoclar anteriores superiores Ivostar tamanho O01, anteriores inferiores Ivostar tamanho 12 e posteriores superiores e inferiores Gnathostar tamanho D80, todos na cor 2B - dispostos de forma triangular sobre os planos de cera;

- Três próteses totais bimaxilares, montadas com os dentes funcionais Dental Vipi - anteriores superiores Biolux tamanho V21, anteriores inferiores Biolux tamanho V3 e posteriores Biolux tamanho P3, todos na cor 66 - dispostos de forma oval sobre os planos de cera;

- Três próteses totais bimaxilares, montadas com os dentes funcionais Dental Vipi - anteriores superiores Biolux tamanho V21, anteriores inferiores Biolux tamanho V3 e posteriores Biolux tamanho P3, todos na cor 66 - dispostos de forma quadrada sobre os planos de cera; 
- Três próteses totais bimaxilares, montadas com os dentes funcionais Dental Vipi - anteriores superiores Biolux tamanho V21, anteriores inferiores Biolux tamanho V3 e posteriores Biolux tamanho P3, todos na cor 66 - dispostos de forma triangular sobre os planos de cera;

4.2.9 Obtenção dos contatos e ajuste oclusal das próteses totais bimaxilares

Para a detecção dos pontos de contato, uma tira de papel para articulação foi interposta em cada lado das arcadas dentárias (Figura 4.36).

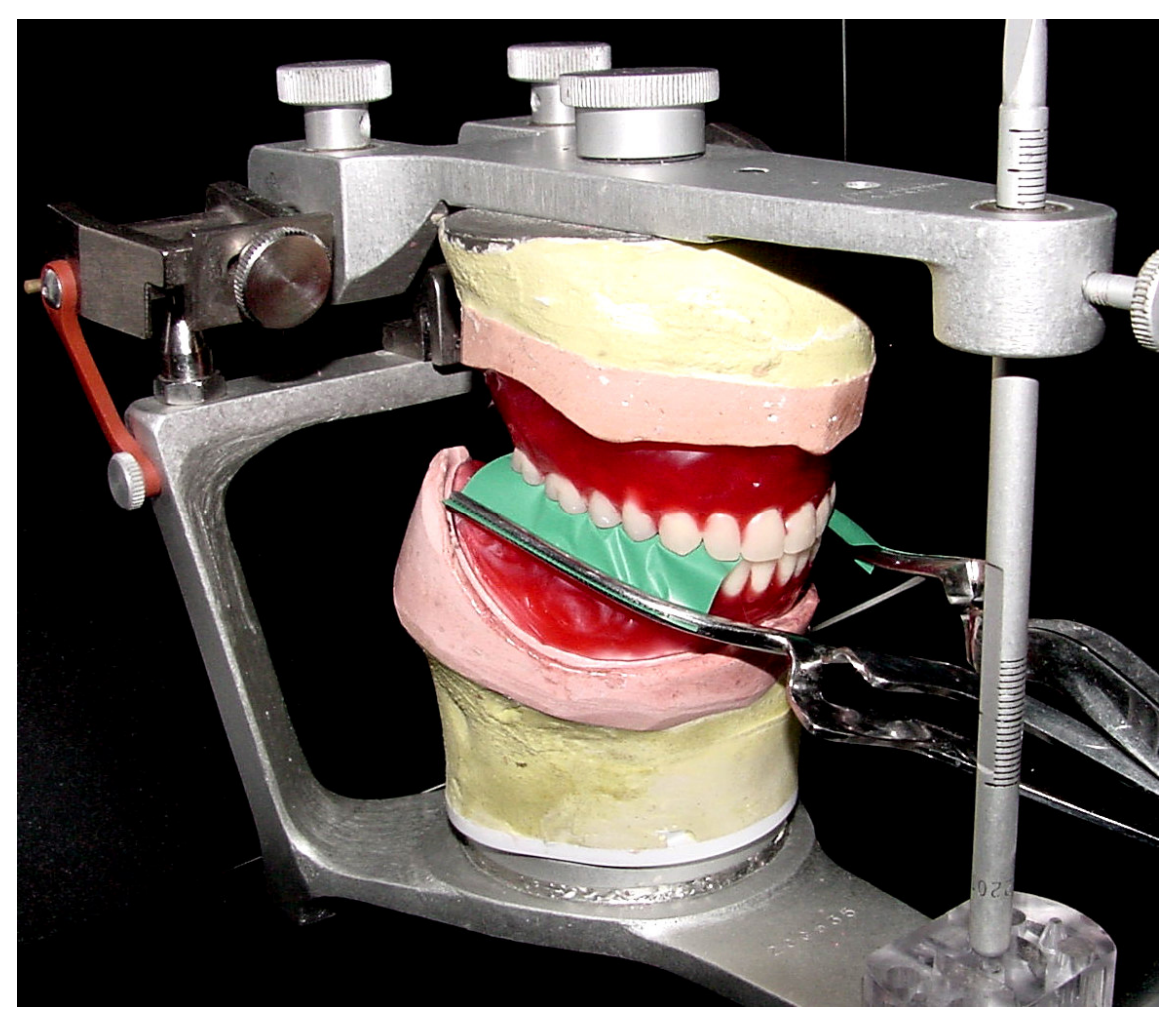

Figura 4.36 - Tiras de carbono, posicionadas com auxílio das pinças, entre as próteses totais superior e inferior 
Para se obter marcas nítidas dos contatos oclusais, o ramo superior do articulador foi movimentado no sentido de abrir e fechar, repetidas vezes.

Examinando-se as marcas de carbono nos dentes, pode estimar-se a intensidade dos toques. Marcas em forma de anel indicavam os contatos mais intensos; as em forma de disco, contatos um pouco menos intensos e as em forma de ponto, contatos com a intensidade desejada. Antes de cada novo registro, os dentes eram limpos, eliminando-se as marcas anteriores do carbono.

Considerava-se concluído o ajuste em oclusão quando se obtinham contatos bilaterais, puntiformes e intensidade uniforme.

A partir deste ajuste inicial, foram realizados os movimentos de protrusão e lateralidades direita e esquerda.

4.2.10 Obtenção da imagem das superfícies oclusais superior e inferior das próteses

Nesta fase, as próteses com as impressões dos contatos oclusais evidenciadas pelo uso do papel para articulação, foram posicionadas em uma base metálica. Esta base continha uma réplica do modelo mestre, utilizada para estabilizar as próteses durante a captura de suas respectivas imagens (Figuras 4.37 e 4.38). 


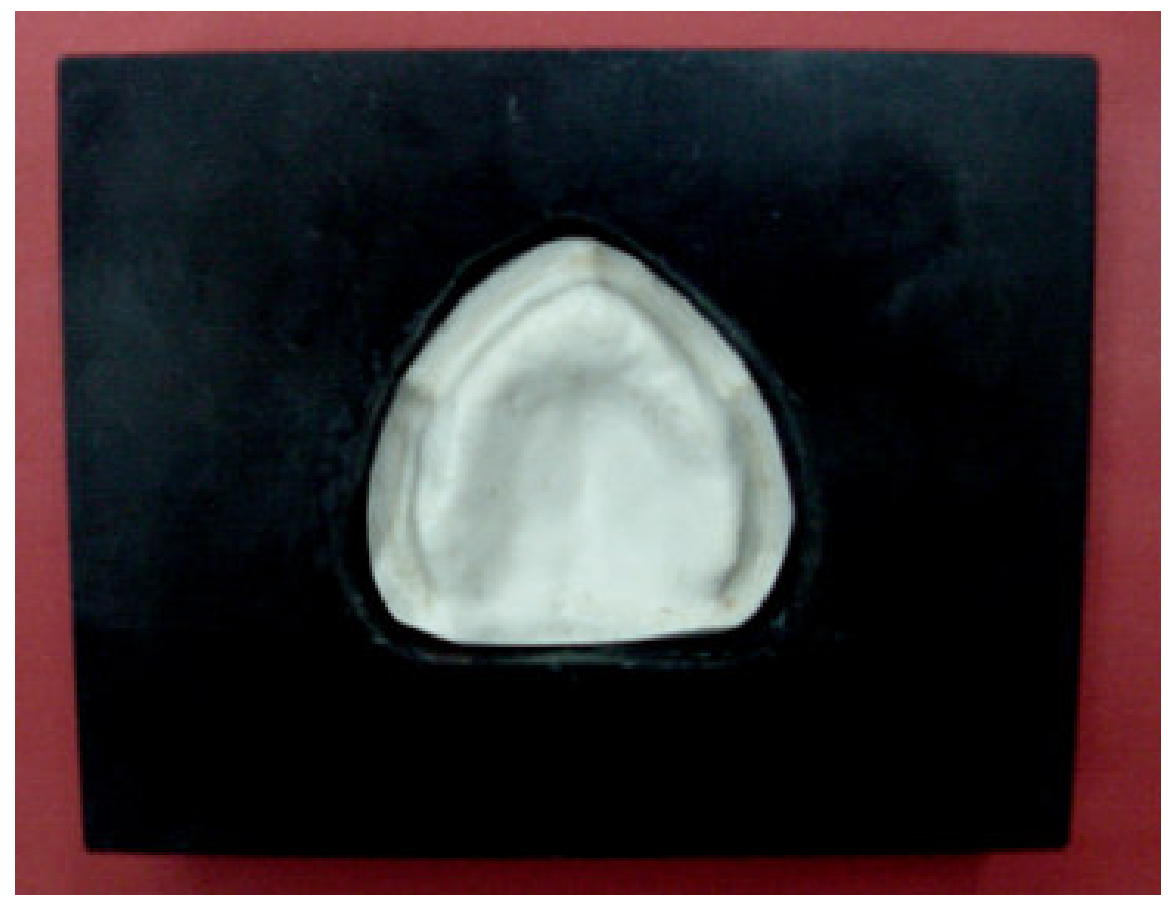

Figura 4.37 - Base metálica contendo a réplica do modelo mestre superior

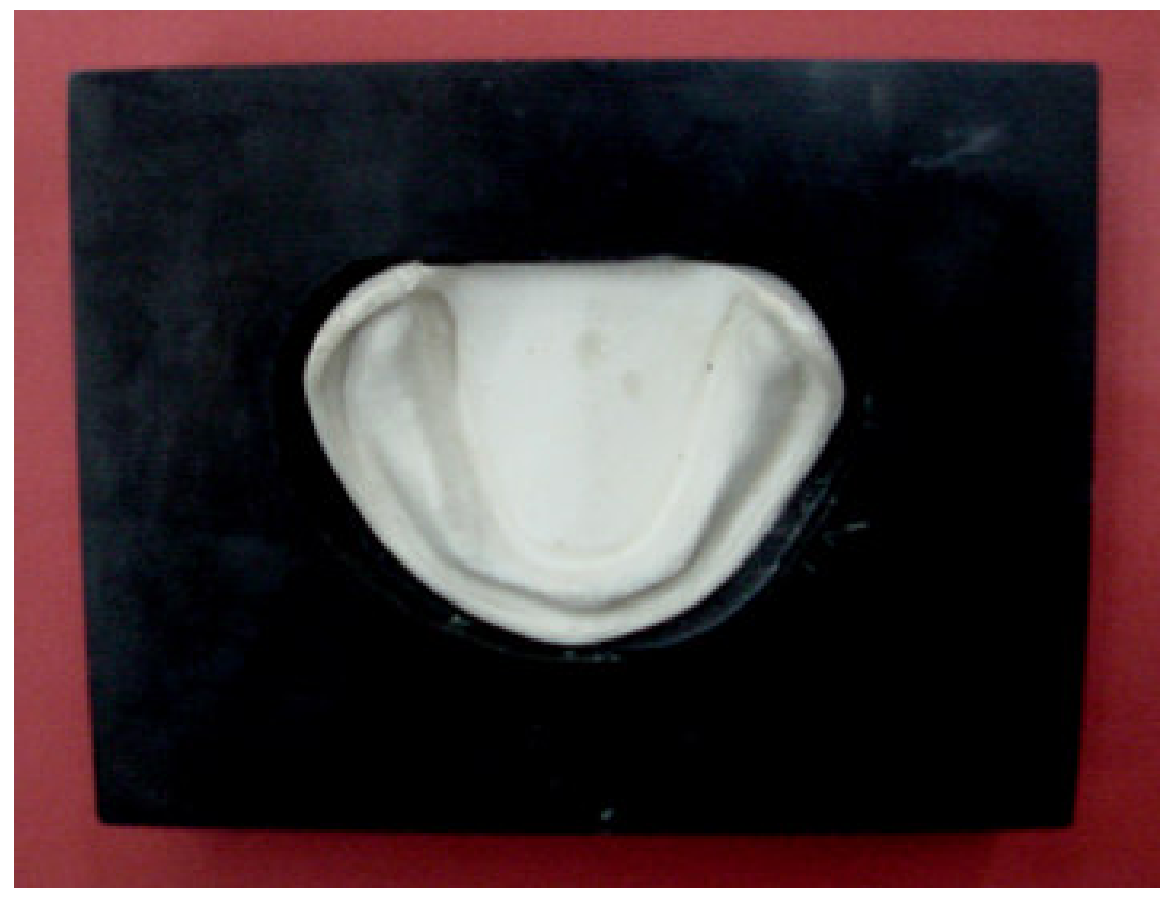

Figura 4.38 - Base metálica contendo a réplica do modelo mestre inferior 
A fim de padronizar a captação das imagens, duas aletas de metal foram dispostas formando um ângulo reto entre si (Figura 4.39), e conseqüentemente, guiavam o reposicionamento das bases metálicas sob a lente macroscópica digital (Figura 4.40). A captura da imagem da superfície oclusal das próteses foi realizada pelo programa Leica Qwin ${ }^{\circledR}$ 550, sendo que, para cada prótese bimaxilar, foram obtidos três registros de cada movimento excursivo, os quais foram denominadas de LATDIR1, LATDIR2, e LATDIR3; LATESQ1,LATESQ2 e LATESQ3; PROT1, PROT2 e PROT3.

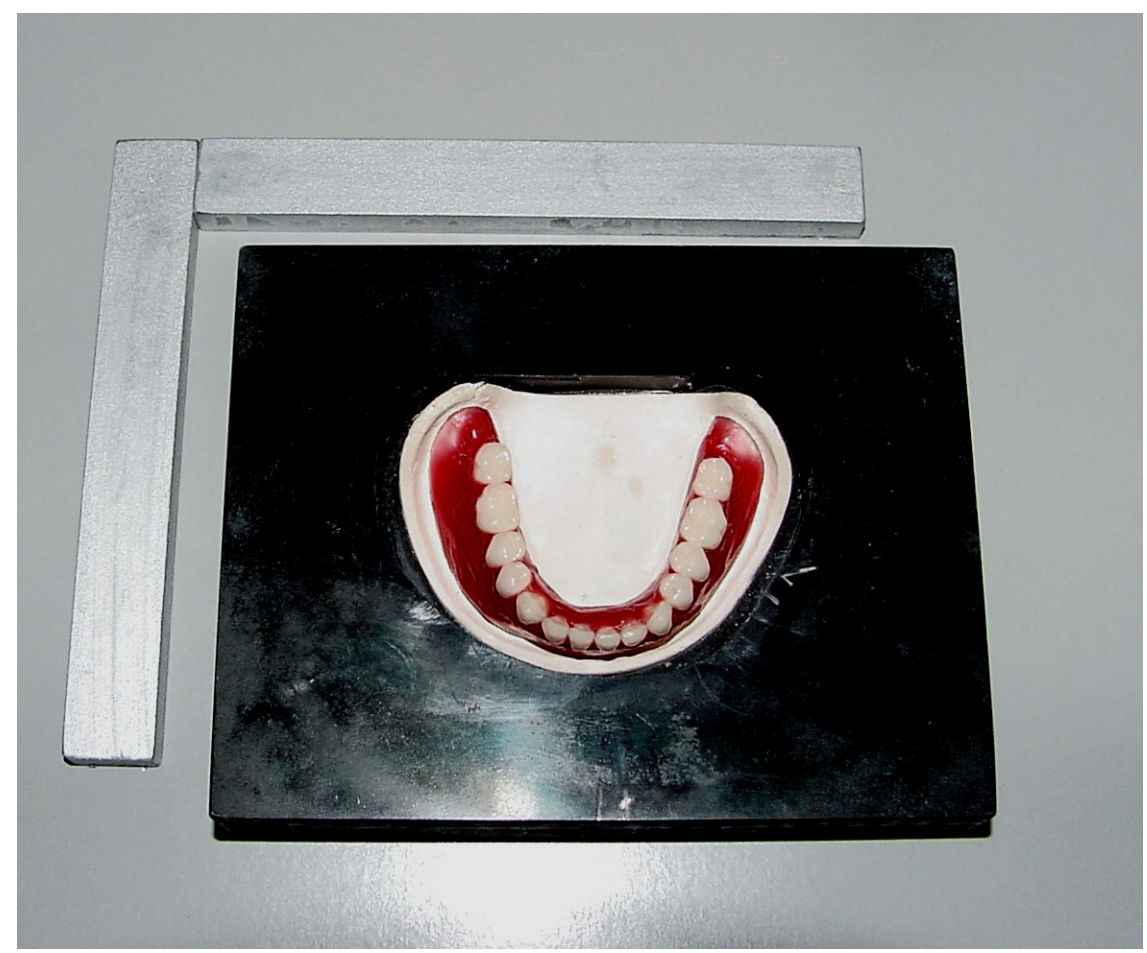

Figura 4.39 - Aletas de metal, para o reposicionamento das bases metálicas sob a lente macroscópica 


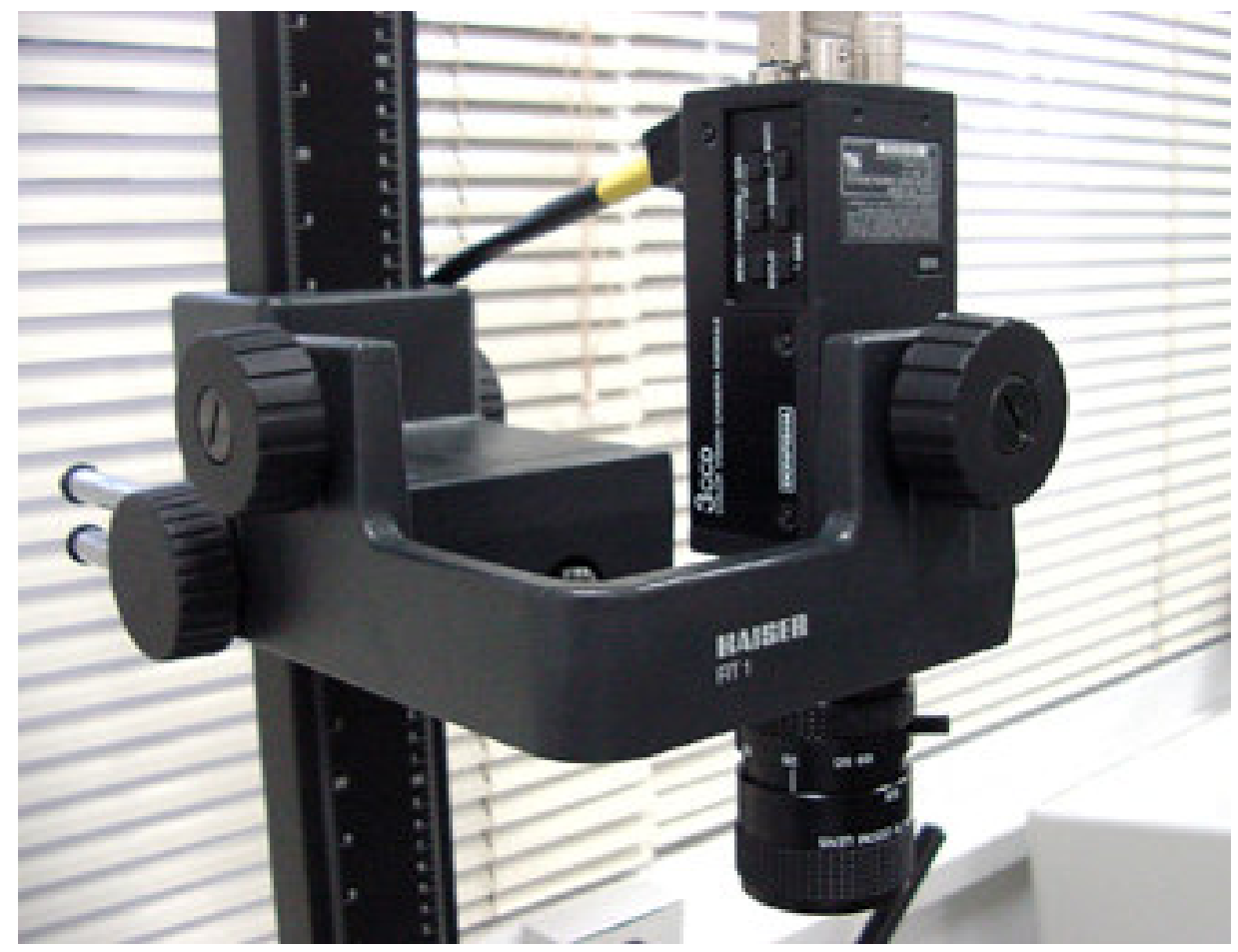

Figura 4.40 - Lente macroscópica digital 
4.2.11 Tratamento e mensuração das marcas oclusais das imagens digitais

As imagens obtidas das próteses foram então tratadas pelo programa Leica Qwin ${ }^{\circledR} 550$ e a partir de sua tela inicial (Figura 4.41), selecionou-se a rotina de tratamento das imagens digitalizadas (Figura 4.42) preconizada por Mazini (2003).

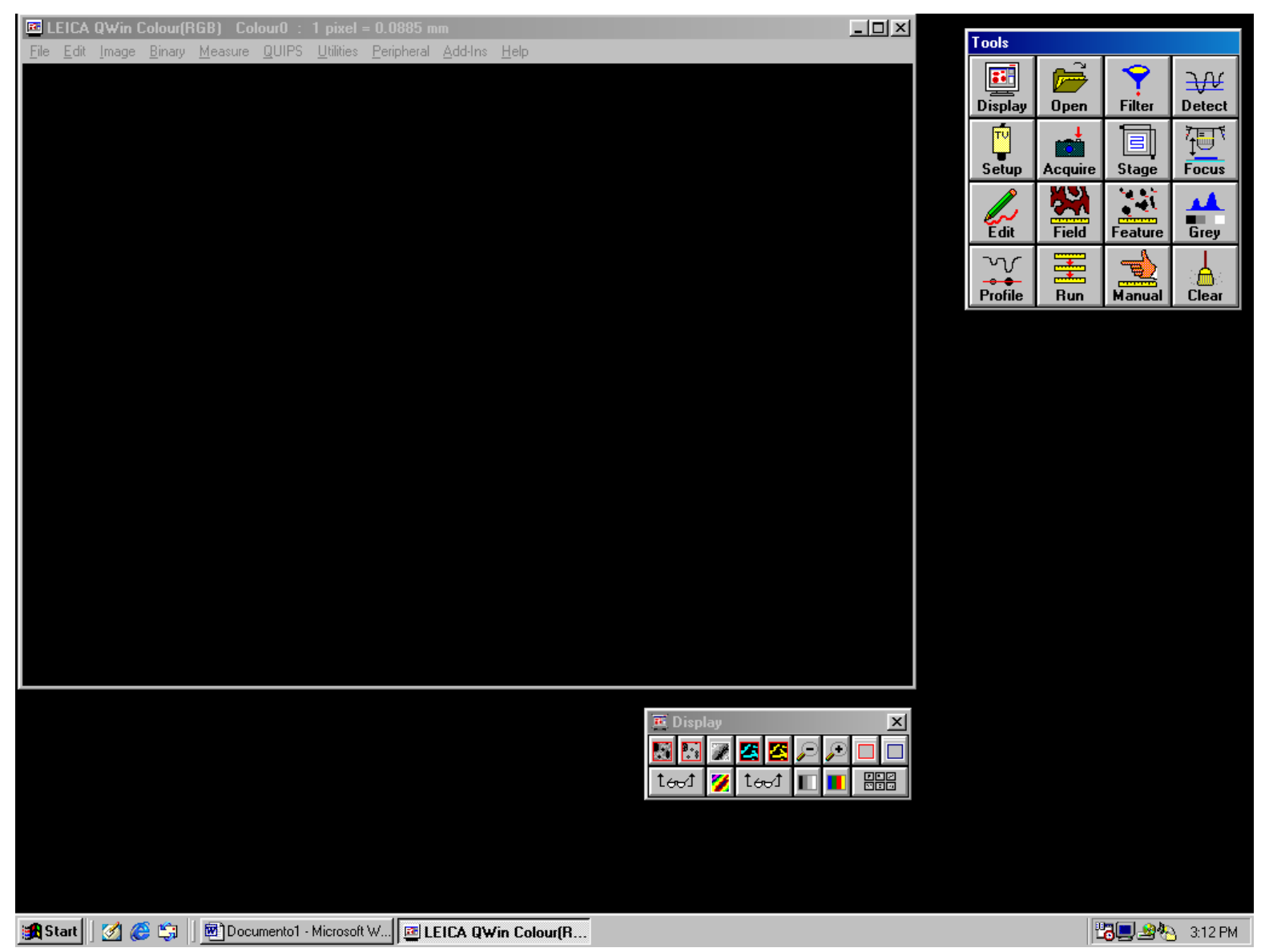

Figura 4.41 - Tela inicial do programa Leica Qwin ${ }^{\circledR} 550$ 


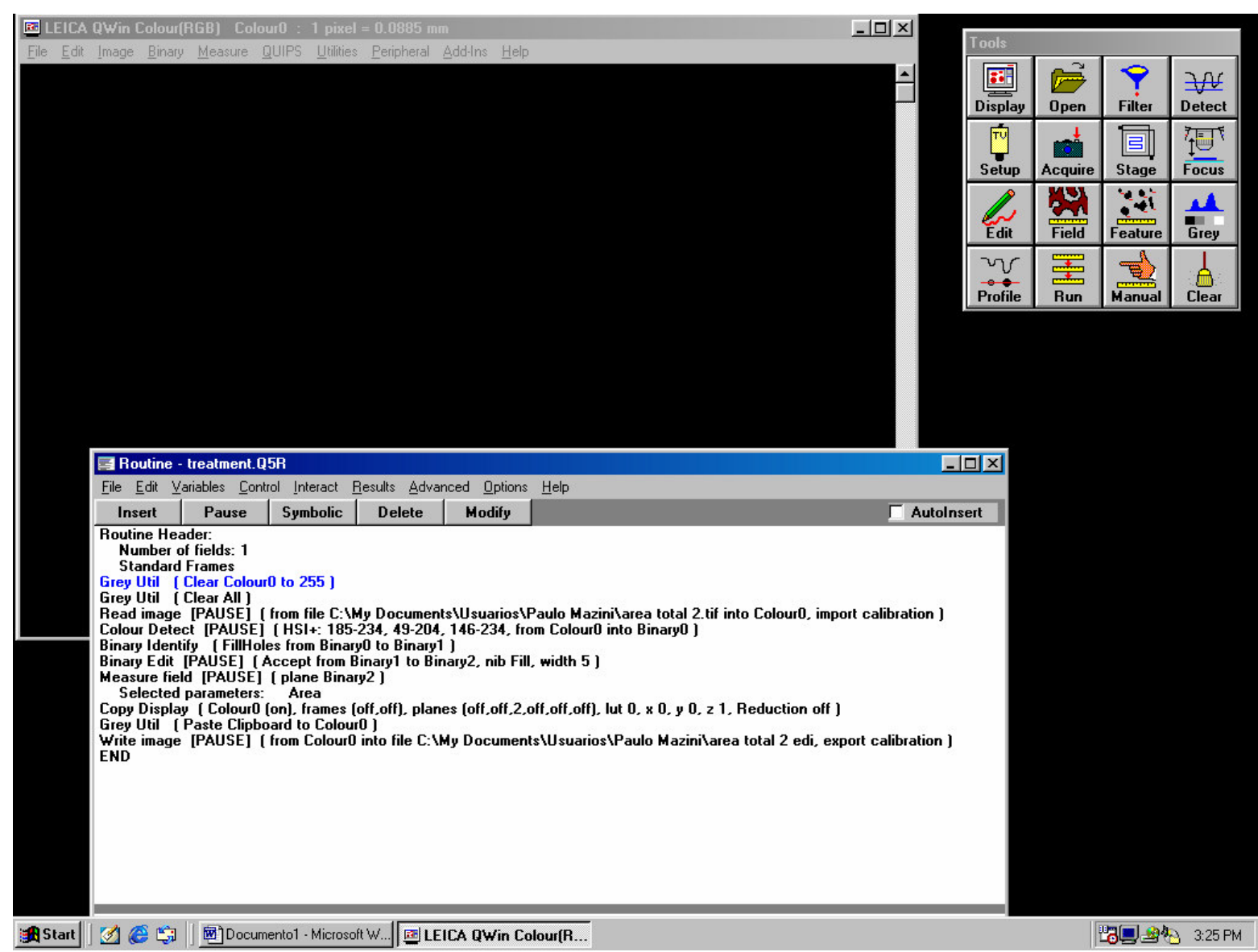

Figura 4.42 - Rotina para o tratamento das imagens digitalizadas

A rotina de tratamento das imagens digitalizadas consiste em uma série de intervenções disponibilizadas pelo programa, no intuito de ajustar as marcas do papel para articulação, selecionar a região de interesse e finalmente mensurar a área delimitada. 
Estabelecida a rotina, o programa abre uma janela para que se selecione a imagem a ser tratada (Figura 4.43).

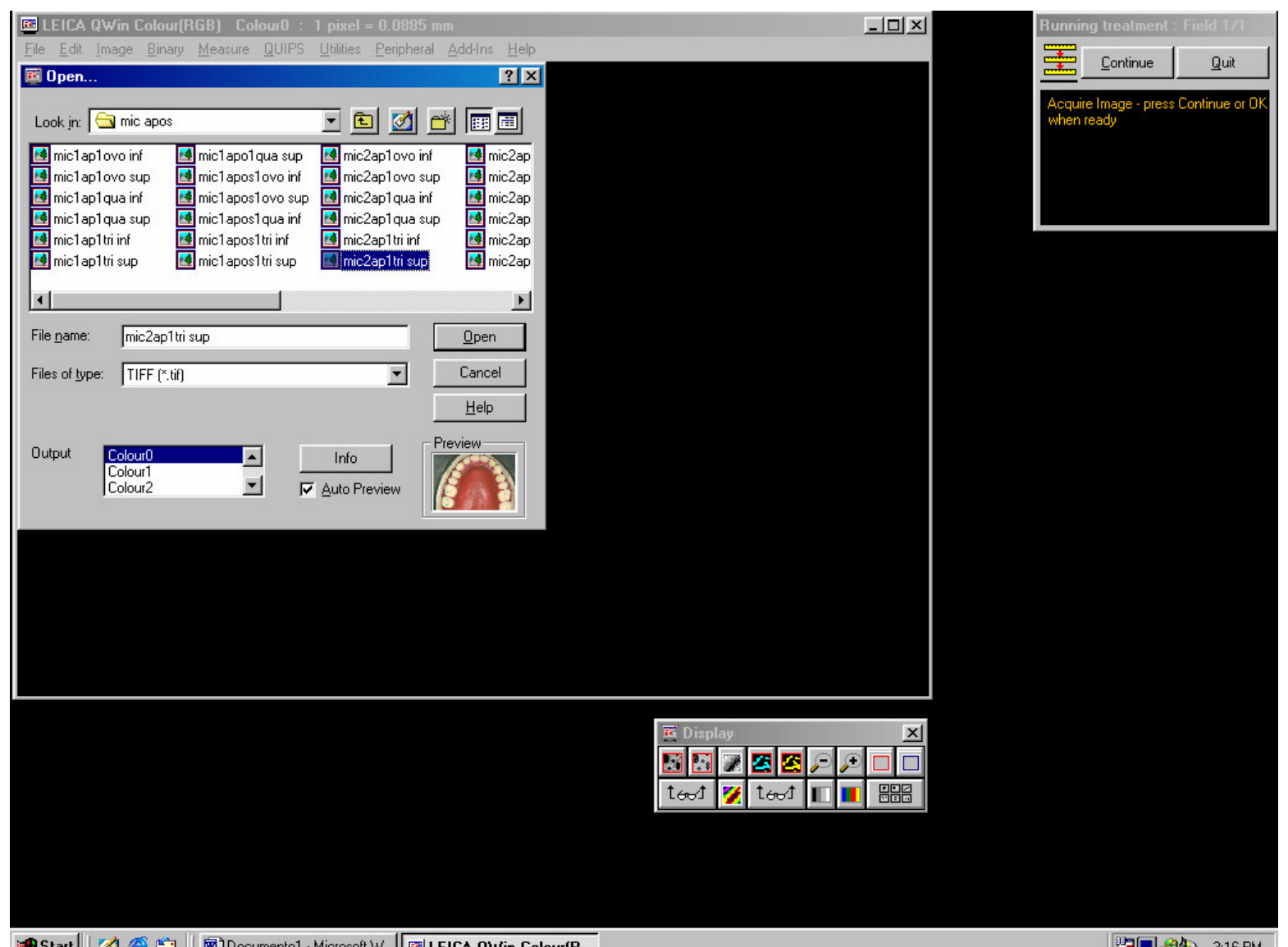

Start||

Figura 4.43 - Seleção e abertura da imagem a ser tratada 
Estabelecido na rotina, o programa efetua o reconhecimento inicial das marcas de carbono. Entretanto, esta identificação não engloba completamente as marcações em verde, correspondentes aos contatos oclusais (Figura 4.44).

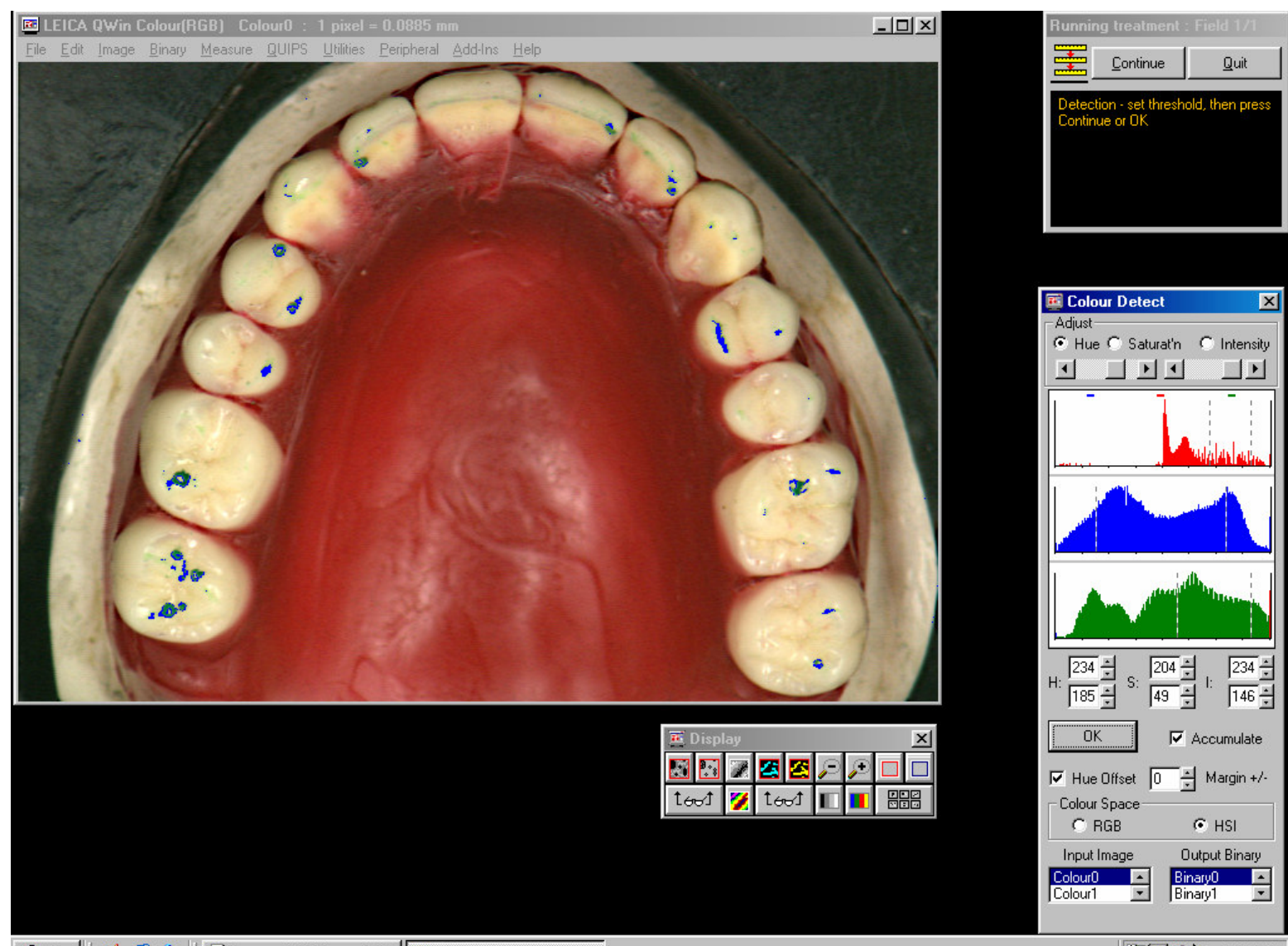

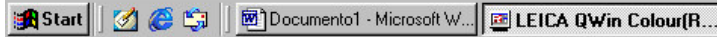

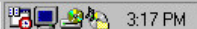

Figura 4.44 - Identificação inicial das marcas do carbono

Para reconhecer e englobar toda a área demarcada pelo papel para articulação, a rotina permitiu um aumento na imagem (Figura 4.45) e, com auxílio do mouse complementou-se a identificação das áreas em verde, correspondentes às marcas do carbono (Figura 4.46). 


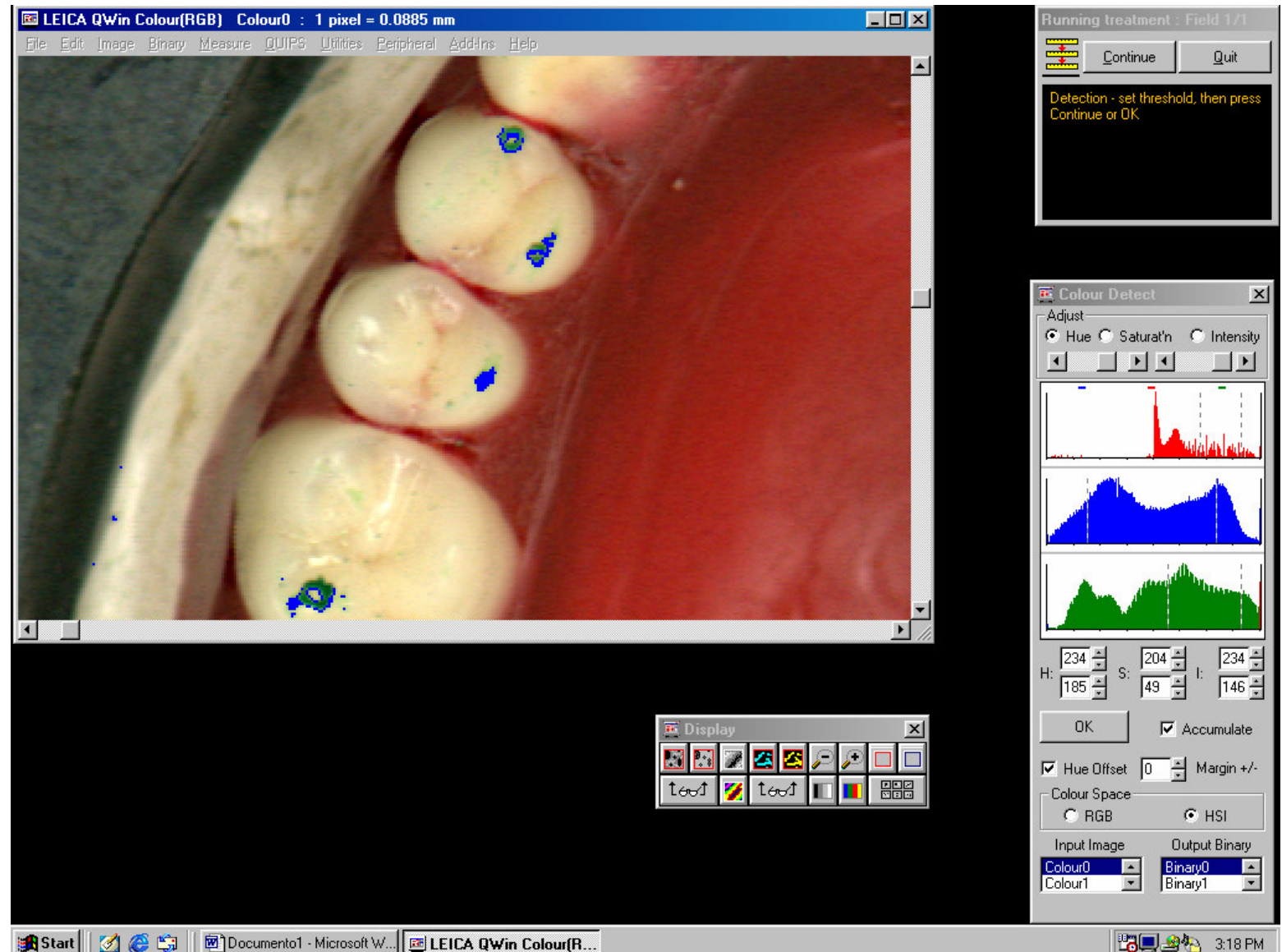

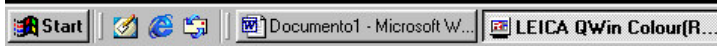

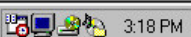

Figura 4.45 - Zoom aplicado sobre a imagem 
Ainda com a imagem ampliada e deslocando-a nos sentidos horizontal e vertical, com auxílio dos cursores, completou-se por toda a arcada a identificação dos contatos oclusais.

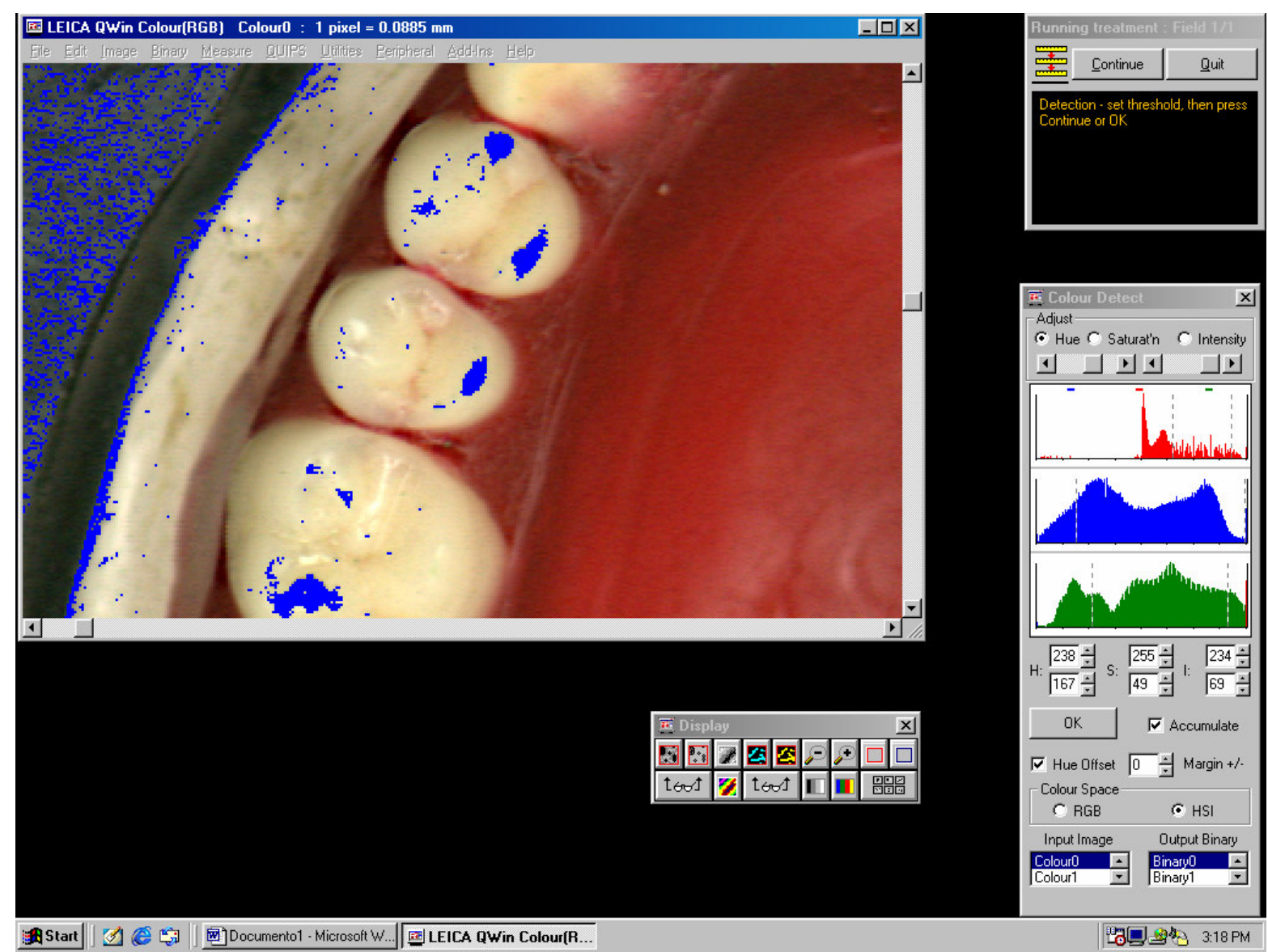

Figura 4.46 - Reconhecimento completo das marcas do carbono 
Foi então acionado o comando para reduzir a ampliação alcançada para a identificação, e a imagem retornou às suas dimensões iniciais (Figura 4.47).

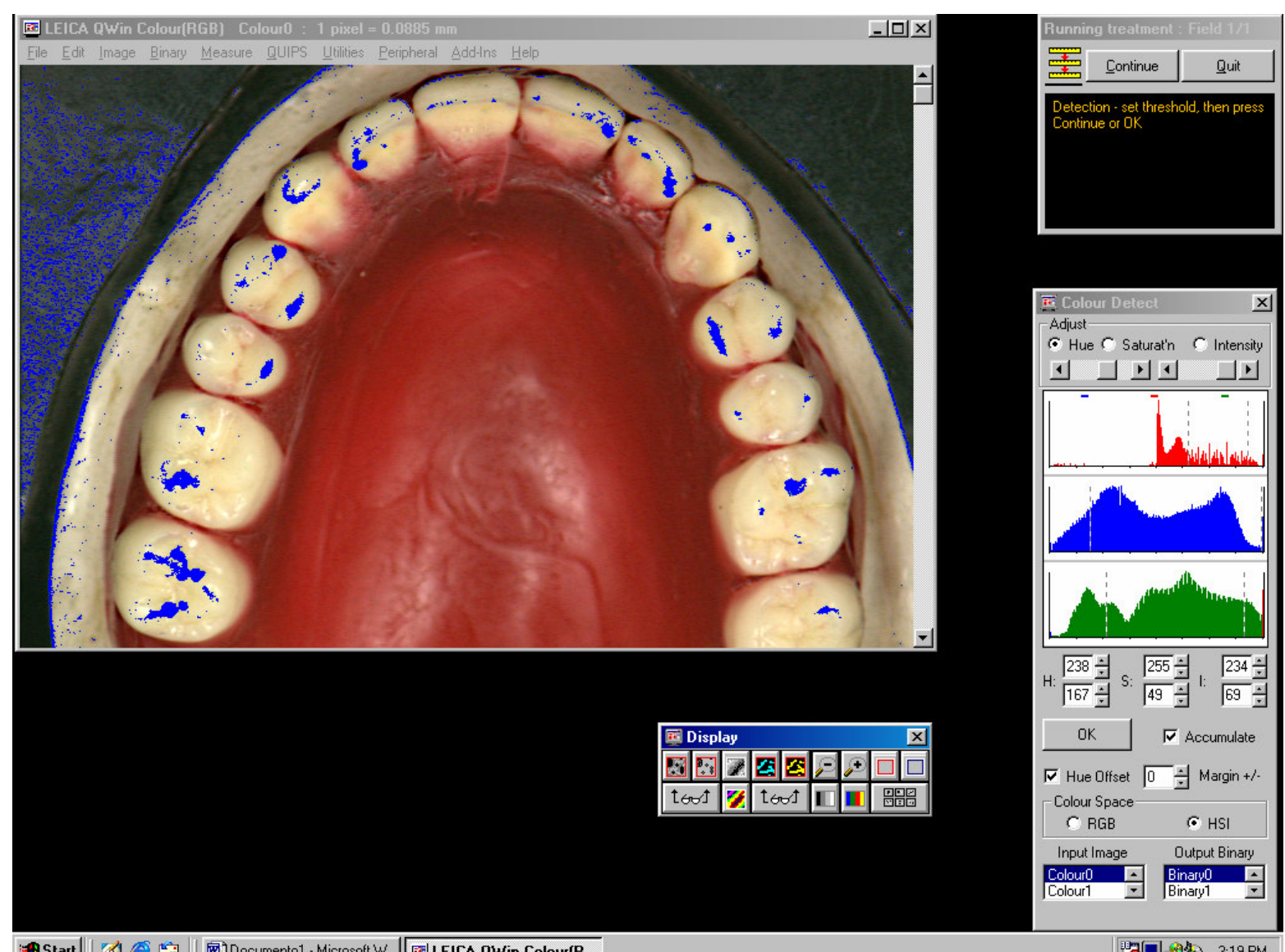

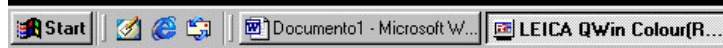

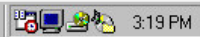

Figura 4.47 - Identificação completa dos contatos oclusais 


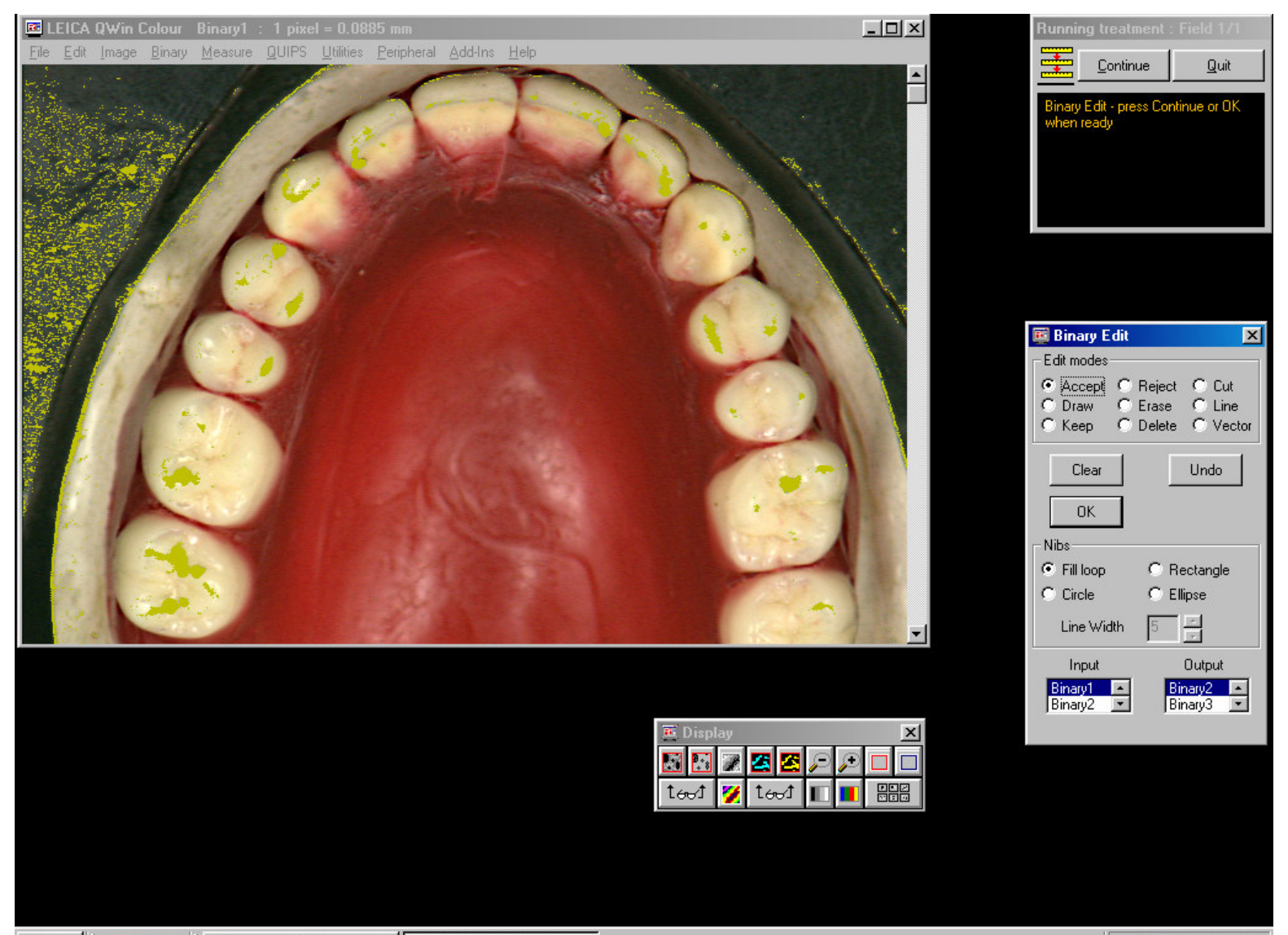

Figura 4.48 - Delimitação da região de interesse

Em seguida, o programa promoveu uma alteração na coloração dos contatos oclusais, visando a delimitação da região de interesse (Figura 4.48). Uma vez que, por semelhança na identificação, alguns dos contatos oclusais apresentavam tonalidades em verde, passíveis de interpretação errônea por estarem próximas às regiões sombreadas, ao longo da superfície oclusal. 


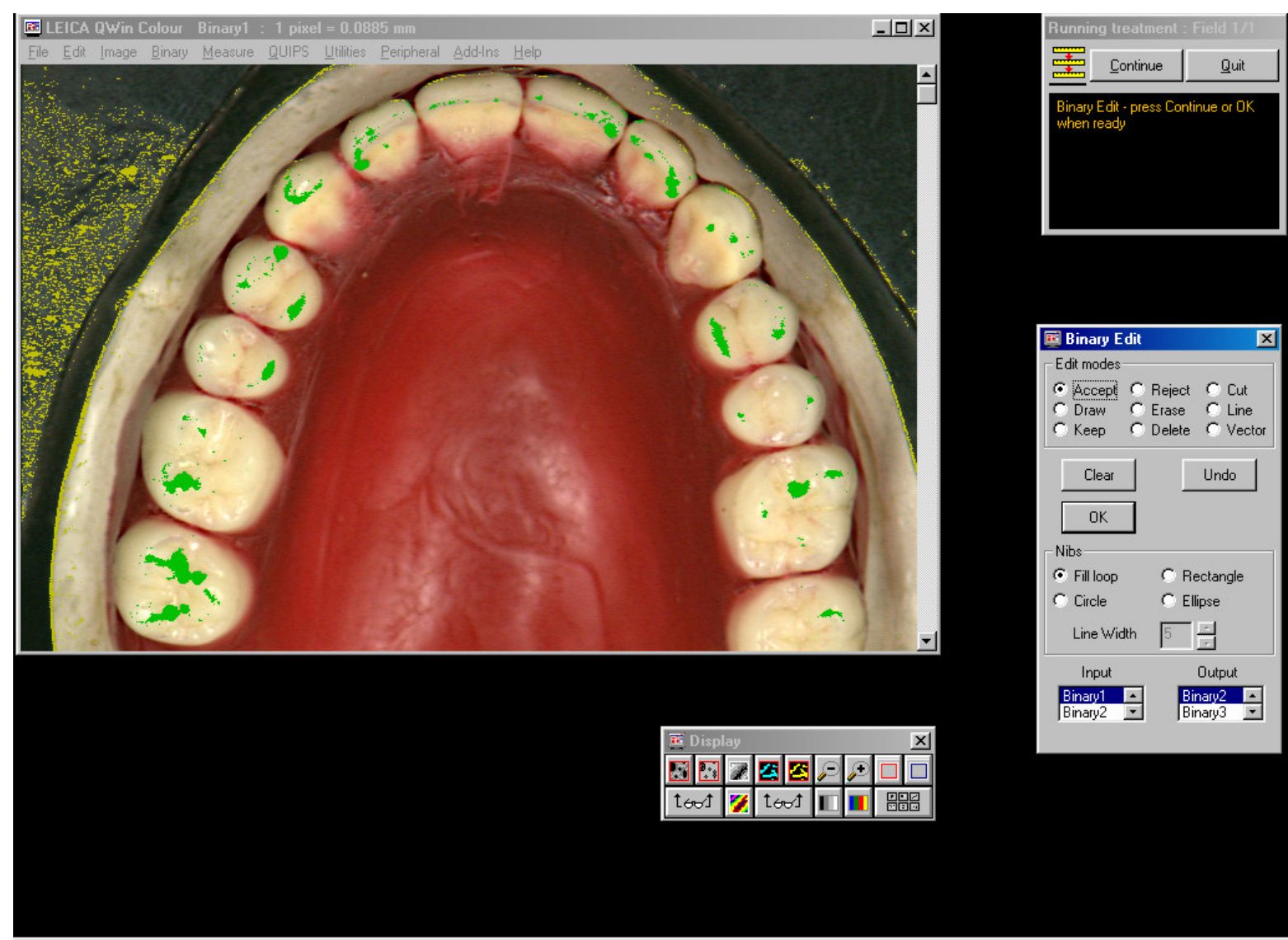

5Start| 近

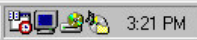

Figura 4.49 - Reconhecimento das superfícies oclusais

Realizada a delimitação da região de interesse, o programa alterou novamente a coloração dos contatos oclusais, para verificação e confirmação dos ajustes executados (Figuras 4.49 e 4.50). 


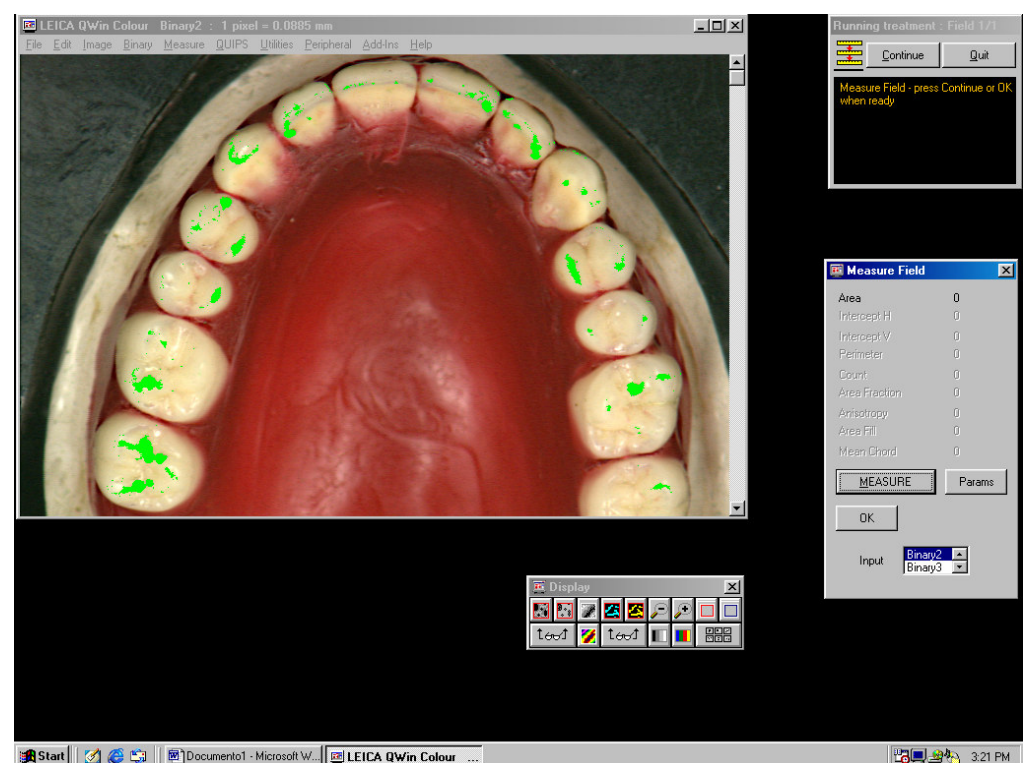

Figura 4.50 - Imagem tratada, antes da mensuração

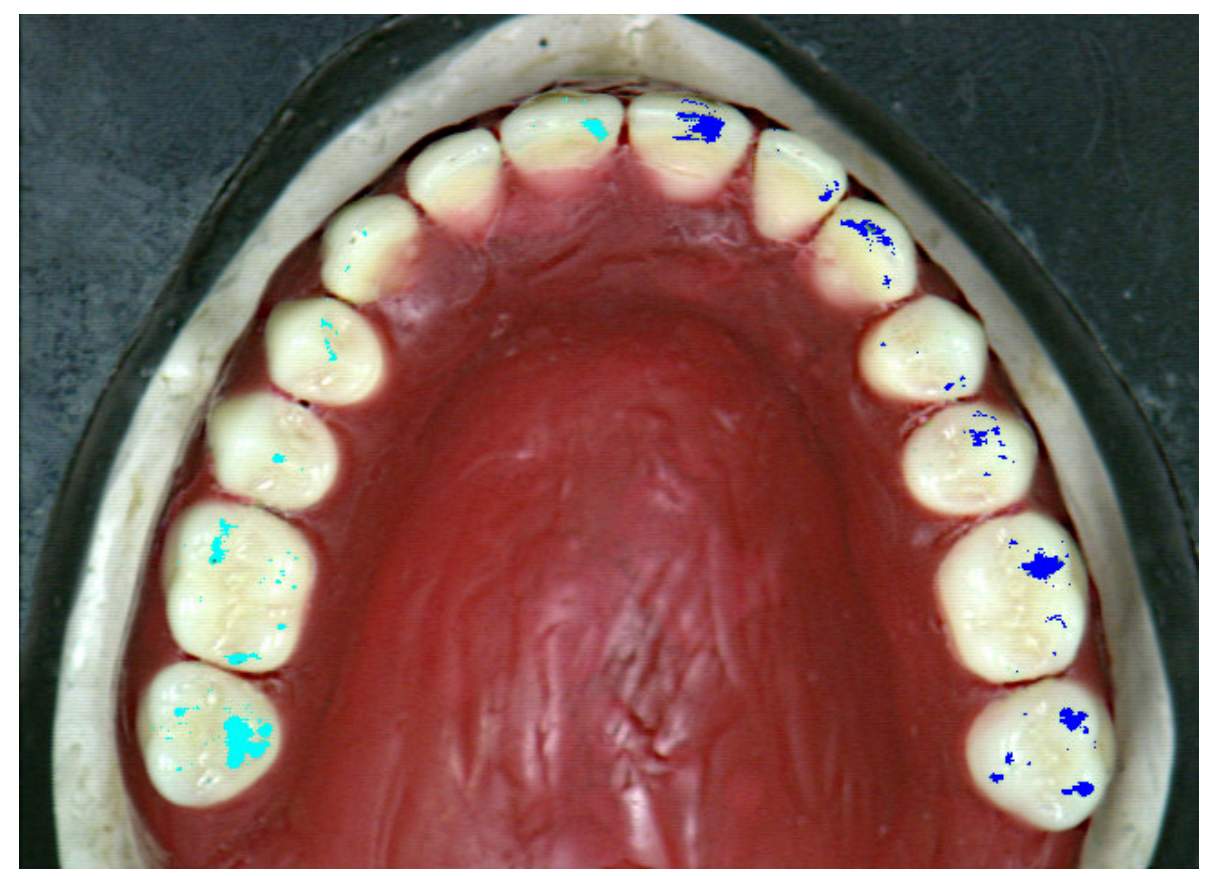

Figura 4.51 - Alteração na rotina, para mensuração de segmento de dentes

Nos registros das lateralidades direita e esquerda, foram estabelecidas duas áreas de mensuração, delimitadas pelos incisivos centrais e os segundos molares dos lados direito e esquerdo (Figura 4.51). Já para os registros de protrusão, a imagem foi dividida em três segmentos a saber: Posterior direito, delimitado pelos 
pré-molares e molares do lado direito; Anterior, delimitado pelos caninos e incisivos; e Posterior esquerdo, delimitado pelos pré-molares e molares do lado esquerdo.

Realizada a delimitação dos segmentos de interesse, o programa exibiu o comando measure, para executar a mensuração das áreas identificadas por cores distintas (Figura 4.51).

No intuito de se observar o padrão de deslocamento da posição de máxima inter-cuspidação para as lateralidades direita e esquerda, e de máxima intercuspidação para a protrusão, submeteu-se ao mesmo tratamento setorial as imagens captadas por Mazini (2003).

Os resultados foram arquivados em uma pasta, aberta também pelo programa, assim como a imagem final, após o tratamento.

A área calculada das imagens projetadas tem uma definição de centésimos de milímetro. Dessa forma, foram obtidas medidas não menores que 0,01 milímetro, as quais foram distribuídas em tabelas e submetidas à análise estatística. 


\section{RESULTADOS}

5.1 Descrição das variáveis para o movimento de protrusão, modelos inferior e superior

5.1.1 Variáveis independentes:

- Forma Oclusal: Anatômica (A), Funcional (F);

- Origem: Nacional (N), Importado (I);

- Forma da Arcada: Quadrangular (Q), Triangular (T), Oval (O);

- Movimento: ProTotal, PostDir, Ant, PostEsq, MicTotal, MicPostDir, MicAnt, MicPostEsq;

- Tratamentos (combinações das categorias das variáveis Forma Oclusal, Origem e Forma da Arcada): ANQ, ANT,ANO, AIQ, AIT, AIO, FNQ, FNT, FNO, FIQ, FIT, FIO

5.1.2 Variável dependente

- Área $\left(\mathrm{em} \mathrm{mm}^{2}\right)$

5.2 Análise estatística para os modelos inferior e superior em protrusão

As Tabelas 5.1 e 5.2. apresentam a média e o desvio padrão da variável Área para cada categoria da variável Tratamentos combinada com cada categoria da variável Movimento, considerando a protrusão inferior e superior, respectivamente. A análise das Tabelas 5.1 e 5.2 mostram que o comportamento da média da variável Área parece se alterar de acordo com o tratamento considerado. 
Tabela 5.1 - Média e desvio padrão (DP) para a variável Área em protrusão inferior

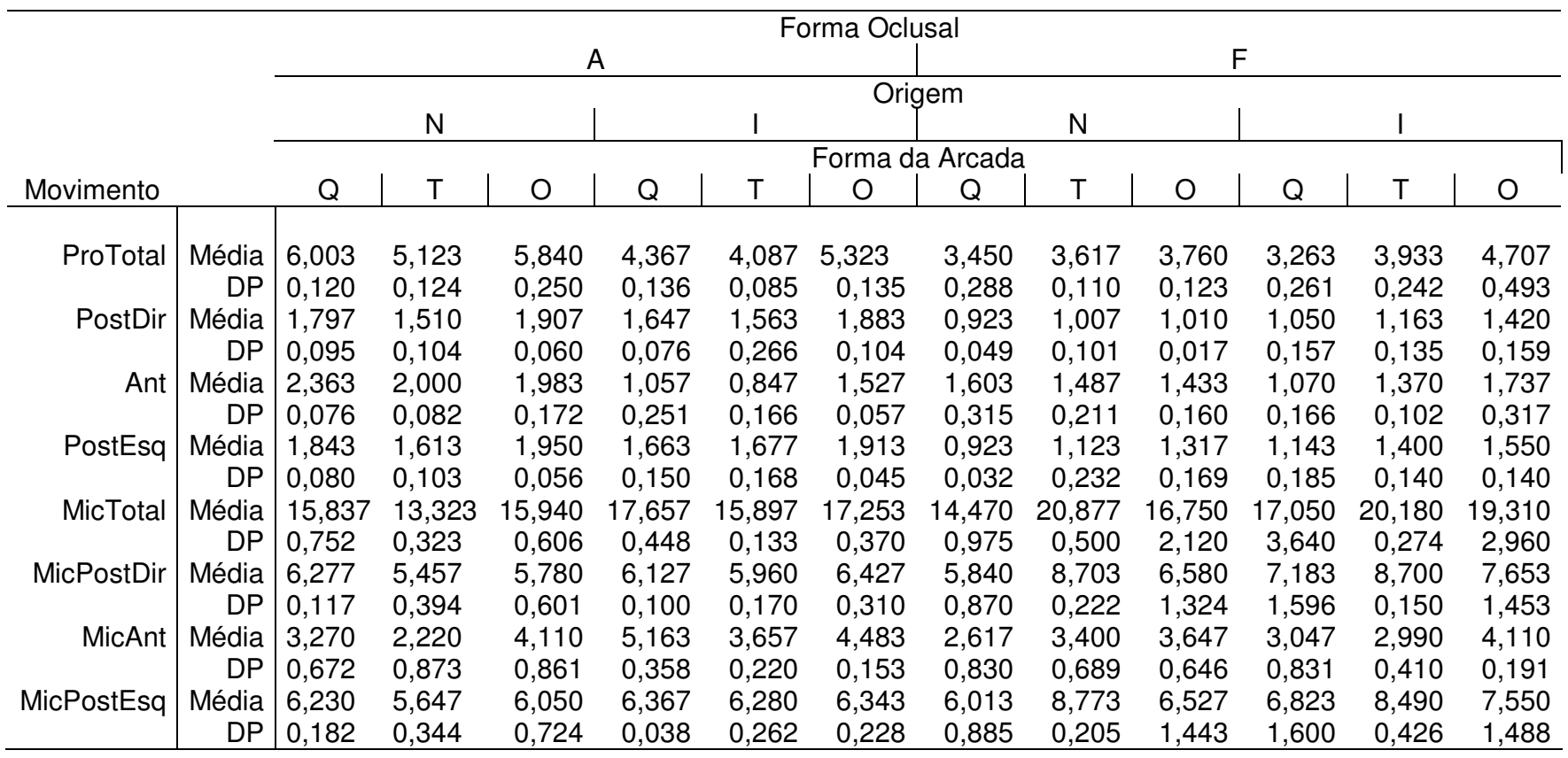

Tabela 5.2 - Média e desvio padrão (DP) para a variável Área em protrusão superior

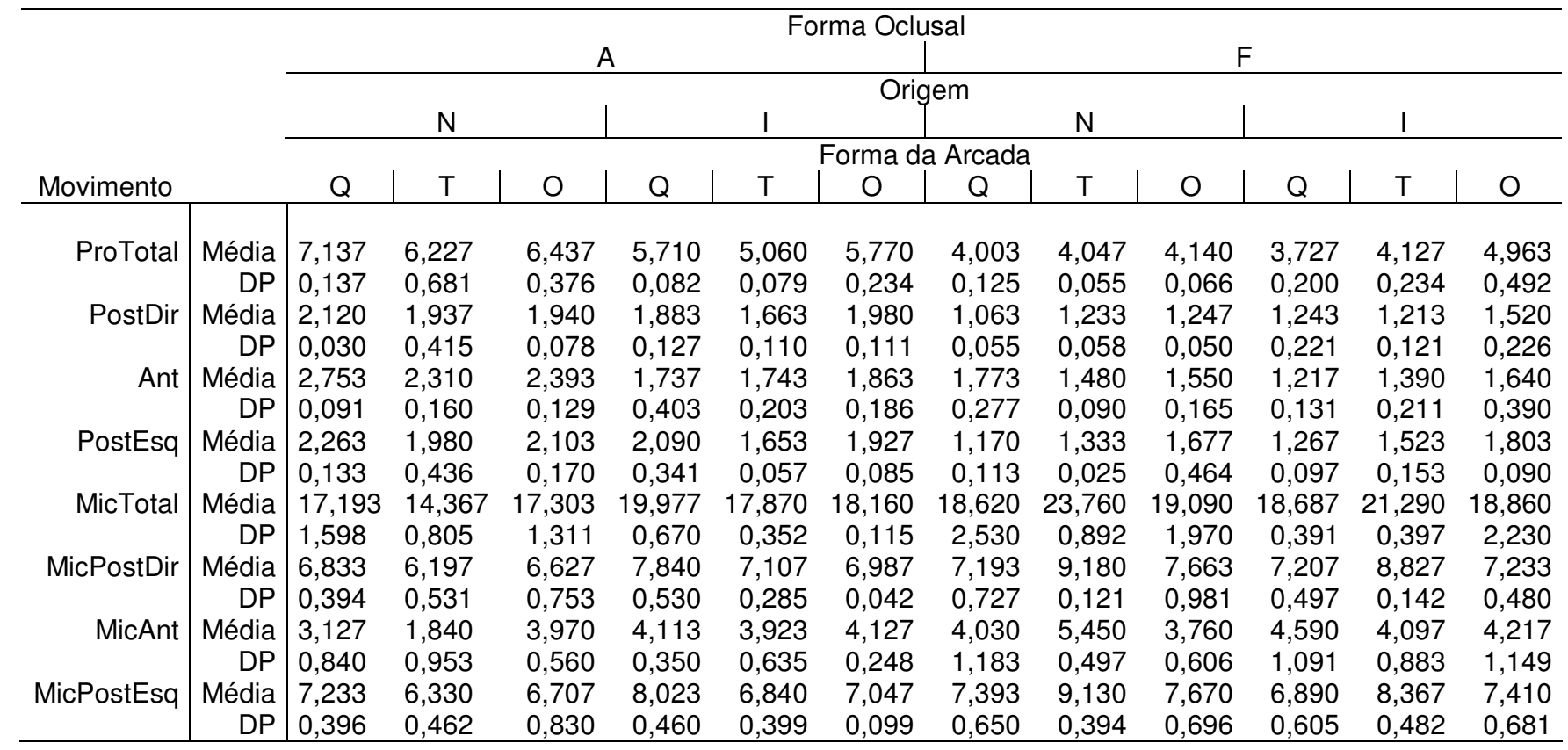

Nosso objetivo foi comparar a média da variável Área total sob os 12 tratamentos formados pelas combinações das categorias das variáveis Forma Oclusal, Origem, Forma da Arcada e Movimento. Como cada prótese foi avaliada sob as seis categorias da variável Movimento, utilizamos para a análise dos dados 
um modelo de análise de variância com medidas repetidas (Neter et al., 1996). Fixado um nível de significância global de 15\% (nível de significância de 1\% para cada teste) mostram-se na Tabela 5.3, para a protrusão do modelo inferior e na Tabela 5.4, para a protrusão do modelo superior, que existem interações entre as variáveis Forma Oclusal e Forma da Arcada ( $P=0 \%)$, Forma Oclusal e Movimento $(P=0 \%)$, Origem e Movimento $(P=0 \%)$, Forma da Arcada e Movimento $(0 \%)$, Forma Oclusal, Origem e Movimento ( $0,4 \%$ e $0,8 \%$ respectivamente) e entre Forma Oclusal, Forma da Arcada e Movimento $(\mathrm{P}=0 \%)$, sobre a média da variável Área total.

Tabela 5.3 - Análise de Variância (ANOVA) para a variável Área em protrusão inferior

\begin{tabular}{lcccc}
\hline Fonte de Variação & Grau de Liberdade & Estatística F & Nível Descritivo P & Significância \\
\hline Forma Oclusal (FO) & 1 & 2,50 & 0,127 & \\
Origem (O) & 1 & 7,19 & 0,013 & \\
Forma da Arcada (FA) & 2 & 4,12 & 0,029 & \\
FOxO & 1 & 0,98 & 0,333 & n.s. \\
FOxFA & 2 & 21,09 & 0,000 & $* \star *$ \\
OxFA & 2 & 0,82 & 0,452 & n.s. \\
FOxOxFA & 2 & 2,12 & 0,141 & n.s. \\
Modelo & 24 & - & - & - \\
Movimento (M) & 7 & 2142,56 & 0,000 & \\
FOxM & 7 & 29,63 & 0,000 & $* * *$ \\
OxM & 7 & 9,60 & 0,000 & $* \star *$ \\
FAxM & 14 & 3,75 & 0,000 & $* * *$ \\
FOxOxM & 7 & 2,83 & 0,008 & $* * *$ \\
FOxFAxM & 14 & 8,47 & 0,000 & $* * *$ \\
OxFAxM & 14 & 0,91 & 0,547 & n.s. \\
FOxOxFAxM & 14 & 1,40 & 0,159 & n.s. \\
Erro & 168 & - & - & - \\
\hline Total & 287 & - & - & - \\
\hline$* * *-P<1 \%$ & & & &
\end{tabular}


Tabela 5.4 - Análise de Variância (ANOVA) para a variável Área em protrusão superior

\begin{tabular}{lcccc}
\hline Fonte de Variação & Grau de liberdade & Estatística F & Nível Descritivo P & Significância \\
\hline Forma Oclusal (FO) & 1 & 2,78 & 0,108 & \\
Origem (O) & 1 & 0,45 & 0,511 & \\
Forma da Arcada (FA) & 2 & 0,48 & 0,623 & \\
FOxO & 1 & 5,60 & 0,026 & n.s. \\
FOxFA & 2 & 25,86 & 0,000 & $* * *$ \\
OxFA & 2 & 0,17 & 0,848 & n.s. \\
FOxOxFA & 2 & 2,89 & 0,075 & n.s. \\
Modelo & 24 & - & - & - \\
Movimento (M) & 7 & 3334,84 & 0,000 & \\
FOxM & 7 & 48,76 & 0,000 & $* * *$ \\
OxM & 7 & 4,45 & 0,000 & $* * *$ \\
FAxM & 14 & 2,45 & 0,004 & $* * *$ \\
FOxOxM & 7 & 13,13 & 0,000 & $* * *$ \\
FOxFAxM & 14 & 11,22 & 0,000 & $* * *$ \\
OxFAxM & 14 & 0,98 & 0,472 & n.s. \\
FOxOxFAxM & 14 & 2,21 & 0,009 & n.s. \\
Erro & 168 & - & - & - \\
\hline Total & 287 & - & - & - \\
\hline$* * *$ P $<1 \%$ & & & &
\end{tabular}

Devido à ocorrência desses efeitos de interação, comparou-se, tanto para a protrusão inferior quanto para a superior, a média da variável Área, sob os 12 Tratamentos, utilizando um modelo de análise de variância com três fatores cruzados fixos e aplicando o método de comparações múltiplas de Tukey em conjunto com o método de agrupamento de médias apresentado por Calinski e Corsten (1985) (nível de significância igual a 1\% para cada teste e coeficiente de confiança global igual a $99 \%$ para o agrupamento de médias), fixando cada uma das categorias da variável Movimento. Nas Tabelas 5.5 a 5.18 apresentam-se os resultados obtidos.

5.2.1. Análise dos tratamentos para ProTotal - Inferior

Na Tabela 5.5 mostram-se os resultados da análise de variância realizada com o objetivo de verificar a influência das variáveis explicativas Forma Oclusal, 
Origem e Forma da Arcada sobre a média da variável Área, fixada a categoria ProTotal da variável Movimento. Na Tabela 5.6, mostram-se os resultados das comparações das médias da variável Área sob os 12 Tratamentos. Da análise da Tabela 5.6 podemos concluir que os tratamentos FNQ e FIQ apresentam os menores valores médios da variável Área e os tratamentos ANQ e ANO os maiores valores.

Tabela 5.5 - Análise de Variância (ANOVA) para a variável Área (ProTotal - Inferior)

\begin{tabular}{lcccc}
\hline Fonte de Variação & Grau de Liberdade & Estatística & Nível Descritivo P & Significância \\
\hline Forma Oclusal (FO) & 1 & 312,47 & 0,000 & \\
Origem (O) & 1 & 21,73 & 0,000 & \\
Forma da Arcada (FA) & 2 & 36,08 & 0,000 & \\
FOxO & 1 & 88,59 & 0,000 & $* * *$ \\
FOxFA & 2 & 14,56 & 0,000 & $* * *$ \\
OxFA & 2 & 18,53 & 0,000 & $* \star$ \\
FOxOxFA & 2 & 0,05 & 0,949 & n.s. \\
Erro & 24 & - & - & - \\
\hline Total & 35 & - & - & -
\end{tabular}

Tabela 5.6 - Agrupamento de médias (ProTotal - Inferior)

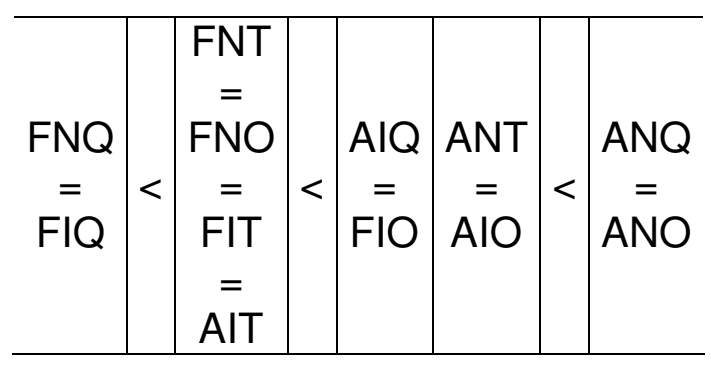


5.2.2. Análise dos tratamentos para PostDir - Inferior e PostEsq - Inferior

Nas Tabelas 5.7 e 5.8 mostram-se os resultados das análises de variância realizadas com o objetivo de verificar a influência das variáveis explicativas Forma Oclusal, Origem e Forma da Arcada sobre a média da variável Área, fixadas as categorias PostDir e PostEsq da variável Movimento. Da análise das Tabelas 5.7 e 5.8 pode-se concluir que existe diferença entre as médias da variável Área para as três formas da arcada $(P=0,000)$, sendo que as médias sob as formas quadrada e triangular são iguais e menores do que sob a forma oval (esses resultados valem para as duas formas oclusais e as duas origens). $\mathrm{Na}$ Tabela 5.9 , exibem-se os resultados das comparações das médias da variável Área sob as combinações das categorias das variáveis explicativas Forma Oclusal e Origem. Da análise da Tabela 5.9, nota-se que sob a combinação FN obteve-se a menor média da variável Área enquanto que sob as combinações $\mathrm{AN}$ e $\mathrm{Al}$ foram encontradas as maiores médias (para as três formas da arcada).

Tabela 5.7 - Análise de Variância (ANOVA) para a variável Área (PostDir - Inferior)

\begin{tabular}{|c|c|c|c|c|}
\hline Fonte de Variação & Grau de Liberdade & Estatística F & Nível Descritivo $\mathrm{P}$ & Significância \\
\hline Forma Oclusal (FO) & 1 & 217,93 & 0,000 & \\
\hline Origem (O) & 1 & 5,14 & 0,033 & \\
\hline Forma da Arcada (FA) & 2 & 12,74 & 0,000 & *** \\
\hline $\mathrm{FOxO}$ & 1 & 10,34 & 0,004 & *** \\
\hline FOxFA & 2 & 4,24 & 0,027 & n.s. \\
\hline OxFA & 2 & 1,98 & 0,159 & n.s. \\
\hline FOxOxFA & 2 & 1,28 & 0,297 & n.s. \\
\hline Erro & 24 & - & - & - \\
\hline Total & 35 & - & - & - \\
\hline
\end{tabular}


Tabela 5.8 - Análise de Variância (ANOVA) para a variável Área (PostEsq - Inferior)

\begin{tabular}{lcccc}
\hline Fonte de Variação & Grau de Liberdade & Estatística F & Nível Descritivo P & Significância \\
\hline Forma Oclusal (FO) & 1 & 134,02 & 0,000 & \\
Origem (O) & 1 & 4,34 & 0,048 & \\
Forma da Arcada (FA) & 2 & 14,60 & 0,000 & $* * *$ \\
FOxO & 1 & 10,19 & 0,004 & $* * *$ \\
FOxFA & 2 & 4,59 & 0,021 & n.s. \\
OxFA & 2 & 0,88 & 0,427 & n.s. \\
FOxOxFA & 2 & 0,36 & 0,702 & n.s. \\
Erro & 24 & - & - & - \\
\hline Total & 35 & - & - & - \\
\hline$* * *-P<1 \%$ & & & &
\end{tabular}

Tabela 5.9 - Agrupamento de médias (PostDir e PostEsq - Inferior)

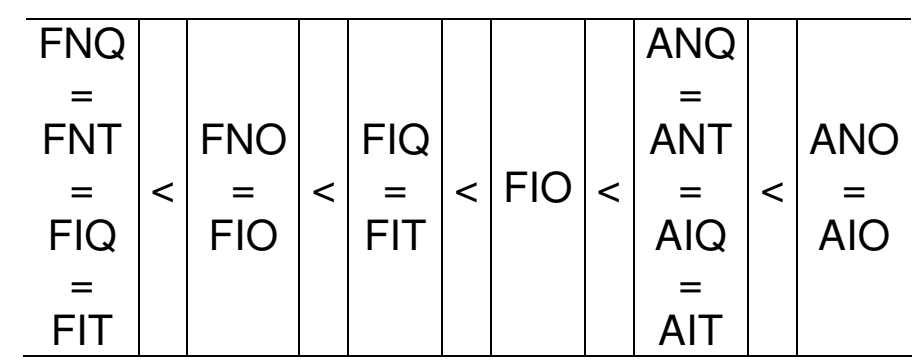

5.2.3. Análise dos tratamentos para Ant - Inferior

$\mathrm{Na}$ Tabela 5.10 mostram-se os resultados da análise de variância realizada com o objetivo de verificar a influência das variáveis explicativas Forma Oclusal, Origem e Forma da Arcada sobre a média da variável Área, fixada a categoria Ant da variável Movimento. Na Tabela 5.11, evidenciam-se os resultados das comparações das médias da variável Área sob os 12 Tratamentos. Da análise da Tabela 5.11 pode-se concluir que os tratamentos AIT, AIQ e FIQ levam aos menores valores médios da variável Área. Os tratamentos ANQ, ANT e ANO levam aos maiores valores médios da variável Área (as médias sob esses três tratamentos são iguais). 
Tabela 5.10 - Análise de Variância (ANOVA) para a variável Área (Ant - Inferior)

\begin{tabular}{lcccc}
\hline Fonte de Variação & Grau de Liberdade & Estatística F & Nível Descritivo P & Significância \\
\hline Forma Oclusal (FO) & 1 & 7,84 & 0,010 & \\
Origem (O) & 1 & 72,07 & 0,000 & \\
Forma da Arcada (FA) & 2 & 4,91 & 0,016 & \\
FOxO & 1 & 44,70 & 0,000 & $* * *$ \\
FOxFA & 2 & 2,91 & 0,074 & n.s. \\
OxFA & 2 & 14,94 & 0,000 & $* \star *$ \\
FOxOxFA & 2 & 0,49 & 0,616 & n.s. \\
Erro & 24 & - & - & - \\
\hline Total & 35 & - & - & - \\
\hline$* * *-P<1 \%$ & & & &
\end{tabular}

Tabela 5.11 - Agrupamento de médias (Ant - Inferior)

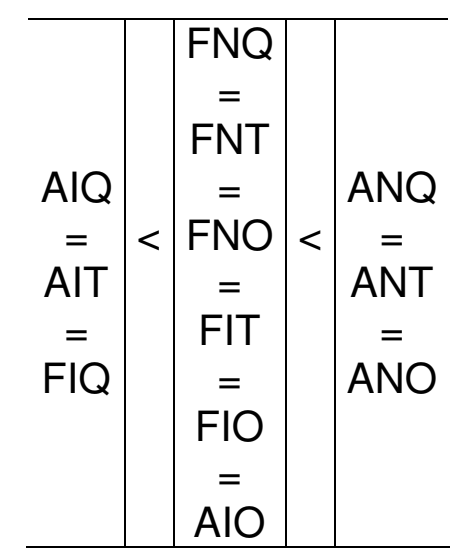

5.2.4. Análise dos tratamentos para ProTotal - Superior

Na Tabela 5.12 mostram-se os resultados da análise de variância realizada com o objetivo de verificar a influência das variáveis explicativas Forma Oclusal, Origem e Forma da Arcada sobre a média da variável Área, fixada a categoria ProTotal da variável Movimento. Na Tabela 5.13, mostram-se os resultados das comparações das médias da variável Área sob os 12 Tratamentos. Da análise da Tabela 5.13 pode-se concluir que os tratamentos FNQ, FNT, FNO, FIQ e FIT 
apresentam os menores valores médios, porém iguais, da variável Área. Já, o tratamento ANQ leva à maior média da variável Área.

Tabela 5.12 - Análise de Variância (ANOVA) para a variável Área (ProTotal - Superior)

\begin{tabular}{lcccc}
\hline Fonte de Variação & Grau de Liberdade & Estatística F & Nível Descritivo P & Significância \\
\hline Forma Oclusal (FO) & 1 & 366,26 & 0,000 & \\
Origem (O) & 1 & 19,77 & 0,000 & \\
Forma da Arcada (FA) & 2 & 7,42 & 0,003 & \\
FOxO & 1 & 43,08 & 0,000 & $* * *$ \\
FOxFA & 2 & 11,50 & 0,000 & $* * *$ \\
OxFA & 2 & 7,68 & 0,003 & $* * *$ \\
FOxOxFA & 2 & 0,26 & 0,771 & n.s. \\
Erro & 24 & - & - & - \\
\hline Total & 35 & - & - & - \\
\hline \multirow{*}{***}{$-\mathrm{P}<1 \%$} & & & &
\end{tabular}

Tabela 5.13 - Agrupamento de médias (ProTotal - Superior)

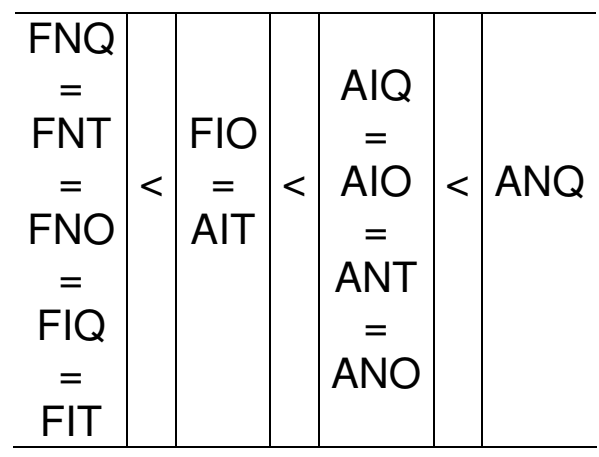

5.2.8. Análise dos tratamentos para PostDir - Superior

Na Tabela 5.14 mostram-se os resultados da análise de variância realizada com o objetivo de verificar a influência das variáveis explicativas Forma Oclusal, Origem e Forma da Arcada sobre a média da variável Área, fixada a categoria PostDir da variável Movimento. Da análise da Tabela 5.14 pode-se concluir que apenas a variável explicativa Forma Oclusal é significante $(P=0,000)$, sendo que a média da variável Área sob F é menor do que sob A (esse resultado vale para as duas categorias da variável Origem e para as três formas da arcada). 
Tabela 5.14 - Análise de Variância (ANOVA) para a variável Área (PostDir - Superior)

\begin{tabular}{lcccc}
\hline Fonte de Variação & Grau de Liberdade & Estatística F & Nível Descritivo P & Significância \\
\hline Forma Oclusal (FO) & 1 & 140,15 & 0,000 & $\star \star *$ \\
Origem (O) & 1 & 0,01 & 0,915 & n.s. \\
Forma da Arcada (FA) & 2 & 2,71 & 0,087 & n.s. \\
FOxO & 1 & 7,14 & 0,013 & n.s. \\
FOxFA & 2 & 2,58 & 0,097 & n.s. \\
OxFA & 2 & 2,45 & 0,107 & n.s. \\
FOxOxFA & 2 & 0,27 & 0,769 & n.s. \\
Erro & 24 & - & - & - \\
\hline Total & 35 & - & - & - \\
\hline$* * *-P<1 \%$ & & & &
\end{tabular}

5.2.5. Análise dos tratamentos para Ant - Superior

Na Tabela 5.15 mostram-se os resultados da análise de variância realizada com o objetivo de verificar a influência das variáveis explicativas Forma Oclusal, Origem e Forma da Arcada sobre a média da variável Área, fixada a categoria Ant da variável Movimento. Da análise da Tabela 5.15, verificou-se que não há efeito da variável explicativa Forma da Arcada $(P=0,259)$. Na Tabela 5.16, apresentam-se os resultados das comparações das médias da variável Área sob as combinações das categorias das variáveis explicativas Forma Oclusal e Origem. Da análise da Tabela 5.16 pode-se concluir que as combinações $\mathrm{FI}, \mathrm{FN}$ e $\mathrm{Al}$ levam aos menores valores médios da variável Área, enquanto que a combinação NA leva ao maior valor médio da variável Área (esses resultados valem para as três formas da arcada). 
Tabela 5.15 - Análise de Variância (ANOVA) para a variável Área (Ant - Superior)

\begin{tabular}{lcccc}
\hline Fonte de Variação & Grau de Liberdade & Estatística F & Nível Descritivo P & Significância \\
\hline Forma Oclusal (FO) & 1 & 68,75 & 0,000 & \\
Origem (O) & 1 & 34,85 & 0,000 & \\
Forma da Arcada (FA) & 2 & 1,43 & 0,259 & n.s. \\
FOxO & 1 & 11,85 & 0,002 & $* \star *$ \\
FOxFA & 2 & 0,74 & 0,489 & n.s. \\
OxFA & 2 & 5,31 & 0,012 & n.s. \\
FOxOxFA & 2 & 0,11 & 0,893 & n.s. \\
Erro & 24 & - & - & - \\
\hline Total & 35 & - & - & - \\
\hline$* * *-P<1 \%$ & & & &
\end{tabular}

Tabela 5.16 - Agrupamento de médias (Ant - Superior)

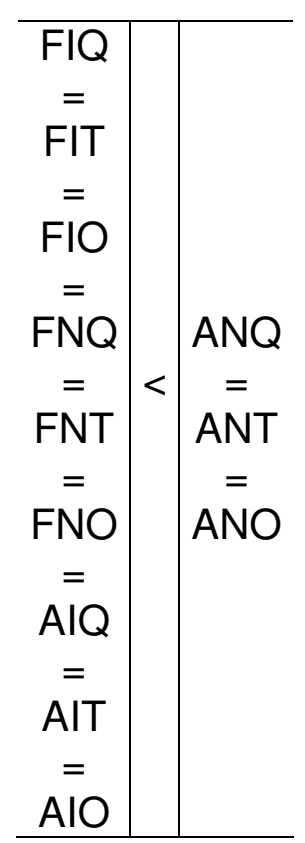

5.2.6. Análise dos tratamentos para PostEsq - Superior

Na Tabela 5.17 mostra-se o resultado da análise de variância realizada com o objetivo de verificar a influência das variáveis explicativas Forma Oclusal, Origem e Forma da Arcada sobre a média da variável Área, fixada a categoria PostEsq da variável Movimento. Da análise desta tabela verificou-se que não há efeito da variável explicativa Origem sobre a média da variável Área $(P=0,572)$, para as três 
formas oclusais e três formas da arcada. Na Tabela 5.18, exibem-se os resultados das comparações das médias da variável Área sob as combinações das categorias das variáveis explicativas Forma Oclusal e Forma da Arcada. Da análise da Tabela 5.18 pode-se concluir que as médias da variável Área sob as combinações FQ e FT são iguais, mas menores do que sob as combinações $F O, A Q, A T$ e $A O$ (as médias são iguais sob essas quatro combinações). Os resultados da análise da Tabela 5.18 são válidos para as duas categorias da variável explicativa Origem.

Tabela 5.17 - Análise de Variância (ANOVA) para a variável Área (PostEsq - Superior)

\begin{tabular}{lcccc}
\hline Fonte de Variação & Grau de Liberdade & Estatística F & Nível Descritivo P & Significância \\
\hline Forma Oclusal (FO) & 1 & 49,88 & 0,000 & \\
Origem (O) & 1 & 0,33 & 0,572 & n.s. \\
Forma da Arcada (FA) & 2 & 3,91 & 0,034 & \\
FOxO & 1 & 5,63 & 0,026 & n.s. \\
FOxFA & 2 & 7,63 & 0,003 & n.s. \\
OxFA & 2 & 0,03 & 0,972 & n.s. \\
FOxOxFA & 2 & 0,25 & 0,777 & - \\
Erro & 24 & - & - & - \\
\hline Total & 35 & - & - &
\end{tabular}

Tabela 5.18 - Agrupamento de médias (PostEsq - Superior)

$$
\begin{array}{c|c|c} 
& & \text { FNO } \\
& \\
& & \\
\text { FIO } \\
= \\
= & & \\
\text { ANQ } \\
\text { FIQ } & & \\
= & & \\
\text { FNT } & & \text { AIQ } \\
= & \\
\text { FIT } & & \text { ANT } \\
= \\
\text { AIT } \\
= \\
\text { ANO } \\
= \\
\text { AIO }
\end{array}
$$


Para comparar as médias da variável Área sob as categorias da variável Movimento, fixou-se cada um dos 12 Tratamentos e foi utilizado um modelo de medidas repetidas com um fator e o método de comparações múltiplas de Tukey (nível de significância global igual a 1\%), tanto para a protrusão inferior quanto para a superior. Nas Tabelas 5.19 a 5.23 apresentam-se os resultados encontrados.

Tabela 5.19 - Comparações das médias da variável Área entre algumas categorias da variável Movimento para os tratamentos AIO, AIQ, ANO, FIT e FNT - Protrusão inferior

\begin{tabular}{c|c|c}
\hline ProTotal & $<$ & MicTotal \\
PostDir & $<$ & MicPostDir \\
Ant & $<$ & MicAnt \\
PostEsq & $<$ & MicPostEsq \\
PostDir & $=$ & PostEsq \\
PostDir & $=$ & Ant \\
Ant & $=$ & PostEsq \\
\hline
\end{tabular}

Tabela 5.20 - Comparações das médias da variável Área entre algumas categorias da variável Movimento para o tratamento ANQ, ANT, FIO, FIQ, FNO e FNQ - Protrusão inferior

\begin{tabular}{c|c|c}
\hline ProTotal & $<$ & MicTotal \\
PostDir & $<$ & MicPostDir \\
Ant & $=$ & MicAnt \\
PostEsq & $<$ & MicPostEsq \\
PostDir & $=$ & PostEsq \\
PostDir & $=$ & Ant \\
Ant & $=$ & PostEsq \\
\hline
\end{tabular}

Tabela 5.21 - Comparações das médias da variável Área entre algumas categorias da variável Movimento para o tratamento AIT - Protrusão inferior

\begin{tabular}{c|c|c}
\hline ProTotal & $<$ & MicTotal \\
PostDir & $<$ & MicPostDir \\
Ant & $<$ & MicAnt \\
PostEsq & $<$ & MicPostEsq \\
PostDir & $=$ & PostEsq \\
PostDir & $=$ & Ant \\
Ant & $<$ & PostEsq \\
\hline
\end{tabular}


Tabela 5.22 - Comparações das médias da variável Área entre algumas categorias da variável Movimento para os tratamentos ANQ, ANT, ANO, FIO, FNO e FNQ - Protrusão superior

\begin{tabular}{c|c|c}
\hline ProTotal & $<$ & MicTotal \\
PostDir & $<$ & MicPostDir \\
Ant & $=$ & MicAnt \\
PostEsq & $<$ & MicPostEsq \\
PostDir & $=$ & PostEsq \\
PostDir & $=$ & Ant \\
Ant & $=$ & PostEsq \\
\hline
\end{tabular}

Tabela 5.23 - Comparações das médias da variável Área entre algumas categorias da variável Movimento para os tratamentos AIT, AIQ, AIO, FIT, FIQ e FNT - Protrusão superior

\begin{tabular}{c|c|c}
\hline ProTotal & $<$ & MicTotal \\
PostDir & $<$ & MicPostDir \\
Ant & $<$ & MicAnt \\
PostEsq & $<$ & MicPostEsq \\
PostDir & $=$ & PostEsq \\
PostDir & $=$ & Ant \\
Ant & $=$ & PostEsq \\
\hline
\end{tabular}

5.3 Descrição das variáveis para o movimento de lateralidades direita e esquerda, modelos superior e inferior

\subsubsection{Variáveis independentes:}

- Forma Oclusal: Anatômica (A), Funcional (F);

- Origem: Nacional (N), Importado (I);

- Forma da Arcada: Quadrangular (Q), Triangular (T), Oval (O) ;

- Movimento (Lateralidade direita inferior): LDTotal, LDTrab., LDBal., MicTotal, MicD, MicE;

- Movimento (Lateralidade esquerda inferior): LETotal, LETrab., LEBal., MicTotal, MicD, MicE;

- Tratamentos (combinações das categorias das variáveis Forma Oclusal, Origem e Forma da Arcada): ANQ, ANT, ANO, AIQ, AIT, AIO, FNQ, FNT, FNO, FIQ, FIT, $\mathrm{FIO}$ 
5.3.2 Variável dependente:

- Área $\left(\mathrm{em} \mathrm{mm}^{2}\right)$

5.4 Análise estatística para o movimento de lateralidades direita e esquerda, para o modelo inferior

As Tabelas 5.24 e 5.25 apresentam a média e o desvio padrão da variável Área para cada categoria da variável Tratamentos combinada com cada categoria da variável Movimento, considerando a lateralidade direita e a lateralidade esquerda, respectivamente. A análise das Tabelas 5.24 e 5.25 mostram que o comportamento da média da variável Área parece se alterar de acordo com o tratamento considerado.

Tabela 5.24 - Média e desvio padrão (DP) para a variável Área (Lateralidade direita)

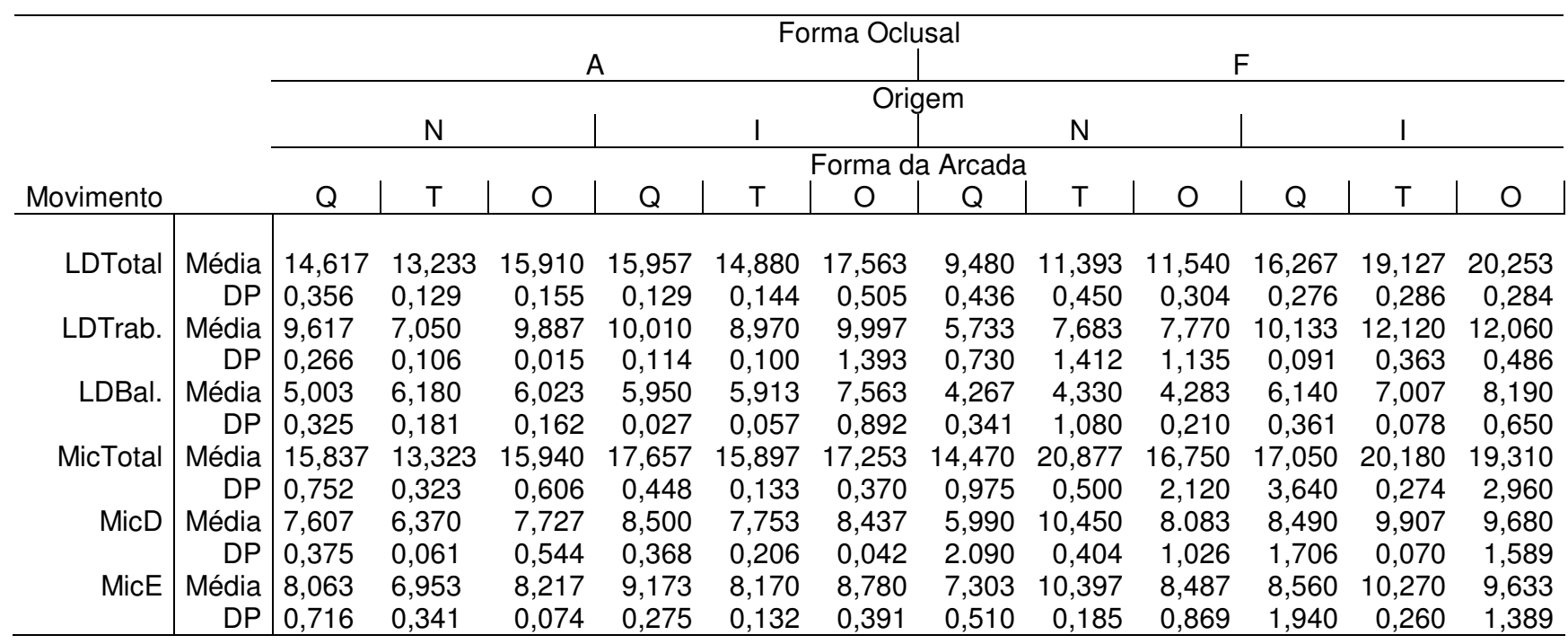


Tabela 5.25 - Média e desvio padrão (DP) para a variável Área (Lateralidade esquerda)

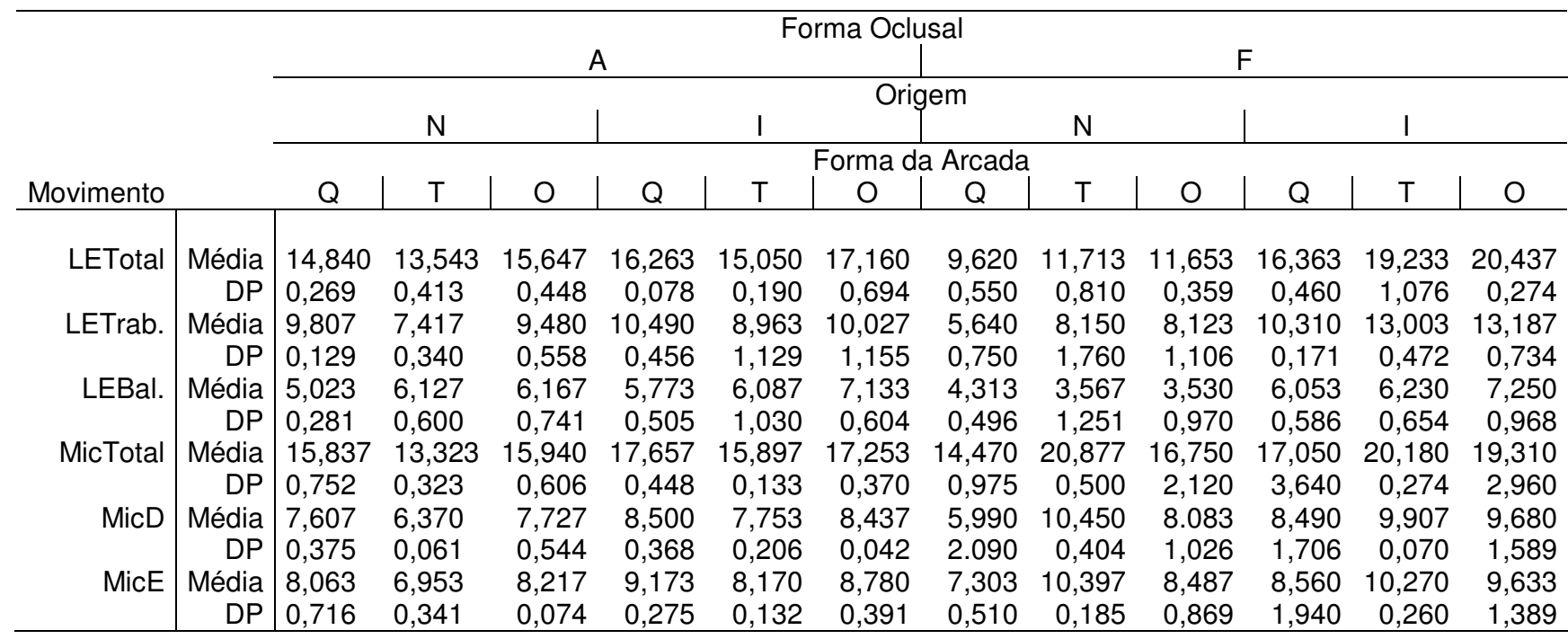

O objetivo desta análise foi comparar a média da variável Área sob os 12 tratamentos formados pelas combinações das categorias das variáveis Forma Oclusal, Origem, Forma da Arcada e Movimento. Como cada prótese foi avaliada sob as seis categorias da variável Movimento, utilizou-se para a análise dos dados um modelo de análise de variância com medidas repetidas (NETER et al., 1996).

Fixado um nível de significância global de 15\% (nível de significância de 1\% para cada teste) para a lateralidade direita (Tabela 5.26), verificou-se que existe interação entre as variáveis Forma Oclusal e Origem $(P=0 \%)$, Forma Oclusal e Forma da Arcada $(P=0 \%)$, Forma Oclusal e Movimento $(P=0 \%)$, Origem e Movimento ( $P=0 \%)$, Forma da Arcada e Movimento (0\%), Forma Oclusal, Origem e Movimento (0\%) e entre Forma Oclusal, Forma da Arcada e Movimento $(P=0 \%)$, sobre a média da variável Área. 
Tabela 5.26 - Análise de Variância (ANOVA) em lateralidade direita para a variável Área.

\begin{tabular}{|c|c|c|c|c|}
\hline Fonte de Variação & Grau de Liberdade & Estatística F & Nível Descritivo P & Significância \\
\hline Forma Oclusal (FO) & 1 & 6,79 & 0,016 & \\
\hline Origem $(\mathrm{O})$ & 1 & 125,12 & 0,000 & \\
\hline Forma da Arcada (FA) & 2 & 12,44 & 0,000 & \\
\hline $\mathrm{FOxO}$ & 1 & 25,41 & 0,000 & $\star \star \star *$ \\
\hline FOxFA & 2 & 30,77 & 0,000 & *** \\
\hline OxFA & 2 & 0,63 & 0,540 & n.s. \\
\hline $\mathrm{FOxOxFA}$ & 2 & 2,19 & 0,134 & n.s. \\
\hline Modelo & 24 & - & & - \\
\hline Movimento (M) & 5 & 1141,71 & 0,000 & \\
\hline FOxM & 5 & 16,78 & 0,000 & *** \\
\hline OxM & 5 & 28,93 & 0,000 & *** \\
\hline FAxM & 10 & 3,77 & 0,000 & *** \\
\hline FOxOxM & 5 & 25,78 & 0,000 & *** \\
\hline FOxFAxM & 10 & 6,47 & 0,000 & $* * *$ \\
\hline OxFAxM & 10 & 1,83 & 0,062 & n.s. \\
\hline $\mathrm{FOxOxFAxM}$ & 10 & 1,93 & 0,048 & n.s. \\
\hline Erro & 120 & - & - & - \\
\hline Total & 215 & - & - & - \\
\hline
\end{tabular}

Para a lateralidade esquerda (Tabela 5.27), verificou-se que existe interação entre as variáveis Forma Oclusal e Origem ( $P=0 \%)$, Forma Oclusal e Forma da Arcada $(P=0 \%)$, Forma Oclusal e Movimento $(P=0 \%)$, Origem e Movimento $(P=$ 0\%), Forma da Arcada e Movimento (1,5\%), Forma Oclusal, Origem e Movimento (0\%) e entre Forma Oclusal, Forma da Arcada e Movimento ( $P=0 \%)$, sobre a média da variável Área. 
Tabela 5.27 - Análise de Variância (ANOVA) em lateralidade esquerda para a variável Área.

\begin{tabular}{lcccc}
\hline Fonte de Variação & Grau de Liberdade & Estatística F & Nível Descritivo P & Significância \\
\hline Forma Oclusal (FO) & 1 & 6,31 & 0,019 & \\
Origem (O) & 1 & 119,12 & 0,000 & \\
Forma da Arcada (FA) & 2 & 9,78 & 0,001 & \\
FOxO & 1 & 25,72 & 0,000 & $* * *$ \\
FOxFA & 2 & 28,59 & 0,000 & $* * *$ \\
OxFA & 2 & 0,69 & 0,511 & n.s. \\
FOxOxFA & 2 & 2,16 & 0,138 & n.s. \\
Modelo & 24 & - & - & - \\
Movimento (M) & 5 & 969,43 & 0,000 & $* * *$ \\
FOxM & 5 & 15,43 & 0,000 & $* * *$ \\
OxM & 5 & 24,22 & 0,000 & n.s. \\
FAxM & 10 & 2,33 & 0,015 & $* * *$ \\
FOxOxM & 5 & 22,05 & 0,000 & n.s. \\
FOxFAxM & 10 & 7,47 & 0,000 & n.s. \\
OxFAxM & 10 & 1,02 & 0,432 & - \\
FOxOxFAxM & 10 & 1,48 & 0,155 & - \\
Erro & 120 & - & - & \\
Total & 215 & - & - & \\
\hline$* * *-P<1 \%$ & & & &
\end{tabular}

Devido à ocorrência destas interações, comparou-se, tanto para a lateralidade direita quanto para a lateralidade esquerda, as médias da variável Área sob os 12 Tratamentos. Para tanto, utilizou-se um modelo de análise de variância com três fatores cruzados fixos onde foi aplicado o método de comparações múltiplas de Tukey em conjunto com o método de agrupamento de médias apresentado por Calinski e Corsten (1985) (nível de significância igual a 1\% para cada teste e coeficiente de confiança global igual a 99\% para o agrupamento de médias), fixando cada uma das categorias da variável Movimento (Tabelas 5.28 a 5.39).

\subsubsection{Análise dos tratamentos para LDTotal}

Na Tabela 5.28 mostram-se os resultados da análise de variância realizada com o objetivo de verificar a influência das variáveis explicativas Forma Oclusal, Origem e Forma da Arcada sobre a média da variável Área, fixada a categoria 
LDTotal da variável Movimento. Na Tabela 5.29, exibem-se os resultados das comparações das médias da variável Área sob os 12 Tratamentos. Da análise da Tabela 5.29 pode-se concluir que o tratamento FNQ apresenta o menor valor médio da variável Área e o tratamento FIO o maior valor.

Tabela 5.28 - Análise de Variância (ANOVA) para a variável Área (LDTotal)

\begin{tabular}{lcccc}
\hline Fonte de Variação & Grau de Liberdade & Estatística F & Nível Descritivo P & Significância \\
\hline Forma Oclusal (FO) & 1 & 42,59 & 0,016 & \\
Origem (O) & 1 & 1968,61 & 0,000 & \\
Forma da Arcada (FA) & 2 & 163,93 & 0,000 & \\
FOxO & 1 & 875,98 & 0,000 & $* * *$ \\
FOxFA & 2 & 99,99 & 0,000 & $* * *$ \\
OxFA & 2 & 9,58 & 0,001 & $* *$ \\
FOxOxFA & 2 & 5,02 & 0,015 & n.s. \\
Erro & 24 & - & - & - \\
\hline Total & 35 & - & - &
\end{tabular}

Tabela 5.29 - Agrupamento de médias (LDTotal)

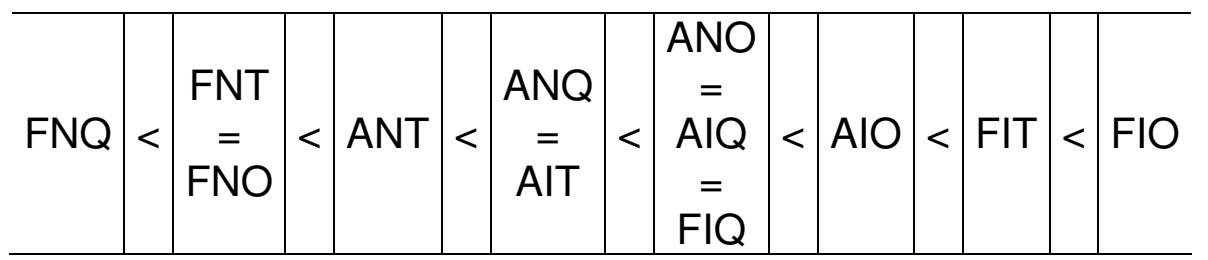

5.4.2 Análise dos tratamentos para LDTrab.

$\mathrm{Na}$ Tabela 5.30 mostram-se os resultados da análise de variância realizada com o objetivo de verificar a influência das variáveis explicativas Forma Oclusal, Origem e Forma da Arcada sobre a média da variável Área, fixada a categoria LDTrab. da variável Movimento. Na Tabela 5.31, demonstram-se os resultados das comparações das médias da variável Área sob os 12 Tratamentos. Da análise da Tabela 5.31 pode-se concluir que não há diferença entre as médias da variável Área para as três formas da arcada sob a combinação FN. Para as combinações Al e FI, não há diferença entre as médias 
da Área sob as três formas da arcada. O tratamento ANT e a combinação FN para as três formas da arcada leva aos menores valores médios da variável Área.

Tabela 5.30 - Análise de Variância (ANOVA) para a variável Área (LDTrab.)

\begin{tabular}{lcccc}
\hline Fonte de Variação & Grau de Liberdade & Estatística F & Nível Descritivo P & Significância \\
\hline Forma Oclusal (FO) & 1 & 0,00 & 0,984 & \\
Origem (O) & 1 & 116,34 & 0,000 & \\
Forma da Arcada (FA) & 2 & 7,95 & 0,002 & \\
FOxO & 1 & 55,12 & 0,000 & $* * *$ \\
FOxFA & 2 & 20,53 & 0,000 & $* * *$ \\
OxFA & 2 & 1,55 & 0,234 & n.s. \\
FOxOxFA & 2 & 1,21 & 0,317 & n.s. \\
Erro & 24 & - & - & - \\
\hline Total & 35 & - & - & - \\
\hline \multirow{*}{***}{$-\mathrm{P}<1 \%$} & & & &
\end{tabular}

Tabela 5.31 - Agrupamento de médias (LDTrab.)

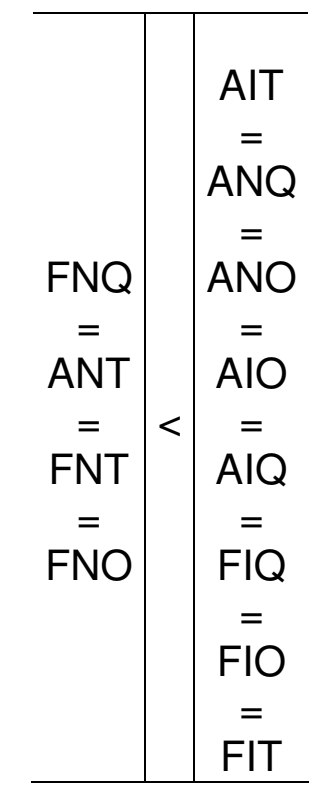

5.4.3 Análise dos tratamentos para LDBal.

$\mathrm{Na}$ Tabela 5.32 mostram-se os resultados da análise de variância realizada com o objetivo de verificar a influência das variáveis explicativas Forma Oclusal, Origem e Forma da Arcada sobre a média da variável Área, fixada a categoria LDBal. da variável Movimento. Na Tabela 5.33, mostram-se os 
resultados das comparações das médias da variável Área sob os 12 Tratamentos. Da análise da Tabela 5.33 pode-se concluir que o tratamento ANQ e a combinação FN para as três formas da arcada leva aos menores valores médios da variável Área. Os tratamentos FIT, AIO e FIO levam aos maiores valores médios da variável Área.

Tabela 5.32 - Análise de Variância (ANOVA) para a variável Área (LDBal.)

\begin{tabular}{lcccc}
\hline Fonte de Variação & Grau de Liberdade & Estatística F & Nível Descritivo P & Significância \\
\hline Forma Oclusal (FO) & 1 & 6,15 & 0,021 & \\
Origem (O) & 1 & 119,96 & 0,000 & \\
Forma da Arcada (FA) & 2 & 17,52 & 0,000 & \\
FOxO & 1 & 40,93 & 0,000 & $* * *$ \\
FOxFA & 2 & 0,26 & 0,774 & n.s. \\
OxFA & 2 & 8,57 & 0,002 & n.s. \\
FOxOxFA & 2 & 3,41 & 0,050 & \\
Erro & 24 & - & - & \\
\hline Total & 35 & - & - &
\end{tabular}

Tabela 5.33 - Agrupamento de médias (LDBal.)

\begin{tabular}{|c|c|c|c|c|}
\hline \multirow{5}{*}{$\begin{array}{c}\text { FNQ } \\
= \\
\text { FNO }\end{array}$} & & & & \\
\hline & & AIT & & \multirow{8}{*}{$\begin{array}{c}\mathrm{FIT} \\
= \\
\mathrm{AIO} \\
= \\
\mathrm{FIO}\end{array}$} \\
\hline & & $=$ & & \\
\hline & & $A \mid Q$ & & \\
\hline & & $=$ & & \\
\hline$=$ & $<$ & ANO & $<$ & \\
\hline FNT & & $=$ & & \\
\hline$=$ & & FIQ & & \\
\hline ANQ & & $\begin{array}{c}= \\
\text { ANT }\end{array}$ & & \\
\hline
\end{tabular}

5.4.4 Análise dos tratamentos para LETotal.

A Tabela 5.34 exibe a comparação dos 12 tratamentos formados pela combinação das categorias das variáveis explicativas Forma Oclusal, Origem e Forma da Arcada, fixada a categoria LETotal da variável Movimento. Na Tabela 
5.35, demonstram-se os resultados das comparações das médias da variável Área sob os 12 Tratamentos. Da análise da Tabela 12 pode-se concluir que o tratamento FNQ apresenta o menor valor médio da variável Área e os tratamentos FIT e FIO os maiores valores.

Tabela 5.34 - Análise de Variância (ANOVA) para a variável Área (LETotal)

\begin{tabular}{|c|c|c|c|c|}
\hline Fonte de Variação & Grau de Liberdade & Estatística F & Nível Descritivo $P$ & Significância \\
\hline Forma Oclusal (FO) & 1 & 10,45 & 0,004 & \\
\hline Origem (O) & 1 & 650,59 & 0,000 & \\
\hline Forma da Arcada (FA) & 2 & 41,20 & 0,000 & \\
\hline $\mathrm{FOxO}$ & 1 & 297,95 & 0,000 & *** \\
\hline FOxFA & 2 & 36,44 & 0,000 & $* * *$ \\
\hline OxFA & 2 & 2,97 & 0,071 & n.s. \\
\hline FOxOxFA & 2 & 2,52 & 0,101 & n.s. \\
\hline Erro & 24 & - & - & - \\
\hline Total & 35 & - & - & - \\
\hline
\end{tabular}

Tabela 5.35 - Agrupamento de médias (LETotal)

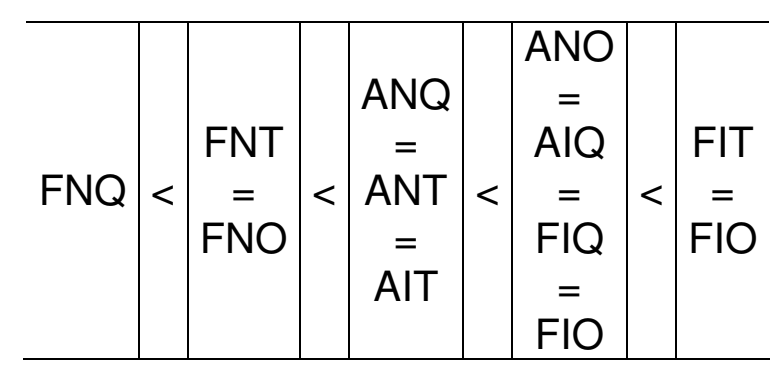

5.4.5 Análise dos tratamentos para LETrab.

$\mathrm{Na}$ Tabela 5.36 mostram-se os resultados da análise de variância realizada com o objetivo de verificar a influência das variáveis explicativas Forma Oclusal, Origem e Forma da Arcada sobre a média da variável Área, fixada a categoria LETrab. da variável Movimento. 
Tabela 5.36 - Análise de Variância (ANOVA) para a variável Área (LETrab.)

\begin{tabular}{lcccc}
\hline Fonte de Variação & Grau de Liberdade & Estatística F & Nível Descritivo P & Significância \\
\hline Forma Oclusal (FO) & 1 & 1,67 & 0,209 & \\
Origem (O) & 1 & 101,44 & 0,000 & \\
Forma da Arcada (FA) & 2 & 5,61 & 0,010 & \\
FOxO & 1 & 46,94 & 0,000 & $* * *$ \\
FOxFA & 2 & 21,82 & 0,000 & $* * *$ \\
OxFA & 2 & 0,30 & 0,742 & n.s. \\
FOxOxFA & 2 & 0,37 & 0,695 & n.s. \\
Erro & 24 & - & - & - \\
\hline Total & 35 & - & - & -
\end{tabular}

Na Tabela 5.37, mostram-se os resultados das comparações das médias da variável Área sob os 12 Tratamentos. Da análise da Tabela 5.37 pode-se concluir que o tratamento FNQ apresenta o menor valor médio da variável Área e os tratamentos FIT e FIO os maiores valores.

Tabela 5.37 - Agrupamento de médias (LETrab.)

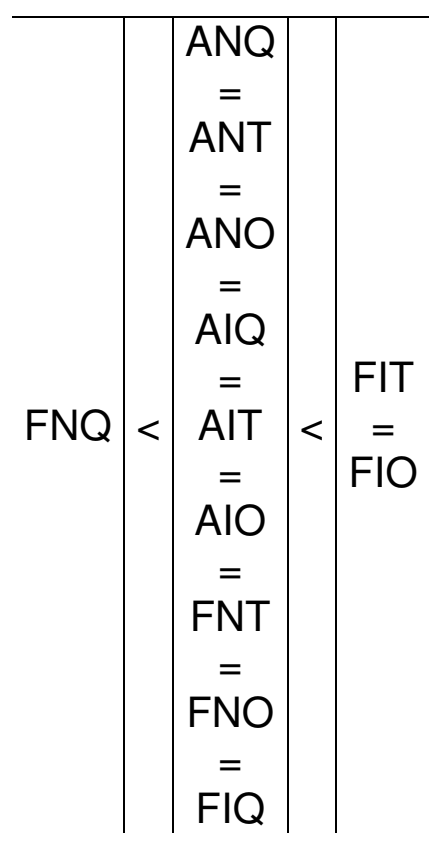




\subsubsection{Análise dos tratamentos para LEBal.}

$\mathrm{Na}$ Tabela 5.38 mostram-se os resultados da análise de variância realizada com o objetivo de verificar a influência das variáveis explicativas Forma Oclusal, Origem e Forma da Arcada sobre a média da variável Área, fixada a categoria LEBal. da variável Movimento. Na Tabela 5.39, demonstram-se os resultados das comparações das médias da variável Área sob os 12 Tratamentos. Da análise da Tabela 5.39 pode-se concluir que a média da variável Área pode ser considerada a mesma sob as três formas da arcada ( $\mathrm{P}$ $=7,8 \%$ ), uma vez que a variável Forma da Arcada não interage com a variável Forma Oclusal $(P=19,4 \%)$, com a variável Origem $(P=16,9 \%)$ e nem com ambas $(P=29,8 \%)$. Da análise da Tabela 5.39 pode-se concluir que a combinação da forma oclusal $\mathrm{F}$ com a origem $\mathrm{N}$ leva ao menor valor médio da variável Área, para as três formas da arcada.

Tabela 5.38 - Análise de Variância (ANOVA) para a variável Área (LEBal.)

\begin{tabular}{lcccc}
\hline Fonte de Variação & Grau de Liberdade & Estatística F & Nível Descritivo P & Significância \\
\hline Forma Oclusal (FO) & 1 & 12,14 & 0,002 & \\
Origem (O) & 1 & 40,49 & 0,000 & \\
Forma da Arcada (FA) & 2 & 2,85 & 0,078 & n.s. \\
FOxO & 1 & 17,52 & 0,000 & n.*. \\
FOxFA & 2 & 1,75 & 0,194 & n.s. \\
OxFA & 2 & 1,92 & 0,169 & n.s. \\
FOxOxFA & 2 & 1,27 & 0,298 & - \\
Erro & 24 & - & - & - \\
\hline Total & 35 & - & - &
\end{tabular}


Tabela 5.39 - Agrupamento de médias (LEBal.)

\begin{tabular}{c|cc}
\hline & & ANQ \\
& \\
& & ANT \\
$=$ & \\
ANO & & \\
FNQ & & AIQ \\
$=$ & $=$ \\
FNT & $<$ & AIT \\
$=$ & $=$ \\
FNO & & AIO \\
$=$ \\
FIQ \\
$=$ \\
FIT \\
$=$ \\
FIO \\
\hline
\end{tabular}

Para comparar as médias da variável Área sob as categorias da variável Movimento, fixou-se cada um dos 12 Tratamentos e utilizou-se um modelo de medidas repetidas com um fator e o método de comparações múltiplas de Tukey (nível de significância global igual a 1\%), tanto para o lado direito quanto para o lado esquerdo inferior. Nas Tabelas 5.40 a 5.51 apresentam-se os resultados encontrados.

Tabela 5.40 - Comparações das médias da variável Área entre algumas categorias da variável Movimento para os tratamentos ANQ e ANO (Lado direito inferior)

\begin{tabular}{c|c|c}
\hline LDBal. & $<$ & LDTrab. \\
LDTrab. & $>$ & MicD \\
LDBal. & $<$ & MicE \\
LDTotal & $=$ & MicTotal \\
\hline
\end{tabular}


Tabela 5.41 - Comparações das médias da variável Área entre algumas categorias da variável Movimento para o tratamento ANT (Lado direito inferior)

\begin{tabular}{c|c|c}
\hline LDBal. & $<$ & LDTrab. \\
LDTrab. & $=$ & MicD \\
LDBal. & $<$ & MicE \\
LDTotal & $=$ & MicTotal \\
\hline
\end{tabular}

Tabela 5.42 - Comparações das médias da variável Área entre algumas categorias da variável Movimento para os tratamentos AIQ, AIT e FIT (Lado direito inferior)

\begin{tabular}{c|c|c}
\hline LDBal. & $<$ & LDTrab. \\
LDTrab. & $>$ & MicD \\
LDBal. & $<$ & MicE \\
LDTotal & $<$ & MicTotal \\
\hline
\end{tabular}

Tabela 5.43 - Comparações das médias da variável Área entre algumas categorias da variável Movimento para os tratamentos AIO, FIQ e FIO (Lado direito inferior)

\begin{tabular}{r|l|l}
\hline LDBal. & $=$ & LDTrab. \\
LDTrab. & $=$ & MicD \\
LDBal. & $=$ & MicE \\
LDTotal & $=$ & MicTotal
\end{tabular}

Tabela 5.44 - Comparações das médias da variável Área entre algumas categorias da variável Movimento para o tratamento FNQ (Lado direito inferior)

\begin{tabular}{c|c|c}
\hline LDBal. & $=$ & LDTrab. \\
LDTrab. & $=$ & MicD \\
LDBal. & $<$ & MicE \\
LDTotal & $<$ & MicTotal
\end{tabular}

Tabela 5.45 - Comparações das médias da variável Área entre algumas categorias da variável Movimento para os tratamentos FNT e FNO (Lado direito inferior)

\begin{tabular}{c|c|c}
\hline LDBal. & $<$ & LDTrab. \\
LDTrab. & $=$ & MicD \\
LDBal. & $<$ & MicE \\
LDTotal & $<$ & MicTotal \\
\hline
\end{tabular}


Tabela 5.46 - Comparações das médias da variável Área entre algumas categorias da variável Movimento para os tratamentos ANQ e FIT (Lado esquerdo inferior)

\begin{tabular}{c|c|c}
\hline LEBal. & $<$ & LETrab. \\
LEBal. & $<$ & MicD \\
LETotal & $=$ & MicTotal \\
LETrab. & $>$ & MicE \\
\hline
\end{tabular}

Tabela 5.47 - Comparações das médias da variável Área entre algumas categorias da variável Movimento para o tratamento ANT e FIQ (Lado esquerdo inferior)

\begin{tabular}{c|c|c}
\hline LEBal. & $=$ & LETrab. \\
LEBal. & $=$ & MicD \\
LETotal & $=$ & MicTotal \\
LETrab. & $=$ & MicE \\
\hline
\end{tabular}

Tabela 5.48 - Comparações das médias da variável Área entre algumas categorias da variável Movimento para os tratamentos AIO, AIT, ANO e FIO (Lado esquerdo inferior)

\begin{tabular}{l|l|c}
\hline LEBal. & $<$ & LETrab. \\
LEBal. & $=$ & MicD \\
LETotal & $=$ & MicTotal \\
LETrab. & $=$ & MicE \\
\hline
\end{tabular}

Tabela 5.49 - Comparações das médias da variável Área entre algumas categorias da variável Movimento para o tratamento AIQ (Lado esquerdo inferior)

\begin{tabular}{c|c|c}
\hline LEBal. & $<$ & LETrab. \\
LEBal. & $<$ & MicD \\
LETotal & $=$ & MicTotal \\
LETrab. & $=$ & MicE \\
\hline
\end{tabular}

Tabela 5.50 - Comparações das médias da variável Área entre algumas categorias da variável Movimento para o tratamento FNQ (Lado esquerdo inferior)

\begin{tabular}{c|l|l}
\hline LEBal. & $=$ & LETrab. \\
LEBal. & $=$ & MicD \\
LETotal & $<$ & MicTotal \\
LETrab. & $=$ & MicE \\
\hline
\end{tabular}


Tabela 5.51 - Comparações das médias da variável Área entre algumas categorias da variável Movimento para os tratamentos FNT e FNO (Lado esquerdo inferior)

\begin{tabular}{c|c|c}
\hline LEBal. & $<$ & LETrab. \\
LEBal. & $<$ & MicD \\
LETotal & $<$ & MicTotal \\
LETrab. & $=$ & MicE \\
\hline
\end{tabular}

5.5 Análise estatística para o movimento de lateralidades direita e esquerda, para o modelo superior

As Tabelas 5.52 e 5.53 apresentam a média e o desvio padrão da variável Área para cada categoria da variável Tratamentos combinada com cada categoria da variável Movimento, considerando a lateralidade direita e a lateralidade esquerda, respectivamente. A análise das Tabelas 5.52 e 5.53 mostra que o comportamento da média da variável Área parece se alterar de acordo com o tratamento considerado.

Tabela 5.52 - Média e desvio padrão (DP) para a variável Área (Lateralidade direita)

\begin{tabular}{|c|c|c|c|c|c|c|c|c|c|c|c|c|c|}
\hline & \multicolumn{13}{|c|}{ Forma Oclusal } \\
\hline & & \multicolumn{6}{|c|}{ 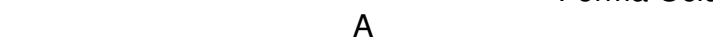 } & \multicolumn{6}{|c|}{$\mathrm{F}$} \\
\hline & & & & & & & Orig & $\mathrm{em}$ & & & & & \\
\hline & & & $\mathrm{N}$ & & & 1 & & & $\mathrm{~N}$ & & & I & \\
\hline & & & & & & & orma da & Arcad & & & & & \\
\hline \multicolumn{2}{|l|}{ Movimento } & Q & $\mathrm{T}$ & $\mathrm{O}$ & Q & $\mathrm{T}$ & 0 & Q & $\mathrm{T}$ & $\mathrm{O}$ & Q & $\mathrm{T}$ & $\mathrm{O}$ \\
\hline \multirow[t]{2}{*}{ LDTotal } & Média & 15,950 & 14,350 & 17,347 & 17,750 & 16,500 & 17,863 & 9,993 & 11,803 & 12,173 & 16,927 & 20,030 & 20,377 \\
\hline & DP & 0,0529 & 0,174 & 0,500 & 0,285 & 0,156 & 0,055 & 0,110 & 0,112 & 0,219 & 0,064 & 0,148 & 0,267 \\
\hline \multirow[t]{2}{*}{ LDTrab. } & Média & 10,230 & 11,073 & 12,390 & 13,867 & 11,893 & 13,050 & 8,140 & 8,263 & 9,413 & 10,673 & 13,363 & 13,630 \\
\hline & DP & 0,070 & 0,110 & 0,357 & 0,376 & 0,211 & 0,089 & 0,380 & 0,240 & 0,235 & 0,675 & 0,319 & 0,061 \\
\hline \multirow[t]{2}{*}{ LDBal. } & Média & 5,720 & 3,278 & 4,957 & 3,883 & 4,607 & 4,813 & 1,853 & 3,540 & 2,760 & 6,253 & 6,667 & 6,747 \\
\hline & DP & 0,027 & 0,155 & 0,172 & 0,125 & 0,055 & 0,070 & 0,270 & 0,128 & 0,229 & 0,611 & 0,406 & 0,241 \\
\hline \multirow[t]{2}{*}{ MicTotal } & Média & 17,193 & 14,367 & 17,303 & 19,977 & 17,870 & 18,160 & 18,62 & 23,760 & 19,090 & 18,687 & 21,290 & 18,86 \\
\hline & DP & 1,598 & 0,805 & 1,311 & 0,670 & 0,352 & 0,115 & 2,53 & 0,892 & 1,970 & 0,391 & 0,397 & 2,23 \\
\hline \multirow[t]{2}{*}{ MicD } & Média & 8,450 & 7,197 & 8,350 & 10,010 & 9,100 & 8,950 & 9,207 & 11,910 & 9,333 & 9,150 & 10,343 & 9,260 \\
\hline & DP & 0,979 & 0,514 & 0,853 & 0,020 & 0,191 & 0,147 & 1,330 & 0,308 & 0,919 & 0,072 & 0,200 & 1,062 \\
\hline \multirow[t]{2}{*}{ MicE } & Média & 8,743 & 7,170 & 8,953 & 9,967 & 8,770 & 9,210 & 9,410 & 11,850 & 9,760 & 9,537 & 10,947 & 9,600 \\
\hline & DP & 0,625 & 0,372 & 0,536 & 0,663 & 0,347 & 0,087 & 1,206 & 0,658 & 1,059 & 0,352 & 0,211 & 1,169 \\
\hline
\end{tabular}


Tabela 5.53 - Média e desvio padrão (DP) para a variável Área (Lateralidade esquerda)

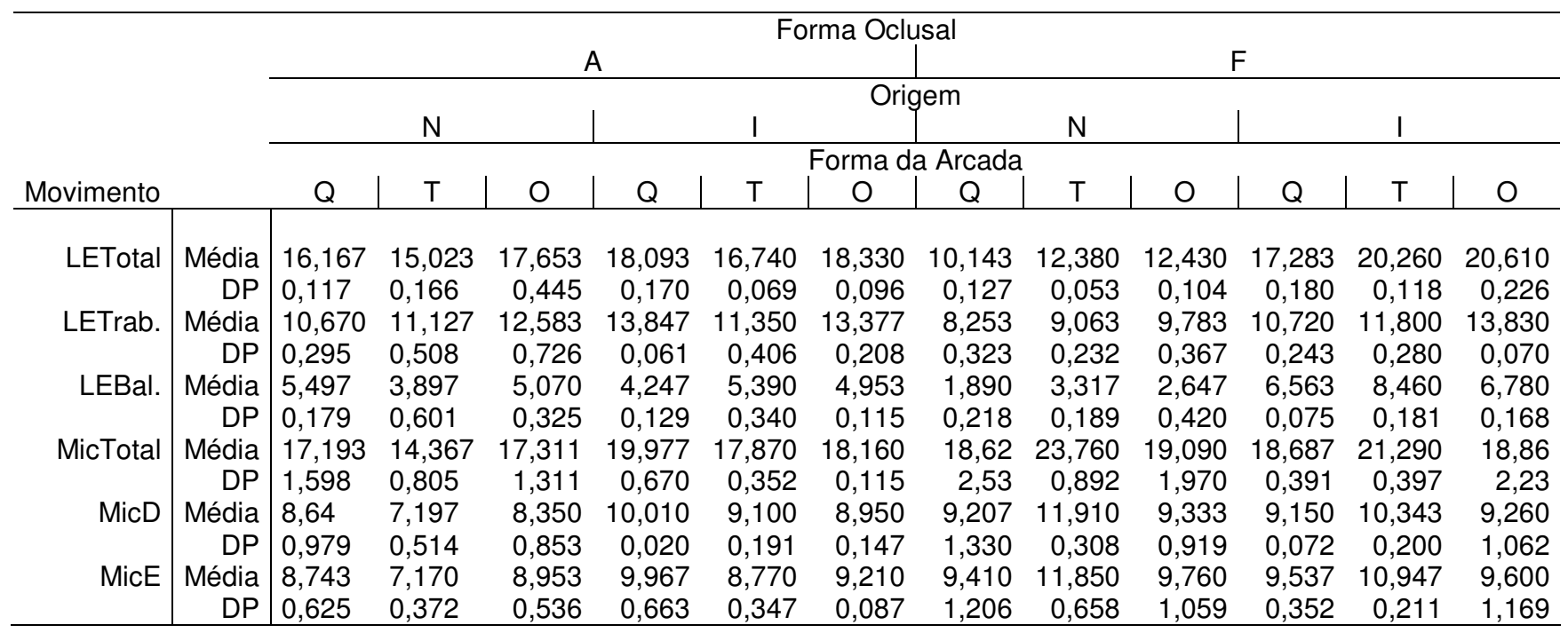

O objetivo desta análise foi comparar a média da variável Área sob os 12 tratamentos formados pelas combinações das categorias das variáveis Forma Oclusal, Origem, Forma da Arcada e Movimento. Como cada prótese foi avaliada sob as seis categorias da variável Movimento, utilizou-se para a análise dos dados um modelo de análise de variância com medidas repetidas (Neter et al., 1996). As Tabelas 5.54 e 5.55 exibem os resultados da análise realizada.

Fixado um nível de significância global de 15\% (nível de significância de 1\% para cada teste) mostramos, na Tabela 5.54, para a lateralidade direita, que há efeito de interação entre as variáveis Forma Oclusal e Origem $(P=0 \%)$, Forma Oclusal e Forma da Arcada ( $P=0 \%)$, Forma Oclusal e Movimento $(P=0 \%)$, Origem e Movimento $(\mathrm{P}=0 \%)$, Forma da Arcada e Movimento (0\%), Forma Oclusal, Origem e Movimento ( $0 \%$ ) e entre Forma Oclusal, Forma da Arcada e Movimento $(P=0 \%)$, sobre a média da variável Área. Para a lateralidade esquerda, mostra-se, na Tabela 5.55, que existe efeito de interação entre as variáveis Forma Oclusal e Origem ( $P=$ 0\%), Forma Oclusal e Forma da Arcada ( $P=0 \%$ ), Forma Oclusal e Movimento ( $P=$ $0 \%$ ), Origem e Movimento ( $P=0 \%)$, Forma da Arcada e Movimento (1,5\%), Forma 
Oclusal, Origem e Movimento (0\%) e entre Forma Oclusal, Forma da Arcada e Movimento $(P=0 \%)$, sobre a média da variável Área.

Tabela 5.54 - Análise de Variância (ANOVA) em lateralidade direita para a variável Área.

\begin{tabular}{|c|c|c|c|c|}
\hline Fonte de Variação & Grau de Liberdade & Estatística F & Nível Descritivo P & Significância \\
\hline Forma Oclusal (FO) & 1 & 6,58 & 0,017 & \\
\hline Origem $(\mathrm{O})$ & 1 & 141,36 & 0,000 & \\
\hline Forma da Arcada (FA) & 2 & 4,21 & 0,027 & \\
\hline $\mathrm{FOxO}$ & 1 & 11,24 & 0,003 & *** \\
\hline FOxFA & 2 & 44,26 & 0,000 & *** \\
\hline OxFA & 2 & 0,63 & 0,541 & n.s. \\
\hline $\mathrm{FOxOxFA}$ & 2 & 4,39 & 0,024 & n.s. \\
\hline Modelo & 24 & - & - & - \\
\hline Movimento (M) & 5 & 2603,79 & 0,000 & \\
\hline FOxM & 5 & 67,07 & 0,000 & *** \\
\hline OxM & 5 & 71,96 & 0,000 & 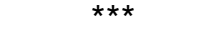 \\
\hline FAxM & 10 & 9,11 & 0,000 & *** \\
\hline FOxOxM & 5 & 89,63 & 0,000 & *** \\
\hline FOxFAxM & 10 & 7,83 & 0,000 & *** \\
\hline OxFAxM & 10 & 1,46 & 0,164 & n.s. \\
\hline FOxOxFAxM & 10 & 7,25 & 0,000 & $\star \star * *$ \\
\hline Erro & 120 & - & - & - \\
\hline Total & 215 & - & - & - \\
\hline
\end{tabular}

Tabela 5.55 - Análise de Variância (ANOVA) em lateralidade esquerda para a variável Área.

\begin{tabular}{lcccc}
\hline Fonte de Variação & Grau de Liberdade & Estatística F & Nível Descritivo P & Significância \\
\hline Forma Oclusal (FO) & 1 & 5,28 & 0,031 & \\
Origem (O) & 1 & 126,87 & 0,000 & \\
Forma da Arcada (FA) & 2 & 4,36 & 0,024 & $* * *$ \\
FOxO & 1 & 10,25 & 0,004 & $* * *$ \\
FOxFA & 2 & 40,49 & 0,000 & n.s. \\
OxFA & 2 & 0,55 & 0,582 & n.s. \\
FOxOxFA & 2 & 3,67 & 0,041 & - \\
Modelo & 24 & 3,96 & 0,000 & $* * *$ \\
Movimento (M) & 5 & 2707,72 & 0,000 & $* * *$ \\
FOxM & 5 & 73,43 & 0,000 & $* * *$ \\
OxM & 5 & 70,97 & 0,000 & $* * *$ \\
FAxM & 10 & 11,86 & 0,000 & $* * *$ \\
FOxOxM & 5 & 97,43 & 0,000 & $* *$ \\
FOxFAxM & 10 & 8,32 & 0,000 & - \\
OxFAxM & 10 & 2,72 & 0,005 & - \\
FOxOxFAxM & 10 & 4,36 & 0,000 & \\
Erro & 120 & - & - & - \\
\hline Total & 215 & - & & \\
$* \star *$ & P $<1 \%$ & & &
\end{tabular}


5.5.1 Análise dos tratamentos para LDTotal.

Na Tabela 5.56 mostram-se os resultados da análise de variância realizada com o objetivo de verificar a influência das variáveis explicativas Forma Oclusal, Origem e Forma da Arcada sobre a média da variável Área, fixada a categoria LDTotal da variável Movimento. Na Tabela 5.57, mostram-se os resultados das comparações das médias da variável Área sob os 12 Tratamentos. Da análise da Tabela 5.57 pode-se concluir que o tratamento FNQ apresenta o menor valor médio da variável Área e os tratamentos FIT e FIO os maiores valores.

Tabela 5.56 - Comparações entre médias da variável Área (LDTotal)

\begin{tabular}{lcccc}
\hline Fonte de Variação & Grau de Liberdade & Estatística F & Nível Descritivo P & Significância \\
\hline Forma Oclusal (FO) & 1 & 381,87 & 0,000 & \\
Origem (O) & 1 & 4135,62 & 0,000 & \\
Forma da Arcada (FA) & 2 & 216,28 & 0,000 & \\
FOxO & 1 & 1906,71 & 0,000 & $* * *$ \\
FOxFA & 2 & 241,67 & 0,000 & $* * *$ \\
OxFA & 2 & 14,54 & 0,000 & $* * *$ \\
FOxOxFA & 2 & 26,70 & 0,000 & - \\
Erro & 24 & - & - & - \\
\hline Total & 35 & - & - &
\end{tabular}

Tabela 5.57 - Agrupamento de médias (LDTotal)

\begin{tabular}{|c|c|c|c|c|c|c|c|c|c|c|c|c|}
\hline $\mathrm{FNQ}$ & $<$ & $\begin{array}{c}\text { FNT } \\
= \\
\text { FNO }\end{array}$ & $<$ & ANT & $<$ & $\begin{array}{c}\text { ANQ } \\
= \\
\text { AIT }\end{array}$ & $<$ & $\begin{array}{c}\mathrm{FIQ} \\
= \\
\mathrm{ANO}\end{array}$ & $<$ & $\begin{array}{c}\mathrm{AIQ} \\
= \\
\mathrm{AIO}\end{array}$ & $<$ & $\begin{array}{c}\text { FIT } \\
= \\
\mathrm{FIO}\end{array}$ \\
\hline
\end{tabular}

5.5.2 Análise dos tratamentos para LDTrab.

Na Tabela 5.58 mostram-se os resultados da análise de variância realizada com o objetivo de verificar a influência das variáveis explicativas Forma Oclusal, 
Origem e Forma da Arcada sobre a média da variável Área, fixada a categoria LDTrab. da variável Movimento. Na Tabela 5.59, mostram-se os resultados das comparações das médias da variável Área sob os 12 Tratamentos. Da análise da Tabela 5.59 pode-se concluir que os tratamentos FNQ e FNT levam aos menores valores médios da variável Área enquanto que os tratamentos AIQ, AIO, FIT e FIO levam aos maiores valores médios.

Tabela 5.58 - Análise de Variância (ANOVA) para a variável Área (LDTrab.)

\begin{tabular}{lcccc}
\hline Fonte de Variação & Grau de Liberdade & Estatística $F$ & Nível Descritivo P & Significância \\
\hline Forma Oclusal (FO) & 1 & 210,99 & 0,000 & \\
Origem (O) & 1 & 746,52 & 0,000 & \\
Forma da Arcada (FA) & 2 & 63,57 & 0,000 & \\
FOxO & 1 & 117,57 & 0,000 & $* \star *$ \\
FOxFA & 2 & 32,42 & 0,000 & $* * *$ \\
OxFA & 2 & 3,66 & 0,041 & n.s. \\
FOxOxFA & 2 & 66,41 & 0,000 & $*$ \\
Erro & 24 & - & - & - \\
\hline Total & 35 & - & - &
\end{tabular}

Tabela 5.59 - Agrupamento de médias (LDTrab.)

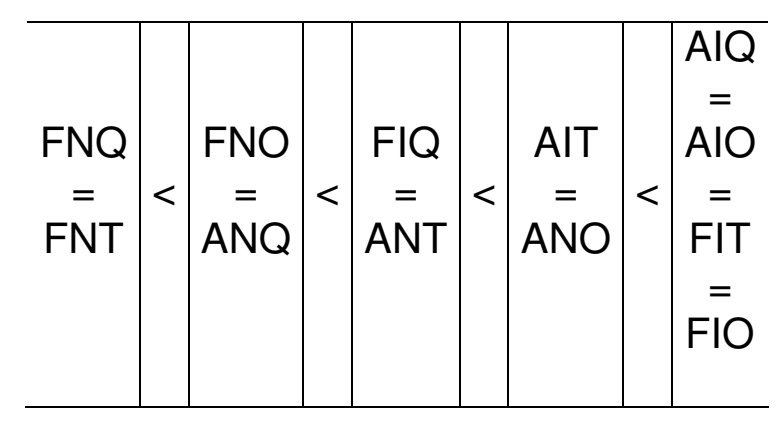

5.5.3 Análise dos tratamentos para LDBal.

$\mathrm{Na}$ Tabela 5.60 mostram-se os resultados da análise de variância realizada com o objetivo de verificar a influência das variáveis explicativas Forma Oclusal, Origem e Forma da Arcada sobre a média da variável Área, fixada a categoria LDBal. da variável Movimento. Na Tabela 5.61, mostram-se os resultados das 
comparações das médias da variável Área sob os 12 Tratamentos. Da análise da Tabela 5.61 pode-se concluir que o tratamento FNQ leva aos menores valores médios da variável Área. Os tratamentos FIQ, FIT e FIO levam aos maiores valores médios da variável Área, sendo que as médias sob estes três tratamentos são iguais.

Tabela 5.60 - Análise de Variância (ANOVA) para a variável Área (LDBal.)

\begin{tabular}{|c|c|c|c|c|}
\hline Fonte de Variação & Grau de Liberdade & Estatística F & Nível Descritivo P & Significância \\
\hline Forma Oclusal (FO) & 1 & 1,17 & 0,291 & \\
\hline Origem (O) & 1 & 433,92 & 0,000 & \\
\hline Forma da Arcada (FA) & 2 & 7,37 & 0,003 & \\
\hline $\mathrm{FOxO}$ & 1 & 543,99 & 0,000 & $\star \star \star *$ \\
\hline FOxFA & 2 & 41,92 & 0,000 & 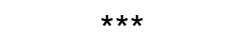 \\
\hline OxFA & 2 & 10,29 & 0,001 & $* * *$ \\
\hline FOxOxFA & 2 & 54,41 & 0,000 & $\star \star * *$ \\
\hline Erro & 24 & - & - & - \\
\hline Total & 35 & - & - & - \\
\hline
\end{tabular}

Tabela 5.61 - Agrupamento de médias (LDBal.)

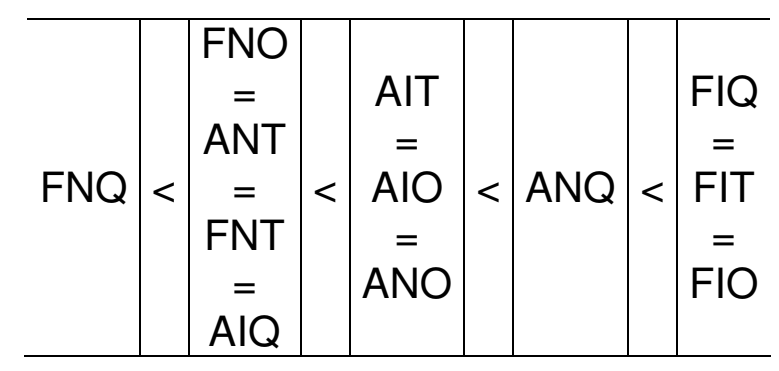

5.5.4 Análise dos tratamentos para LETotal.

A Tabela 5.62 exibe a comparação dos 12 tratamentos formados pela combinação das categorias das variáveis explicativas Forma Oclusal, Origem e Forma da Arcada, fixada a categoria LETotal da variável Movimento. Na Tabela 5.63, demonstram-se os resultados das comparações das médias da variável Área sob os 12 Tratamentos. Da análise da Tabela 5.63 pode-se concluir que o 
tratamento FNQ apresenta o menor valor médio da variável Área e os tratamentos FIT e FIO os maiores valores.

Tabela 5.62 - Análise de Variância (ANOVA) para a variável Área (LETotal)

\begin{tabular}{lcccc}
\hline Fonte de Variação & Grau de Liberdade & Estatística F & Nível Descritivo P & Significância \\
\hline Forma Oclusal (FO) & 1 & 579,73 & 0,000 & \\
Origem (O) & 1 & 5542,94 & 0,000 & \\
Forma da Arcada (FA) & 2 & 302,09 & 0,000 & \\
FOxO & 1 & 2608,84 & 0,000 & $* * *$ \\
FOxFA & 2 & 326,31 & 0,000 & $* * *$ \\
OxFA & 2 & 3,19 & 0,059 & n.s. \\
FOxOxFA & 2 & 29,06 & 0,000 & - \\
Erro & 24 & - & - & - \\
\hline Total & 35 & - & - &
\end{tabular}

Tabela 5.63 - Agrupamento de médias (LETotal)

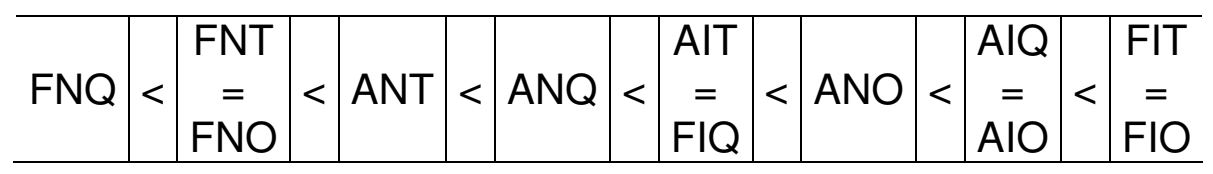

\subsubsection{Análise dos tratamentos para LETrab.}

Na Tabela 5.64 mostram-se os resultados da análise de variância realizada com o objetivo de verificar a influência das variáveis explicativas Forma Oclusal, Origem e Forma da Arcada sobre a média da variável Área, fixada a categoria LETrab. da variável Movimento. Na Tabela 5.65, apresentam-se os resultados das comparações das médias da variável Área sob os 12 Tratamentos. Da análise da Tabela 5.65 pode-se concluir que o tratamento FNQ apresenta o menor valor médio da variável Área e os tratamentos AIQ, AIO e FIO os maiores valores. 
Tabela 5.64 - Análise de Variância (ANOVA) para a variável Área (LETrab.)

\begin{tabular}{lcccc}
\hline Fonte de Variação & Grau de Liberdade & Estatística F & Nível Descritivo P & Significância \\
\hline Forma Oclusal (FO) & 1 & 178,18 & 0,000 & \\
Origem (O) & 1 & 356,54 & 0,000 & \\
Forma da Arcada (FA) & 2 & 74,85 & 0,000 & \\
FOxO & 1 & 50,45 & 0,000 & $* * *$ \\
FOxFA & 2 & 25,85 & 0,000 & $* \star *$ \\
OxFA & 2 & 11,23 & 0,000 & $* \star$ \\
FOxOxFA & 2 & 26,28 & 0,000 & $*$ \\
Erro & 24 & - & - & - \\
Total & 35 & - & - &
\end{tabular}

Tabela 5.65 - Agrupamento de médias (LETrab.)

\begin{tabular}{|c|c|c|c|c|c|c|c|c|}
\hline FNQ & $<$ & $\begin{array}{c}\text { FNT } \\
= \\
\text { FNO }\end{array}$ & $<$ & \begin{tabular}{|c|} 
ANT \\
$=$ \\
AIT \\
$=$ \\
FIQ \\
$=$ \\
FIT
\end{tabular} & $<$ & ANO & $<$ & $\begin{array}{l}\mathrm{AIQ} \\
= \\
\mathrm{AIO} \\
= \\
\mathrm{FIO}\end{array}$ \\
\hline
\end{tabular}

5.5.6 Análise dos tratamentos para LEBal.

Na Tabela 5.66 mostram-se os resultados da análise de variância realizada com o objetivo de verificar a influência das variáveis explicativas Forma Oclusal, Origem e Forma da Arcada sobre a média da variável Área, fixada a categoria LEBal. da variável Movimento. Na Tabela 5.67, apresentam-se os resultados das comparações das médias da variável Área sob os 12 Tratamentos. Da análise da Tabela 5.67 pode-se concluir que o tratamento FNQ apresenta o menor valor médio da variável Área e o tratamento FIT os maiores valores. 
Tabela 5.66 - Análise de Variância (ANOVA) para a variável Área (LEBal.)

\begin{tabular}{lcccc}
\hline Fonte de Variação & Grau de Liberdade & Estatística F & Nível Descritivo P & Significância \\
\hline Forma Oclusal (FO) & 1 & 1,12 & 0,300 & \\
Origem (O) & 1 & 612,06 & 0,000 & \\
Forma da Arcada (FA) & 2 & 19,14 & 0,000 & \\
FOxO & 1 & 590,23 & 0,000 & $* * *$ \\
FOxFA & 2 & 37,52 & 0,000 & $* * *$ \\
OxFA & 2 & 27,09 & 0,000 & $* *$ \\
FOxOxFA & 2 & 12,86 & 0,000 & - \\
Erro & 24 & - & - & - \\
Total & 35 & - & - &
\end{tabular}

Tabela 5.67 - Agrupamento de médias (LEBal.)

\begin{tabular}{|c|c|c|c|c|c|c|c|c|c|c|}
\hline FNQ & $<$ & $\begin{array}{c}\text { FNT } \\
= \\
\text { FNO }\end{array}$ & $<$ & $\begin{array}{c}\text { ANT } \\
= \\
\text { AIQ }\end{array}$ & $<$ & $\begin{array}{c}\text { ANQ } \\
= \\
\text { ANO } \\
= \\
\text { AIT } \\
= \\
\text { AIO }\end{array}$ & $<$ & $\begin{array}{l}\mathrm{FIQ} \\
= \\
\mathrm{FIO}\end{array}$ & $<$ & FIT \\
\hline
\end{tabular}

Para comparar as médias da variável Área sob as categorias da variável Movimento, foram fixados cada um dos 12 Tratamentos e utilizou-se um modelo de medidas repetidas com um fator e o método de comparações múltiplas de Tukey (nível de significância global igual a 1\%), para as lateralidades direita e esquerda. Nas Tabelas 5.68 a 5.79 apresentam-se os resultados encontrados.

Tabela 5.68 - Comparações das médias da variável Área entre algumas categorias da variável Movimento para o tratamento ANQ (Lado direito superior)

\begin{tabular}{c|c|c}
\hline LDBal. & $<$ & LETrab. \\
LDBal. & $<$ & MicE \\
LDTotal & $=$ & MicTotal \\
LDTrab. & $=$ & MicD \\
\hline
\end{tabular}

Tabela 5.69 - Comparações das médias da variável Área entre algumas categorias da variável Movimento para os tratamentos ANT, ANO e AIO (Lado direito superior)

\begin{tabular}{l|l|c}
\hline LDBal. & $<$ & LETrab. \\
LDBal. & $<$ & MicE \\
LDTotal & $=$ & MicTotal \\
LDTrab. & $>$ & MicD \\
\hline
\end{tabular}


Tabela 5.70 - Comparações das médias da variável Área entre algumas categorias da variável Movimento para os tratamentos AIQ, AIT e FIT (Lado direito superior)

\begin{tabular}{c|c|c}
\hline LDBal. & $<$ & LETrab. \\
LDBal. & $<$ & MicE \\
LDTotal & $<$ & MicTotal \\
LDTrab. & $>$ & MicD \\
\hline
\end{tabular}

Tabela 5.71 - Comparações das médias da variável Área entre algumas categorias da variável Movimento para os tratamentos FNO, FIQ e FNQ (Lado direito superior)

\begin{tabular}{c|c|c}
\hline LDBal. & $<$ & LETrab. \\
LDBal. & $<$ & MicE \\
LDTotal & $<$ & MicTotal \\
LDTrab. & $=$ & MicD \\
\hline
\end{tabular}

Tabela 5.72 - Comparações das médias da variável Área entre algumas categorias da variável Movimento para o tratamento FNT (Lado direito superior)

\begin{tabular}{c|c|c}
\hline LDBal. & $<$ & LETrab. \\
LDBal. & $<$ & MicE \\
LDTotal & $<$ & MicTotal \\
LDTrab. & $<$ & MicD \\
\hline
\end{tabular}

Tabela 5.73 - Comparações das médias da variável Área entre algumas categorias da variável Movimento para o tratamento FIO (Lado direito superior)

\begin{tabular}{c|c|c}
\hline LDBal. & $<$ & LETrab. \\
LDBal. & $=$ & MicE \\
LDTotal & $=$ & MicTotal \\
LDTrab. & $>$ & MicD \\
\hline
\end{tabular}

Tabela 5.74 - Comparações das médias da variável Área entre algumas categorias da variável Movimento para o tratamento ANQ (Lado esquerdo superior)

\begin{tabular}{c|c|c}
\hline LEBal. & $<$ & LETrab. \\
LEBal. & $<$ & MicD \\
LETotal & $=$ & MicTotal \\
LETrab. & $=$ & MicE \\
\hline
\end{tabular}

Tabela 5.75 - Comparações das médias da variável Área entre algumas categorias da variável Movimento para os tratamentos ANT, ANO, AIT e AIO (Lado esquerdo superior)

\begin{tabular}{c|c|c}
\hline LEBal. & $<$ & LETrab. \\
LEBal. & $<$ & MicD \\
LETotal & $=$ & MicTotal \\
LETrab. & $>$ & MicE \\
\hline
\end{tabular}


Tabela 5.76 - Comparações das médias da variável Área entre algumas categorias da variável Movimento para os tratamentos AIQ, FIQ e FIT (Lado esquerdo superior)

\begin{tabular}{c|c|c}
\hline LEBal. & $<$ & LETrab. \\
LEBal. & $<$ & MicD \\
LETotal & $<$ & MicTotal \\
LETrab. & $>$ & MicE \\
\hline
\end{tabular}

Tabela 5.77 - Comparações das médias da variável Área entre algumas categorias da variável Movimento para os tratamentos FNO e FNQ (Lado esquerdo superior)

\begin{tabular}{c|c|c}
\hline LEBal. & $<$ & LETrab. \\
LEBal. & $<$ & MicD \\
LETotal & $<$ & MicTotal \\
LETrab. & $=$ & MicE \\
\hline
\end{tabular}

Tabela 5.78 - Comparações das médias da variável Área entre algumas categorias da variável Movimento para o tratamento FNT (Lado esquerdo superior)

\begin{tabular}{l|c|c}
\hline LEBal. & $<$ & LETrab. \\
LEBal. & $<$ & MicD \\
LETotal & $<$ & MicTotal \\
LETrab. & $<$ & MicE \\
\hline
\end{tabular}

Tabela 5.79 - Comparações das médias da variável Área entre algumas categorias da variável Movimento para o tratamento FIO (Lado esquerdo superior)

\begin{tabular}{c|c|c}
\hline LEBal. & $<$ & LETrab. \\
LEBal. & $=$ & MicD \\
LETotal & $=$ & MicTotal \\
LETrab. & $>$ & MicE \\
\hline
\end{tabular}




\section{DISCUSSÃO}

O estudo dos movimentos mandibulares continua sendo muito importante na confecção de próteses totais. A metodologia apresentada nesta pesquisa procurou auxiliar a compreensão de uma das características da dinâmica mandibular. Entretanto, por se tratar de um assunto muito complexo, se faz necessário esclarecer alguns pontos propostos por essa metodologia e ao mesmo tempo, elencar outros fatores diretamente relacionados ao assunto.

Optou-se por um estudo in vitro, uma vez que os conhecimentos de oclusão que preconizam a "liberdade em cêntrica" (BEYRON, 1969; RAMFJORD e ASH, 1984) ou a "cêntrica longa" (DAWSON, 1979), assim como estudos sobre a mastigação que demonstram que o padrão normal do movimento mandibular consiste de pequenos movimentos laterais e uma combinação entre movimentos laterais e protrusivos, ou seja, uma laterotrusão, presente em noventa por cento (90\%) dos casos nos movimentos de lateralidade da mandíbula (HATUSHIKANO, 2006), além da discussão entre as possíveis lateralidades de Bennett ou Centrífuga, consistiriam em fatores que aumentariam ainda mais o número de variáveis envolvidas, inviabilizando o estudo.

A contração de polimerização das resinas para bases de próteses (RIZATTIBARBOSA e DALLARI, 1996; GUARNIERI, 2006) mostra-se outro fator importante a ser considerado, que justifica o fato de termos mensurado a área dos contatos oclusais em próteses totais ainda na fase de montagem na cera. Esta escolha 
adveio da consciência das grandes mudanças oclusais verificadas após o ciclo de polimerização da resina, capazes de reduzir em até $50 \%$ o número de contatos e a relação oclusal entre os dentes (WESLEY et al., 1973). Essas alterações praticamente obrigam a remontagem das próteses no articulador, para que se aumente o número de contatos, otimizando a relação maxilo-mandibular e consequentemente a distribuição das forças oclusais (BOENING; WALTER, 1992).

A partir dos resultados obtidos, notou-se um comportamento semelhante na variável forma das arcadas entre as montagens triangulares e quadradas. Este resultado pode ser explicado pelo fato de que a disposição dos dentes artificiais mostra-se muito semelhante, uma vez que, ao dividirmos os dentes artificiais por segmentos, teríamos: dentes posteriores direitos, dentes anteriores e dentes posteriores esquerdos. Na comparação entre esses segmentos, a grande diferença entre os formatos triangular e quadrado é notada no segmento dos dentes anteriores. Como na posição de máxima intercuspidação, em próteses totais, não existe a obrigatoriedade de toques entre os dentes anteriores (SCHUYLER, 1935), justifica-se o comportamento semelhante entre esses dois formatos, assim como os resultados em protrusão, os quais não apresentaram diferenças significativas na área total obtida, tanto para 0 modelo superior quanto para o modelo inferior, principalmente nos segmentos posteriores direito e esquerdo. Em contra-partida, para o formato oval, a disposição dos dentes posteriores não obedece ao mesmo padrão estabelecido para os formatos triangular e quadrado. Nestes últimos, os dentes posteriores estão dispostos ao longo de um segmento de reta, com os sulcos mésio-distais alinhados. No formato oval, os dentes posteriores estão dispostos em curva, como se estivessem sobre dois segmentos de reta, um para os pré-molares e 
outro para os molares, ou seja, os molares são posicionados em uma posição mais palatina (modelo superior) ou lingual (modelo inferior) em relação aos pré-molares. Dessa forma, os dentes não apresentam um alinhamento retilíneo de seus sulcos principais, os mésio-distais, influenciando nos deslocamentos laterais do modelo superior sobre o modelo inferior.

Uma das maiores dificuldades encontradas neste trabalho foi a impossibilidade de comparar os resultados obtidos ou discutí-los em relação a trabalhos anteriores, uma vez que a literatura pesquisada nos mostrou uma grande diversidade de números de contatos oclusais, tanto para dentados como para edentados (DAHLBERG, 1942; SCHUYLER, 1947; ADAMS; ZANDER, 1964; ARAÚJO, 1972; GOMES, 1987), assim como as variações de indivíduo para indivíduo, conforme a anatomia cuspídica (BREWER; HUDSON, 1961). Um aspecto que diferencia este trabalho em relação aos estudos anteriores é a metodologia aplicada, que contempla a utilização de papel para articulação de quatro micras na cor verde. Não se descobriu a causa exata para o fato de a captura das imagens ter se mostrado de melhor qualidadeem relação ao estudo anterior, mas sabe-se que o fato de os monitores e sistemas de imagem digital trabalharem com as cores vermelha, verde e azul (RGB) pode ter contribuído para este ocorrido. Tais fatos nos levam a refletir sobre o brilhantismo dos pesquisadores do passado, uma vez que, sem os recursos de hoje, conseguiam observar e demonstrar algumas das conclusões que ora se apresentam. O que se pode afirmar, sem que pareça uma grande novidade ou algo revolucionário, diante dos achados que revelam que o lado de trabalho apresenta maiores áreas de contato que o lado de balanceio, nos movimentos de lateralidade? Ou que, nos registros de protrusão, as áreas 
encontradas mostram-se menores que as áreas totais na posição de máxima intercuspidação? A maior discussão que podemos realizar em torno desta pesquisa e dos resultados obtidos é que devemos reverenciar os grandes pensadores e pesquisadores do passado. Aqueles que, somente contando o número de contatos oclusais, conseguiram desenvolver conceitos que agora, com auxílio tecnológico, conseguimos melhor compreender. 


\section{CONCLUSÃO}

Os resultados permitiram-nos concluir que:

7.1 No modelo superior:

7.1.1 As áreas totais em MIC foram maiores que as áreas totais em protrusão;

7.1.2 Em protrusão, os segmentos posterior direito, anterior e posterior esquerdo, apresentaram áreas iguais;

7.1.3 Nos movimentos de lateralidade direita e esquerda, as áreas totais foram menores ou iguais que as áreas totais obtidas em MIC;

7.1.4 Nos movimentos de lateralidade direita e esquerda, as áreas no lado de trabalho foram maiores que as áreas no lado de balanceio;

7.1.5 $\mathrm{Na}$ lateralidade direita, a área no lado de trabalho foi maior que a área do segmento direito do registro em MIC;

7.1.6 Na lateralidade esquerda, a área no lado de trabalho foi maior que a área do segmento esquerdo do registro em MIC; 
7.1.7 Na lateralidade direita, a área no lado de balanceio foi menor que a área do segmento esquerdo do registro em MIC;

7.1.8 Na lateralidade esquerda, a área no lado de balanceio foi menor que a área do segmento direito do registro em MIC. 
7.2 No modelo inferior:

7.2.1 As áreas totais em MIC foram maiores que as áreas totais em protrusão;

7.2.2 Em protrusão, de forma geral, os segmentos posterior direito, anterior e posterior esquerdo, apresentaram áreas iguais;

7.2.3 Nos movimentos de lateralidade direita e esquerda, as áreas totais foram iguais ou menores que as áreas totais obtidas em MIC;

7.2.4 Nos movimentos de lateralidade direita e esquerda, as áreas no lado de trabalho foram maiores ou iguais que as áreas no lado de balanceio;

7.2.5 Na lateralidade direita, as áreas no lado de trabalho foram maiores ou iguais que as áreas do segmento direito do registro em MIC;

7.2.6 Na lateralidade esquerda, as áreas no lado de trabalho foram, em geral, maiores que as áreas do segmento esquerdo do registro em MIC;

7.2.7 $\mathrm{Na}$ lateralidade direita, as áreas no lado de balanceio foram, em geral, menores que as áreas do segmento esquerdo do registro em MIC;

7.2.8 Na lateralidade esquerda, as áreas no lado de balanceio foram menores que as áreas do segmento direito do registro em MIC. 


\section{REFERÊNCIAS ${ }^{1}$}

Adams SH, Zander HA. Functional tooth contacts in lateral and in centric occlusion. J Am Dent Assoc 1964;69(4):465-76.

Appelbaum M. Theories of posterior tooth selecion: porcelain versus acrylic. Dent Clin North Am 1984;28(2):299-306.

Araújo, ENG. Pontos de contato entre as arcadas antagonistas em oclusão central. [Dissertação de Mestrado]. Bauru: Faculdade de Odontologia da USP; 1972.

Atwood DA. Reduction of residual ridges: a major oral disease entity. J Prosthet Dent $1971 ; 26(3): 266-79$

Baba K, Tsukiyama Y, Clarck GT. Reliability, validity, and utility of various occlusal measurement methods and techniques. J Prosthet Dent 2000; 83(1):83-9.

Bergs $\mathrm{E}$. The influence of cusped and cuspless teeth on patient satisfaction with complete dentures. A 2 year follow-up study. J Prosthet Dent 1988; 16(6):269-76.

Beyron H. Optimal occlusion. Dent Clin North Am 1969;13(3):537-53.

Boening $\mathrm{KW}$, Walter $\mathrm{MH}$. Computer-aided evaluation of occlusal load in complete dentures. J Prosthet Dent 1992;67(3):339-44.

Brewer AA, Hudson DC. Application of miniaturized eletronic devices to the study of tooth contact in complete dentures. J Prosthet Dent 1961;11(1):62-72.

Calinski T, Corsten LCA. Clustering means in ANOVA by simultaneous testing. Biometrics 1985;41:39-48.

Christensen FT. The effects of change in the incisal guide angle on cusp angulation. J Prosthet Dent 1971;26(1):93-8.

\footnotetext{
${ }^{1}$ De acordo com Estilo Vancouver. Abreviatura de periódicos segundo base de dados MEDLINE.
} 
Dahlberg B. The masticating effect. Acta Med Scand Monogr 1942; 109(1):65.

Eid ES, Razek KA, Shaaban SA. Wear of acrylic teeth. Egypt Dent J 1972; 18(4):423-32.

Franks ST. A clinical appraisal of acrylic tooth wear. Dent Practit 1962; 12(5):149-53.

Frechette AR. Mastigatory forces associated with the use of various types of artificial teeth. J Prosthet Dent 1955;5(2):252-67.

Gaver $\mathrm{OH}$. Chossing posterior teeth for complete dentures. J Ala Dent Assoc $1981 ; 65(1): 26-7$.

Gomes MAO. Oclusão em prótese total: estudo dos contatos de trabalho e balanceio [Dissertação de Mestrado]. São Paulo: Faculdade de Odontologia da USP; 1987.

Goodkind RJ. A practical approach to balancing complete denture occlusions. J Prosthet Dent 1971;26(1):85-92.

Griffiths NHC, Ramachandra S, Hedge BG. Resin posterior teeth with amalgam restorations for complete dentures. J Indian Dent Assoc 1970; 42(2):47-50.

Guarnieri TC. Avaliação in vitro das variações posicionais da cabeça da mandíbula na fossa articular decorrentes da alteração dimensional de resinas acrílicas para base de prótese total submetidas a diferentes técnicas de processamento [Tese de Doutorado]. São Paulo: Faculdade de Odontologia da USP; 2006.

Hanau RL. Articulation defined, analysed and formulated. J Am Dent Ass 1926;13(12):1694-709.

Hardy IR. Technique for use of non-anatomic acrylic posterior teeth. D Dig 1942;48(12):562-6.

Hatushikano EJ. Análise da laterotrusão condilar nos movimentos de lateralidade centrífuga e de bennett em edentados completos [Tese de Doutorado]. São Paulo: Faculdade de Odontologia da USP; 2006. 
Honda MO. Estudo da união entre a base de resina acrílica termicamente ativada e o dente de resina acrílica com modificação em sua interface [Dissertação de Mestrado]. São Paulo: Faculdade de Odontologia da USP; 2001.

Ingervall $B$. Tooth contacts on the functional and non-functional side in children and young adults. Arch Oral Biol 1972;17(1):191-200.

Jacobs R, Van Steenberghe D, Nys MN, Naert I. Maxillary bone resorption in patients with mandibular implant-supported overdentures or fixed prostheses. J Prosthet Dent 1993;70(2):135-40.

Jankelson B, Hoffman GM, Hendron JA. The physiology of the stomatognathic system. J Am Dent Assoc 1953;46(4):375-86.

Johnson W. A study of stress distribution in complete upper dentures. Dent Pract Dent Rec 1965;15(10):374-9.

Jordan LG. Developments in the occlusal pattern of artificial teeth, by Irving R. Hardy. J Prosthet Dent 1951;1(1-2):29-32.

Jozefowicz $\mathrm{W}$. The influence of wearing dentures on residual ridges: A comparative study. J Prosthet Dent 1970;24(2):137-44.

Kaires AK. A study of occlusal surface contacts in artificial dentures. J Prosthet Dent 1957;7(4):553-64.

Kaires AK. A study of partial denture design and mastigatory pressures in a mandibular bilateral distal extension and management of posterior teeth. J Prosthet Dent 1958;8(2):340-5.

Kapur KK, Soman S, Shapiro S. The effect of denture factors on masticatory performance. J Prosthet Dent 1965;15(5):857-66.

Kelsey C. Alveolar bone resorption under complete dentures. J Prosthet Dent $1971 ; 25(2): 152-61$.

Kelsey C, Coplowitz J, Schoonmaker M. Effects of occlusal forms on preassure bending during mastigation with complete dentures. J Dent Res 1976;55(2):312. 
Kumagai $\mathrm{H}$, Suzuki T, Hamada T, Sondang P, Fujitani M, Nikawa $\mathrm{H}$. Occlusal force distribution on the dental arch during various levels of clenching. J Oral Rehabil 1999;26(12):932-5.

Kydd WL. Complete denture base deformation with varied occlusal tooth form. J Prosthet Dent 1956;6(5):714-8.

Landa JS. Biologic significance of balanced occlusion and balanced articulation in complete denture service. J Am Dent Assoc 1962; 65(4):489-94.

Larkin JD. Tooth contacts in denture occlusion: centric and eccentric. Dent Clin North Am 1971;15(4):861-74.

Levin B. A reevaluation of Hanau's Laws of Articulation and the Hanau Quint. J Prosthet Dent 1978;39(3):254-8.

Lindquist LW, Carlsson GE. Long-term effects on chewing with mandibular fixed prostheses on osseointegrated implants. Acta Odontol Scand 1985; 43(1):39-45.

Manly RS, Vinton P. Factors influencing denture function. J Prosthet Dent 1951;1(5):576-8.

Manly RS, Vinton P. A survey of the chewing ability of denture wearers. J Dent Res $1951 ; 30(3): 314-21$.

Mazini P. Avaliação da area de contato dos dentes artificiais em função da forma oclusal e da forma das arcadas [Dissertação de Mestrado]. São Paulo: Faculdade de Odontologia da USP; 2003.

Meyer FS. A new, simple and achúrate technic for obtaining balanced and functional occlusion. J Am Dent Assoc 1934;21(2):195-203.

Moses CH. Evolution of natural and artificial teeth. J Prosthet Dent 1968; 19(1):33-5.

Nars MF, George WA, Travaglini EA, Scott RH. The relative efficiency of different types of posterior teeth. J Prosthet Dent 1967;18(1):3-11. 
Neill DJ. Studies of tooth contact in complete dentures. Br Dent J 1967; 123(8):36978.

Neter J, Kutner MH, Nachtshein CJ, Wasserman W. Applied linear statistical models. $4^{\text {th }}$ ed. Chicago: Irwin; 1996.

Ohguri T, Kawano F, Ichikawa T, Matsumoto N. Influence of occlusal scheme on the pressure distribution under a complete denture. Int J Prosthodont 1999;12(4):353-8.

Paterson AH. Construction of artificial dentures. Dent Cosmos 1923; 65(7):679-89.

Payne SH. A study of posterior occlusion in duplicate dentures. J Prosthet Dent $1951 ; 1(3): 322-6$.

Payne SH. A comparative study of posterior occlusion. J Prosthet Dent 1952; 2(5):661-6.

Pleasure M A. Anatomic versus non-anatomic teeth. J Prosthet Dent 1953; $3(6): 747-54$.

Ramfjord, S. P. Is it realy necessary to record jaw movements? Quintessence Int, 1982;13(2):187-93.

Ribeiro MS. Análise do efeito da repulsão magnética em usuários de próteses totais e portadores de distúrbios têmporo mandibulares [Dissertação de Mestrado]. São Paulo: Faculdade de Odontologia da USP; 2002.

Rizzati-Barbosa CM, Dallari A. Alterações oclusais da prótese total antes e após sua polimerização. Análise da variação do ângulo das cúspides do primeiro molar superior. RGO 1996; 44(2):83-6.

Saito T, Fava P, Matsura K. Ajuste oclusal. Rev Assoc Paul Cir Dent 1977; $31(3): 175-97$.

Saizar P. Prostodoncia total. $2^{\mathrm{a}}$ ed. Buenos Aires: Mundi; 1972.

Schuyler $\mathrm{CH}$. Fundamental principles in the correction of occlusal disharmony, natural and artificial. J Am Dent Assoc 1935;22(7):1193-202. 
Schuyler $\mathrm{CH}$. Correction of occlusal disharmony of the natural dentition. $\mathrm{N}$ Y Dent J 1947;13(8):445-62.

Shanahan TEJ. Dental physiology for dentures. J Prosthet Dent 1952;2(1):3-11.

Sharry JJ, Askew HC, Hoyer H. A study of the influence of occlusal planes on strains in the edentulous maxillae and mandible. J Prosthet Dent 1956; 6(6):768-74.

Sharry JJ, Askew HC, Hoyer H. Influence of artificial tooth forms on bone deformation beneath complete dentures. J Dent Res 1960;39(2):253-7.

Shetty NS. Comparative observations of the use of cusp and zero-degree posterior teeth. J Prosthet Dent 1984;51(4):459-60.

Stromberg WR. A method of measuring forces of denture bases against supporting tissues. J Prosthet Dent 1955;5(2):268-8.

Suzuki T, Kumagai H, Yoshitomi N, McGlumphy EA. Occlusal contacts of edentulous patients with mandibular hybrid dentures opposing maxillary complete dentures. Int J Oral Maxillofac Implants 1999;14(4):504-9.

Swenson MG. Dentaduras completas. 2ª Ed. Argentina: La Medica; 1958.

Swoope CC, Kydd WL. The effect of cusp form of occlusal surface area on denture base conformation. J Prosthet Dent 1966;16(1):34-43.

Tallgren $\mathrm{A}$. The continuing reduction of the residual alveolar ridges in complete denture wearers: a mixed longitudinal study covering 25 years. J Prosthet Dent $1972 ; 27(2): 120-32$.

Tamaki T. Curva de compensação [Tese de Livre - Docência]. São Paulo: Faculdade de Odontologia daUSP; 1960.

Tamaki T, Tamaki ST. Oclusão em dentaduras completas. Rev Farm Odontol $1971 ; 37: 231-4$.

Tamaki T, Tamaki ST. Dentaduras completas: prática de laboratório. $2^{\mathrm{a}}$ ed. São Paulo: Sarvier; 1980. 
Thompson MJ. Masticatory efficiency as related to cusp form in denture prothesis. $J$ Am Dent Assoc 1937;24(2):207-19.

Thomson JC. Attrition of acrylic teeth. Dent Pract Dent Rec 1965;15(7):233-6.

Trapozzano VR, Lazzari JB. An experimental study of the testing of occlusal patterns of the same denture base. J Prosthet Dent 1952;2(4):440-57.

Trapozzano VR. Testing of occlusal patterns of the same denture base. J Prosthet Dent 1959;9(1):53-69.

Trapozzano VR. Tests of balanced and nonbalanced occlusions. J Prosthet Dent 1960;10(3):476-87.

Trapozzano VR. Laws of articulation. J Prosthet Dent 1963;13(1):34-44.

Weinberg LA. A cinematic study of centric and eccentric occlusions. J Prosthet Dent 1964;14(2):290-3.

Wesley RC, Henderson D, Frazier QZ, Rayson JH, Ellinger CW, Lutes MR, et al. Processing changes in complete dentures: posterior tooth contacts and pin opening. J Prosthet Dent 1973;29(1):46-54.

Woda A, Vigneron P, Kay D. Nonfunctional and functional occlusal contacts: a review of the literature. J Prosthet Dent 1979;42(3):335-41.

Woelfel JB, Hickey JC, Allison ML. Effect of posterior tooth form on jaw and denture movement. J Prosthet Dent 1962;12(5):922-39.

Woelfel JB, Winter CM, Igarashi T. Five year cephalometric study of mandibular ridge resorption with different posterior occlusal forms. Part I. Denture reconstruction and initial comparison. J Prosthet Dent 1976; 36(6):602-23.

Yamaguchi FJ. Avaliação dos efeitos da alteração dimensional de resinas acrílicas para base de prótese total submetidas a diferentes técnicas de processamento avaliados ao nível condilar [Tese de Doutorado]. São Paulo: Faculdade de Odontologia da USP; 2006. 
Zarb GA, Schmitt A. The longitudinal clinical effectiveness of osseointegrated dental implants: the Toronto study. Part III: problems and complications encountered. J Prosthet Dent 1990;64(3):185-94. 
APÊNDICE 
APENDICE A - Quadro de médias das áreas em protrusão do modelo superior

\begin{tabular}{|c|c|c|c|c|c|}
\hline $\begin{array}{c}\text { Forma } \\
\text { Oclusal }\end{array}$ & Origem & Arcada & Modelo & Movimento & Area \\
\hline A & $\mathrm{N}$ & $\mathrm{Q}$ & 1 & ProTotal & 7.23 \\
\hline $\mathrm{A}$ & $\mathrm{N}$ & $\mathrm{Q}$ & 1 & PostDir & 2.15 \\
\hline $\mathrm{A}$ & $\mathrm{N}$ & $\mathrm{Q}$ & 1 & Ant & 2.85 \\
\hline $\mathrm{A}$ & $\mathrm{N}$ & $\mathrm{Q}$ & 1 & PostEsq & 2.23 \\
\hline $\mathrm{A}$ & $\mathrm{N}$ & $\mathrm{Q}$ & 1 & MICTotal & 17.38 \\
\hline $\mathrm{A}$ & $\mathrm{N}$ & $\mathrm{Q}$ & 1 & MicPostDir & 7.03 \\
\hline $\mathrm{A}$ & $\mathrm{N}$ & $\mathrm{Q}$ & 1 & MicAnt & 3.14 \\
\hline $\mathrm{A}$ & $\mathrm{N}$ & $\mathrm{Q}$ & 1 & MicPostEsq & 7.21 \\
\hline $\mathrm{A}$ & $\mathrm{N}$ & $\mathrm{Q}$ & 2 & ProTotal & 6.98 \\
\hline $\mathrm{A}$ & $\mathrm{N}$ & $\mathrm{Q}$ & 2 & PostDir & 2.09 \\
\hline $\mathrm{A}$ & $\mathrm{N}$ & $\mathrm{Q}$ & 2 & Ant & 2.74 \\
\hline $\mathrm{A}$ & $\mathrm{N}$ & $\mathrm{Q}$ & 2 & PostEsq & 2.15 \\
\hline $\mathrm{A}$ & $\mathrm{N}$ & $\mathrm{Q}$ & 2 & MICTotal & 15.51 \\
\hline $\mathrm{A}$ & $\mathrm{N}$ & $\mathrm{Q}$ & 2 & MicPostDir & 6.38 \\
\hline $\mathrm{A}$ & $\mathrm{N}$ & $\mathrm{Q}$ & 2 & MicAnt & 2.28 \\
\hline $\mathrm{A}$ & $\mathrm{N}$ & $\mathrm{Q}$ & 2 & MicPostEsq & 6.85 \\
\hline $\mathrm{A}$ & $\mathrm{N}$ & $\mathrm{Q}$ & 3 & ProTotal & 7.2 \\
\hline $\mathrm{A}$ & $\mathrm{N}$ & $\mathrm{Q}$ & 3 & PostDir & 2.12 \\
\hline $\mathrm{A}$ & $\mathrm{N}$ & $\mathrm{Q}$ & 3 & Ant & 2.67 \\
\hline $\mathrm{A}$ & $\mathrm{N}$ & $\mathrm{Q}$ & 3 & PostEsq & 2.41 \\
\hline $\mathrm{A}$ & $\mathrm{N}$ & $\mathrm{Q}$ & 3 & MICTotal & 18.69 \\
\hline $\mathrm{A}$ & $\mathrm{N}$ & $\mathrm{Q}$ & 3 & MicPostDir & 7.09 \\
\hline $\mathrm{A}$ & $\mathrm{N}$ & $\mathrm{Q}$ & 3 & MicAnt & 3.96 \\
\hline $\mathrm{A}$ & $\mathrm{N}$ & $\mathrm{Q}$ & 3 & MicPostEsq & 7.64 \\
\hline $\mathrm{A}$ & $\mathrm{N}$ & $\mathrm{T}$ & 1 & ProTotal & 6.99 \\
\hline $\mathrm{A}$ & $\mathrm{N}$ & $\mathrm{T}$ & 1 & PostDir & 2.36 \\
\hline $\mathrm{A}$ & $\mathrm{N}$ & $\mathrm{T}$ & 1 & Ant & 2.15 \\
\hline $\mathrm{A}$ & $\mathrm{N}$ & $\mathrm{T}$ & 1 & PostEsq & 2.48 \\
\hline $\mathrm{A}$ & $\mathrm{N}$ & $\mathrm{T}$ & 1 & MICTotal & 14.39 \\
\hline $\mathrm{A}$ & $\mathrm{N}$ & $\mathrm{T}$ & 1 & MicPostDir & 6.8 \\
\hline $\mathrm{A}$ & $\mathrm{N}$ & $\mathrm{T}$ & 1 & MicAnt & 0.85 \\
\hline $\mathrm{A}$ & $\mathrm{N}$ & $\mathrm{T}$ & 1 & MicPostEsq & 6.74 \\
\hline $\mathrm{A}$ & $\mathrm{N}$ & $\mathrm{T}$ & 2 & ProTotal & 6.01 \\
\hline $\mathrm{A}$ & $\mathrm{N}$ & $\mathrm{T}$ & 2 & PostDir & 1.92 \\
\hline $\mathrm{A}$ & $\mathrm{N}$ & $\mathrm{T}$ & 2 & Ant & 2.31 \\
\hline $\mathrm{A}$ & $\mathrm{N}$ & $\mathrm{T}$ & 2 & PostEsq & 1.78 \\
\hline $\mathrm{A}$ & $\mathrm{N}$ & $\mathrm{T}$ & 2 & MICTotal & 13.55 \\
\hline $\mathrm{A}$ & $\mathrm{N}$ & $\mathrm{T}$ & 2 & MicPostDir & 5.8 \\
\hline $\mathrm{A}$ & $\mathrm{N}$ & $\mathrm{T}$ & 2 & MicAnt & 1.92 \\
\hline $\mathrm{A}$ & $\mathrm{N}$ & $\mathrm{T}$ & 2 & MicPostEsq & 5.83 \\
\hline $\mathrm{A}$ & $\mathrm{N}$ & $\mathrm{T}$ & 3 & ProTotal & 5.68 \\
\hline $\mathrm{A}$ & $\mathrm{N}$ & $\mathrm{T}$ & 3 & PostDir & 1.53 \\
\hline $\mathrm{A}$ & $\mathrm{N}$ & $\mathrm{T}$ & 3 & Ant & 2.47 \\
\hline $\mathrm{A}$ & $\mathrm{N}$ & $\mathrm{T}$ & 3 & PostEsq & 1.68 \\
\hline $\mathrm{A}$ & $\mathrm{N}$ & $\mathrm{T}$ & 3 & MICTotal & 15.16 \\
\hline & & & & \\
\hline
\end{tabular}




\begin{tabular}{|c|c|c|c|c|c|}
\hline A & $\mathrm{N}$ & $\mathrm{T}$ & 3 & MicPostDir & 5.99 \\
\hline$A$ & $\mathrm{~N}$ & $\mathrm{~T}$ & 3 & MicAnt & 2.75 \\
\hline A & $\mathrm{N}$ & $\mathrm{T}$ & 3 & MicPostEsq & 6.42 \\
\hline$A$ & $\mathrm{~N}$ & $\mathrm{O}$ & 1 & ProTotal & 6.2 \\
\hline$A$ & $\mathrm{~N}$ & $\mathrm{O}$ & 1 & PostDir & 1.89 \\
\hline A & $\mathrm{N}$ & $\mathrm{O}$ & 1 & Ant & 2.3 \\
\hline$A$ & $\mathrm{~N}$ & $\mathrm{O}$ & 1 & PostEsq & 2.01 \\
\hline A & $\mathrm{N}$ & $\mathrm{O}$ & 1 & MICTotal & 17.25 \\
\hline$A$ & $\mathrm{~N}$ & $\mathrm{O}$ & 1 & MicPostDir & 7 \\
\hline A & $\mathrm{N}$ & $\mathrm{O}$ & 1 & MicAnt & 3.36 \\
\hline A & $\mathrm{N}$ & $\mathrm{O}$ & 1 & MicPostEsq & 6.89 \\
\hline$A$ & $\mathrm{~N}$ & $\mathrm{O}$ & 2 & ProTotal & 6.87 \\
\hline$A$ & $\mathrm{~N}$ & $\mathrm{O}$ & 2 & PostDir & 2.03 \\
\hline A & $\mathrm{N}$ & $\mathrm{O}$ & 2 & Ant & 2.54 \\
\hline$A$ & $\mathrm{~N}$ & $\mathrm{O}$ & 2 & PostEsq & 2.3 \\
\hline A & $\mathrm{N}$ & $\mathrm{O}$ & 2 & MICTotal & 16.02 \\
\hline A & $\mathrm{N}$ & $\mathrm{O}$ & 2 & MicPostDir & 5.76 \\
\hline$A$ & $\mathrm{~N}$ & $\mathrm{O}$ & 2 & MicAnt & 4.46 \\
\hline$A$ & $\mathrm{~N}$ & $\mathrm{O}$ & 2 & MicPostEsq & 5.8 \\
\hline A & $\mathrm{N}$ & $\mathrm{O}$ & 3 & ProTotal & 6.24 \\
\hline A & $\mathrm{N}$ & $\mathrm{O}$ & 3 & PostDir & 1.9 \\
\hline$A$ & $\mathrm{~N}$ & $\mathrm{O}$ & 3 & Ant & 2.34 \\
\hline$A$ & $\mathrm{~N}$ & $\mathrm{O}$ & 3 & PostEsq & 2 \\
\hline$A$ & $\mathrm{~N}$ & $\mathrm{O}$ & 3 & MICTotal & 18.64 \\
\hline$A$ & $\mathrm{~N}$ & $\mathrm{O}$ & 3 & MicPostDir & 7.12 \\
\hline A & $\mathrm{N}$ & $\mathrm{O}$ & 3 & MicAnt & 4.09 \\
\hline A & $\mathrm{N}$ & $\mathrm{O}$ & 3 & MicPostEsq & 7.43 \\
\hline A & 1 & Q & 1 & ProTotal & 5.64 \\
\hline$A$ & 1 & Q & 1 & PostDir & 1.86 \\
\hline$A$ & $\mathrm{I}$ & Q & 1 & Ant & 1.79 \\
\hline A & 1 & Q & 1 & PostEsq & 1.99 \\
\hline A & 1 & Q & 1 & MICTotal & 19.25 \\
\hline$A$ & 1 & Q & 1 & MicPostDir & 7.23 \\
\hline A & 1 & Q & 1 & MicAnt & 4.51 \\
\hline$A$ & 1 & Q & 1 & MicPostEsq & 7.51 \\
\hline$A$ & 1 & Q & 2 & ProTotal & 5.8 \\
\hline$A$ & 1 & Q & 2 & PostDir & 2.02 \\
\hline A & I & $\bar{Q}$ & 2 & Ant & 1.31 \\
\hline$A$ & 1 & Q & 2 & PostEsq & 2.47 \\
\hline A & 1 & Q & 2 & MICTotal & 20.11 \\
\hline$A$ & 1 & Q & 2 & MicPostDir & 8.1 \\
\hline A & 1 & Q & 2 & MicAnt & 3.85 \\
\hline$A$ & 1 & Q & 2 & MicPostEsq & 8.16 \\
\hline A & 1 & Q & 3 & ProTotal & 5.69 \\
\hline$A$ & 1 & Q & 3 & PostDir & 1.77 \\
\hline A & 1 & Q & 3 & Ant & 2.11 \\
\hline$A$ & 1 & Q & 3 & PostEsq & 1.81 \\
\hline$A$ & I & Q & 3 & MICTotal & 20.57 \\
\hline
\end{tabular}

(continua) 


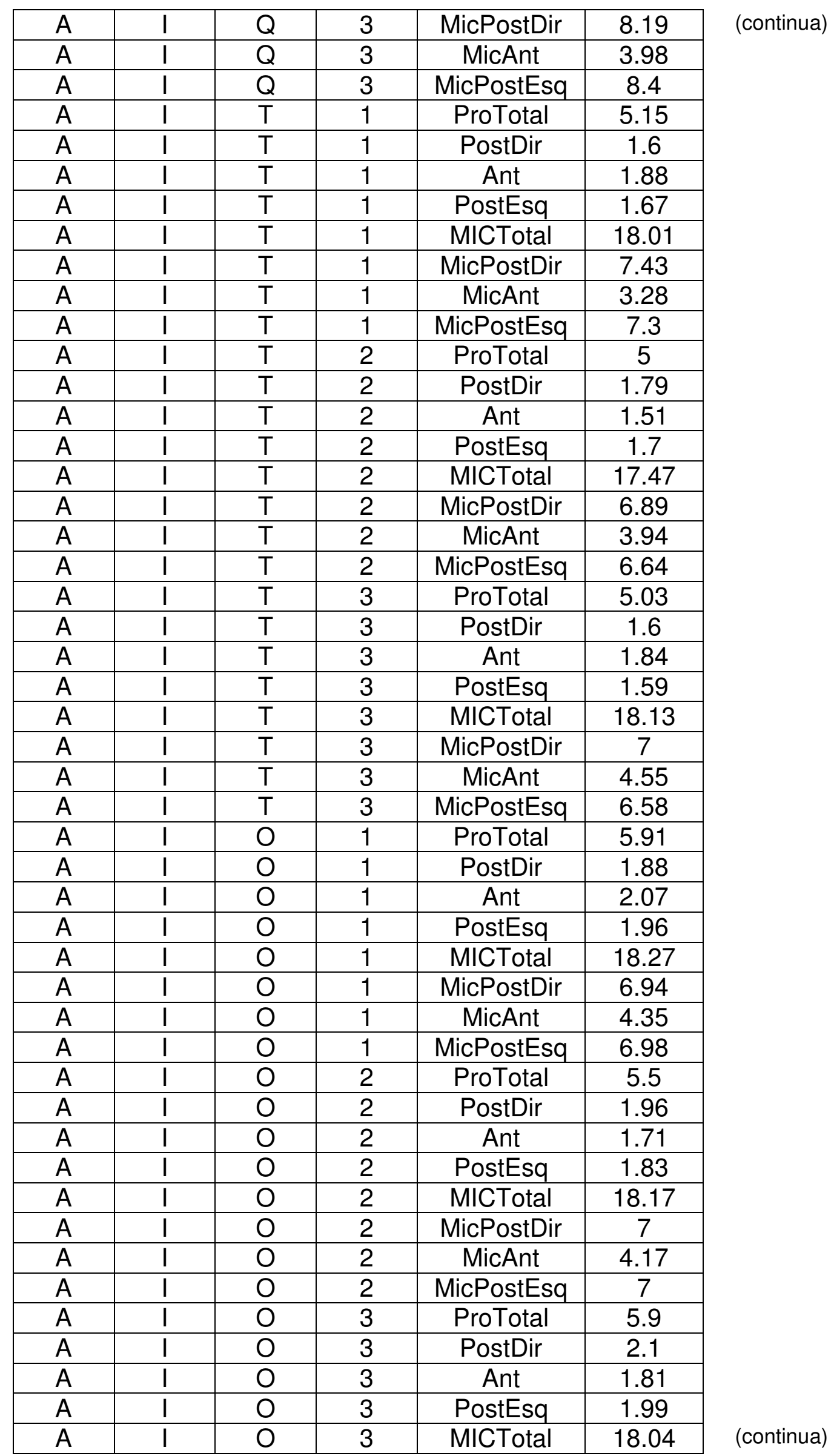




\begin{tabular}{|c|c|c|c|c|c|}
\hline A & 1 & $\mathrm{O}$ & 3 & MicPostDir & 7.02 \\
\hline $\mathrm{A}$ & I & $\mathrm{O}$ & 3 & MicAnt & 3.86 \\
\hline A & 1 & $\mathrm{O}$ & 3 & MicPostEsq & 7.16 \\
\hline$F$ & $\mathrm{~N}$ & $Q$ & 1 & ProTotal & 4 \\
\hline $\mathrm{F}$ & $\mathrm{N}$ & Q & 1 & PostDir & 1.09 \\
\hline $\mathrm{F}$ & $\mathrm{N}$ & Q & 1 & Ant & 1.81 \\
\hline $\mathrm{F}$ & $\mathrm{N}$ & Q & 1 & PostEsq & 1.1 \\
\hline $\mathrm{F}$ & $\mathrm{N}$ & $\mathrm{Q}$ & 1 & MICTotal & 18.38 \\
\hline $\mathrm{F}$ & $\mathrm{N}$ & Q & 1 & MicPostDir & 6.99 \\
\hline $\mathrm{F}$ & $\mathrm{N}$ & Q & 1 & MicAnt & 4.13 \\
\hline $\mathrm{F}$ & $\mathrm{N}$ & Q & 1 & MicPostEsq & 7.26 \\
\hline $\mathrm{F}$ & $\mathrm{N}$ & Q & 2 & ProTotal & 3.88 \\
\hline $\mathrm{F}$ & $\mathrm{N}$ & $\mathrm{Q}$ & 2 & PostDir & 1.1 \\
\hline $\mathrm{F}$ & $\mathrm{N}$ & Q & 2 & Ant & 1.48 \\
\hline $\mathrm{F}$ & $\mathrm{N}$ & Q & 2 & PostEsq & 1.3 \\
\hline $\mathrm{F}$ & $\mathrm{N}$ & $\mathrm{Q}$ & 2 & MICTotal & 21.26 \\
\hline $\mathrm{F}$ & $\mathrm{N}$ & Q & 2 & MicPostDir & 8 \\
\hline $\mathrm{F}$ & $\mathrm{N}$ & Q & 2 & MicAnt & 5.16 \\
\hline $\mathrm{F}$ & $\mathrm{N}$ & Q & 2 & MicPostEsq & 8.1 \\
\hline $\mathrm{F}$ & $\mathrm{N}$ & Q & 3 & ProTotal & 4.13 \\
\hline $\mathrm{F}$ & $\mathrm{N}$ & Q & 3 & PostDir & 1 \\
\hline $\mathrm{F}$ & $\mathrm{N}$ & Q & 3 & Ant & 2.03 \\
\hline $\mathrm{F}$ & $\mathrm{N}$ & Q & 3 & PostEsq & 1.11 \\
\hline $\mathrm{F}$ & $\mathrm{N}$ & $\mathrm{Q}$ & 3 & MICTotal & 16.21 \\
\hline $\mathrm{F}$ & $\mathrm{N}$ & Q & 3 & MicPostDir & 6.59 \\
\hline $\mathrm{F}$ & $\mathrm{N}$ & Q & 3 & MicAnt & 2.8 \\
\hline $\mathrm{F}$ & $\mathrm{N}$ & $\mathrm{Q}$ & 3 & MicPostEsq & 6.82 \\
\hline $\mathrm{F}$ & $\mathrm{N}$ & $\mathrm{T}$ & 1 & ProTotal & 3.99 \\
\hline $\mathrm{F}$ & $\mathrm{N}$ & $\mathrm{T}$ & 1 & PostDir & 1.2 \\
\hline$F$ & $\mathrm{~N}$ & $T$ & 1 & Ant & 1.48 \\
\hline $\mathrm{F}$ & $\mathrm{N}$ & $\mathrm{T}$ & 1 & PostEsq & 1.31 \\
\hline $\mathrm{F}$ & $\mathrm{N}$ & $\mathrm{T}$ & 1 & MICTotal & 23.02 \\
\hline $\mathrm{F}$ & $\mathrm{N}$ & $T$ & 1 & MicPostDir & 9.12 \\
\hline $\mathrm{F}$ & $\mathrm{N}$ & $\mathrm{T}$ & 1 & MicAnt & 5.22 \\
\hline $\mathrm{F}$ & $\mathrm{N}$ & $\mathrm{T}$ & 1 & MicPostEsq & 8.68 \\
\hline $\mathrm{F}$ & $\mathrm{N}$ & $\mathrm{T}$ & 2 & ProTotal & 4.05 \\
\hline $\mathrm{F}$ & $\mathrm{N}$ & $\mathrm{T}$ & 2 & PostDir & 1.3 \\
\hline $\mathrm{F}$ & $\mathrm{N}$ & $T$ & 2 & Ant & 1.39 \\
\hline$F$ & $\mathrm{~N}$ & $T$ & 2 & PostEsq & 1.36 \\
\hline $\mathrm{F}$ & $\mathrm{N}$ & $\mathrm{T}$ & 2 & MICTotal & 24.75 \\
\hline $\mathrm{F}$ & $\mathrm{N}$ & $T$ & 2 & MicPostDir & 9.32 \\
\hline $\mathrm{F}$ & $\mathrm{N}$ & $\mathrm{T}$ & 2 & MicAnt & 6.02 \\
\hline $\mathrm{F}$ & $\mathrm{N}$ & $\mathrm{T}$ & 2 & MicPostEsq & 9.41 \\
\hline $\mathrm{F}$ & $\mathrm{N}$ & $\mathrm{T}$ & 3 & ProTotal & 4.1 \\
\hline $\mathrm{F}$ & $\mathrm{N}$ & $T$ & 3 & PostDir & 1.2 \\
\hline $\mathrm{F}$ & $\mathrm{N}$ & $T$ & 3 & Ant & 1.57 \\
\hline $\mathrm{F}$ & $\mathrm{N}$ & $\mathrm{T}$ & 3 & PostEsq & 1.33 \\
\hline $\mathrm{F}$ & $\mathrm{N}$ & $\mathrm{T}$ & 3 & MICTotal & 23.51 \\
\hline
\end{tabular}

(continua) 


\begin{tabular}{|c|c|c|c|c|c|c|}
\hline $\mathrm{F}$ & $\mathrm{N}$ & $\mathrm{T}$ & 3 & MicPostDir & 9.1 & (continua) \\
\hline $\mathrm{F}$ & $\mathrm{N}$ & $\mathrm{T}$ & 3 & MicAnt & 5.11 & \\
\hline $\mathrm{F}$ & $\mathrm{N}$ & $\mathrm{T}$ & 3 & MicPostEsq & 9.3 & \\
\hline $\mathrm{F}$ & $\mathrm{N}$ & $\mathrm{O}$ & 1 & ProTotal & 4.2 & \\
\hline $\mathrm{F}$ & $\mathrm{N}$ & $\mathrm{O}$ & 1 & PostDir & 1.3 & \\
\hline $\mathrm{F}$ & $\mathrm{N}$ & $\mathrm{O}$ & 1 & Ant & 1.45 & \\
\hline $\mathrm{F}$ & $\mathrm{N}$ & $\mathrm{O}$ & 1 & PostEsq & 1.45 & \\
\hline $\mathrm{F}$ & $\mathrm{N}$ & $\mathrm{O}$ & 1 & MICTotal & 21.04 & \\
\hline $\mathrm{F}$ & $\mathrm{N}$ & $\mathrm{O}$ & 1 & MicPostDir & 8.49 & \\
\hline $\mathrm{F}$ & $\mathrm{N}$ & $\mathrm{O}$ & 1 & MicAnt & 4.41 & \\
\hline $\mathrm{F}$ & $\mathrm{N}$ & $\mathrm{O}$ & 1 & MicPostEsq & 8.14 & \\
\hline $\mathrm{F}$ & $\mathrm{N}$ & $\mathrm{O}$ & 2 & ProTotal & 4.15 & \\
\hline $\mathrm{F}$ & $\mathrm{N}$ & $\mathrm{O}$ & 2 & PostDir & 1.2 & \\
\hline $\mathrm{F}$ & $\mathrm{N}$ & $\mathrm{O}$ & 2 & Ant & 1.74 & \\
\hline $\mathrm{F}$ & $\mathrm{N}$ & $\mathrm{O}$ & 2 & PostEsq & 2.21 & \\
\hline $\mathrm{F}$ & $\mathrm{N}$ & $\mathrm{O}$ & 2 & MICTotal & 19.13 & \\
\hline $\mathrm{F}$ & $\mathrm{N}$ & 0 & 2 & MicPostDir & 7.92 & \\
\hline $\mathrm{F}$ & $\mathrm{N}$ & $\mathrm{O}$ & 2 & MicAnt & 3.21 & \\
\hline $\mathrm{F}$ & $\mathrm{N}$ & $\mathrm{O}$ & 2 & MicPostEsq & 8 & \\
\hline $\mathrm{F}$ & $\mathrm{N}$ & $\mathrm{O}$ & 3 & ProTotal & 4.07 & \\
\hline $\mathrm{F}$ & $\mathrm{N}$ & $\mathrm{O}$ & 3 & PostDir & 1.24 & \\
\hline $\mathrm{F}$ & $\mathrm{N}$ & $\mathrm{O}$ & 3 & Ant & 1.46 & \\
\hline $\mathrm{F}$ & $\mathrm{N}$ & $\mathrm{O}$ & 3 & PostEsq & 1.37 & \\
\hline $\mathrm{F}$ & $\mathrm{N}$ & $\mathrm{O}$ & 3 & MICTotal & 17.11 & \\
\hline $\mathrm{F}$ & $\mathrm{N}$ & $\mathrm{O}$ & 3 & MicPostDir & 6.58 & \\
\hline $\mathrm{F}$ & $\mathrm{N}$ & $\mathrm{O}$ & 3 & MicAnt & 3.66 & \\
\hline $\mathrm{F}$ & $\mathrm{N}$ & $\mathrm{O}$ & 3 & MicPostEsq & 6.87 & \\
\hline $\mathrm{F}$ & 1 & Q & 1 & ProTotal & 3.5 & \\
\hline $\mathrm{F}$ & I & Q & 1 & PostDir & 1 & \\
\hline $\mathrm{F}$ & I & Q & 1 & Ant & 1.34 & \\
\hline $\mathrm{F}$ & 1 & Q & 1 & PostEsq & 1.16 & \\
\hline $\mathrm{F}$ & I & Q & 1 & MICTotal & 18.97 & \\
\hline $\mathrm{F}$ & 1 & Q & 1 & MicPostDir & 7.73 & \\
\hline $\mathrm{F}$ & 1 & Q & 1 & MicAnt & 3.74 & \\
\hline $\mathrm{F}$ & I & Q & 1 & MicPostEsq & 7.5 & \\
\hline $\mathrm{F}$ & 1 & $\bar{Q}$ & 2 & ProTotal & 3.88 & \\
\hline $\mathrm{F}$ & I & Q & 2 & PostDir & 1.3 & \\
\hline $\mathrm{F}$ & I & Q & 2 & Ant & 1.23 & \\
\hline $\mathrm{F}$ & I & Q & 2 & PostEsq & 1.35 & \\
\hline $\mathrm{F}$ & 1 & Q & 2 & MICTotal & 18.24 & \\
\hline $\mathrm{F}$ & 1 & Q & 2 & MicPostDir & 7.15 & \\
\hline $\mathrm{F}$ & $\mathrm{I}$ & Q & 2 & MicAnt & 4.21 & \\
\hline $\mathrm{F}$ & 1 & Q & 2 & MicPostEsq & 6.88 & \\
\hline $\mathrm{F}$ & 1 & Q & 3 & ProTotal & 3.8 & \\
\hline $\mathrm{F}$ & I & Q & 3 & PostDir & 1.43 & \\
\hline $\mathrm{F}$ & 1 & Q & 3 & Ant & 1.08 & \\
\hline $\mathrm{F}$ & 1 & $\bar{Q}$ & 3 & PostEsq & 1.29 & \\
\hline $\mathrm{F}$ & I & Q & 3 & MICTotal & 18.85 & ontinua) \\
\hline
\end{tabular}




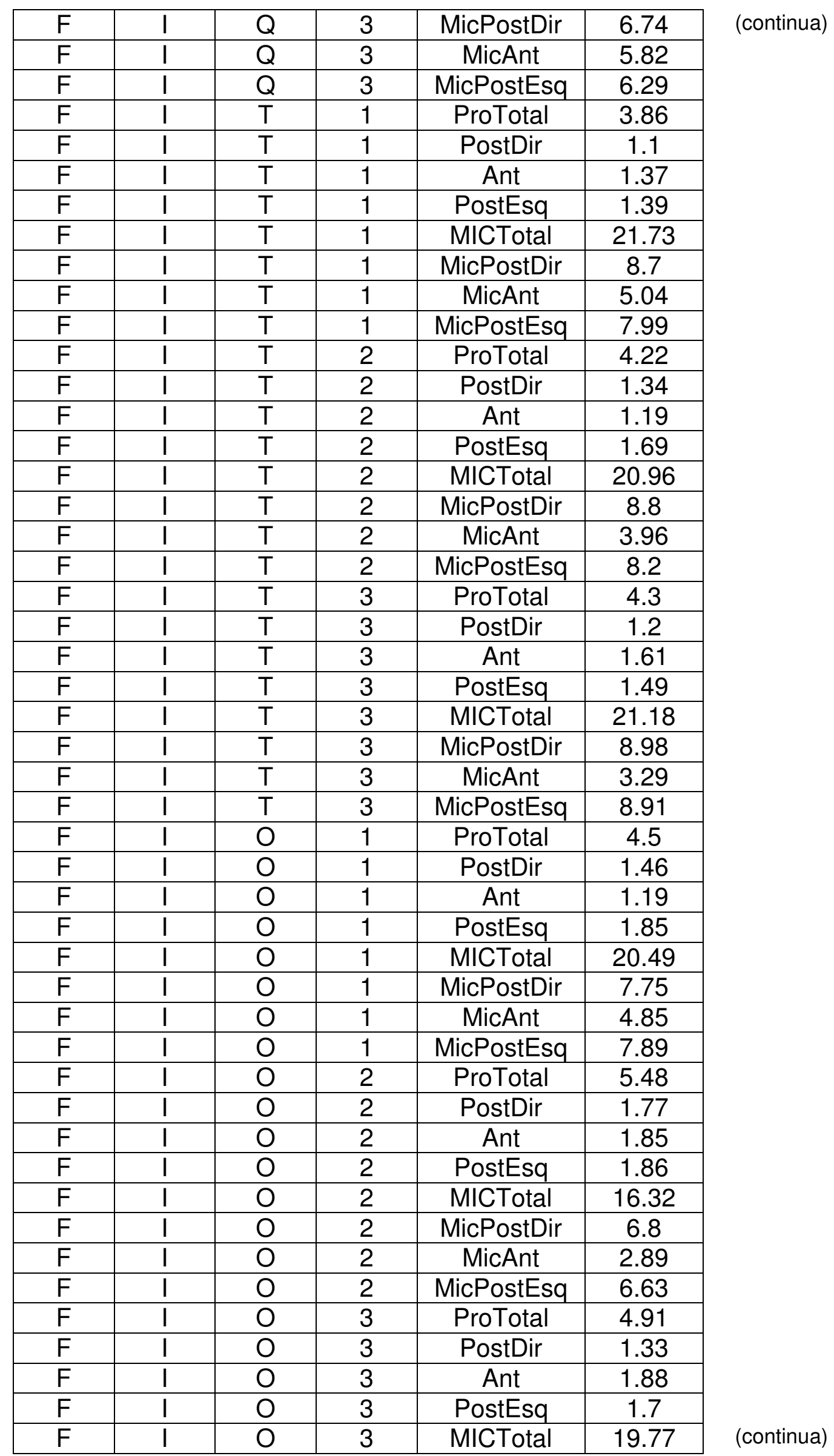




\begin{tabular}{|c|c|c|c|c|c|}
\hline $\mathrm{F}$ & $\mathrm{I}$ & $\mathrm{O}$ & 3 & MicPostDir & 7.15 \\
\hline $\mathrm{F}$ & $\mathrm{I}$ & $\mathrm{O}$ & 3 & MicAnt & 4.91 \\
\hline $\mathrm{F}$ & $\mathrm{I}$ & $\mathrm{O}$ & 3 & MicPostEsq & 7.71 \\
\hline
\end{tabular}


APENDICE B- Quadro de médias das áreas em protrusão do modelo inferior

\begin{tabular}{|c|c|c|c|c|c|}
\hline $\begin{array}{l}\text { Forma } \\
\text { Oclusal }\end{array}$ & Origem & Arcada & Modelo & Movimento & Area \\
\hline A & $\mathrm{N}$ & Q & 1 & ProTotal & 6.12 \\
\hline A & $\mathrm{N}$ & $\mathrm{Q}$ & 1 & PostDir & 1.89 \\
\hline$A$ & $\mathrm{~N}$ & $\mathrm{Q}$ & 1 & Ant & 2.31 \\
\hline$A$ & $\mathrm{~N}$ & $\mathrm{Q}$ & 1 & PostEsq & 1.92 \\
\hline$A$ & $\mathrm{~N}$ & $\mathrm{Q}$ & 1 & MICTotal & 15.72 \\
\hline$A$ & $\mathrm{~N}$ & $\mathrm{Q}$ & 1 & MicPostDir & 6.19 \\
\hline A & $\mathrm{N}$ & Q & 1 & MicAnt & 3.33 \\
\hline$A$ & $\mathrm{~N}$ & $\mathrm{Q}$ & 1 & MicPostEsq & 6.02 \\
\hline A & $\mathrm{N}$ & Q & 2 & ProTotal & 5.88 \\
\hline$A$ & $\mathrm{~N}$ & $\mathrm{Q}$ & 2 & PostDir & 1.7 \\
\hline$A$ & $\mathrm{~N}$ & $\mathrm{Q}$ & 2 & Ant & 2.33 \\
\hline A & $\mathrm{N}$ & $\mathrm{Q}$ & 2 & PostEsq & 1.85 \\
\hline A & $\mathrm{N}$ & $\mathrm{Q}$ & 2 & MICTotal & 15.15 \\
\hline A & $\mathrm{N}$ & $\mathrm{Q}$ & 2 & MicPostDir & 6.23 \\
\hline A & $\mathrm{N}$ & $\mathrm{Q}$ & 2 & MicAnt & 2.57 \\
\hline$A$ & $\mathrm{~N}$ & $\mathrm{Q}$ & 2 & MicPostEsq & 6.35 \\
\hline$A$ & $\mathrm{~N}$ & $\mathrm{Q}$ & 3 & ProTotal & 6.01 \\
\hline A & $\mathrm{N}$ & Q & 3 & PostDir & 1.8 \\
\hline$A$ & $\mathrm{~N}$ & $\mathrm{Q}$ & 3 & Ant & 2.45 \\
\hline$A$ & $\mathrm{~N}$ & $\mathrm{Q}$ & 3 & PostEsq & 1.76 \\
\hline A & $\mathrm{N}$ & Q & 3 & MICTotal & 16.64 \\
\hline$A$ & $\mathrm{~N}$ & Q & 3 & MicPostDir & 6.41 \\
\hline A & $\mathrm{N}$ & $\mathrm{Q}$ & 3 & MicAnt & 3.91 \\
\hline$A$ & $\mathrm{~N}$ & $\mathrm{Q}$ & 3 & MicPostEsq & 6.32 \\
\hline A & $\mathrm{N}$ & $T$ & 1 & ProTotal & 5.2 \\
\hline$A$ & $\mathrm{~N}$ & $T$ & 1 & PostDir & 1.58 \\
\hline A & $\mathrm{N}$ & $T$ & 1 & Ant & 1.98 \\
\hline$A$ & $\mathrm{~N}$ & $T$ & 1 & PostEsq & 1.64 \\
\hline A & $\mathrm{N}$ & $\mathrm{T}$ & 1 & MICTotal & 13.43 \\
\hline$A$ & $\mathrm{~N}$ & $T$ & 1 & MicPostDir & 5.12 \\
\hline$A$ & $\mathrm{~N}$ & $T$ & 1 & MicAnt & 3.05 \\
\hline$A$ & $\mathrm{~N}$ & $T$ & 1 & MicPostEsq & 5.26 \\
\hline$A$ & $\mathrm{~N}$ & $T$ & 2 & ProTotal & 5.19 \\
\hline A & $\mathrm{N}$ & $T$ & 2 & PostDir & 1.56 \\
\hline A & $\mathrm{N}$ & $T$ & 2 & Ant & 1.93 \\
\hline A & $\mathrm{N}$ & $T$ & 2 & PostEsq & 1.7 \\
\hline A & $\mathrm{N}$ & $T$ & 2 & MICTotal & 12.96 \\
\hline A & $\mathrm{N}$ & $T$ & 2 & MicPostDir & 5.89 \\
\hline$A$ & $\mathrm{~N}$ & $T$ & 2 & MicAnt & 1.31 \\
\hline A & $\mathrm{N}$ & $T$ & 2 & MicPostEsq & 5.76 \\
\hline A & $\mathrm{N}$ & $T$ & 3 & ProTotal & 4.98 \\
\hline$A$ & $\mathrm{~N}$ & $T$ & 3 & PostDir & 1.39 \\
\hline A & $\mathrm{N}$ & $T$ & 3 & Ant & 2.09 \\
\hline A & $\mathrm{N}$ & $T$ & 3 & PostEsq & 1.5 \\
\hline$A$ & $\mathrm{~N}$ & $T$ & 3 & MICTotal & 13.58 \\
\hline
\end{tabular}




\begin{tabular}{|c|c|c|c|c|c|c|}
\hline$A$ & $\mathrm{~N}$ & $\mathrm{~T}$ & 3 & MicPostDir & 5.36 & (continua) \\
\hline$A$ & $\mathrm{~N}$ & $\mathrm{~T}$ & 3 & MicAnt & 2.3 & \\
\hline A & $\mathrm{N}$ & $\mathrm{T}$ & 3 & MicPostEsq & 5.92 & \\
\hline$A$ & $\mathrm{~N}$ & $\mathrm{O}$ & 1 & ProTotal & 5.64 & \\
\hline A & $\mathrm{N}$ & $\mathrm{O}$ & 1 & PostDir & 1.9 & \\
\hline A & $\mathrm{N}$ & $\mathrm{O}$ & 1 & Ant & 1.8 & \\
\hline$A$ & $\mathrm{~N}$ & $\mathrm{O}$ & 1 & PostEsq & 1.94 & \\
\hline$A$ & $\mathrm{~N}$ & $\mathrm{O}$ & 1 & MICTotal & 16.07 & \\
\hline A & $\mathrm{N}$ & $\mathrm{O}$ & 1 & MicPostDir & 6.24 & \\
\hline$A$ & $\mathrm{~N}$ & $\mathrm{O}$ & 1 & MicAnt & 3.23 & \\
\hline A & $\mathrm{N}$ & $\mathrm{O}$ & 1 & MicPostEsq & 6.6 & \\
\hline$A$ & $\mathrm{~N}$ & $\mathrm{O}$ & 2 & ProTotal & 6.12 & \\
\hline$A$ & $\mathrm{~N}$ & $\mathrm{O}$ & 2 & PostDir & 1.97 & \\
\hline A & $\mathrm{N}$ & $\mathrm{O}$ & 2 & Ant & 2.14 & \\
\hline A & $\mathrm{N}$ & $\mathrm{O}$ & 2 & PostEsq & 2.01 & \\
\hline A & $\mathrm{N}$ & $\mathrm{O}$ & 2 & MICTotal & 15.28 & \\
\hline A & $\mathrm{N}$ & $\mathrm{O}$ & 2 & MicPostDir & 5.1 & \\
\hline$A$ & $\mathrm{~N}$ & $\mathrm{O}$ & 2 & MicAnt & 4.95 & \\
\hline$A$ & $\mathrm{~N}$ & $\mathrm{O}$ & 2 & MicPostEsq & 5.23 & \\
\hline A & $\mathrm{N}$ & $\mathrm{O}$ & 3 & ProTotal & 5.76 & \\
\hline$A$ & $\mathrm{~N}$ & $\mathrm{O}$ & 3 & PostDir & 1.85 & \\
\hline A & $\mathrm{N}$ & $\mathrm{O}$ & 3 & Ant & 2.01 & \\
\hline$A$ & $\mathrm{~N}$ & $\mathrm{O}$ & 3 & PostEsq & 1.9 & \\
\hline A & $\mathrm{N}$ & $\mathrm{O}$ & 3 & MICTotal & 16.47 & \\
\hline A & $\mathrm{N}$ & $\mathrm{O}$ & 3 & MicPostDir & 6 & \\
\hline A & $\mathrm{N}$ & $\mathrm{O}$ & 3 & MicAnt & 4.15 & \\
\hline A & $\mathrm{N}$ & $\mathrm{O}$ & 3 & MicPostEsq & 6.32 & \\
\hline A & 1 & $Q$ & 1 & ProTotal & 4.32 & \\
\hline$A$ & I & $\mathrm{Q}$ & 1 & PostDir & 1.73 & \\
\hline A & I & $Q$ & 1 & Ant & 0.77 & \\
\hline A & I & $Q$ & 1 & PostEsq & 1.82 & \\
\hline A & 1 & $Q$ & 1 & MICTotal & 17.94 & \\
\hline A & 1 & $Q$ & 1 & MicPostDir & 6.12 & \\
\hline A & I & $\mathrm{Q}$ & 1 & MicAnt & 5.47 & \\
\hline$A$ & I & $Q$ & 1 & MicPostEsq & 6.35 & \\
\hline A & I & $Q$ & 2 & ProTotal & 4.52 & \\
\hline A & 1 & $Q$ & 2 & PostDir & 1.63 & \\
\hline$A$ & I & $Q$ & 2 & Ant & 1.24 & \\
\hline$A$ & I & $Q$ & 2 & PostEsq & 1.65 & \\
\hline A & 1 & $Q$ & 2 & MICTotal & 17.14 & \\
\hline A & 1 & $Q$ & 2 & MicPostDir & 6.03 & \\
\hline A & I & $\mathrm{Q}$ & 2 & MicAnt & 4.77 & \\
\hline$A$ & 1 & $Q$ & 2 & MicPostEsq & 6.34 & \\
\hline A & I & $Q$ & 3 & ProTotal & 4.26 & \\
\hline A & 1 & $Q$ & 3 & PostDir & 1.58 & \\
\hline A & 1 & $Q$ & 3 & Ant & 1.16 & \\
\hline A & 1 & $Q$ & 3 & PostEsq & 1.52 & \\
\hline A & I & Q & 3 & MICTotal & 17.89 & (continua) \\
\hline
\end{tabular}




\begin{tabular}{|c|c|c|c|c|c|c|}
\hline A & 1 & $\mathrm{Q}$ & 3 & MicPostDir & 6.23 & (continua) \\
\hline$A$ & $\mathrm{I}$ & $Q$ & 3 & MicAnt & 5.25 & \\
\hline A & I & $Q$ & 3 & MicPostEsq & 6.41 & \\
\hline A & I & $\mathrm{T}$ & 1 & ProTotal & 3.99 & \\
\hline A & 1 & $\mathrm{~T}$ & 1 & PostDir & 1.4 & \\
\hline A & 1 & $\mathrm{~T}$ & 1 & Ant & 1.02 & \\
\hline$A$ & I & $\mathrm{T}$ & 1 & PostEsq & 1.57 & \\
\hline$A$ & I & $\mathrm{T}$ & 1 & MICTotal & 15.93 & \\
\hline A & $\mathrm{I}$ & $\mathrm{T}$ & 1 & MicPostDir & 5.96 & \\
\hline$A$ & I & $\mathrm{T}$ & 1 & MicAnt & 3.65 & \\
\hline A & I & $\mathrm{T}$ & 1 & MicPostEsq & 6.32 & \\
\hline$A$ & 1 & $\mathrm{~T}$ & 2 & ProTotal & 4.15 & \\
\hline$A$ & 1 & $\mathrm{~T}$ & 2 & PostDir & 1.87 & \\
\hline A & 1 & $\mathrm{~T}$ & 2 & Ant & 0.69 & \\
\hline A & 1 & $\mathrm{~T}$ & 2 & PostEsq & 1.59 & \\
\hline A & I & $\mathrm{T}$ & 2 & MICTotal & 15.75 & \\
\hline A & 1 & $\mathrm{~T}$ & 2 & MicPostDir & 5.79 & \\
\hline A & I & $\mathrm{T}$ & 2 & MicAnt & 3.44 & \\
\hline$A$ & I & $\mathrm{T}$ & 2 & MicPostEsq & 6.52 & \\
\hline A & I & $\mathrm{T}$ & 3 & ProTotal & 4.12 & \\
\hline$A$ & I & $\mathrm{T}$ & 3 & PostDir & 1.42 & \\
\hline A & 1 & $\mathrm{~T}$ & 3 & Ant & 0.83 & \\
\hline$A$ & I & $\mathrm{T}$ & 3 & PostEsq & 1.87 & \\
\hline A & 1 & $\mathrm{~T}$ & 3 & MICTotal & 16.01 & \\
\hline A & $\mathrm{I}$ & $\mathrm{T}$ & 3 & MicPostDir & 6.13 & \\
\hline A & 1 & $\mathrm{~T}$ & 3 & MicAnt & 3.88 & \\
\hline$A$ & 1 & $\mathrm{~T}$ & 3 & MicPostEsq & 6 & \\
\hline A & 1 & $\mathrm{O}$ & 1 & ProTotal & 5.19 & \\
\hline A & 1 & $\mathrm{O}$ & 1 & PostDir & 1.8 & \\
\hline A & $\mathrm{I}$ & $\mathrm{O}$ & 1 & Ant & 1.48 & \\
\hline A & I & $\mathrm{O}$ & 1 & PostEsq & 1.91 & \\
\hline A & I & $\mathrm{O}$ & 1 & MICTotal & 17.04 & \\
\hline$A$ & 1 & $\mathrm{O}$ & 1 & MicPostDir & 6.3 & \\
\hline A & I & $\mathrm{O}$ & 1 & MicAnt & 4.6 & \\
\hline A & 1 & $\mathrm{O}$ & 1 & MicPostEsq & 6.14 & \\
\hline$A$ & I & $\mathrm{O}$ & 2 & ProTotal & 5.32 & \\
\hline A & 1 & $\mathrm{O}$ & 2 & PostDir & 1.85 & \\
\hline A & I & $\mathrm{O}$ & 2 & Ant & 1.51 & \\
\hline$A$ & I & $\mathrm{O}$ & 2 & PostEsq & 1.96 & \\
\hline A & 1 & $\mathrm{O}$ & 2 & MICTotal & 17.04 & \\
\hline$A$ & 1 & $\mathrm{O}$ & 2 & MicPostDir & 6.2 & \\
\hline A & I & $\mathrm{O}$ & 2 & MicAnt & 4.54 & \\
\hline A & I & $\mathrm{O}$ & 2 & MicPostEsq & 6.3 & \\
\hline A & I & $\mathrm{O}$ & 3 & ProTotal & 5.46 & \\
\hline$A$ & I & $\mathrm{O}$ & 3 & PostDir & 2 & \\
\hline A & I & 0 & 3 & Ant & 1.59 & \\
\hline A & I & $\mathrm{O}$ & 3 & PostEsq & 1.87 & \\
\hline A & 1 & $\mathrm{O}$ & 3 & MICTotal & 17.68 & (continua) \\
\hline
\end{tabular}




\begin{tabular}{|c|c|c|c|c|c|c|}
\hline A & 1 & 0 & 3 & MicPostDir & 6.78 & (continua) \\
\hline$A$ & I & $\mathrm{O}$ & 3 & MicAnt & 4.31 & \\
\hline$A$ & 1 & $\mathrm{O}$ & 3 & MicPostEsq & 6.59 & \\
\hline$F$ & $\mathrm{~N}$ & $\mathrm{Q}$ & 1 & ProTotal & 3.12 & \\
\hline $\mathrm{F}$ & $\mathrm{N}$ & Q & 1 & PostDir & 0.98 & \\
\hline $\mathrm{F}$ & $\mathrm{N}$ & Q & 1 & Ant & 1.24 & \\
\hline $\mathrm{F}$ & $\mathrm{N}$ & $Q$ & 1 & PostEsq & 0.9 & \\
\hline$F$ & $\mathrm{~N}$ & Q & 1 & MICTotal & 14.67 & \\
\hline$F$ & $\mathrm{~N}$ & Q & 1 & MicPostDir & 5.86 & \\
\hline $\mathrm{F}$ & $\mathrm{N}$ & $Q$ & 1 & MicAnt & 2.91 & \\
\hline $\mathrm{F}$ & $\mathrm{N}$ & Q & 1 & MicPostEsq & 5.9 & \\
\hline $\mathrm{F}$ & $\mathrm{N}$ & $Q$ & 2 & ProTotal & 3.65 & \\
\hline $\mathrm{F}$ & $\mathrm{N}$ & $\mathrm{Q}$ & 2 & PostDir & 0.9 & \\
\hline $\mathrm{F}$ & $\mathrm{N}$ & $\mathrm{Q}$ & 2 & Ant & 1.79 & \\
\hline $\mathrm{F}$ & $\mathrm{N}$ & Q & 2 & PostEsq & 0.96 & \\
\hline $\mathrm{F}$ & $\mathrm{N}$ & $Q$ & 2 & MICTotal & 15.33 & \\
\hline$F$ & $\mathrm{~N}$ & Q & 2 & MicPostDir & 6.7 & \\
\hline $\mathrm{F}$ & $\mathrm{N}$ & $Q$ & 2 & MicAnt & 1.68 & \\
\hline $\mathrm{F}$ & $\mathrm{N}$ & $Q$ & 2 & MicPostEsq & 6.95 & \\
\hline $\mathrm{F}$ & $\mathrm{N}$ & Q & 3 & ProTotal & 3.58 & \\
\hline$F$ & $\mathrm{~N}$ & $Q$ & 3 & PostDir & 0.89 & \\
\hline$F$ & $\mathrm{~N}$ & Q & 3 & Ant & 1.78 & \\
\hline $\mathrm{F}$ & $\mathrm{N}$ & Q & 3 & PostEsq & 0.91 & \\
\hline $\mathrm{F}$ & $\mathrm{N}$ & Q & 3 & MICTotal & 13.41 & \\
\hline $\mathrm{F}$ & $\mathrm{N}$ & $Q$ & 3 & MicPostDir & 4.96 & \\
\hline $\mathrm{F}$ & $\mathrm{N}$ & Q & 3 & MicAnt & 3.26 & \\
\hline $\mathrm{F}$ & $\mathrm{N}$ & $Q$ & 3 & MicPostEsq & 5.19 & \\
\hline $\mathrm{F}$ & $\mathrm{N}$ & $\mathrm{T}$ & 1 & ProTotal & 3.49 & \\
\hline $\mathrm{F}$ & $\mathrm{N}$ & $\mathrm{T}$ & 1 & PostDir & 0.9 & \\
\hline $\mathrm{F}$ & $\mathrm{N}$ & $\mathrm{T}$ & 1 & Ant & 1.73 & \\
\hline $\mathrm{F}$ & $\mathrm{N}$ & $\mathrm{T}$ & 1 & PostEsq & 0.86 & \\
\hline $\mathrm{F}$ & $\mathrm{N}$ & $\mathrm{T}$ & 1 & MICTotal & 21.15 & \\
\hline $\mathrm{F}$ & $\mathrm{N}$ & $\mathrm{T}$ & 1 & MicPostDir & 8.94 & \\
\hline $\mathrm{F}$ & $\mathrm{N}$ & $\mathrm{T}$ & 1 & MicAnt & 3.61 & \\
\hline$F$ & $\mathrm{~N}$ & $\mathrm{~T}$ & 1 & MicPostEsq & 8.6 & \\
\hline$F$ & $\mathrm{~N}$ & $\mathrm{~T}$ & 2 & ProTotal & 3.67 & \\
\hline $\mathrm{F}$ & $\mathrm{N}$ & $\mathrm{T}$ & 2 & PostDir & 1.1 & \\
\hline $\mathrm{F}$ & $\mathrm{N}$ & $\mathrm{T}$ & 2 & Ant & 1.36 & \\
\hline $\mathrm{F}$ & $\mathrm{N}$ & $\mathrm{T}$ & 2 & PostEsq & 1.21 & \\
\hline $\mathrm{F}$ & $\mathrm{N}$ & $\mathrm{T}$ & 2 & MICTotal & 20.30 & \\
\hline $\mathrm{F}$ & $\mathrm{N}$ & $\mathrm{T}$ & 2 & MicPostDir & 8.67 & \\
\hline $\mathrm{F}$ & $\mathrm{N}$ & $\mathrm{T}$ & 2 & MicAnt & 2.63 & \\
\hline$F$ & $\mathrm{~N}$ & $\mathrm{~T}$ & 2 & MicPostEsq & 9 & \\
\hline $\mathrm{F}$ & $\mathrm{N}$ & $\mathrm{T}$ & 3 & ProTotal & 3.69 & \\
\hline $\mathrm{F}$ & $\mathrm{N}$ & $\mathrm{T}$ & 3 & PostDir & 1.02 & \\
\hline $\mathrm{F}$ & $\mathrm{N}$ & $\mathrm{T}$ & 3 & Ant & 1.37 & \\
\hline$F$ & $\mathrm{~N}$ & $T$ & 3 & PostEsq & 1.3 & \\
\hline $\mathrm{F}$ & $\mathrm{N}$ & $\mathrm{T}$ & 3 & MICTotal & 21.18 & (continua) \\
\hline
\end{tabular}




\begin{tabular}{|c|c|c|c|c|c|c|}
\hline $\mathrm{F}$ & $\mathrm{N}$ & $\mathrm{T}$ & 3 & MicPostDir & 8.5 & (continua) \\
\hline $\mathrm{F}$ & $\mathrm{N}$ & $\mathrm{T}$ & 3 & MicAnt & 3.96 & \\
\hline $\mathrm{F}$ & $\mathrm{N}$ & $\mathrm{T}$ & 3 & MicPostEsq & 8.72 & \\
\hline $\mathrm{F}$ & $\mathrm{N}$ & $\mathrm{O}$ & 1 & ProTotal & 3.85 & \\
\hline $\mathrm{F}$ & $\mathrm{N}$ & $\mathrm{O}$ & 1 & PostDir & 1 & \\
\hline $\mathrm{F}$ & $\mathrm{N}$ & $\mathrm{O}$ & 1 & Ant & 1.61 & \\
\hline $\mathrm{F}$ & $\mathrm{N}$ & $\mathrm{O}$ & 1 & PostEsq & 1.24 & \\
\hline $\mathrm{F}$ & $\mathrm{N}$ & $\mathrm{O}$ & 1 & MICTotal & 18.55 & \\
\hline $\mathrm{F}$ & $\mathrm{N}$ & $\mathrm{O}$ & 1 & MicPostDir & 7.65 & \\
\hline $\mathrm{F}$ & $\mathrm{N}$ & $\mathrm{O}$ & 1 & MicAnt & 3.1 & \\
\hline $\mathrm{F}$ & $\mathrm{N}$ & $\mathrm{O}$ & 1 & MicPostEsq & 7.8 & \\
\hline $\mathrm{F}$ & $\mathrm{N}$ & $\mathrm{O}$ & 2 & ProTotal & 3.62 & \\
\hline $\mathrm{F}$ & $\mathrm{N}$ & $\mathrm{O}$ & 2 & PostDir & 1.03 & \\
\hline$F$ & $\mathrm{~N}$ & $\mathrm{O}$ & 2 & Ant & 1.39 & \\
\hline$F$ & $\mathrm{~N}$ & $\mathrm{O}$ & 2 & PostEsq & 1.2 & \\
\hline $\mathrm{F}$ & $\mathrm{N}$ & $\mathrm{O}$ & 2 & MICTotal & 17.29 & \\
\hline $\mathrm{F}$ & $\mathrm{N}$ & $\mathrm{O}$ & 2 & MicPostDir & 6.99 & \\
\hline $\mathrm{F}$ & $\mathrm{N}$ & $\mathrm{O}$ & 2 & MicAnt & 3.48 & \\
\hline$F$ & $\mathrm{~N}$ & $\mathrm{O}$ & 2 & MicPostEsq & 6.82 & \\
\hline $\mathrm{F}$ & $\mathrm{N}$ & $\mathrm{O}$ & 3 & ProTotal & 3.81 & \\
\hline $\mathrm{F}$ & $\mathrm{N}$ & $\mathrm{O}$ & 3 & PostDir & 1 & \\
\hline$F$ & $\mathrm{~N}$ & $\mathrm{O}$ & 3 & Ant & 1.3 & \\
\hline $\mathrm{F}$ & $\mathrm{N}$ & $\mathrm{O}$ & 3 & PostEsq & 1.51 & \\
\hline$F$ & $\mathrm{~N}$ & $\mathrm{O}$ & 3 & MICTotal & 14.42 & \\
\hline $\mathrm{F}$ & $\mathrm{N}$ & $\mathrm{O}$ & 3 & MicPostDir & 5.1 & \\
\hline $\mathrm{F}$ & $\mathrm{N}$ & $\mathrm{O}$ & 3 & MicAnt & 4.36 & \\
\hline$F$ & $\mathrm{~N}$ & $\mathrm{O}$ & 3 & MicPostEsq & 4.96 & \\
\hline$F$ & I & Q & 1 & ProTotal & 2.99 & \\
\hline$F$ & I & $\mathrm{Q}$ & 1 & PostDir & 0.87 & \\
\hline $\mathrm{F}$ & 1 & Q & 1 & Ant & 1.19 & \\
\hline $\mathrm{F}$ & I & Q & 1 & PostEsq & 0.93 & \\
\hline$F$ & I & Q & 1 & MICTotal & 16.97 & \\
\hline$F$ & I & $\bar{Q}$ & 1 & MicPostDir & 6.68 & \\
\hline $\mathrm{F}$ & I & Q & 1 & MicAnt & 3.79 & \\
\hline $\mathrm{F}$ & 1 & $Q$ & 1 & MicPostEsq & 6.5 & \\
\hline$F$ & $\mathrm{I}$ & $\mathrm{Q}$ & 2 & ProTotal & 3.51 & \\
\hline$F$ & I & $\mathrm{Q}$ & 2 & PostDir & 1.12 & \\
\hline$F$ & I & Q & 2 & Ant & 1.14 & \\
\hline $\mathrm{F}$ & $\mathrm{I}$ & $Q$ & 2 & PostEsq & 1.25 & \\
\hline $\mathrm{F}$ & 1 & Q & 2 & MICTotal & 20.73 & \\
\hline $\mathrm{F}$ & I & Q & 2 & MicPostDir & 8.97 & \\
\hline$F$ & I & $\mathrm{Q}$ & 2 & MicAnt & 3.2 & \\
\hline $\mathrm{F}$ & I & $Q$ & 2 & MicPostEsq & 8.56 & \\
\hline$F$ & $\mathrm{I}$ & $\mathrm{Q}$ & 3 & ProTotal & 3.29 & \\
\hline $\mathrm{F}$ & 1 & $\mathrm{Q}$ & 3 & PostDir & 1.16 & \\
\hline$F$ & I & Q & 3 & Ant & 0.88 & \\
\hline $\mathrm{F}$ & I & $\mathrm{Q}$ & 3 & PostEsq & 1.25 & \\
\hline $\mathrm{F}$ & I & $Q$ & 3 & MICTotal & 13.46 & (continua) \\
\hline
\end{tabular}




\begin{tabular}{|c|c|c|c|c|c|c|}
\hline$F$ & I & $Q$ & 3 & MicPostDir & 5.9 & (continua) \\
\hline $\mathrm{F}$ & I & $\bar{Q}$ & 3 & MicAnt & 2.15 & \\
\hline $\mathrm{F}$ & I & Q & 3 & MicPostEsq & 5.41 & \\
\hline $\mathrm{F}$ & I & $\bar{T}$ & 1 & ProTotal & 3.66 & \\
\hline $\mathrm{F}$ & I & $\mathrm{T}$ & 1 & PostDir & 1.03 & \\
\hline$F$ & I & $\mathrm{T}$ & 1 & Ant & 1.39 & \\
\hline $\mathrm{F}$ & I & $\mathrm{T}$ & 1 & PostEsq & 1.24 & \\
\hline $\mathrm{F}$ & I & $\mathrm{T}$ & 1 & MICTotal & 20.39 & \\
\hline $\mathrm{F}$ & 1 & $\mathrm{~T}$ & 1 & MicPostDir & 8.7 & \\
\hline $\mathrm{F}$ & $\mathrm{I}$ & $\mathrm{T}$ & 1 & MicAnt & 2.92 & \\
\hline $\mathrm{F}$ & I & $\mathrm{T}$ & 1 & MicPostEsq & 8.77 & \\
\hline $\mathrm{F}$ & I & $\mathrm{T}$ & 2 & ProTotal & 4.02 & \\
\hline $\mathrm{F}$ & I & $\mathrm{T}$ & 2 & PostDir & 1.3 & \\
\hline$F$ & I & $\mathrm{T}$ & 2 & Ant & 1.26 & \\
\hline$F$ & $\mathrm{I}$ & $\mathrm{T}$ & 2 & PostEsq & 1.46 & \\
\hline $\mathrm{F}$ & I & $\mathrm{T}$ & 2 & MICTotal & 20.28 & \\
\hline$F$ & I & $\mathrm{T}$ & 2 & MicPostDir & 8.85 & \\
\hline $\mathrm{F}$ & I & $\mathrm{T}$ & 2 & MicAnt & 3.43 & \\
\hline$F$ & I & $\mathrm{T}$ & 2 & MicPostEsq & 8 & \\
\hline $\mathrm{F}$ & 1 & $\mathrm{~T}$ & 3 & ProTotal & 4.12 & \\
\hline $\mathrm{F}$ & I & $\mathrm{T}$ & 3 & PostDir & 1.16 & \\
\hline $\mathrm{F}$ & 1 & $\mathrm{~T}$ & 3 & Ant & 1.46 & \\
\hline$F$ & I & $\mathrm{T}$ & 3 & PostEsq & 1.5 & \\
\hline $\mathrm{F}$ & 1 & $\mathrm{~T}$ & 3 & MICTotal & 19.87 & \\
\hline $\mathrm{F}$ & I & $\mathrm{T}$ & 3 & MicPostDir & 8.55 & \\
\hline $\mathrm{F}$ & I & $\mathrm{T}$ & 3 & MicAnt & 2.62 & \\
\hline $\mathrm{F}$ & I & $\mathrm{T}$ & 3 & MicPostEsq & 8.7 & \\
\hline$F$ & 1 & $\mathrm{O}$ & 1 & ProTotal & 4.15 & \\
\hline $\mathrm{F}$ & I & $\mathrm{O}$ & 1 & PostDir & 1.3 & \\
\hline $\mathrm{F}$ & I & $\mathrm{O}$ & 1 & Ant & 1.4 & \\
\hline $\mathrm{F}$ & I & $\mathrm{O}$ & 1 & PostEsq & 1.45 & \\
\hline$F$ & I & $\mathrm{O}$ & 1 & MICTotal & 22.61 & \\
\hline $\mathrm{F}$ & I & $\mathrm{O}$ & 1 & MicPostDir & 9.32 & \\
\hline $\mathrm{F}$ & I & $\mathrm{O}$ & 1 & MicAnt & 4.09 & \\
\hline $\mathrm{F}$ & 1 & $\mathrm{O}$ & 1 & MicPostEsq & 9.2 & \\
\hline$F$ & I & $\mathrm{O}$ & 2 & ProTotal & 5.09 & \\
\hline $\mathrm{F}$ & 1 & $\mathrm{O}$ & 2 & PostDir & 1.6 & \\
\hline $\mathrm{F}$ & I & $\mathrm{O}$ & 2 & Ant & 1.78 & \\
\hline $\mathrm{F}$ & I & $\mathrm{O}$ & 2 & PostEsq & 1.71 & \\
\hline $\mathrm{F}$ & I & $\mathrm{O}$ & 2 & MICTotal & 16.89 & \\
\hline $\mathrm{F}$ & I & $\mathrm{O}$ & 2 & MicPostDir & 6.65 & \\
\hline $\mathrm{F}$ & I & $\mathrm{O}$ & 2 & MicAnt & 3.93 & \\
\hline$F$ & I & $\mathrm{O}$ & 2 & MicPostEsq & 6.31 & \\
\hline$F$ & I & $\mathrm{O}$ & 3 & ProTotal & 4.88 & \\
\hline $\mathrm{F}$ & I & $\mathrm{O}$ & 3 & PostDir & 1.36 & \\
\hline$F$ & I & $\mathrm{O}$ & 3 & Ant & 2.03 & \\
\hline $\mathrm{F}$ & I & $\mathrm{O}$ & 3 & PostEsq & 1.49 & \\
\hline $\mathrm{F}$ & I & $\mathrm{O}$ & 3 & MICTotal & 18.44 & (continua) \\
\hline
\end{tabular}




\begin{tabular}{|c|c|c|c|c|c|}
\hline $\mathrm{F}$ & $\mathrm{I}$ & $\mathrm{O}$ & 3 & MicPostDir & 6.99 \\
\hline $\mathrm{F}$ & $\mathrm{I}$ & $\mathrm{O}$ & 3 & MicAnt & 4.31 \\
\hline $\mathrm{F}$ & $\mathrm{I}$ & $\mathrm{O}$ & 3 & MicPostEsq & 7.14 \\
\hline
\end{tabular}


APENDICE C- Quadro de médias das áreas em lateralidade direita do modelo superior

\begin{tabular}{|c|c|c|c|c|c|}
\hline $\begin{array}{l}\text { Forma } \\
\text { Oclusal }\end{array}$ & Origem & Arcada & Modelo & Tratamento & Area \\
\hline A & $\mathrm{N}$ & Q & 1 & LDTotal & 15,89 \\
\hline A & $\mathrm{N}$ & Q & 1 & LDTrab & 10,16 \\
\hline A & $\mathrm{N}$ & $\mathrm{Q}$ & 1 & LDBal & 5,73 \\
\hline$A$ & $\mathrm{~N}$ & Q & 1 & MICTotal & 17,38 \\
\hline A & $\mathrm{N}$ & $\mathrm{Q}$ & 1 & MicD & 8,64 \\
\hline A & $\mathrm{N}$ & $\mathrm{Q}$ & 1 & MicE & 8,74 \\
\hline A & $\mathrm{N}$ & Q & 2 & LDTotal & 15,97 \\
\hline$A$ & $\mathrm{~N}$ & Q & 2 & LDTrab & 10,23 \\
\hline A & $\mathrm{N}$ & Q & 2 & LDBal & 5,74 \\
\hline A & $\mathrm{N}$ & $\mathrm{Q}$ & 2 & MICTotal & 15,51 \\
\hline A & $\mathrm{N}$ & $\mathrm{Q}$ & 2 & MicD & 7,39 \\
\hline A & $\mathrm{N}$ & $\mathrm{Q}$ & 2 & MicE & 8,12 \\
\hline$A$ & $\mathrm{~N}$ & $\mathrm{Q}$ & 3 & LDTotal & 15,99 \\
\hline A & $\mathrm{N}$ & $\bar{Q}$ & 3 & LDTrab & 10,3 \\
\hline A & $\mathrm{N}$ & Q & 3 & LDBal & 5,69 \\
\hline$A$ & $\mathrm{~N}$ & Q & 3 & MICTotal & 18,69 \\
\hline A & $\mathrm{N}$ & Q & 3 & MicD & 9,32 \\
\hline A & $\mathrm{N}$ & Q & 3 & MicE & 9,37 \\
\hline$A$ & $\mathrm{~N}$ & $T$ & 1 & LDTotal & 14,43 \\
\hline$A$ & $\mathrm{~N}$ & $T$ & 1 & LDTrab & 11,2 \\
\hline A & $\mathrm{N}$ & $T$ & 1 & LDBal & 3,23 \\
\hline $\mathrm{A}$ & $\mathrm{N}$ & $T$ & 1 & MICTotal & 14,39 \\
\hline A & $\mathrm{N}$ & $T$ & 1 & MicD & 7 \\
\hline$A$ & $\mathrm{~N}$ & $T$ & 1 & MicE & 7,39 \\
\hline$A$ & $\mathrm{~N}$ & $T$ & 2 & LDTotal & 14,15 \\
\hline A & $\mathrm{N}$ & $T$ & 2 & LDTrab & 11 \\
\hline A & $\mathrm{N}$ & $T$ & 2 & LDBal & 3,15 \\
\hline A & $\mathrm{N}$ & $T$ & 2 & MICTotal & 13,55 \\
\hline A & $\mathrm{N}$ & $T$ & 2 & MicD & 6,81 \\
\hline A & $\mathrm{N}$ & $T$ & 2 & MicE & 6,74 \\
\hline A & $\mathrm{N}$ & $T$ & 3 & LDTotal & 14,47 \\
\hline A & $\mathrm{N}$ & $T$ & 3 & LDTrab & 11,02 \\
\hline $\mathrm{A}$ & $\mathrm{N}$ & $T$ & 3 & LDBal & 3,45 \\
\hline $\mathrm{A}$ & $\mathrm{N}$ & $T$ & 3 & MICTotal & 15,16 \\
\hline A & $\mathrm{N}$ & $T$ & 3 & MicD & 7,78 \\
\hline$A$ & $\mathrm{~N}$ & $T$ & 3 & MicE & 7,38 \\
\hline A & $\mathrm{N}$ & $\mathrm{O}$ & 1 & LDTotal & 16,8 \\
\hline A & $\mathrm{N}$ & 0 & 1 & LDTrab & 11,98 \\
\hline A & $\mathrm{N}$ & $\mathrm{O}$ & 1 & LDBal & 4,82 \\
\hline A & $\mathrm{N}$ & $\mathrm{O}$ & 1 & MICTotal & 17,25 \\
\hline A & $\mathrm{N}$ & $\mathrm{O}$ & 1 & MicD & 8,06 \\
\hline A & $\mathrm{N}$ & $\mathrm{O}$ & 1 & MicE & 9,19 \\
\hline A & $\mathrm{N}$ & $\mathrm{O}$ & 2 & LDTotal & 17,46 \\
\hline A & $\mathrm{N}$ & $\mathrm{O}$ & 2 & LDTrab & 12,56 \\
\hline
\end{tabular}




\begin{tabular}{|c|c|c|c|c|c|c|}
\hline$A$ & $\mathrm{~N}$ & $\mathrm{O}$ & 2 & LDBal & 4,9 & (continua) \\
\hline$A$ & $\mathrm{~N}$ & $\mathrm{O}$ & 2 & MICTotal & 16,02 & \\
\hline$A$ & $\mathrm{~N}$ & 0 & 2 & MicD & 7,68 & \\
\hline$A$ & $\mathrm{~N}$ & $\mathrm{O}$ & 2 & MicE & 8,34 & \\
\hline A & $\mathrm{N}$ & $\mathrm{O}$ & 3 & LDTotal & 17,78 & \\
\hline$A$ & $\mathrm{~N}$ & $\mathrm{O}$ & 3 & LDTrab & 12,63 & \\
\hline$A$ & $\mathrm{~N}$ & $\mathrm{O}$ & 3 & LDBal & 5,15 & \\
\hline$A$ & $\mathrm{~N}$ & $\mathrm{O}$ & 3 & MICTotal & 18,64 & \\
\hline$A$ & $\mathrm{~N}$ & $\mathrm{O}$ & 3 & MicD & 9,31 & \\
\hline$A$ & $\mathrm{~N}$ & $\mathrm{O}$ & 3 & MicE & 9,33 & \\
\hline A & I & Q & 1 & LDTotal & 17,69 & \\
\hline$A$ & I & Q & 1 & LDTrab & 13,68 & \\
\hline$A$ & 1 & $Q$ & 1 & LDBal & 4,01 & \\
\hline$A$ & I & $Q$ & 1 & MICTotal & 19,25 & \\
\hline$A$ & I & $Q$ & 1 & MicD & 10,01 & \\
\hline$A$ & I & $\mathrm{Q}$ & 1 & MicE & 9,24 & \\
\hline A & I & $Q$ & 2 & LDTotal & 17,5 & \\
\hline$A$ & 1 & $Q$ & 2 & LDTrab & 13,62 & \\
\hline$A$ & I & $Q$ & 2 & LDBal & 3,88 & \\
\hline A & I & $\bar{Q}$ & 2 & MICTotal & 20,11 & \\
\hline$A$ & I & $Q$ & 2 & MicD & 9,99 & \\
\hline$A$ & 1 & $Q$ & 2 & MicE & 10,12 & \\
\hline$A$ & I & $Q$ & 3 & LDTotal & 18,06 & \\
\hline$A$ & 1 & $Q$ & 3 & LDTrab & 14,3 & \\
\hline$A$ & I & $\mathrm{Q}$ & 3 & LDBal & 3,76 & \\
\hline$A$ & I & Q & 3 & MICTotal & 20,57 & \\
\hline$A$ & I & $Q$ & 3 & MicD & 10,03 & \\
\hline$A$ & 1 & Q & 3 & MicE & 10,54 & \\
\hline$A$ & I & $\mathrm{T}$ & 1 & LDTotal & 16,32 & \\
\hline$A$ & I & $T$ & 1 & LDTrab & 11,65 & \\
\hline A & I & $\mathrm{T}$ & 1 & LDBal & 4,67 & \\
\hline$A$ & I & $\mathrm{T}$ & 1 & MICTotal & 18,01 & \\
\hline$A$ & $\mathrm{I}$ & $T$ & 1 & MicD & 9,32 & \\
\hline A & I & $T$ & 1 & MicE & 8,69 & \\
\hline$A$ & $\mathrm{I}$ & $T$ & 2 & LDTotal & 16,58 & \\
\hline$A$ & I & $\mathrm{T}$ & 2 & LDTrab & 12 & \\
\hline$A$ & 1 & $T$ & 2 & LDBal & 4,58 & \\
\hline$A$ & I & $\mathrm{T}$ & 2 & MICTotal & 17,47 & \\
\hline$A$ & I & $\mathrm{T}$ & 2 & MicD & 9 & \\
\hline$A$ & I & $\mathrm{T}$ & 2 & MicE & 8,47 & \\
\hline$A$ & I & $\mathrm{T}$ & 3 & LDTotal & 16,6 & \\
\hline$A$ & I & $\mathrm{T}$ & 3 & LDTrab & 12,03 & \\
\hline$A$ & I & $T$ & 3 & LDBal & 4,57 & \\
\hline$A$ & I & $\mathrm{T}$ & 3 & MICTotal & 18,13 & \\
\hline$A$ & I & $\mathrm{T}$ & 3 & MicD & 8,98 & \\
\hline$A$ & 1 & $T$ & 3 & MicE & 9,15 & \\
\hline$A$ & I & $\mathrm{O}$ & 1 & LDTotal & 17,89 & \\
\hline$A$ & I & 0 & 1 & LDTrab & 13,15 & (continua) \\
\hline
\end{tabular}




\begin{tabular}{|c|c|c|c|c|c|c|}
\hline$A$ & I & $\mathrm{O}$ & 1 & LDBal & 4,74 & (continua) \\
\hline$A$ & I & $\mathrm{O}$ & 1 & MICTotal & 18,27 & \\
\hline$A$ & I & 0 & 1 & MicD & 9,12 & \\
\hline$A$ & I & $\mathrm{O}$ & 1 & MicE & 9,15 & \\
\hline A & I & $\mathrm{O}$ & 2 & LDTotal & 17,9 & \\
\hline$A$ & I & $\mathrm{O}$ & 2 & LDTrab & 13,02 & \\
\hline$A$ & I & $\mathrm{O}$ & 2 & LDBal & 4,88 & \\
\hline$A$ & I & $\mathrm{O}$ & 2 & MICTotal & 18,17 & \\
\hline$A$ & 1 & $\mathrm{O}$ & 2 & MicD & 8,86 & \\
\hline$A$ & I & $\mathrm{O}$ & 2 & MicE & 9,31 & \\
\hline A & I & $\mathrm{O}$ & 3 & LDTotal & 17,8 & \\
\hline$A$ & I & $\mathrm{O}$ & 3 & LDTrab & 12,98 & \\
\hline$A$ & 1 & $\mathrm{O}$ & 3 & LDBal & 4,82 & \\
\hline$A$ & I & $\mathrm{O}$ & 3 & MICTotal & 18,04 & \\
\hline$A$ & I & $\mathrm{O}$ & 3 & MicD & 8,87 & \\
\hline$A$ & I & $\mathrm{O}$ & 3 & MicE & 9,17 & \\
\hline $\mathrm{F}$ & $\mathrm{N}$ & $Q$ & 1 & LDTotal & 10,1 & \\
\hline$F$ & $\mathrm{~N}$ & $Q$ & 1 & LDTrab & 8,52 & \\
\hline$F$ & $\mathrm{~N}$ & $Q$ & 1 & LDBal & 1,58 & \\
\hline $\mathrm{F}$ & $\mathrm{N}$ & $\bar{Q}$ & 1 & MICTotal & 18,38 & \\
\hline $\mathrm{F}$ & $\bar{N}$ & $Q$ & 1 & MicD & 9,02 & \\
\hline $\mathrm{F}$ & $\mathrm{N}$ & $Q$ & 1 & MicE & 9,36 & \\
\hline$F$ & $\mathrm{~N}$ & $Q$ & 2 & LDTotal & 10 & \\
\hline $\mathrm{F}$ & $\mathrm{N}$ & $Q$ & 2 & LDTrab & 8,14 & \\
\hline $\mathrm{F}$ & $\mathrm{N}$ & $\mathrm{Q}$ & 2 & LDBal & 1,86 & \\
\hline $\mathrm{F}$ & $\mathrm{N}$ & $Q$ & 2 & MICTotal & 21,26 & \\
\hline$F$ & $\mathrm{~N}$ & $Q$ & 2 & MicD & 10,62 & \\
\hline $\mathrm{F}$ & $\mathrm{N}$ & Q & 2 & MicE & 10,64 & \\
\hline $\mathrm{F}$ & $\mathrm{N}$ & $\mathrm{Q}$ & 3 & LDTotal & 9,88 & \\
\hline$F$ & $\mathrm{~N}$ & Q & 3 & LDTrab & 7,76 & \\
\hline $\mathrm{F}$ & $\mathrm{N}$ & $Q$ & 3 & LDBal & 2,12 & \\
\hline$F$ & $\mathrm{~N}$ & $Q$ & 3 & MICTotal & 16,21 & \\
\hline $\mathrm{F}$ & $\mathrm{N}$ & $\bar{Q}$ & 3 & MicD & 7,98 & \\
\hline $\mathrm{F}$ & $\mathrm{N}$ & Q & 3 & MicE & 8,23 & \\
\hline $\mathrm{F}$ & $\mathrm{N}$ & $\mathrm{T}$ & 1 & LDTotal & 11,9 & \\
\hline$F$ & $\mathrm{~N}$ & $\mathrm{~T}$ & 1 & LDTrab & 8,47 & \\
\hline $\mathrm{F}$ & $\mathrm{N}$ & $T$ & 1 & LDBal & 3,43 & \\
\hline $\mathrm{F}$ & $\mathrm{N}$ & $\mathrm{T}$ & 1 & MICTotal & 23,02 & \\
\hline $\mathrm{F}$ & $\mathrm{N}$ & $\mathrm{T}$ & 1 & MicD & 11,56 & \\
\hline $\mathrm{F}$ & $\mathrm{N}$ & $\mathrm{T}$ & 1 & MicE & 11,46 & \\
\hline $\mathrm{F}$ & $\mathrm{N}$ & $\mathrm{T}$ & 2 & LDTotal & 11,83 & \\
\hline $\mathrm{F}$ & $\mathrm{N}$ & $\mathrm{T}$ & 2 & LDTrab & 8,32 & \\
\hline$F$ & $\mathrm{~N}$ & $T$ & 2 & LDBal & 3,51 & \\
\hline $\mathrm{F}$ & $\mathrm{N}$ & $\mathrm{T}$ & 2 & MICTotal & 24,75 & \\
\hline $\mathrm{F}$ & $\mathrm{N}$ & $\mathrm{T}$ & 2 & MicD & 12,14 & \\
\hline$F$ & $\mathrm{~N}$ & $T$ & 2 & MicE & 12,61 & \\
\hline $\mathrm{F}$ & $\mathrm{N}$ & $\mathrm{T}$ & 3 & LDTotal & 11,68 & \\
\hline $\mathrm{F}$ & $\mathrm{N}$ & $\mathrm{T}$ & 3 & LDTrab & 8 & (continua) \\
\hline
\end{tabular}




\begin{tabular}{|c|c|c|c|c|c|c|}
\hline $\mathrm{F}$ & $\mathrm{N}$ & $T$ & 3 & LDBal & 3,68 & (continua) \\
\hline $\mathrm{F}$ & $\mathrm{N}$ & $\mathrm{T}$ & 3 & MICTotal & 23,51 & \\
\hline $\mathrm{F}$ & $\mathrm{N}$ & $\mathrm{T}$ & 3 & MicD & 12,03 & \\
\hline $\mathrm{F}$ & $\mathrm{N}$ & $T$ & 3 & MicE & 11,48 & \\
\hline $\mathrm{F}$ & $\mathrm{N}$ & 0 & 1 & LDTotal & 12 & \\
\hline $\mathrm{F}$ & $\mathrm{N}$ & $\mathrm{O}$ & 1 & LDTrab & 9,15 & \\
\hline$F$ & $\mathrm{~N}$ & $\mathrm{O}$ & 1 & LDBal & 2,85 & \\
\hline $\mathrm{F}$ & $\mathrm{N}$ & $\mathrm{O}$ & 1 & MICTotal & 21,04 & \\
\hline $\mathrm{F}$ & $\mathrm{N}$ & $\mathrm{O}$ & 1 & MicD & 10,17 & \\
\hline $\mathrm{F}$ & $\mathrm{N}$ & $\mathrm{O}$ & 1 & MicE & 10,87 & \\
\hline $\mathrm{F}$ & $\mathrm{N}$ & $\mathrm{O}$ & 2 & LDTotal & 12,1 & \\
\hline $\mathrm{F}$ & $\mathrm{N}$ & $\mathrm{O}$ & 2 & LDTrab & 9,6 & \\
\hline $\mathrm{F}$ & $\mathrm{N}$ & $\mathrm{O}$ & 2 & LDBal & 2,5 & \\
\hline $\mathrm{F}$ & $\mathrm{N}$ & $\mathrm{O}$ & 2 & MICTotal & 19,13 & \\
\hline $\mathrm{F}$ & $\mathrm{N}$ & $\mathrm{O}$ & 2 & MicD & 9,48 & \\
\hline$F$ & $\mathrm{~N}$ & $\mathrm{O}$ & 2 & MicE & 9,65 & \\
\hline $\mathrm{F}$ & $\mathrm{N}$ & 0 & 3 & LDTotal & 12,42 & \\
\hline $\mathrm{F}$ & $\mathrm{N}$ & $\mathrm{O}$ & 3 & LDTrab & 9,49 & \\
\hline $\mathrm{F}$ & $\mathrm{N}$ & $\mathrm{O}$ & 3 & LDBal & 2,93 & \\
\hline$F$ & $\mathrm{~N}$ & 0 & 3 & MICTotal & 17,11 & \\
\hline $\mathrm{F}$ & $\mathrm{N}$ & 0 & 3 & MicD & 8,35 & \\
\hline $\mathrm{F}$ & $\mathrm{N}$ & $\mathrm{O}$ & 3 & MicE & 8,76 & \\
\hline $\mathrm{F}$ & I & $Q$ & 1 & LDTotal & 16,88 & \\
\hline $\mathrm{F}$ & 1 & $Q$ & 1 & LDTrab & 10,23 & \\
\hline$F$ & I & $Q$ & 1 & LDBal & 6,65 & \\
\hline $\mathrm{F}$ & I & Q & 1 & MICTotal & 18,97 & \\
\hline$F$ & $\mathrm{I}$ & $\mathrm{Q}$ & 1 & MicD & 9,13 & \\
\hline $\mathrm{F}$ & I & $Q$ & 1 & MicE & 9,84 & \\
\hline$F$ & 1 & $Q$ & 2 & LDTotal & 16,9 & \\
\hline $\mathrm{F}$ & I & $\bar{Q}$ & 2 & LDTrab & 10,34 & \\
\hline $\mathrm{F}$ & I & $Q$ & 2 & LDBal & 6,56 & \\
\hline $\mathrm{F}$ & I & $Q$ & 2 & MICTotal & 18,24 & \\
\hline $\mathrm{F}$ & 1 & $Q$ & 2 & MicD & 9,09 & \\
\hline $\mathrm{F}$ & I & Q & 2 & MicE & 9,15 & \\
\hline $\mathrm{F}$ & I & $\mathrm{Q}$ & 3 & LDTotal & 17 & \\
\hline $\mathrm{F}$ & I & $Q$ & 3 & LDTrab & 11,45 & \\
\hline $\mathrm{F}$ & 1 & $Q$ & 3 & LDBal & 5,55 & \\
\hline$F$ & I & $Q$ & 3 & MICTotal & 18,85 & \\
\hline $\mathrm{F}$ & I & $Q$ & 3 & MicD & 9,23 & \\
\hline $\mathrm{F}$ & I & $Q$ & 3 & MicE & 9,62 & \\
\hline $\mathrm{F}$ & 1 & $\mathrm{~T}$ & 1 & LDTotal & 20,1 & \\
\hline$F$ & I & $\mathrm{T}$ & 1 & LDTrab & 13,6 & \\
\hline $\mathrm{F}$ & 1 & $T$ & 1 & LDBal & 6,5 & \\
\hline $\mathrm{F}$ & I & $\mathrm{T}$ & 1 & MICTotal & 21,73 & \\
\hline$F$ & $\mathrm{I}$ & $T$ & 1 & MicD & 10,54 & \\
\hline$F$ & 1 & $\mathrm{~T}$ & 1 & MicE & 11,19 & \\
\hline$F$ & I & $\mathrm{T}$ & 2 & LDTotal & 19,86 & \\
\hline $\mathrm{F}$ & I & $\mathrm{T}$ & 2 & LDTrab & 13,49 & (continua) \\
\hline
\end{tabular}




\begin{tabular}{|c|c|c|c|c|c|}
\hline $\mathrm{F}$ & $\mathrm{I}$ & $\mathrm{T}$ & 2 & LDBal & 6,37 \\
\hline $\mathrm{F}$ & $\mathrm{I}$ & $\mathrm{T}$ & 2 & MICTotal & 20,96 \\
\hline $\mathrm{F}$ & $\mathrm{I}$ & $\mathrm{T}$ & 2 & MicD & 10,14 \\
\hline $\mathrm{F}$ & $\mathrm{I}$ & $\mathrm{T}$ & 2 & MicE & 10,82 \\
\hline $\mathrm{F}$ & $\mathrm{I}$ & $\mathrm{T}$ & 3 & LDTotal & 20,13 \\
\hline $\mathrm{F}$ & $\mathrm{I}$ & $\mathrm{T}$ & 3 & LDTrab & 13 \\
\hline $\mathrm{F}$ & $\mathrm{I}$ & $\mathrm{T}$ & 3 & LDBal & 7,13 \\
\hline $\mathrm{F}$ & $\mathrm{I}$ & $\mathrm{T}$ & 3 & MICTotal & 21,18 \\
\hline $\mathrm{F}$ & $\mathrm{I}$ & $\mathrm{T}$ & 3 & MicD & 10,35 \\
\hline $\mathrm{F}$ & $\mathrm{I}$ & $\mathrm{T}$ & 3 & MicE & 10,83 \\
\hline $\mathrm{F}$ & $\mathrm{I}$ & $\mathrm{O}$ & 1 & LDTotal & 20,07 \\
\hline $\mathrm{F}$ & $\mathrm{I}$ & $\mathrm{O}$ & 1 & LDTrab & 13,6 \\
\hline $\mathrm{F}$ & $\mathrm{I}$ & $\mathrm{O}$ & 1 & LDBal & 6,47 \\
\hline $\mathrm{F}$ & $\mathrm{I}$ & $\mathrm{O}$ & 1 & MICTotal & 20,49 \\
\hline $\mathrm{F}$ & $\mathrm{I}$ & $\mathrm{O}$ & 1 & MicD & 10,08 \\
\hline $\mathrm{F}$ & $\mathrm{I}$ & $\mathrm{O}$ & 1 & MicE & 10,41 \\
\hline $\mathrm{F}$ & $\mathrm{I}$ & $\mathrm{O}$ & 2 & LDTotal & 20,5 \\
\hline $\mathrm{F}$ & $\mathrm{I}$ & $\mathrm{O}$ & 2 & LDTrab & 13,59 \\
\hline $\mathrm{F}$ & $\mathrm{I}$ & $\mathrm{O}$ & 2 & LDBal & 6,91 \\
\hline $\mathrm{F}$ & $\mathrm{I}$ & $\mathrm{O}$ & 2 & MICTotal & 16,32 \\
\hline $\mathrm{F}$ & $\mathrm{I}$ & $\mathrm{O}$ & 2 & MicD & 8,06 \\
\hline $\mathrm{F}$ & $\mathrm{I}$ & $\mathrm{O}$ & 2 & MicE & 8,26 \\
\hline $\mathrm{F}$ & $\mathrm{I}$ & $\mathrm{O}$ & 3 & LDTotal & 20,56 \\
\hline $\mathrm{F}$ & $\mathrm{I}$ & $\mathrm{O}$ & 3 & LDTrab & 13,7 \\
\hline $\mathrm{F}$ & $\mathrm{I}$ & $\mathrm{O}$ & 3 & LDBal & 6,86 \\
\hline $\mathrm{F}$ & $\mathrm{I}$ & $\mathrm{O}$ & 3 & MICTotal & 19,77 \\
\hline $\mathrm{F}$ & $\mathrm{I}$ & $\mathrm{O}$ & 3 & MicD & 9,64 \\
\hline $\mathrm{F}$ & $\mathrm{I}$ & $\mathrm{O}$ & 3 & MicE & 10,13 \\
\hline
\end{tabular}


APENDICE D - Quadro de médias das áreas em lateralidade esquerda do modelo superior

\begin{tabular}{|c|c|c|c|c|c|}
\hline $\begin{array}{l}\text { Forma } \\
\text { Oclusal }\end{array}$ & Origem & Arcada & Modelo & Tratamento & Area \\
\hline$A$ & $\mathrm{~N}$ & Q & 1 & LETotal & 16,12 \\
\hline A & $\mathrm{N}$ & Q & 1 & LETrab & 10,58 \\
\hline A & $\mathrm{N}$ & $\mathrm{Q}$ & 1 & LEBal & 5,54 \\
\hline A & $\mathrm{N}$ & Q & 1 & MICTotal & 17,38 \\
\hline A & $\mathrm{N}$ & $\mathrm{Q}$ & 1 & MicD & 8,64 \\
\hline A & $\mathrm{N}$ & $\mathrm{Q}$ & 1 & MicE & 8,74 \\
\hline A & $\mathrm{N}$ & Q & 2 & LETotal & 16,08 \\
\hline$A$ & $\mathrm{~N}$ & Q & 2 & LETrab & 10,43 \\
\hline A & $\mathrm{N}$ & Q & 2 & LEBal & 5,65 \\
\hline A & $\mathrm{N}$ & $\mathrm{Q}$ & 2 & MICTotal & 15,51 \\
\hline A & $\mathrm{N}$ & $Q$ & 2 & MicD & 7,39 \\
\hline A & $\mathrm{N}$ & $\mathrm{Q}$ & 2 & MicE & 8,12 \\
\hline A & $\mathrm{N}$ & Q & 3 & LETotal & 16,3 \\
\hline A & $\mathrm{N}$ & $\mathrm{Q}$ & 3 & LETrab & 11 \\
\hline A & $\mathrm{N}$ & Q & 3 & LEBal & 5,3 \\
\hline A & $\mathrm{N}$ & Q & 3 & MICTotal & 18,69 \\
\hline A & $\mathrm{N}$ & Q & 3 & MicD & 9,32 \\
\hline A & $\mathrm{N}$ & Q & 3 & MicE & 9,37 \\
\hline A & $\mathrm{N}$ & $T$ & 1 & LETotal & 15,2 \\
\hline A & $\mathrm{N}$ & $T$ & 1 & LETrab & 10,68 \\
\hline A & $\mathrm{N}$ & $T$ & 1 & LEBal & 4,52 \\
\hline A & $\mathrm{N}$ & $T$ & 1 & MICTotal & 14,39 \\
\hline A & $\mathrm{N}$ & $T$ & 1 & MicD & 7 \\
\hline A & $\mathrm{N}$ & $T$ & 1 & MicE & 7,39 \\
\hline A & $\mathrm{N}$ & $T$ & 2 & LETotal & 14,87 \\
\hline A & $\mathrm{N}$ & $T$ & 2 & LETrab & 11,02 \\
\hline$A$ & $\mathrm{~N}$ & $T$ & 2 & LEBal & 3,85 \\
\hline$A$ & $\mathrm{~N}$ & $T$ & 2 & MICTotal & 13,55 \\
\hline A & $\mathrm{N}$ & $T$ & 2 & MicD & 6,81 \\
\hline A & $\mathrm{N}$ & $T$ & 2 & MicE & 6,74 \\
\hline A & $\mathrm{N}$ & $T$ & 3 & LETotal & 15 \\
\hline A & $\mathrm{N}$ & $T$ & 3 & LETrab & 11,68 \\
\hline A & $\mathrm{N}$ & $T$ & 3 & LEBal & 3,32 \\
\hline A & $\mathrm{N}$ & $T$ & 3 & MICTotal & 15,16 \\
\hline A & $\mathrm{N}$ & $T$ & 3 & MicD & 7,78 \\
\hline A & $\mathrm{N}$ & $T$ & 3 & MicE & 7,38 \\
\hline A & $\mathrm{N}$ & $\mathrm{O}$ & 1 & LETotal & 17,21 \\
\hline A & $\mathrm{N}$ & $\mathrm{O}$ & 1 & LETrab & 12,01 \\
\hline A & $\mathrm{N}$ & $\mathrm{O}$ & 1 & LEBal & 5,2 \\
\hline A & $\mathrm{N}$ & $\mathrm{O}$ & 1 & MICTotal & 17,25 \\
\hline A & $\mathrm{N}$ & $\mathrm{O}$ & 1 & MicD & 8,06 \\
\hline A & $\mathrm{N}$ & $\mathrm{O}$ & 1 & MicE & 9,19 \\
\hline A & $\mathrm{N}$ & $\mathrm{O}$ & 2 & LETotal & 17,65 \\
\hline A & $\mathrm{N}$ & $\mathrm{O}$ & 2 & LETrab & 12,34 \\
\hline
\end{tabular}




\begin{tabular}{|c|c|c|c|c|c|c|}
\hline A & $\mathrm{N}$ & $\mathrm{O}$ & 2 & LEBal & 5,31 & (continua) \\
\hline$A$ & $\mathrm{~N}$ & $\mathrm{O}$ & 2 & MICTotal & 16,02 & \\
\hline A & $\mathrm{N}$ & $\mathrm{O}$ & 2 & MicD & 7,68 & \\
\hline$A$ & $\mathrm{~N}$ & $\mathrm{O}$ & 2 & MicE & 8,34 & \\
\hline A & $\mathrm{N}$ & $\mathrm{O}$ & 3 & LETotal & 18,1 & \\
\hline A & $\mathrm{N}$ & $\mathrm{O}$ & 3 & LETrab & 13,4 & \\
\hline A & $\mathrm{N}$ & $\mathrm{O}$ & 3 & LEBal & 4,7 & \\
\hline$A$ & $\mathrm{~N}$ & $\mathrm{O}$ & 3 & MICTotal & 18,64 & \\
\hline A & $\mathrm{N}$ & $\mathrm{O}$ & 3 & MicD & 9,31 & \\
\hline A & $\mathrm{N}$ & $\mathrm{O}$ & 3 & MicE & 9,33 & \\
\hline A & $\mathrm{I}$ & Q & 1 & LETotal & 18 & \\
\hline$A$ & 1 & Q & 1 & LETrab & 13,86 & \\
\hline A & 1 & Q & 1 & LEBal & 4,14 & \\
\hline A & 1 & Q & 1 & MICTotal & 19,25 & \\
\hline$A$ & $\mathrm{I}$ & Q & 1 & MicD & 10,01 & \\
\hline$A$ & $\mathrm{I}$ & $\mathrm{Q}$ & 1 & MicE & 9,24 & \\
\hline A & 1 & $Q$ & 2 & LETotal & 17,99 & \\
\hline A & $\mathrm{I}$ & $\mathrm{Q}$ & 2 & LETrab & 13,78 & \\
\hline$A$ & I & Q & 2 & LEBal & 4,21 & \\
\hline A & 1 & $Q$ & 2 & MICTotal & 20,11 & \\
\hline$A$ & $\mathrm{I}$ & Q & 2 & MicD & 9,99 & \\
\hline$A$ & $\mathrm{I}$ & Q & 2 & MicE & 10,12 & \\
\hline$A$ & $\mathrm{I}$ & Q & 3 & LETotal & 18,29 & \\
\hline A & 1 & $\mathrm{Q}$ & 3 & LETrab & 13,9 & \\
\hline$A$ & I & $\bar{Q}$ & 3 & LEBal & 4,39 & \\
\hline A & 1 & Q & 3 & MICTotal & 20,57 & \\
\hline$A$ & $\mathrm{I}$ & Q & 3 & MicD & 10,03 & \\
\hline A & 1 & $Q$ & 3 & MicE & 10,54 & \\
\hline A & $\mathrm{I}$ & $\mathrm{T}$ & 1 & LETotal & 16,82 & \\
\hline$A$ & $\mathrm{~T}$ & $\mathrm{~T}$ & 1 & LETrab & 11,8 & \\
\hline A & 1 & $\mathrm{~T}$ & 1 & LEBal & 5,02 & \\
\hline A & 1 & $\mathrm{~T}$ & 1 & MICTotal & 18,01 & \\
\hline$A$ & 1 & $T$ & 1 & MicD & 9,32 & \\
\hline A & 1 & $\mathrm{~T}$ & 1 & MicE & 8,69 & \\
\hline A & 1 & $\mathrm{~T}$ & 2 & LETotal & 16,7 & \\
\hline A & I & $\mathrm{T}$ & 2 & LETrab & 11,01 & \\
\hline$A$ & $\mathrm{I}$ & $\mathrm{T}$ & 2 & LEBal & 5,69 & \\
\hline$A$ & $\mathrm{I}$ & $\mathrm{T}$ & 2 & MICTotal & 17,47 & \\
\hline A & $\mathrm{I}$ & $\mathrm{T}$ & 2 & MicD & 9 & \\
\hline A & 1 & $T$ & 2 & MicE & 8,47 & \\
\hline$A$ & 1 & $\mathrm{~T}$ & 3 & LETotal & 16,7 & \\
\hline A & 1 & $\mathrm{~T}$ & 3 & LETrab & 11,24 & \\
\hline A & $\mathrm{I}$ & $T$ & 3 & LEBal & 5,46 & \\
\hline$A$ & 1 & $T$ & 3 & MICTotal & 18,13 & \\
\hline$A$ & $\mathrm{I}$ & $T$ & 3 & MicD & 8,98 & \\
\hline A & 1 & $\mathrm{~T}$ & 3 & MicE & 9,15 & \\
\hline$A$ & 1 & $\mathrm{O}$ & 1 & LETotal & 18,37 & \\
\hline A & 1 & $\mathrm{O}$ & 1 & LETrab & 13,42 & (continua) \\
\hline
\end{tabular}




\begin{tabular}{|c|c|c|c|c|c|c|}
\hline A & I & 0 & 1 & LEBal & 4,95 & (continua) \\
\hline$A$ & 1 & 0 & 1 & MICTotal & 18,27 & \\
\hline A & I & $\mathrm{O}$ & 1 & MicD & 9,12 & \\
\hline$A$ & I & $\mathrm{O}$ & 1 & MicE & 9,15 & \\
\hline A & I & $\mathrm{O}$ & 2 & LETotal & 18,4 & \\
\hline A & 1 & $\mathrm{O}$ & 2 & LETrab & 13,56 & \\
\hline$A$ & I & 0 & 2 & LEBal & 4,84 & \\
\hline$A$ & 1 & $\mathrm{O}$ & 2 & MICTotal & 18,17 & \\
\hline$A$ & 1 & $\mathrm{O}$ & 2 & MicD & 8,86 & \\
\hline$A$ & 1 & $\mathrm{O}$ & 2 & MicE & 9,31 & \\
\hline$A$ & I & $\mathrm{O}$ & 3 & LETotal & 18,22 & \\
\hline$A$ & 1 & $\mathrm{O}$ & 3 & LETrab & 13,15 & \\
\hline$A$ & I & $\mathrm{O}$ & 3 & LEBal & 5,07 & \\
\hline$A$ & 1 & $\mathrm{O}$ & 3 & MICTotal & 18,04 & \\
\hline$A$ & I & 0 & 3 & MicD & 8,87 & \\
\hline$A$ & 1 & $\mathrm{O}$ & 3 & MicE & 9,17 & \\
\hline $\mathrm{F}$ & $\mathrm{N}$ & Q & 1 & LETotal & 10,24 & \\
\hline $\mathrm{F}$ & $\mathrm{N}$ & Q & 1 & LETrab & 8,6 & \\
\hline $\mathrm{F}$ & $\mathrm{N}$ & Q & 1 & LEBal & 1,64 & \\
\hline$F$ & $\mathrm{~N}$ & Q & 1 & MICTotal & 18,38 & \\
\hline$F$ & $\mathrm{~N}$ & $Q$ & 1 & MicD & 9,02 & \\
\hline $\mathrm{F}$ & $\mathrm{N}$ & Q & 1 & MicE & 9,36 & \\
\hline $\mathrm{F}$ & $\mathrm{N}$ & $Q$ & 2 & LETotal & 10,19 & \\
\hline $\mathrm{F}$ & $\mathrm{N}$ & $\mathrm{Q}$ & 2 & LETrab & 8,2 & \\
\hline $\mathrm{F}$ & $\mathrm{N}$ & $Q$ & 2 & LEBal & 1,99 & \\
\hline $\mathrm{F}$ & $\mathrm{N}$ & Q & 2 & MICTotal & 21,26 & \\
\hline $\mathrm{F}$ & $\mathrm{N}$ & $Q$ & 2 & MicD & 10,62 & \\
\hline $\mathrm{F}$ & $\mathrm{N}$ & Q & 2 & MicE & 10,64 & \\
\hline$F$ & $\mathrm{~N}$ & Q & 3 & LETotal & 10 & \\
\hline $\mathrm{F}$ & $\mathrm{N}$ & Q & 3 & LETrab & 7,96 & \\
\hline $\mathrm{F}$ & $\mathrm{N}$ & Q & 3 & LEBal & 2,04 & \\
\hline $\mathrm{F}$ & $\mathrm{N}$ & Q & 3 & MICTotal & 16,21 & \\
\hline$F$ & $\mathrm{~N}$ & Q & 3 & MicD & 7,98 & \\
\hline $\mathrm{F}$ & $\mathrm{N}$ & Q & 3 & MicE & 8,23 & \\
\hline $\mathrm{F}$ & $\mathrm{N}$ & $\mathrm{T}$ & 1 & LETotal & 12,32 & \\
\hline $\mathrm{F}$ & $\mathrm{N}$ & $\mathrm{T}$ & 1 & LETrab & 8,87 & \\
\hline $\mathrm{F}$ & $\mathrm{N}$ & $\mathrm{T}$ & 1 & LEBal & 3,45 & \\
\hline$F$ & $\mathrm{~N}$ & $\mathrm{~T}$ & 1 & MICTotal & 23,02 & \\
\hline$F$ & $\mathrm{~N}$ & $\mathrm{~T}$ & 1 & MicD & 11,56 & \\
\hline $\mathrm{F}$ & $\mathrm{N}$ & $\mathrm{T}$ & 1 & MicE & 11,46 & \\
\hline$F$ & $\mathrm{~N}$ & $\mathrm{~T}$ & 2 & LETotal & 12,4 & \\
\hline $\mathrm{F}$ & $\mathrm{N}$ & $\mathrm{T}$ & 2 & LETrab & 9 & \\
\hline $\mathrm{F}$ & $\mathrm{N}$ & $\mathrm{T}$ & 2 & LEBal & 3,4 & \\
\hline $\mathrm{F}$ & $\mathrm{N}$ & $\mathrm{T}$ & 2 & MICTotal & 24,75 & \\
\hline $\mathrm{F}$ & $\mathrm{N}$ & $\mathrm{T}$ & 2 & MicD & 12,14 & \\
\hline$F$ & $\mathrm{~N}$ & $\mathrm{~T}$ & 2 & MicE & 12,61 & \\
\hline$F$ & $\mathrm{~N}$ & $\mathrm{~T}$ & 3 & LETotal & 12,42 & \\
\hline$F$ & $\mathrm{~N}$ & $\mathrm{~T}$ & 3 & LETrab & 9,32 & (continua) \\
\hline
\end{tabular}




\begin{tabular}{|c|c|c|c|c|c|}
\hline $\mathrm{F}$ & $\mathrm{N}$ & $\mathrm{T}$ & 3 & LEBal & 3,1 \\
\hline $\mathrm{F}$ & $\mathrm{N}$ & $\mathrm{T}$ & 3 & MICTotal & 23,51 \\
\hline $\mathrm{F}$ & $\mathrm{N}$ & $\mathrm{T}$ & 3 & MicD & 12,03 \\
\hline $\mathrm{F}$ & $\mathrm{N}$ & $\mathrm{T}$ & 3 & MicE & 11,48 \\
\hline $\mathrm{F}$ & $\mathrm{N}$ & $\mathrm{O}$ & 1 & LETotal & 12,48 \\
\hline $\mathrm{F}$ & $\mathrm{N}$ & $\mathrm{O}$ & 1 & LETrab & 9,36 \\
\hline $\mathrm{F}$ & $\mathrm{N}$ & $\mathrm{O}$ & 1 & LEBal & 3,12 \\
\hline $\mathrm{F}$ & $\mathrm{N}$ & $\mathrm{O}$ & 1 & MICTotal & 21,04 \\
\hline $\mathrm{F}$ & $\mathrm{N}$ & $\mathrm{O}$ & 1 & MicD & 10,17 \\
\hline $\mathrm{F}$ & $\mathrm{N}$ & $\mathrm{O}$ & 1 & MicE & 10,87 \\
\hline $\mathrm{F}$ & $\mathrm{N}$ & $\mathrm{O}$ & 2 & LETotal & 12,5 \\
\hline $\mathrm{F}$ & $\mathrm{N}$ & $\mathrm{O}$ & 2 & LETrab & 10 \\
\hline $\mathrm{F}$ & $\mathrm{N}$ & $\mathrm{O}$ & 2 & LEBal & 2,5 \\
\hline $\mathrm{F}$ & $\mathrm{N}$ & $\mathrm{O}$ & 2 & MICTotal & 19,13 \\
\hline $\mathrm{F}$ & $\mathrm{N}$ & $\mathrm{O}$ & 2 & MicD & 9,48 \\
\hline $\mathrm{F}$ & $\mathrm{N}$ & $\mathrm{O}$ & 2 & MicE & 9,65 \\
\hline $\mathrm{F}$ & $\mathrm{N}$ & $\mathrm{O}$ & 3 & LETotal & 12,31 \\
\hline $\mathrm{F}$ & $\mathrm{N}$ & $\mathrm{O}$ & 3 & LETrab & 9,99 \\
\hline $\mathrm{F}$ & $\mathrm{N}$ & $\mathrm{O}$ & 3 & LEBal & 2,32 \\
\hline $\mathrm{F}$ & $\mathrm{N}$ & $\mathrm{O}$ & 3 & MICTotal & 17,11 \\
\hline $\mathrm{F}$ & $\mathrm{N}$ & $\mathrm{O}$ & 3 & MicD & 8,35 \\
\hline $\mathrm{F}$ & $\mathrm{N}$ & $\mathrm{O}$ & 3 & MicE & 8,76 \\
\hline $\mathrm{F}$ & $\mathrm{I}$ & $\mathrm{Q}$ & 1 & LETotal & 17,2 \\
\hline $\mathrm{F}$ & $\mathrm{I}$ & $\mathrm{Q}$ & 1 & LETrab & 10,56 \\
\hline $\mathrm{F}$ & $\mathrm{I}$ & $\mathrm{Q}$ & 1 & LEBal & 6,64 \\
\hline $\mathrm{F}$ & $\mathrm{I}$ & $\mathrm{Q}$ & 1 & MICTotal & 18,97 \\
\hline $\mathrm{F}$ & $\mathrm{I}$ & $\mathrm{Q}$ & 1 & MicD & 9,13 \\
\hline $\mathrm{F}$ & $\mathrm{I}$ & $\mathrm{Q}$ & 1 & MicE & 9,84 \\
\hline $\mathrm{F}$ & $\mathrm{I}$ & $\mathrm{Q}$ & 2 & LETotal & 17,16 \\
\hline $\mathrm{F}$ & $\mathrm{I}$ & $\mathrm{Q}$ & 2 & LETrab & 10,6 \\
\hline $\mathrm{F}$ & $\mathrm{I}$ & $\mathrm{Q}$ & 2 & LEBal & 6,56 \\
\hline $\mathrm{F}$ & $\mathrm{I}$ & $\mathrm{Q}$ & 2 & MICTotal & 18,24 \\
\hline $\mathrm{F}$ & $\mathrm{I}$ & $\mathrm{Q}$ & 2 & MicD & 9,09 \\
\hline $\mathrm{F}$ & $\mathrm{I}$ & $\mathrm{Q}$ & 2 & MicE & 9,15 \\
\hline $\mathrm{F}$ & $\mathrm{I}$ & $\mathrm{Q}$ & 3 & LETotal & 17,49 \\
\hline $\mathrm{F}$ & $\mathrm{I}$ & $\mathrm{Q}$ & 3 & LETrab & 11 \\
\hline $\mathrm{F}$ & $\mathrm{I}$ & $\mathrm{Q}$ & 3 & LEBal & 6,49 \\
\hline $\mathrm{F}$ & $\mathrm{I}$ & $\mathrm{Q}$ & 3 & MICTotal & 18,85 \\
\hline $\mathrm{F}$ & $\mathrm{I}$ & $\mathrm{Q}$ & 3 & MicD & 9,23 \\
\hline $\mathrm{F}$ & $\mathrm{I}$ & $\mathrm{Q}$ & 3 & MicE & 9,62 \\
\hline $\mathrm{F}$ & $\mathrm{I}$ & $\mathrm{T}$ & 1 & LETotal & 20,36 \\
\hline $\mathrm{F}$ & $\mathrm{I}$ & $\mathrm{T}$ & 1 & LETrab & 11,92 \\
\hline $\mathrm{F}$ & $\mathrm{I}$ & $\mathrm{T}$ & 1 & LEBal & 8,44 \\
\hline $\mathrm{F}$ & $\mathrm{I}$ & $\mathrm{T}$ & 1 & MICTotal & 21,73 \\
\hline $\mathrm{F}$ & $\mathrm{I}$ & $\mathrm{T}$ & 1 & MicD & 10,54 \\
\hline $\mathrm{F}$ & $\mathrm{I}$ & $\mathrm{T}$ & 1 & MicE & 11,19 \\
\hline $\mathrm{F}$ & $\mathrm{I}$ & $\mathrm{T}$ & 2 & LETotal & 20,13 \\
\hline $\mathrm{F}$ & $\mathrm{I}$ & $\mathrm{T}$ & 2 & LETrab & 11,48 \\
\hline & & & & & \\
\hline
\end{tabular}




\begin{tabular}{|c|c|c|c|c|c|}
\hline $\mathrm{F}$ & $\mathrm{I}$ & $\mathrm{T}$ & 2 & LEBal & 8,65 \\
\hline $\mathrm{F}$ & $\mathrm{I}$ & $\mathrm{T}$ & 2 & MICTotal & 20,96 \\
\hline $\mathrm{F}$ & $\mathrm{I}$ & $\mathrm{T}$ & 2 & MicD & 10,14 \\
\hline $\mathrm{F}$ & $\mathrm{I}$ & $\mathrm{T}$ & 2 & MicE & 10,82 \\
\hline $\mathrm{F}$ & $\mathrm{I}$ & $\mathrm{T}$ & 3 & LETotal & 20,29 \\
\hline $\mathrm{F}$ & $\mathrm{I}$ & $\mathrm{T}$ & 3 & LETrab & 12 \\
\hline $\mathrm{F}$ & $\mathrm{I}$ & $\mathrm{T}$ & 3 & LEBal & 8,29 \\
\hline $\mathrm{F}$ & $\mathrm{I}$ & $\mathrm{T}$ & 3 & MICTotal & 21,18 \\
\hline $\mathrm{F}$ & $\mathrm{I}$ & $\mathrm{T}$ & 3 & MicD & 10,35 \\
\hline $\mathrm{F}$ & $\mathrm{I}$ & $\mathrm{T}$ & 3 & MicE & 10,83 \\
\hline $\mathrm{F}$ & $\mathrm{I}$ & $\mathrm{O}$ & 1 & LETotal & 20,37 \\
\hline $\mathrm{F}$ & $\mathrm{I}$ & $\mathrm{O}$ & 1 & LETrab & 13,78 \\
\hline $\mathrm{F}$ & $\mathrm{I}$ & $\mathrm{O}$ & 1 & LEBal & 6,59 \\
\hline $\mathrm{F}$ & $\mathrm{I}$ & $\mathrm{O}$ & 1 & MICTotal & 20,49 \\
\hline $\mathrm{F}$ & $\mathrm{I}$ & $\mathrm{O}$ & 1 & MicD & 10,08 \\
\hline $\mathrm{F}$ & $\mathrm{I}$ & $\mathrm{O}$ & 1 & MicE & 10,41 \\
\hline $\mathrm{F}$ & $\mathrm{I}$ & $\mathrm{O}$ & 2 & LETotal & 20,64 \\
\hline $\mathrm{F}$ & $\mathrm{I}$ & $\mathrm{O}$ & 2 & LETrab & 13,8 \\
\hline $\mathrm{F}$ & $\mathrm{I}$ & $\mathrm{O}$ & 2 & LEBal & 6,84 \\
\hline $\mathrm{F}$ & $\mathrm{I}$ & $\mathrm{O}$ & 2 & MICTotal & 16,32 \\
\hline $\mathrm{F}$ & $\mathrm{I}$ & $\mathrm{O}$ & 2 & MicD & 8,06 \\
\hline $\mathrm{F}$ & $\mathrm{I}$ & $\mathrm{O}$ & 2 & MicE & 8,26 \\
\hline $\mathrm{F}$ & $\mathrm{I}$ & $\mathrm{O}$ & 3 & LETotal & 20,82 \\
\hline $\mathrm{F}$ & $\mathrm{I}$ & $\mathrm{O}$ & 3 & LETrab & 13,91 \\
\hline $\mathrm{F}$ & $\mathrm{I}$ & $\mathrm{O}$ & 3 & LEBal & 6,91 \\
\hline $\mathrm{F}$ & $\mathrm{I}$ & $\mathrm{O}$ & 3 & MICTotal & 19,77 \\
\hline $\mathrm{F}$ & $\mathrm{I}$ & $\mathrm{O}$ & 3 & MicD & 9,64 \\
\hline $\mathrm{F}$ & $\mathrm{I}$ & $\mathrm{O}$ & 3 & MicE & 10,13 \\
\hline & & & & & \\
\hline
\end{tabular}

(conclusão) 
APENDICE E - Quadro de médias das áreas em lateralidade direita do modelo inferior

\begin{tabular}{|c|c|c|c|c|c|}
\hline $\begin{array}{l}\text { Forma } \\
\text { Oclusal }\end{array}$ & Origem & Arcada & Modelo & Tratamento & Area \\
\hline$A$ & $\mathrm{~N}$ & $Q$ & 1 & LDTotal & 14.22 \\
\hline$A$ & $\mathrm{~N}$ & $Q$ & 1 & LDTrab & 9.55 \\
\hline$A$ & $\mathrm{~N}$ & $Q$ & 1 & LDBal & 4.68 \\
\hline A & $\mathrm{N}$ & $Q$ & 1 & MICTotal & 15.72 \\
\hline$A$ & $\mathrm{~N}$ & $\mathrm{Q}$ & 1 & MicD & 7.38 \\
\hline$A$ & $\mathrm{~N}$ & $Q$ & 1 & MicE & 8.34 \\
\hline$A$ & $\mathrm{~N}$ & $Q$ & 2 & LDTotal & 14.72 \\
\hline$A$ & $\mathrm{~N}$ & $Q$ & 2 & LDTrab & 9.39 \\
\hline A & $\mathrm{N}$ & $\mathrm{Q}$ & 2 & LDBal & 5.33 \\
\hline$A$ & $\mathrm{~N}$ & $Q$ & 2 & MICTotal & 15.15 \\
\hline$A$ & $\mathrm{~N}$ & $Q$ & 2 & MicD & 7.40 \\
\hline$A$ & $\mathrm{~N}$ & $\mathrm{Q}$ & 2 & MicE & 7.25 \\
\hline $\mathrm{A}$ & $\mathrm{N}$ & $Q$ & 3 & LDTotal & 14.91 \\
\hline$A$ & $\mathrm{~N}$ & $\mathrm{Q}$ & 3 & LDTrab & 9.91 \\
\hline A & $\mathrm{N}$ & $Q$ & 3 & LDBal & 5.00 \\
\hline$A$ & $\mathrm{~N}$ & $Q$ & 3 & MICTotal & 16.64 \\
\hline A & $\mathrm{N}$ & $Q$ & 3 & MicD & 8.04 \\
\hline$A$ & $\mathrm{~N}$ & $Q$ & 3 & MicE & 8.60 \\
\hline$A$ & $\mathrm{~N}$ & $\mathrm{~T}$ & 1 & LDTotal & 13.38 \\
\hline$A$ & $\mathrm{~N}$ & $\mathrm{~T}$ & 1 & LDTrab & 7.01 \\
\hline A & $\mathrm{N}$ & $\mathrm{T}$ & 1 & LDBal & 6.37 \\
\hline$A$ & $\mathrm{~N}$ & $\mathrm{~T}$ & 1 & MICTotal & 13.43 \\
\hline A & $\mathrm{N}$ & $\mathrm{T}$ & 1 & MicD & 6.30 \\
\hline$A$ & $\mathrm{~N}$ & $\mathrm{~T}$ & 1 & MicE & 7.13 \\
\hline$A$ & $\mathrm{~N}$ & $\mathrm{~T}$ & 2 & LDTotal & 13.14 \\
\hline$A$ & $\mathrm{~N}$ & $T$ & 2 & LDTrab & 6.97 \\
\hline$A$ & $\mathrm{~N}$ & $\mathrm{~T}$ & 2 & LDBal & 6.16 \\
\hline$A$ & $\mathrm{~N}$ & $\mathrm{~T}$ & 2 & MICTotal & 12.96 \\
\hline A & $\mathrm{N}$ & $\mathrm{T}$ & 2 & MicD & 6.40 \\
\hline$A$ & $\mathrm{~N}$ & $\mathrm{~T}$ & 2 & MicE & 6.56 \\
\hline$A$ & $\mathrm{~N}$ & $\mathrm{~T}$ & 3 & LDTotal & 13.18 \\
\hline A & $\mathrm{N}$ & $\mathrm{T}$ & 3 & LDTrab & 7.17 \\
\hline$A$ & $\mathrm{~N}$ & $\mathrm{~T}$ & 3 & LDBal & 6.01 \\
\hline$A$ & $\mathrm{~N}$ & $\mathrm{~T}$ & 3 & MICTotal & 13.58 \\
\hline$A$ & $\mathrm{~N}$ & $\mathrm{~T}$ & 3 & MicD & 6.41 \\
\hline$A$ & $\mathrm{~N}$ & $\mathrm{~T}$ & 3 & MicE & 7.17 \\
\hline$A$ & $\mathrm{~N}$ & 0 & 1 & LDTotal & 15.75 \\
\hline A & $\mathrm{N}$ & 0 & 1 & LDTrab & 9.90 \\
\hline$A$ & $\mathrm{~N}$ & $\mathrm{O}$ & 1 & LDBal & 5.85 \\
\hline$A$ & $\mathrm{~N}$ & $\mathrm{O}$ & 1 & MICTotal & 16.07 \\
\hline$A$ & $\mathrm{~N}$ & $\mathrm{O}$ & 1 & MicD & 7.89 \\
\hline$A$ & $\mathrm{~N}$ & $\mathrm{O}$ & 1 & MicE & 8.19 \\
\hline A & $\mathrm{N}$ & 0 & 2 & LDTotal & 15.92 \\
\hline$A$ & $\mathrm{~N}$ & 0 & 2 & LDTrab & 9.87 \\
\hline
\end{tabular}




\begin{tabular}{|c|c|c|c|c|c|c|}
\hline A & $\mathrm{N}$ & $\mathrm{O}$ & 2 & LDBal & 6.05 & (continua) \\
\hline$A$ & $\mathrm{~N}$ & $\mathrm{O}$ & 2 & MICTotal & 15.28 & \\
\hline A & $\mathrm{N}$ & $\mathrm{O}$ & 2 & MicD & 7.12 & \\
\hline$A$ & $\mathrm{~N}$ & $\mathrm{O}$ & 2 & MicE & 8.16 & \\
\hline A & $\mathrm{N}$ & $\mathrm{O}$ & 3 & LDTotal & 16.06 & \\
\hline A & $\mathrm{N}$ & $\mathrm{O}$ & 3 & LDTrab & 9.89 & \\
\hline$A$ & $\mathrm{~N}$ & $\mathrm{O}$ & 3 & LDBal & 6.17 & \\
\hline$A$ & $\mathrm{~N}$ & $\mathrm{O}$ & 3 & MICTotal & 16.47 & \\
\hline$A$ & $\mathrm{~N}$ & $\mathrm{O}$ & 3 & $\mathrm{MicD}$ & 8.17 & \\
\hline$A$ & $\mathrm{~N}$ & $\mathrm{O}$ & 3 & MicE & 8.30 & \\
\hline A & 1 & Q & 1 & LDTotal & 15.92 & \\
\hline$A$ & $\mathrm{I}$ & Q & 1 & LDTrab & 9.96 & \\
\hline A & 1 & Q & 1 & LDBal & 5.97 & \\
\hline A & 1 & Q & 1 & MICTotal & 17.94 & \\
\hline$A$ & I & Q & 1 & MicD & 8.45 & \\
\hline A & I & $\mathrm{Q}$ & 1 & MicE & 9.49 & \\
\hline A & 1 & Q & 2 & LDTotal & 15.85 & \\
\hline$A$ & 1 & Q & 2 & LDTrab & 9.93 & \\
\hline$A$ & $\mathrm{I}$ & Q & 2 & LDBal & 5.92 & \\
\hline A & $\mathrm{I}$ & Q & 2 & MICTotal & 17.14 & \\
\hline A & I & Q & 2 & MicD & 8.16 & \\
\hline$A$ & 1 & Q & 2 & MicE & 9.03 & \\
\hline$A$ & I & Q & 3 & LDTotal & 16.10 & \\
\hline$A$ & I & Q & 3 & LDTrab & 10.14 & \\
\hline$A$ & I & Q & 3 & LDBal & 5.96 & \\
\hline A & 1 & Q & 3 & MICTotal & 17.89 & \\
\hline A & I & $\mathrm{Q}$ & 3 & MicD & 8.89 & \\
\hline A & 1 & Q & 3 & MicE & 9.00 & \\
\hline$A$ & $\mathrm{I}$ & $T$ & 1 & LDTotal & 14.72 & \\
\hline$A$ & $\mathrm{I}$ & $T$ & 1 & LDTrab & 8.87 & \\
\hline A & I & $\mathrm{T}$ & 1 & LDBal & 5.85 & \\
\hline A & I & $\mathrm{T}$ & 1 & MICTotal & 15.93 & \\
\hline$A$ & $\mathrm{I}$ & $T$ & 1 & MicD & 7.66 & \\
\hline A & 1 & $\mathrm{~T}$ & 1 & MicE & 8.27 & \\
\hline$A$ & I & $\mathrm{T}$ & 2 & LDTotal & 14.92 & \\
\hline$A$ & I & $\mathrm{T}$ & 2 & LDTrab & 8.97 & \\
\hline$A$ & I & $\mathrm{T}$ & 2 & LDBal & 5.96 & \\
\hline$A$ & I & $T$ & 2 & MICTotal & 15.75 & \\
\hline A & I & $\mathrm{T}$ & 2 & MicD & 7.61 & \\
\hline A & I & $\mathrm{T}$ & 2 & MicE & 8.22 & \\
\hline$A$ & $\mathrm{I}$ & $T$ & 3 & LDTotal & 15.00 & \\
\hline A & 1 & $\mathrm{~T}$ & 3 & LDTrab & 9.07 & \\
\hline$A$ & I & $\mathrm{T}$ & 3 & LDBal & 5.93 & \\
\hline$A$ & I & $\mathrm{T}$ & 3 & MICTotal & 16.01 & \\
\hline$A$ & $\mathrm{I}$ & $\mathrm{T}$ & 3 & MicD & 7.99 & \\
\hline$A$ & I & $\mathrm{T}$ & 3 & MicE & 8.02 & \\
\hline$A$ & I & $\mathrm{O}$ & 1 & LDTotal & 16.98 & \\
\hline$A$ & I & $\mathrm{O}$ & 1 & LDTrab & 8.39 & (continua) \\
\hline
\end{tabular}




\begin{tabular}{|c|c|c|c|c|c|c|}
\hline A & 1 & $\mathrm{O}$ & 1 & LDBal & 8.59 & (continua) \\
\hline$A$ & I & $\mathrm{O}$ & 1 & MICTotal & 17.04 & \\
\hline A & I & $\mathrm{O}$ & 1 & MicD & 8.39 & \\
\hline$A$ & I & $\mathrm{O}$ & 1 & MicE & 8.59 & \\
\hline A & I & $\mathrm{O}$ & 2 & LDTotal & 17.86 & \\
\hline A & $\mathrm{I}$ & $\mathrm{O}$ & 2 & LDTrab & 10.87 & \\
\hline$A$ & $\mathrm{I}$ & $\mathrm{O}$ & 2 & LDBal & 6.98 & \\
\hline$A$ & 1 & $\mathrm{O}$ & 2 & MICTotal & 17.04 & \\
\hline$A$ & $\mathrm{I}$ & $\mathrm{O}$ & 2 & $\mathrm{MicD}$ & 8.47 & \\
\hline$A$ & $\mathrm{I}$ & $\mathrm{O}$ & 2 & MicE & 8.52 & \\
\hline A & 1 & $\mathrm{O}$ & 3 & LDTotal & 17.85 & \\
\hline$A$ & $\mathrm{I}$ & $\mathrm{O}$ & 3 & LDTrab & 10.73 & \\
\hline$A$ & $\mathrm{I}$ & $\mathrm{O}$ & 3 & LDBal & 7.12 & \\
\hline A & 1 & $\mathrm{O}$ & 3 & MICTotal & 17.68 & \\
\hline$A$ & I & $\mathrm{O}$ & 3 & MicD & 8.45 & \\
\hline A & I & $\mathrm{O}$ & 3 & MicE & 9.23 & \\
\hline $\mathrm{F}$ & $\mathrm{N}$ & Q & 1 & LDTotal & 9.90 & \\
\hline $\mathrm{F}$ & $\mathrm{N}$ & Q & 1 & LDTrab & 5.83 & \\
\hline $\mathrm{F}$ & $\mathrm{N}$ & Q & 1 & LDBal & 4.07 & \\
\hline $\mathrm{F}$ & $\mathrm{N}$ & Q & 1 & MICTotal & 14.67 & \\
\hline $\mathrm{F}$ & $\mathrm{N}$ & Q & 1 & MicD & 6.84 & \\
\hline$F$ & $\mathrm{~N}$ & Q & 1 & MicE & 7.29 & \\
\hline $\mathrm{F}$ & $\mathrm{N}$ & Q & 2 & LDTotal & 9.51 & \\
\hline $\mathrm{F}$ & $\mathrm{N}$ & Q & 2 & LDTrab & 6.41 & \\
\hline$F$ & $\mathrm{~N}$ & Q & 2 & LDBal & 4.66 & \\
\hline $\mathrm{F}$ & $\mathrm{N}$ & Q & 2 & MICTotal & 15.33 & \\
\hline $\mathrm{F}$ & $\mathrm{N}$ & $\mathrm{Q}$ & 2 & MicD & 7.51 & \\
\hline $\mathrm{F}$ & $\mathrm{N}$ & Q & 2 & MicE & 7.82 & \\
\hline $\mathrm{F}$ & $\mathrm{N}$ & Q & 3 & LDTotal & 9.03 & \\
\hline $\mathrm{F}$ & $\mathrm{N}$ & Q & 3 & LDTrab & 4.96 & \\
\hline $\mathrm{F}$ & $\mathrm{N}$ & Q & 3 & LDBal & 4.07 & \\
\hline $\mathrm{F}$ & $\mathrm{N}$ & Q & 3 & MICTotal & 13.41 & \\
\hline $\mathrm{F}$ & $\mathrm{N}$ & Q & 3 & MicD & 3.61 & \\
\hline $\mathrm{F}$ & $\mathrm{N}$ & Q & 3 & MicE & 6.80 & \\
\hline $\mathrm{F}$ & $\mathrm{N}$ & $\mathrm{T}$ & 1 & LDTotal & 11.04 & \\
\hline $\mathrm{F}$ & $\mathrm{N}$ & $\mathrm{T}$ & 1 & LDTrab & 6.08 & \\
\hline $\mathrm{F}$ & $\mathrm{N}$ & $\mathrm{T}$ & 1 & LDBal & 5.29 & \\
\hline $\mathrm{F}$ & $\mathrm{N}$ & $T$ & 1 & MICTotal & 21.15 & \\
\hline $\mathrm{F}$ & $\mathrm{N}$ & $\mathrm{T}$ & 1 & MicD & 10.78 & \\
\hline $\mathrm{F}$ & $\mathrm{N}$ & $\mathrm{T}$ & 1 & MicE & 10.28 & \\
\hline $\mathrm{F}$ & $\mathrm{N}$ & $T$ & 2 & LDTotal & 11.24 & \\
\hline $\mathrm{F}$ & $\mathrm{N}$ & $\mathrm{T}$ & 2 & LDTrab & 8.23 & \\
\hline $\mathrm{F}$ & $\mathrm{N}$ & $\mathrm{T}$ & 2 & LDBal & 4.54 & \\
\hline $\mathrm{F}$ & $\mathrm{N}$ & $\mathrm{T}$ & 2 & MICTotal & 20.30 & \\
\hline $\mathrm{F}$ & $\bar{N}$ & $T$ & 2 & MicD & 10.00 & \\
\hline $\mathrm{F}$ & $\mathrm{N}$ & $\mathrm{T}$ & 2 & MicE & 10.30 & \\
\hline $\mathrm{F}$ & $\bar{N}$ & $\mathrm{~T}$ & 3 & LDTotal & 11.90 & \\
\hline $\mathrm{F}$ & $\mathrm{N}$ & $\mathrm{T}$ & 3 & LDTrab & 8.74 & (continua) \\
\hline
\end{tabular}




\begin{tabular}{|c|c|c|c|c|c|}
\hline $\mathrm{F}$ & $\mathrm{N}$ & $\mathrm{T}$ & 3 & LDBal & 3.16 \\
\hline $\mathrm{F}$ & $\mathrm{N}$ & $\mathrm{T}$ & 3 & MICTotal & 21.18 \\
\hline $\mathrm{F}$ & $\mathrm{N}$ & $\mathrm{T}$ & 3 & MicD & 10.57 \\
\hline $\mathrm{F}$ & $\mathrm{N}$ & $\mathrm{T}$ & 3 & MicE & 10.61 \\
\hline $\mathrm{F}$ & $\mathrm{N}$ & $\mathrm{O}$ & 1 & LDTotal & 11.60 \\
\hline $\mathrm{F}$ & $\mathrm{N}$ & $\mathrm{O}$ & 1 & LDTrab & 7.10 \\
\hline $\mathrm{F}$ & $\mathrm{N}$ & $\mathrm{O}$ & 1 & LDBal & 4.50 \\
\hline $\mathrm{F}$ & $\mathrm{N}$ & $\mathrm{O}$ & 1 & MICTotal & 18.55 \\
\hline $\mathrm{F}$ & $\mathrm{N}$ & $\mathrm{O}$ & 1 & MicD & 8.86 \\
\hline $\mathrm{F}$ & $\mathrm{N}$ & $\mathrm{O}$ & 1 & MicE & 9.14 \\
\hline $\mathrm{F}$ & $\mathrm{N}$ & $\mathrm{O}$ & 2 & LDTotal & 11.81 \\
\hline $\mathrm{F}$ & $\mathrm{N}$ & $\mathrm{O}$ & 2 & LDTrab & 9.08 \\
\hline $\mathrm{F}$ & $\mathrm{N}$ & $\mathrm{O}$ & 2 & LDBal & 4.27 \\
\hline $\mathrm{F}$ & $\mathrm{N}$ & $\mathrm{O}$ & 2 & MICTotal & 17.29 \\
\hline $\mathrm{F}$ & $\mathrm{N}$ & $\mathrm{O}$ & 2 & MicD & 8.47 \\
\hline $\mathrm{F}$ & $\mathrm{N}$ & $\mathrm{O}$ & 2 & MicE & 8.82 \\
\hline $\mathrm{F}$ & $\mathrm{N}$ & $\mathrm{O}$ & 3 & LDTotal & 11.21 \\
\hline $\mathrm{F}$ & $\mathrm{N}$ & $\mathrm{O}$ & 3 & LDTrab & 7.13 \\
\hline $\mathrm{F}$ & $\mathrm{N}$ & $\mathrm{O}$ & 3 & LDBal & 4.08 \\
\hline $\mathrm{F}$ & $\mathrm{N}$ & $\mathrm{O}$ & 3 & MICTotal & 14.42 \\
\hline $\mathrm{F}$ & $\mathrm{N}$ & $\mathrm{O}$ & 3 & MicD & 6.92 \\
\hline $\mathrm{F}$ & $\mathrm{N}$ & $\mathrm{O}$ & 3 & MicE & 7.50 \\
\hline $\mathrm{F}$ & $\mathrm{I}$ & $\mathrm{Q}$ & 1 & LDTotal & 16.57 \\
\hline $\mathrm{F}$ & $\mathrm{I}$ & $\mathrm{Q}$ & 1 & LDTrab & 10.03 \\
\hline $\mathrm{F}$ & $\mathrm{I}$ & $\mathrm{Q}$ & 1 & LDBal & 6.55 \\
\hline $\mathrm{F}$ & $\mathrm{I}$ & $\mathrm{Q}$ & 1 & MICTotal & 16.97 \\
\hline $\mathrm{F}$ & $\mathrm{I}$ & $\mathrm{Q}$ & 1 & MicD & 8.33 \\
\hline $\mathrm{F}$ & $\mathrm{I}$ & $\mathrm{Q}$ & 1 & MicE & 8.63 \\
\hline $\mathrm{F}$ & $\mathrm{I}$ & $\mathrm{Q}$ & 2 & LDTotal & 16.03 \\
\hline $\mathrm{F}$ & $\mathrm{I}$ & $\mathrm{Q}$ & 2 & LDTrab & 10.17 \\
\hline $\mathrm{F}$ & $\mathrm{I}$ & $\mathrm{Q}$ & 2 & LDBal & 5.87 \\
\hline $\mathrm{F}$ & $\mathrm{I}$ & $\mathrm{Q}$ & 2 & MICTotal & 20.73 \\
\hline $\mathrm{F}$ & $\mathrm{I}$ & $\mathrm{Q}$ & 2 & MicD & 10.27 \\
\hline $\mathrm{F}$ & $\mathrm{I}$ & $\mathrm{Q}$ & 2 & MicE & 10.46 \\
\hline $\mathrm{F}$ & $\mathrm{I}$ & $\mathrm{Q}$ & 3 & LDTotal & 16.20 \\
\hline $\mathrm{F}$ & $\mathrm{I}$ & $\mathrm{Q}$ & 3 & LDTrab & 10.20 \\
\hline $\mathrm{F}$ & $\mathrm{I}$ & $\mathrm{Q}$ & 3 & LDBal & 6.00 \\
\hline $\mathrm{F}$ & $\mathrm{I}$ & $\mathrm{Q}$ & 3 & MICTotal & 13.46 \\
\hline $\mathrm{F}$ & $\mathrm{I}$ & $\mathrm{Q}$ & 3 & MicD & 6.87 \\
\hline $\mathrm{F}$ & $\mathrm{I}$ & $\mathrm{Q}$ & 3 & MicE & 6.59 \\
\hline $\mathrm{F}$ & $\mathrm{I}$ & $\mathrm{T}$ & 1 & LDTotal & 19.06 \\
\hline $\mathrm{F}$ & $\mathrm{I}$ & $\mathrm{T}$ & 1 & LDTrab & 12.03 \\
\hline $\mathrm{F}$ & $\mathrm{I}$ & $\mathrm{T}$ & 1 & LDBal & 7.03 \\
\hline $\mathrm{F}$ & $\mathrm{I}$ & $\mathrm{T}$ & 1 & MICTotal & 20.39 \\
\hline $\mathrm{F}$ & $\mathrm{I}$ & $\mathrm{T}$ & 1 & MicD & 9.98 \\
\hline $\mathrm{F}$ & $\mathrm{I}$ & $\mathrm{T}$ & 1 & MicE & 10.41 \\
\hline $\mathrm{F}$ & $\mathrm{I}$ & $\mathrm{T}$ & 2 & LDTotal & 18.88 \\
\hline $\mathrm{F}$ & $\mathrm{I}$ & $\mathrm{T}$ & 2 & LDTrab & 11.81 \\
\hline & & & & & \\
(continua)
\end{tabular}




\begin{tabular}{|c|c|c|c|c|c|}
\hline $\mathrm{F}$ & $\mathrm{I}$ & $\mathrm{T}$ & 2 & LDBal & 7.07 \\
\hline $\mathrm{F}$ & $\mathrm{I}$ & $\mathrm{T}$ & 2 & MICTotal & 20.28 \\
\hline $\mathrm{F}$ & $\mathrm{I}$ & $\mathrm{T}$ & 2 & MicD & 9.84 \\
\hline $\mathrm{F}$ & $\mathrm{I}$ & $\mathrm{T}$ & 2 & MicE & 10.43 \\
\hline $\mathrm{F}$ & $\mathrm{I}$ & $\mathrm{T}$ & 3 & LDTotal & 19.44 \\
\hline $\mathrm{F}$ & $\mathrm{I}$ & $\mathrm{T}$ & 3 & LDTrab & 12.52 \\
\hline $\mathrm{F}$ & $\mathrm{I}$ & $\mathrm{T}$ & 3 & LDBal & 6.92 \\
\hline $\mathrm{F}$ & $\mathrm{I}$ & $\mathrm{T}$ & 3 & MICTotal & 19.87 \\
\hline $\mathrm{F}$ & $\mathrm{I}$ & $\mathrm{T}$ & 3 & MicD & 9.90 \\
\hline $\mathrm{F}$ & $\mathrm{I}$ & $\mathrm{T}$ & 3 & MicE & 9.97 \\
\hline $\mathrm{F}$ & $\mathrm{I}$ & $\mathrm{O}$ & 1 & LDTotal & 20.00 \\
\hline $\mathrm{F}$ & $\mathrm{I}$ & $\mathrm{O}$ & 1 & LDTrab & 12.56 \\
\hline $\mathrm{F}$ & $\mathrm{I}$ & $\mathrm{O}$ & 1 & LDBal & 7.44 \\
\hline $\mathrm{F}$ & $\mathrm{I}$ & $\mathrm{O}$ & 1 & MICTotal & 22.61 \\
\hline $\mathrm{F}$ & $\mathrm{I}$ & $\mathrm{O}$ & 1 & MicD & 11.39 \\
\hline $\mathrm{F}$ & $\mathrm{I}$ & $\mathrm{O}$ & 1 & MicE & 11.22 \\
\hline $\mathrm{F}$ & $\mathrm{I}$ & $\mathrm{O}$ & 2 & LDTotal & 20.56 \\
\hline $\mathrm{F}$ & $\mathrm{I}$ & $\mathrm{O}$ & 2 & LDTrab & 12.03 \\
\hline $\mathrm{F}$ & $\mathrm{I}$ & $\mathrm{O}$ & 2 & LDBal & 8.53 \\
\hline $\mathrm{F}$ & $\mathrm{I}$ & $\mathrm{O}$ & 2 & MICTotal & 16.89 \\
\hline $\mathrm{F}$ & $\mathrm{I}$ & $\mathrm{O}$ & 2 & MicD & 8.25 \\
\hline $\mathrm{F}$ & $\mathrm{I}$ & $\mathrm{O}$ & 2 & MicE & 8.64 \\
\hline $\mathrm{F}$ & $\mathrm{I}$ & $\mathrm{O}$ & 3 & LDTotal & 20.20 \\
\hline $\mathrm{F}$ & $\mathrm{I}$ & $\mathrm{O}$ & 3 & LDTrab & 11.59 \\
\hline $\mathrm{F}$ & $\mathrm{I}$ & $\mathrm{O}$ & 3 & LDBal & 8.60 \\
\hline $\mathrm{F}$ & $\mathrm{I}$ & $\mathrm{O}$ & 3 & MICTotal & 18.44 \\
\hline $\mathrm{F}$ & $\mathrm{I}$ & $\mathrm{O}$ & 3 & MicD & 9.40 \\
\hline $\mathrm{F}$ & $\mathrm{I}$ & $\mathrm{O}$ & 3 & MicE & 9.04 \\
\hline & & & & & \\
\hline
\end{tabular}


APENDICE F - Quadro de médias das áreas em lateralidade esquerda do modelo inferior

\begin{tabular}{|c|c|c|c|c|c|}
\hline $\begin{array}{l}\text { Forma } \\
\text { Oclusal }\end{array}$ & Origem & Arcada & Modelo & Tratamento & Area \\
\hline A & $\mathrm{N}$ & Q & 1 & LETotal & 14,53 \\
\hline$A$ & $\mathrm{~N}$ & $Q$ & 1 & LETrab & 9,77 \\
\hline A & $\mathrm{N}$ & $\mathrm{Q}$ & 1 & LEBal & 4,73 \\
\hline$A$ & $\mathrm{~N}$ & Q & 1 & MICTotal & 15.72 \\
\hline$A$ & $\mathrm{~N}$ & $\mathrm{Q}$ & 1 & MicD & 7.38 \\
\hline$A$ & $\mathrm{~N}$ & $\mathrm{Q}$ & 1 & MicE & 8.34 \\
\hline A & $\mathrm{N}$ & Q & 2 & LETotal & 14,99 \\
\hline$A$ & $\mathrm{~N}$ & $Q$ & 2 & LETrab & 9,7 \\
\hline A & $\mathrm{N}$ & $\mathrm{Q}$ & 2 & LEBal & 5,29 \\
\hline$A$ & $\mathrm{~N}$ & $Q$ & 2 & MICTotal & 15.15 \\
\hline$A$ & $\mathrm{~N}$ & $Q$ & 2 & MicD & 7.40 \\
\hline$A$ & $\mathrm{~N}$ & Q & 2 & MicE & 7.25 \\
\hline$A$ & $\mathrm{~N}$ & $Q$ & 3 & LETotal & 15 \\
\hline$A$ & $\mathrm{~N}$ & Q & 3 & LETrab & 9,95 \\
\hline A & $\mathrm{N}$ & Q & 3 & LEBal & 5,05 \\
\hline$A$ & $\mathrm{~N}$ & Q & 3 & MICTotal & 16.64 \\
\hline A & $\mathrm{N}$ & Q & 3 & MicD & 8.04 \\
\hline A & $\mathrm{N}$ & Q & 3 & MicE & 8.60 \\
\hline$A$ & $\mathrm{~N}$ & $T$ & 1 & LETotal & 14,02 \\
\hline A & $\mathrm{N}$ & $T$ & 1 & LETrab & 7,3 \\
\hline A & $\mathrm{N}$ & $\mathrm{T}$ & 1 & LEBal & 6,72 \\
\hline$A$ & $\mathrm{~N}$ & $T$ & 1 & MICTotal & 13.43 \\
\hline A & $\mathrm{N}$ & $\mathrm{T}$ & 1 & MicD & 6.30 \\
\hline$A$ & $\mathrm{~N}$ & $T$ & 1 & MicE & 7.13 \\
\hline$A$ & $\mathrm{~N}$ & $T$ & 2 & LETotal & 13,29 \\
\hline$A$ & $\mathrm{~N}$ & $T$ & 2 & LETrab & 7,15 \\
\hline$A$ & $\mathrm{~N}$ & $T$ & 2 & LEBal & 6,14 \\
\hline$A$ & $\mathrm{~N}$ & $T$ & 2 & MICTotal & 12.96 \\
\hline$A$ & $\mathrm{~N}$ & $\mathrm{~T}$ & 2 & MicD & 6.40 \\
\hline$A$ & $\mathrm{~N}$ & $T$ & 2 & MicE & 6.56 \\
\hline A & $\mathrm{N}$ & $T$ & 3 & LETotal & 13,32 \\
\hline A & $\mathrm{N}$ & $\mathrm{T}$ & 3 & LETrab & 7,8 \\
\hline$A$ & $\mathrm{~N}$ & $T$ & 3 & LEBal & 5,52 \\
\hline$A$ & $\mathrm{~N}$ & $T$ & 3 & MICTotal & 13.58 \\
\hline A & $\mathrm{N}$ & $T$ & 3 & MicD & 6.41 \\
\hline$A$ & $\mathrm{~N}$ & $T$ & 3 & MicE & 7.17 \\
\hline$A$ & $\mathrm{~N}$ & $\mathrm{O}$ & 1 & LETotal & 15,92 \\
\hline A & $\mathrm{N}$ & 0 & 1 & LETrab & 10 \\
\hline$A$ & $\mathrm{~N}$ & $\mathrm{O}$ & 1 & LEBal & 5,92 \\
\hline$A$ & $\mathrm{~N}$ & $\mathrm{O}$ & 1 & MICTotal & 16.07 \\
\hline$A$ & $\mathrm{~N}$ & $\mathrm{O}$ & 1 & MicD & 7.89 \\
\hline$A$ & $\mathrm{~N}$ & $\mathrm{O}$ & 1 & MicE & 8.19 \\
\hline A & $\mathrm{N}$ & 0 & 2 & LETotal & 15,13 \\
\hline A & $\mathrm{N}$ & 0 & 2 & LETrab & 9,55 \\
\hline
\end{tabular}




\begin{tabular}{|c|c|c|c|c|c|c|}
\hline A & $\mathrm{N}$ & $\mathrm{O}$ & 2 & LEBal & 5,58 & (continua) \\
\hline$A$ & $\mathrm{~N}$ & $\mathrm{O}$ & 2 & MICTotal & 15.28 & \\
\hline A & $\mathrm{N}$ & $\mathrm{O}$ & 2 & MicD & 7.12 & \\
\hline$A$ & $\mathrm{~N}$ & $\mathrm{O}$ & 2 & MicE & 8.16 & \\
\hline A & $\mathrm{N}$ & $\mathrm{O}$ & 3 & LETotal & 15,89 & \\
\hline A & $\mathrm{N}$ & $\mathrm{O}$ & 3 & LETrab & 8,89 & \\
\hline A & $\mathrm{N}$ & $\mathrm{O}$ & 3 & LEBal & 7 & \\
\hline A & $\mathrm{N}$ & $\mathrm{O}$ & 3 & MICTotal & 16.47 & \\
\hline$A$ & $\mathrm{~N}$ & $\mathrm{O}$ & 3 & MicD & 8.17 & \\
\hline A & $\mathrm{N}$ & $\mathrm{O}$ & 3 & MicE & 8.30 & \\
\hline A & I & Q & 1 & LETotal & 16,2 & \\
\hline$A$ & I & Q & 1 & LETrab & 11,01 & \\
\hline A & 1 & $Q$ & 1 & LEBal & 5,19 & \\
\hline A & 1 & Q & 1 & MICTotal & 17.94 & \\
\hline$A$ & $\mathrm{I}$ & Q & 1 & MicD & 8.45 & \\
\hline$A$ & I & Q & 1 & MicE & 9.49 & \\
\hline A & 1 & Q & 2 & LETotal & 16,24 & \\
\hline A & I & Q & 2 & LETrab & 10,16 & \\
\hline$A$ & 1 & Q & 2 & LEBal & 6,08 & \\
\hline A & 1 & Q & 2 & MICTotal & 17.14 & \\
\hline$A$ & $\mathrm{I}$ & Q & 2 & MicD & 8.16 & \\
\hline A & $\mathrm{I}$ & $\mathrm{Q}$ & 2 & MicE & 9.03 & \\
\hline$A$ & I & Q & 3 & LETotal & 16,35 & \\
\hline A & $\mathrm{I}$ & $Q$ & 3 & LETrab & 10,3 & \\
\hline A & $\mathrm{I}$ & $\mathrm{Q}$ & 3 & LEBal & 6,05 & \\
\hline A & 1 & Q & 3 & MICTotal & 17.89 & \\
\hline$A$ & I & Q & 3 & MicD & 8.89 & \\
\hline A & 1 & Q & 3 & MicE & 9.00 & \\
\hline A & I & $\mathrm{T}$ & 1 & LETotal & 14,89 & \\
\hline$A$ & $\mathrm{I}$ & $\mathrm{T}$ & 1 & LETrab & 9,13 & \\
\hline A & 1 & $\mathrm{~T}$ & 1 & LEBal & 5,76 & \\
\hline A & 1 & $\mathrm{~T}$ & 1 & MICTotal & 15.93 & \\
\hline A & $\mathrm{I}$ & $T$ & 1 & MicD & 7.66 & \\
\hline A & 1 & $\mathrm{~T}$ & 1 & MicE & 8.27 & \\
\hline A & $\mathrm{I}$ & $\mathrm{T}$ & 2 & LETotal & 15 & \\
\hline$A$ & 1 & $T$ & 2 & LETrab & 7,76 & \\
\hline$A$ & 1 & $T$ & 2 & LEBal & 7,24 & \\
\hline$A$ & 1 & $T$ & 2 & MICTotal & 15.75 & \\
\hline$A$ & 1 & $T$ & 2 & MicD & 7.61 & \\
\hline A & 1 & $\mathrm{~T}$ & 2 & MicE & 8.22 & \\
\hline$A$ & $\mathrm{I}$ & $T$ & 3 & LETotal & 15,26 & \\
\hline A & 1 & $\mathrm{~T}$ & 3 & LETrab & 10 & \\
\hline$A$ & $\mathrm{I}$ & $\mathrm{T}$ & 3 & LEBal & 5,26 & \\
\hline A & $\mathrm{I}$ & $T$ & 3 & MICTotal & 16.01 & \\
\hline$A$ & I & $T$ & 3 & MicD & 7.99 & \\
\hline A & 1 & $\mathrm{~T}$ & 3 & MicE & 8.02 & \\
\hline$A$ & I & $\mathrm{O}$ & 1 & LETotal & 16,72 & \\
\hline A & 1 & $\mathrm{O}$ & 1 & LETrab & 8,89 & ontinua) \\
\hline
\end{tabular}




\begin{tabular}{|c|c|c|c|c|c|c|}
\hline A & $\mathrm{I}$ & $\mathrm{O}$ & 1 & LEBal & 7,83 & (continua) \\
\hline A & I & 0 & 1 & MICTotal & 17.04 & \\
\hline A & $I$ & $\mathrm{O}$ & 1 & MicD & 8.39 & \\
\hline$A$ & I & $\mathrm{O}$ & 1 & MicE & 8.59 & \\
\hline A & I & $\mathrm{O}$ & 2 & LETotal & 16,8 & \\
\hline A & I & $\mathrm{O}$ & 2 & LETrab & 9,99 & \\
\hline$A$ & $I$ & $\mathrm{O}$ & 2 & LEBal & 6,81 & \\
\hline A & I & $\mathrm{O}$ & 2 & MICTotal & 17.04 & \\
\hline A & I & $\mathrm{O}$ & 2 & MicD & 8.47 & \\
\hline$A$ & I & $\mathrm{O}$ & 2 & MicE & 8.52 & \\
\hline$A$ & I & $\mathrm{O}$ & 3 & LETotal & 17,96 & \\
\hline$A$ & $I$ & $\mathrm{O}$ & 3 & LETrab & 11,2 & \\
\hline$A$ & I & $\mathrm{O}$ & 3 & LEBal & 6,76 & \\
\hline A & I & $\mathrm{O}$ & 3 & MICTotal & 17.68 & \\
\hline A & 1 & $\mathrm{O}$ & 3 & MicD & 8.45 & \\
\hline$A$ & 1 & $\mathrm{O}$ & 3 & MicE & 9.23 & \\
\hline $\mathrm{F}$ & $\mathrm{N}$ & $Q$ & 1 & LETotal & 10,18 & \\
\hline $\mathrm{F}$ & $\mathrm{N}$ & $Q$ & 1 & LETrab & 5,3 & \\
\hline $\mathrm{F}$ & $\mathrm{N}$ & $Q$ & 1 & LEBal & 4,88 & \\
\hline$F$ & $\mathrm{~N}$ & $Q$ & 1 & MICTotal & 14.67 & \\
\hline $\mathrm{F}$ & $\mathrm{N}$ & $\mathrm{Q}$ & 1 & MicD & 6.84 & \\
\hline $\mathrm{F}$ & $\bar{N}$ & $\mathrm{Q}$ & 1 & MicE & 7.29 & \\
\hline$F$ & $\mathrm{~N}$ & Q & 2 & LETotal & 9,6 & \\
\hline$F$ & $\mathrm{~N}$ & $Q$ & 2 & LETrab & 6,5 & \\
\hline $\mathrm{F}$ & $\mathrm{N}$ & $Q$ & 2 & LEBal & 4,1 & \\
\hline $\mathrm{F}$ & $\mathrm{N}$ & $Q$ & 2 & MICTotal & 15.33 & \\
\hline $\mathrm{F}$ & $\mathrm{N}$ & $Q$ & 2 & MicD & 7.51 & \\
\hline$F$ & $\mathrm{~N}$ & $Q$ & 2 & MicE & 7.82 & \\
\hline$F$ & $\mathrm{~N}$ & $Q$ & 3 & LETotal & 9,08 & \\
\hline $\mathrm{F}$ & $\mathrm{N}$ & $\mathrm{Q}$ & 3 & LETrab & 5,12 & \\
\hline $\mathrm{F}$ & $\mathrm{N}$ & $Q$ & 3 & LEBal & 3,96 & \\
\hline $\mathrm{F}$ & $\mathrm{N}$ & $Q$ & 3 & MICTotal & 13.41 & \\
\hline$F$ & $\mathrm{~N}$ & $Q$ & 3 & MicD & 3.61 & \\
\hline $\mathrm{F}$ & $\mathrm{N}$ & $Q$ & 3 & MicE & 6.80 & \\
\hline $\mathrm{F}$ & $\mathrm{N}$ & $\mathrm{T}$ & 1 & LETotal & 11 & \\
\hline$F$ & $\mathrm{~N}$ & $T$ & 1 & LETrab & 6,12 & \\
\hline$F$ & $\mathrm{~N}$ & $\mathrm{~T}$ & 1 & LEBal & 4,88 & \\
\hline$F$ & $\mathrm{~N}$ & $\mathrm{~T}$ & 1 & MICTotal & 21.15 & \\
\hline $\mathrm{F}$ & $\mathrm{N}$ & $\mathrm{T}$ & 1 & MicD & 10.78 & \\
\hline $\mathrm{F}$ & $\mathrm{N}$ & $\mathrm{T}$ & 1 & MicE & 10.28 & \\
\hline$F$ & $\mathrm{~N}$ & $\mathrm{~T}$ & 2 & LETotal & 11,56 & \\
\hline $\mathrm{F}$ & $\mathrm{N}$ & $\mathrm{T}$ & 2 & LETrab & 9,17 & \\
\hline $\mathrm{F}$ & $\mathrm{N}$ & $\mathrm{T}$ & 2 & LEBal & 2,39 & \\
\hline $\mathrm{F}$ & $\mathrm{N}$ & $T$ & 2 & MICTotal & 20.30 & \\
\hline$F$ & $\mathrm{~N}$ & $\mathrm{~T}$ & 2 & MicD & 10.00 & \\
\hline$F$ & $\mathrm{~N}$ & $\mathrm{~T}$ & 2 & MicE & 10.30 & \\
\hline$F$ & $\mathrm{~N}$ & $\mathrm{~T}$ & 3 & LETotal & 12,58 & \\
\hline$F$ & $\mathrm{~N}$ & $\mathrm{~T}$ & 3 & LETrab & 9,15 & (continua) \\
\hline
\end{tabular}




\begin{tabular}{|c|c|c|c|c|c|c|}
\hline $\mathrm{F}$ & $\mathrm{N}$ & $\bar{T}$ & 3 & LEBal & 3,43 & (continua) \\
\hline $\mathrm{F}$ & $\mathrm{N}$ & $\mathrm{T}$ & 3 & MICTotal & 21.18 & \\
\hline$F$ & $\mathrm{~N}$ & $\mathrm{~T}$ & 3 & MicD & 10.57 & \\
\hline $\mathrm{F}$ & $\mathrm{N}$ & $\mathrm{T}$ & 3 & MicE & 10.61 & \\
\hline$F$ & $\mathrm{~N}$ & $\mathrm{O}$ & 1 & LETotal & 11,77 & \\
\hline $\mathrm{F}$ & $\mathrm{N}$ & $\mathrm{O}$ & 1 & LETrab & 7,26 & \\
\hline$F$ & $\mathrm{~N}$ & $\mathrm{O}$ & 1 & LEBal & 4,51 & \\
\hline$F$ & $\mathrm{~N}$ & $\mathrm{O}$ & 1 & MICTotal & 18.55 & \\
\hline$F$ & $\mathrm{~N}$ & $\mathrm{O}$ & 1 & MicD & 8.86 & \\
\hline $\mathrm{F}$ & $\bar{N}$ & $\mathrm{O}$ & 1 & MicE & 9.14 & \\
\hline $\mathrm{F}$ & $\mathrm{N}$ & 0 & 2 & LETotal & 11,94 & \\
\hline$F$ & $\mathrm{~N}$ & $\mathrm{O}$ & 2 & LETrab & 9,37 & \\
\hline $\mathrm{F}$ & $\mathrm{N}$ & $\mathrm{O}$ & 2 & LEBal & 2,57 & \\
\hline $\mathrm{F}$ & $\mathrm{N}$ & $\mathrm{O}$ & 2 & MICTotal & 17.29 & \\
\hline $\mathrm{F}$ & $\mathrm{N}$ & $\mathrm{O}$ & 2 & MicD & 8.47 & \\
\hline$F$ & $\mathrm{~N}$ & $\mathrm{O}$ & 2 & MicE & 8.82 & \\
\hline $\mathrm{F}$ & $\mathrm{N}$ & $\mathrm{O}$ & 3 & LETotal & 11,25 & \\
\hline$F$ & $\mathrm{~N}$ & $\mathrm{O}$ & 3 & LETrab & 7,74 & \\
\hline $\mathrm{F}$ & $\mathrm{N}$ & $\mathrm{O}$ & 3 & LEBal & 3,51 & \\
\hline$F$ & $\mathrm{~N}$ & $\mathrm{O}$ & 3 & MICTotal & 14.42 & \\
\hline$F$ & $\mathrm{~N}$ & $\mathrm{O}$ & 3 & MicD & 6.92 & \\
\hline$F$ & $\mathrm{~N}$ & $\mathrm{O}$ & 3 & MicE & 7.50 & \\
\hline $\mathrm{F}$ & 1 & $Q$ & 1 & LETotal & 16,88 & \\
\hline $\mathrm{F}$ & 1 & $Q$ & 1 & LETrab & 10,15 & \\
\hline$F$ & 1 & $Q$ & 1 & LEBal & 6,73 & \\
\hline$F$ & 1 & $Q$ & 1 & MICTotal & 16.97 & \\
\hline $\mathrm{F}$ & I & $\mathrm{Q}$ & 1 & MicD & 8.33 & \\
\hline $\mathrm{F}$ & 1 & $Q$ & 1 & MicE & 8.63 & \\
\hline$F$ & 1 & $Q$ & 2 & LETotal & 16 & \\
\hline$F$ & $\mathrm{I}$ & $\mathrm{Q}$ & 2 & LETrab & 10,29 & \\
\hline $\mathrm{F}$ & I & $Q$ & 2 & LEBal & 5,71 & \\
\hline $\mathrm{F}$ & I & $Q$ & 2 & MICTotal & 20.73 & \\
\hline $\mathrm{F}$ & I & $Q$ & 2 & MicD & 10.27 & \\
\hline$F$ & I & $Q$ & 2 & MicE & 10.46 & \\
\hline$F$ & I & $\mathrm{Q}$ & 3 & LETotal & 16,21 & \\
\hline $\mathrm{F}$ & I & $Q$ & 3 & LETrab & 10,49 & \\
\hline $\mathrm{F}$ & 1 & $Q$ & 3 & LEBal & 5,72 & \\
\hline$F$ & 1 & $Q$ & 3 & MICTotal & 13.46 & \\
\hline$F$ & $\mathrm{I}$ & $Q$ & 3 & MicD & 6.87 & \\
\hline $\mathrm{F}$ & I & $Q$ & 3 & MicE & 6.59 & \\
\hline $\mathrm{F}$ & 1 & $\mathrm{~T}$ & 1 & LETotal & 19,72 & \\
\hline$F$ & 1 & $\mathrm{~T}$ & 1 & LETrab & 13,05 & \\
\hline$F$ & 1 & $\mathrm{~T}$ & 1 & LEBal & 6,67 & \\
\hline$F$ & I & $\mathrm{T}$ & 1 & MICTotal & 20.39 & \\
\hline $\mathrm{F}$ & I & $\mathrm{T}$ & 1 & MicD & 9.98 & \\
\hline $\mathrm{F}$ & 1 & $\mathrm{~T}$ & 1 & MicE & 10.41 & \\
\hline$F$ & $\mathrm{I}$ & $\mathrm{T}$ & 2 & LETotal & 18 & \\
\hline $\mathrm{F}$ & I & $\mathrm{T}$ & 2 & LETrab & 12,51 & (continua) \\
\hline
\end{tabular}




\begin{tabular}{|c|c|c|c|c|c|}
\hline $\mathrm{F}$ & $\mathrm{I}$ & $\mathrm{T}$ & 2 & LEBal & 5,49 \\
\hline $\mathrm{F}$ & $\mathrm{I}$ & $\mathrm{T}$ & 2 & MICTotal & 20.28 \\
\hline $\mathrm{F}$ & $\mathrm{I}$ & $\mathrm{T}$ & 2 & MicD & 9.84 \\
\hline $\mathrm{F}$ & $\mathrm{I}$ & $\mathrm{T}$ & 2 & MicE & 10.43 \\
\hline $\mathrm{F}$ & $\mathrm{I}$ & $\mathrm{T}$ & 3 & LETotal & 19,98 \\
\hline $\mathrm{F}$ & $\mathrm{I}$ & $\mathrm{T}$ & 3 & LETrab & 13,45 \\
\hline $\mathrm{F}$ & $\mathrm{I}$ & $\mathrm{T}$ & 3 & LEBal & 6,53 \\
\hline $\mathrm{F}$ & $\mathrm{I}$ & $\mathrm{T}$ & 3 & MICTotal & 19.87 \\
\hline $\mathrm{F}$ & $\mathrm{I}$ & $\mathrm{T}$ & 3 & MicD & 9.90 \\
\hline $\mathrm{F}$ & $\mathrm{I}$ & $\mathrm{T}$ & 3 & MicE & 9.97 \\
\hline $\mathrm{F}$ & $\mathrm{I}$ & $\mathrm{O}$ & 1 & LETotal & 20,14 \\
\hline $\mathrm{F}$ & $\mathrm{I}$ & $\mathrm{O}$ & 1 & LETrab & 13,65 \\
\hline $\mathrm{F}$ & $\mathrm{I}$ & $\mathrm{O}$ & 1 & LEBal & 6,49 \\
\hline $\mathrm{F}$ & $\mathrm{I}$ & $\mathrm{O}$ & 1 & MICTotal & 22.61 \\
\hline $\mathrm{F}$ & $\mathrm{I}$ & $\mathrm{O}$ & 1 & MicD & 11.39 \\
\hline $\mathrm{F}$ & $\mathrm{I}$ & $\mathrm{O}$ & 1 & MicE & 11.22 \\
\hline $\mathrm{F}$ & $\mathrm{I}$ & $\mathrm{O}$ & 2 & LETotal & 20,49 \\
\hline $\mathrm{F}$ & $\mathrm{I}$ & $\mathrm{O}$ & 2 & LETrab & 13,57 \\
\hline $\mathrm{F}$ & $\mathrm{I}$ & $\mathrm{O}$ & 2 & LEBal & 6,92 \\
\hline $\mathrm{F}$ & $\mathrm{I}$ & $\mathrm{O}$ & 2 & MICTotal & 16.89 \\
\hline $\mathrm{F}$ & $\mathrm{I}$ & $\mathrm{O}$ & 2 & MicD & 8.25 \\
\hline $\mathrm{F}$ & $\mathrm{I}$ & $\mathrm{O}$ & 2 & MicE & 8.64 \\
\hline $\mathrm{F}$ & $\mathrm{I}$ & $\mathrm{O}$ & 3 & LETotal & 20,68 \\
\hline $\mathrm{F}$ & $\mathrm{I}$ & $\mathrm{O}$ & 3 & LETrab & 12,34 \\
\hline $\mathrm{F}$ & $\mathrm{I}$ & $\mathrm{O}$ & 3 & LEBal & 8,34 \\
\hline $\mathrm{F}$ & $\mathrm{I}$ & $\mathrm{O}$ & 3 & MICTotal & 18.44 \\
\hline $\mathrm{F}$ & $\mathrm{I}$ & $\mathrm{O}$ & 3 & MicD & 9.40 \\
\hline $\mathrm{F}$ & $\mathrm{I}$ & $\mathrm{O}$ & 3 & MicE & 9.04 \\
\hline & & & & & \\
\hline
\end{tabular}

